Universidad de Lima

Facultad de Ingeniería Industrial

Carrera de Ingeniería Industrial

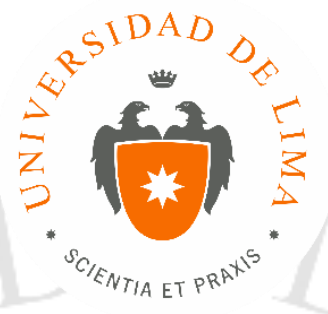

\title{
MEJORA EN LA ESTRUCTURA ORGANIZACIONAL DE LA EMPRESA FAMILIAR ABC S.A.C.
}

Trabajo de investigación para optar por el Título Profesional de Ingeniero Industrial

\section{J. Sebastián Jean-Mairet Zimic}

Código 20020418

Oscar A. Mariñas Tapia

Código 20021336

\author{
Asesor \\ Carlos Chirinos Cuadros
}

Lima - Perú

Diciembre de 2015 


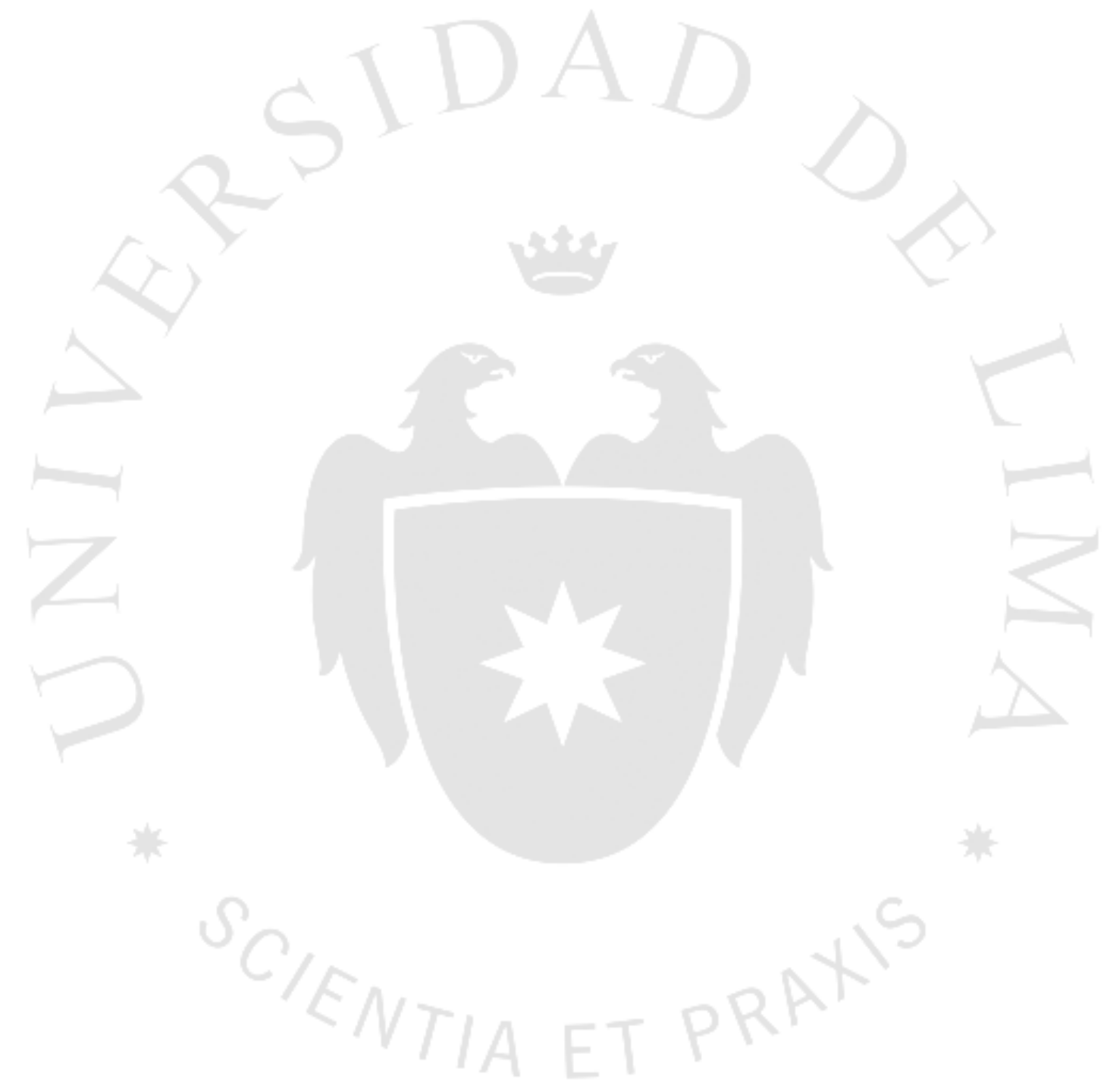




\section{MEJORA EN LA ESTRUCTURA ORGANIZACIONAL DE LA EMPRESA FAMILIAR ABC S.A.C.}




\section{TABLA DE CONTENIDO}

RESUMEN EJECUTIVO................................................ 11

EXECUTIVE RESUME ................................................. 12

CAPÍTULO I. CONSIDERACIONES GENERALES DE LA

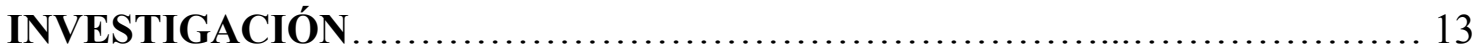

1.1. Antecedentes de la empresa.................................... 13

1.1.1. Breve descripción de la empresa y reseña histórica..................13

1.1.2. Descripción de los productos o servicios ofrecidos..................15

1.1.3. Descripción del mercado objetivo de la empresa....................17

1.1.4. Estrategia general de la empresa...............................18

1.1.5. Descripción de la problemática actual...........................19

1.2.Objetivos de la investigación...................................... 19

1.2.1. Objetivo general........................................ 19

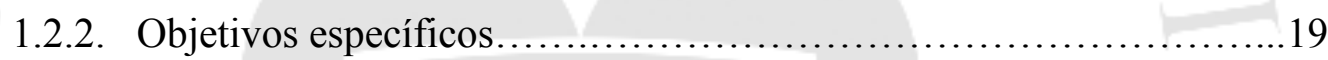

1.3. Alcance y limitaciones de la investigación..........................20

1.4. Justificación de la investigación...................................20

1.4.1. Técnica.....................................................20

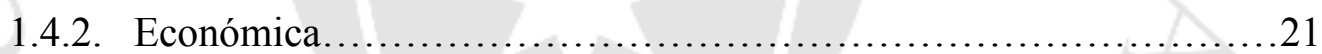

1.4.3. Social.................................................21

1.5. Hipótesis de la investigación...................................21

1.6. Marco referencial de la investigación...............................22

1.7. Marco conceptual........................................... 23

\section{CAPÍTULO II. ANÁLISIS SITUACIONAL DE LA EMPRESA Y SELECCIÓN DEL PROCESO A SER MEJORADO ...................................... 24}

2.1. Análisis Externo de la Empresa.......................................24

2.1.1. Análisis del entorno global.................................24

2.1.2. Análisis del entorno competitivo...............................28

2.1.3. Identificación y evaluación de las oportunidades y amenazas del

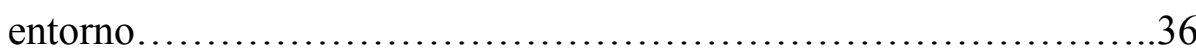

2.2. Análisis Interno de la Empresa.........................................38 
2.2.1. Análisis del direccionamiento estratégico: visión, misión y objetivos organizacionales .38

2.2.2. Análisis de la estructura organizacional.........................42

2.2.3. Identificación y descripción general de los procesos claves...........45

2.2.4. Análisis de los indicadores generales de desempeño de los procesos claves.

2.2.5. Determinación de posibles oportunidades de mejora (hallazgo de problemas)

2.2.6. Identificación y evaluación de las fortalezas y debilidades de la empresa...................................................64

2.2.7. Selección del sistema o proceso a mejorar.........................66

\section{CAPÍTULO III. DIAGNÓTICO DEL PROCESO OBJETO DE ESTUDIO .....69}

3.1 Análisis del proceso objeto de estudio...............................69

3.1.1 Descripción detallada del proceso objeto de estudio.................69

3.1.2 Análisis de los indicadores específicos de desempeño del proceso.....72

3.2 Determinación de las causas raíz de los problemas hallados................80

CAPÍTULO IV. DETERMINACIÓN DE LA PROPUESTA DE SOLUCIÓN.... 98

4.1. Planteamiento de alternativas de solución.............................. 98

4.2. Selección de alternativas de solución..................................102

4.2.1 Determinación y ponderación de criterios evaluación de las alternativas....................................................

4.2.2 Evaluación cualitativa y/o cuantitativa de alternativas de solución...105

4.2.3 Priorización de soluciones seleccionadas............................107

CAPÍtUlO V. DESARROLLO Y PLANIFICACIÓN DE LAS

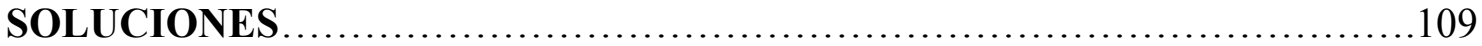

5.1.Ingeniería de la solución.......................................... 109

5.2.Plan de implementación de la solución...............................155

5.2.1 Determinación de objetivos y metas............................ 155

5.2.2 Elaboración del presupuesto general requerido para la ejecución de la solución 


\section{CAPÍTULO VI. EVALUACIÓN DE LA SOLUCIÓN Y BENEFICIOS}

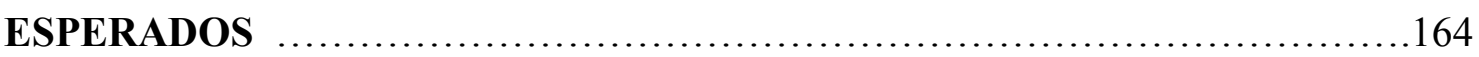

6.1. Evaluación económica financiera de la solución.........................164

6.2. Análisis del impacto social y ambiental de la solución....................174

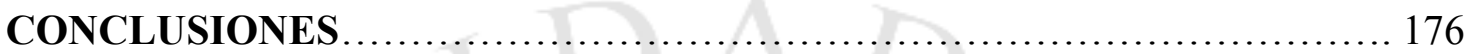

RECOMENDACIONES................................................. 178

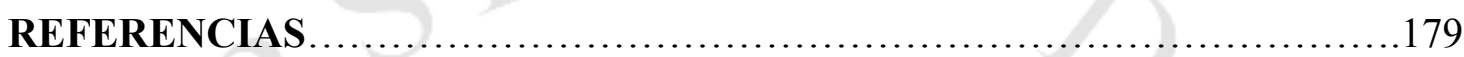

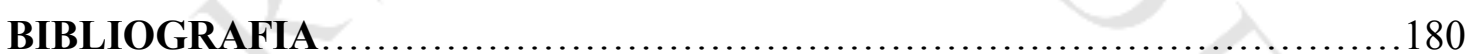

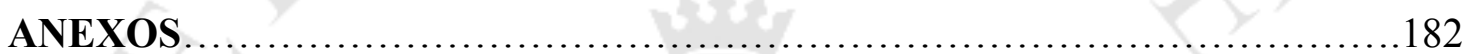




\section{ÍNDICE DE TABLAS}

Tabla 1.1 Ventas por tipo de producto (año 2012)................................ 17

Tabla 1.2 Ventas de maquinaria (año 2012) .................................. 17

Tabla 2.2 Importaciones de empresas principales del sector......................31

Tabla 2.3 Participación en importaciones del sector................................ 31

Tabla 2.3 Matriz EFE........................................................ 37

Tabla 2.4 Indicadores de administración y finanzas..............................50

Tabla 2.5 Venta de maquinaria y consumibles ............................... 57

Tabla 2.6 Nivel de cuentas por cobrar.......................................58

Tabla 2.7 Rotación de inventarios.......................................60

Tabla 2.8 Ventas de servicio técnico.......................................61

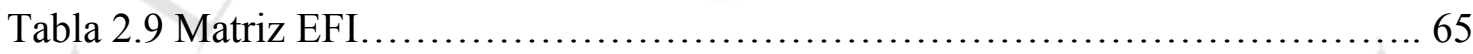

Tabla 2.10 Ranking de factores para selección de proceso a mejorar................68

Tabla 3.1 Rotación de Inventarios............................................. 72

Tabla 3.2 Venta de maquinaria............................................ 74

Tabla 3.3 Número de clientes............................................. 75

Tabla 3.4 Costos/Gastos de Ventas vs. Ventas................................. 76

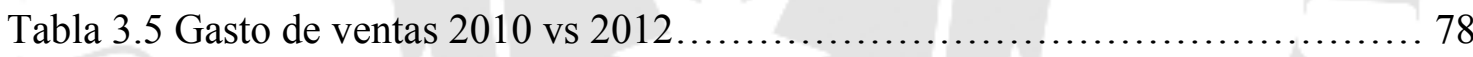

Tabla 3.6 Rotación de cuentas por cobrar........................................ 79

Tabla 3.7 Matriz de enfrentamiento de causa raíz................................ 96

Tabla 3.8 Clasificación ABC de causas raíz....................................... 97

Tabla 4.1 Matriz de Enfrentamiento de Factores................................... 104

Tabla 4.2 Ranking de Factores............................................... 106

Tabla 5.1 Cuadro de Mando Integral.......................................... 115

Tabla 5.2 Modelo cuadro proyección de venta .............................. 120

Tabla 5.3 Propuesta de modelo de seguimiento de ventas......................... 124

Tabla 5.4 Formato de encuesta de satisfacción del cliente........................ 129

Tabla 5.5 Formato recopilación de información de la competencia..................135

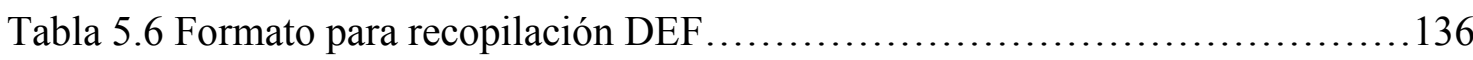

Tabla 5.7 Descripción del nuevo perfil del puesto Gerente General.................139

Tabla 5.8 Descripción del nuevo perfil del puesto Gerente Comercial............... 140

Tabla 5.9 Descripción del nuevo perfil del puesto Vendedor........................141 
Tabla 5.10 Descripción del nuevo perfil del puesto Jefe de Servicio Técnico.........142

Tabla 5.11 Descripción del nuevo perfil del puesto Jefe Administrativo...............143

Tabla 5.12 Descripción del nuevo perfil del puesto Supervisor de cobranzas..........144

Tabla 5.13Descripción del nuevo perfil del puesto Administrador DEF S.A.C. .......145

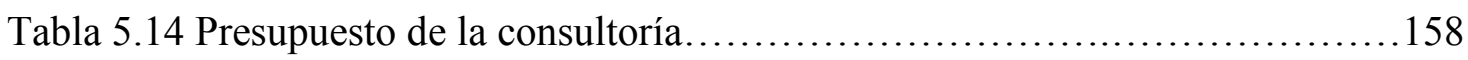

Tabla 5.15 Presupuesto de horas-hombre por capacitación........................158

Tabla 5.16 Presupuesto de recursos para capacitaciones...........................159

Tabla 5.17 Presupuesto de liquidación de personal de ventas..................... 159

Tabla 6.1 Estados de resultados por escenarios............................... 168

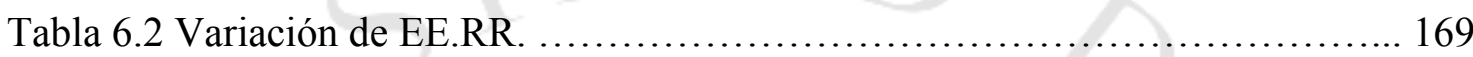

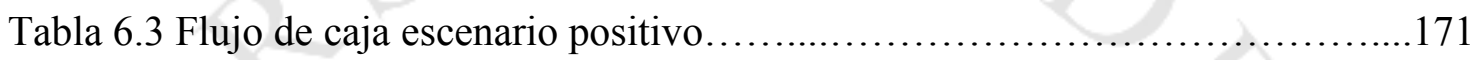

Tabla 6.4 Flujo de caja escenario conservador............................... 172

Tabla 6.5 Flujo de caja escenario negativo..................................... 173

Tabla 6.6 Indicadores de evaluación económica................................... 174 


\section{ÍNDICE DE FIGURAS}

Figura 2.1 Evolución del crecimiento de los subsectores manufactura y construcción..26

Figura 2.2 Grupos estratégicos del sector.................................. 34

Figura 2.3 Evolución de los grupos estratégicos del sector (2003 vs. 2013) ........... 35

Figura 2.4 Modelo de negocio Canvas.........................................41

Figura 2.5 Organigrama........................................................... 42

Figura 2.6 Mapa de procesos.............................................. 46

Figura 2.7 Indicadores de liquidez.................................... 51

Figura 2.8 Indicadores de Solvencia........................................ 52

Figura 2.9 Endeudamiento............................................. 53

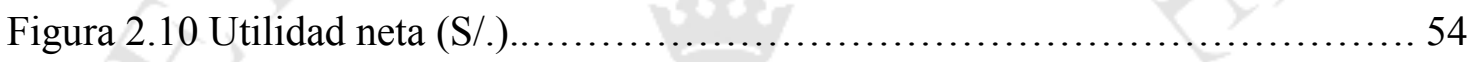

Figura 2.11 Indicadores de Rentabilidad..................................55

Figura 2.12 Gastos administrativos vs. Ebitda.................................... 55

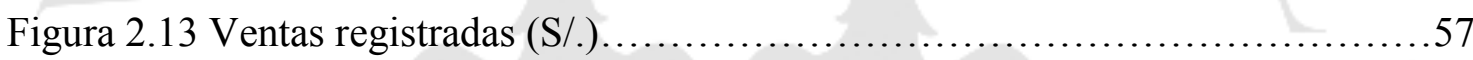

Figura 2.14 Nivel de cuentas por cobrar.................................... 59

Figura 2.15 Rotación de inventarios..................................... 60

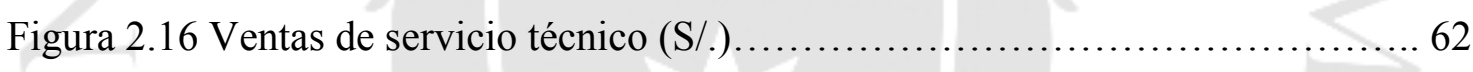

Figura 3.1 Diagrama de bloques del proceso de venta de maquinaria..................71

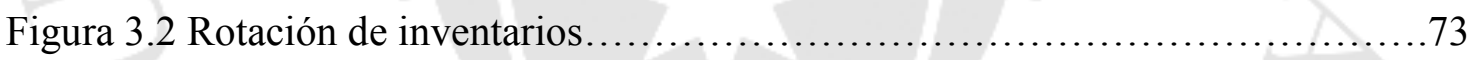

Figura 3.3 Venta de maquinaria $(\mathrm{S} /$.$) ................................... 75$

Figura 3.4 Costos/Gastos de Ventas vs. Ventas................................ 77

Figura 3.5 Rotación de cuentas por cobrar y días de crédito........................ 79

Figura 3.6 Diagrama de causa-efecto del problema "Baja rentabilidad"............... 84

Figura 3.7 Diagrama de causas raíz del problema "Estancamiento de las ventas de maquinaria" ........................................................ 92

Figura 3.8 Diagrama de causas raíz del problema "Exceso de Inventarios"........... 93

Figura 3.9 Diagrama de causas raíz del problema "Cuentas por cobrar en exceso"....94

Figura 3.10 Diagrama de causa raíz problema "exceso gasto de ventas"............. 95

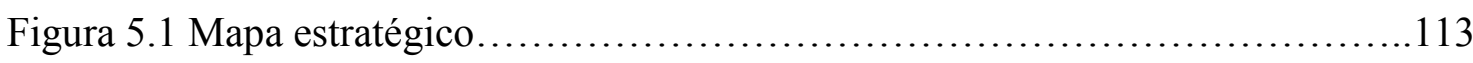

Figura 5.2 Diagrama de flujo del nuevo proceso de venta de maquinaria............130

Figura 5.3 Diagrama de flujo del subproceso "pronóstico de ventas"................131

Figura 5.4 Diagrama de flujo del subproceso "pedido de mercadería"...............132 
Figura 5.5 Diagrama de flujo del subproceso "cierre de venta".

Figura 5.6 Diagrama de flujo del subproceso "despacho de producto"

Figura 5.7 Nuevo organigrama propuesto................................. 138

Figura 5.8 Nuevo modelo de negocio Canvas.................................... 154

Figura 5.9 Diagrama de Gantt para la implementación de las soluciones.............160

Figura 5.10 Continuación de diagrama de Gantt para la implementación de las soluciones (I)

Figura 5.11 Continuación de diagrama de Gantt para la implementación de las soluciones (II)

Figura 5.12 Continuación de diagrama de Gantt para la implementación de las soluciones (III) 163 


\section{RESUMEN EJECUTIVO}

El presente trabajo de investigación se realizó con el objetivo de mejorar el proceso comercial de la empresa ABC S.A.C., con el fin de que las soluciones propuestas ayuden a la empresa a mejorar su rentabilidad.

Inicialmente se realizó una descripción de la empresa y sus principales productos, así como también de su mercado y estrategia, para luego plantear los objetivos y la justificación de la presente investigación.

Se procedió luego a realizar un diagnóstico del entorno de la empresa a través del análisis de Michael Porter, para luego realizar un diagnóstico de los procesos internos, llegando a identificar los diferentes problemas presentes en la empresa; tras el análisis se seleccionó el proceso de venta de maquinaria para realizar la mejora.

En el siguiente capítulo, se realizó un diagnóstico del proceso de venta de maquinaria con mayor nivel de detalle, identificando la problemática presente en el proceso, así como también las causas raíz que originan los problemas.

Seguidamente se plantearon soluciones para los problemas encontrados, las cuales fueron evaluadas en base a cinco criterios de selección, resultando como soluciones elegidas la creación de procedimientos del proceso de ventas, la implementación de un plan de capacitación y la implementación de un sistema de indicadores de gestión, soluciones que son desarrolladas en el siguiente capítulo.

Finalmente se realizó una evaluación cuantitativa y cualitativa del plan de mejora, con la finalidad de verificar la viabilidad de su implementación. Tras la evaluación se determinaron indicadores económicos alentadores, los que determinaron la viabilidad de las tres soluciones planteadas. 


\section{EXECUTIVE RESUME}

This investigation Project was made in order to improve the commercial process of the company ABC S.A.C., with the objective that the proposed solutions help the Company to improve its profitability.

First, it was made a description of the company and its main products, the market in which it operates and the strategy it uses, and then the objectives and the justification of the investigation were defined.

Then a diagnosis of the environment of the company was made using the Porter's analysis, followed by a diagnosis of the internal processes, identifying the problems that the company has; after the analysis, the machinery sales process was selected to make the improvement.

In the next chapter, it was made a detailed diagnosis of the machinery sales process, identifying the problems of the process and the main causes that originate them.

Next the solutions to the problems were proposed and evaluated in five different factors, resulting three as the chosen solutions: the creation of procedures of the sales process, the implementation of a training program, and the implementation of an indicators system for management. These solutions are developed in the following chapter.

Finally, it was made a qualitative and quantitative evaluation of the improvement project, with the objective of verifying the feasibility of its implementation. After the evaluation, the results obtained for the economic indicators were encouraging, which confirms the feasibility of the three proposed solutions. 


\section{CAPÍTULO I. CONSIDERACIONES GENERALES DE LA INVESTIGACIÓN}

\subsection{Antecedentes de la empresa}

\subsubsection{Breve descripción de la empresa y reseña histórica}

ABC S.A.C. es una empresa que se dedica a la importación y comercialización de maquinaria, herramientas e insumos para la industria de la segunda transformación de la madera y sus derivados, completando su oferta con el servicio técnico (mantenimiento) a la maquinaria y el servicio de afilado a las herramientas utilizadas en dicha maquinaria, luego de la compra de la empresa DEF S.A.C..

ABC S.A.C. lidera el mercado de la venta de maquinaria utilizada en la segunda transformación de la madera. Además ha sido uno de los agentes más importantes en la industrialización de la carpintería de madera en el Perú, especialmente en lo que respecta a sus derivados.

Fundada en 1955, inició operaciones en un pequeño local alquilado en el distrito de Lima. Al inicio la empresa de dedicó a la venta de herramientas, las cuales se compraban en el mercado local. Luego, hacia fines de los años 50 e inicios de los 60, la empresa empezó a vender maquinaria importada para la primera transformación de la madera.

La dictadura militar iniciada en 1968 intentó fomentar la producción nacional mediante un control de importaciones, lo cual desaceleró el crecimiento de la empresa. Una de las medidas de la empresa para mantener su nivel de ingresos consistió en pasar a la venta de maquinaria para carpintería (segunda transformación), dejando de lado poco a poco la venta de maquinaria para la primera transformación. Este mal momento se prolongó hasta la década de los 80 , donde las mejoras económicas no fueron las indicadas. 
A inicios de la década de los 90, luego de participar en un feria internacional y previniendo el consumo de los tableros aglomerados a futuro, la empresa decide importar la primera escuadradora de la marca Robland. Un año más tarde, gracias al éxito de ventas de las escuadradoras, se crea el área de Servicio Técnico y luego se consigue la representación de Cehisa, enchapadoras españolas líderes del mercado en la actualidad. El crecimiento en esta década fue muy rápido, pero, lamentablemente, desordenado.

A inicios del año 2000 se compra el local de Villa el Salvador, estratégicamente ubicado en el Parque Industrial, conocido también como la "capital del mueble". Aprovechando el espacio disponible, se inicia el manejo de máquinas en stock, lo cual tuvo un impacto positivo en las ventas. Con el crecimiento y reconocimiento de la empresa, tanto local como internacionalmente, vinieron otras representadas de renombre, entre las cuales figura Weinig de Alemania.

En el año 2008 se buscó iniciar la profesionalización de la empresa, para lo cual se formó un Directorio con poca presencia y participación de los socios. Dicho Directorio, en el año 2010, sugirió la contratación de un Gerente General especializado en temas comerciales y, a su vez, aumentar los niveles de apalancamiento financiero. También se cierra la compra de DEF S.A.C., empresa que se dedicaba al afilado de herramientas de corte, especialmente las madereras. De esta manera el abanico de productos y servicios ofrecidos por la empresa se volvió completo.

Los resultados no fueron los esperados. Si bien es cierto los niveles de venta aumentaron, se descuidaron los costos de venta, los procesos y controles internos y se perdió de vista la misión de la empresa: brindar soluciones integrales a los clientes y a la industria. En otras palabras, se creció sin control organizacional ni financiero.

La contratación de un nuevo Gerente General logró iniciar un proceso de reestructuración, pero la velocidad en la aplicación de las medidas a tomar no fue suficiente. Además se descuidó el aspecto comercial y se perdió gran parte de la participación de mercado a manos de nuevos competidores, los cuales se caracterizan por tener mayor agilidad al momento de tomar decisiones. 
Finalmente son los socios quienes deciden tomar el control de la Gerencia de la empresa. Parte de este trabajo considera las medidas tomadas por este comité de Gerencia y los resultados de los mismos, así como también será una guía para una futura reestructuración.

\subsubsection{Descripción de los productos o servicios ofrecidos}

ABC S.A.C. se dedica a la comercialización de maquinaria y herramientas para la madera. Entre dichos productos destacan:

- Enchapadoras marca M2: máquina que se utiliza para pegar un canto plástico en el tablero aglomerado. Estas enchapadoras son también las más vendidas del Perú y estuvieron cerca de ser un genérico como el caso de las escuadradoras M1.

- Escuadradoras marca M1: son máquinas utilizadas para el corte de los tableros aglomerados. El modelo comercializado por la empresa es el más conocido y vendido a nivel nacional, al punto de que el nombre M1 representa un genérico para escuadradoras.

- Cortadoras verticales: como su nombre lo indica, cortan tableros aglomerados, los cuales se posicionan de forma vertical en la máquina ahorrando espacio. ABC S.A.C. representa a dos fabricantes europeos de prestigio mundial.

- Soluciones integrales para grandes industrias: reducir los tiempos de producción, integrar todos los procesos y tener la menor cantidad de desperdicios y almacenes intermedios es a lo que deben de aspirar los fabricantes de muebles. Gracias a la representación de M3 de Alemania, ABC S.A.C. puede ofrecer desde cortadoras y enchapadoras de alta producción, así como programas de optimización de producción.

- Maquinaria para la industria de la madera: se refiere a toda máquina utilizada para procesar la madera en una segunda transformación (básicamente producción de molduras, pisos y mobiliario). Dentro de este grupo máquinas, se comercializan moldureras, cepilladoras, lijadoras, etc. La empresa representa a M6 (maquinaria de alta gama que permite acabados de excelente calidad) y a M4 (maquinaria con buena relación precio calidad).

- Herramientas y cola: se manejan distintas marcas para las distintas herramientas y sus propósitos. La variedad manejada permite cubrir aproximadamente el $80 \%$ 
del mercado de herramientas para la segunda transformación de la madera. En cuanto a la cola utilizada en las enchapadoras para el pegado de los cantos, se maneja la marca M7 de España en amplias variedades, las cuales varían dependiendo del color, el tipo de canto (curvo o recto) y la temperatura de aplicación y exterior.

Asimismo, ABC S.A.C. ofrece servicios que soportan la venta de los productos detallados líneas arriba. Entre ellos están:

- Servicio técnico de maquinaria: se dedica a la instalación de la maquinaria, a los mantenimientos reactivos y preventivos (casi todos son reactivos) y a la venta de repuestos. Importante mencionar que solo se realizan los servicios técnicos a la maquinaria que la empresa vendió o representa. Lamentablemente no se lleva un registro adecuado de todos los servicios brindados y el control sobre los repuestos deja mucho que desear. Siempre se ha buscado que este servicio se maneje como una rama independiente del negocio.

- Servicio de afilado: llega gracias a la compra de DEF S.A.C.. Este servicio consiste en el afilado de todas las herramientas utilizadas en la segunda transformación de la madera, ya sean vendidas por ABC S.A.C. o cualquier otra empresa. A la fecha, la contabilidad de ambas empresas se maneja por separado, por lo cual no se está considerando la información de DEF S.A.C..

En los siguientes cuadros basados en las ventas del año 2012 se puede observar la importancia y el peso de cada producto o servicio en las ventas totales de la empresa: 
Tabla 1.1

Ventas por tipo de producto (año 2012)

\begin{tabular}{|l|r|r|}
\hline Producto / Servicio & \multicolumn{1}{|c|}{ Ventas S/. } & \multicolumn{1}{c|}{ \% de ventas } \\
\hline Maquinaria & $7,303,779$ & $75 \%$ \\
\hline Consumibles & $1,168,605$ & $12 \%$ \\
\hline Servicio Técnico & $1,265,988$ & $13 \%$ \\
\hline Total & $\mathbf{9 , 7 3 8 , 3 7 2}$ & $\mathbf{1 0 0 \%}$ \\
\hline
\end{tabular}

Fuente: ABC S.A.C.

Elaboración propia

Tabla 1.2

Ventas de maquinaria (año 2012)

\begin{tabular}{|l|r|r|}
\hline \multicolumn{1}{|c|}{ Producto } & Ventas S/. & \multicolumn{1}{c|}{ \% de ventas } \\
\hline Escuadradora & $2,796,062$ & $38 \%$ \\
\hline Enchapadora & $2,134,987$ & $29 \%$ \\
\hline Cortadora Vertical & $1,026,147$ & $14 \%$ \\
\hline Sol. Int. Homag & 691,615 & $9 \%$ \\
\hline Maquinaria p/ madera & 654,967 & $9 \%$ \\
\hline Total & $\mathbf{7 , 3 0 3 , 7 7 9}$ & $\mathbf{1 0 0 \%}$ \\
\hline
\end{tabular}

Fuente: ABC S.A.C.

Elaboración propia

De los cuadros expuestos, podemos notar que la venta de maquinaria representa el 75\% del total de ingresos por ventas de ABC S.A.C., y dentro de este rubro, el 67\% de las ventas corresponden a escuadradoras y enchapadoras, siendo los productos bandera comercializados por la empresa, por lo cual para el análisis de procesos claves se tomará en cuenta la venta de maquinaria para el estudio de su problemática.

\subsubsection{Descripción del mercado objetivo de la empresa.}

ABC S.A.C. tiene como mercado objetivo la industria de la segunda transformación de la madera. Al ser un sector pequeño, no se limita a atender a ciertas empresas, sino que se atiende a cualquier posible interesado en los productos y servicios comercializados. Así, los clientes van desde un pequeño carpintero que requiere de 
alguna herramienta o que está pensando en comprar su primera máquina, hasta grandes empresas o grupos económicos que realizan compras de toda una línea de producción, pasando también por licitaciones del Estado.

- Emprendedores y pequeños carpinteros: es poco el volumen de compra de cada uno, pero hay gran cantidad de ellos. Es un nicho interesante ya que es la manera de conseguir nuevos clientes y volverlos cautivos y fieles a la empresa.

- Empresas medianas: son empresas que ya tienen cierto crecimiento y poder adquisitivo. Probablemente ya cuentan con alguna máquina y siempre están buscando mejorar.

- Empresas grandes: en el sector se encuentras pocas empresas como estas. Son las más atractivas ya que cuentan con poder adquisitivo y son los modelos a seguir de todos los emprendedores y empresas medianas - pequeñas.

- Clientes corporativos: como su nombre lo indican, son corporaciones con gran poder adquisitivo y que siempre intentan lograr mejores condiciones comerciales. Es un mercado interesante ya que sirven como referencia para clientes más pequeños.

- Licitaciones: en su mayoría son encargadas por el Estado, pero también hay algunas de otras instituciones. Los márgenes no son muy atractivos, pero lo interesante son los volúmenes de venta.

La atención de todas estas empresas e instituciones se da a nivel nacional, con especial atención en Lima por ser el lugar donde se encuentran las oficinas de la empresa.

\subsubsection{Estrategia general de la empresa}

Desde sus inicios, ABC S.A.C. optó por una estrategia de diferenciación, ya que siempre se ha caracterizado por vender calidad y buen servicio antes que productos de bajo precio. Al ser una empresa familiar, esta línea de pensamiento fue traspasada a las nuevas generaciones con facilidad y se ha mantenido así. Lamentablemente la Gerencia General no ha sabido elaborar un documento que contenga las estrategias específicas del negocio para el mediano y largo plazo. 


\subsubsection{Descripción de la problemática actual}

La empresa se encuentra sumida en fuertes obligaciones financieras con terceros, debido a una mala administración del crédito que impulsó las ventas en su momento pero se volvió un problema debido al considerable incremento de las cuentas por cobrar, siendo que muchas de ellas no se han podido cobrar hasta el momento. Asimismo, ABC S.A.C. cuenta con una estructura comercial muy costosa y poco adecuada para el mercado, con escasos procesos internos instaurados y prácticamente sin ningún tipo de control sobre ellos.

\subsection{Objetivos de la investigación (general y específicos)}

\subsubsection{Objetivo general}

Realizar un diagnóstico de la situación de ABC S.A.C. y plantear acciones de mejora en su proceso comercial, teniendo como finalidad la estabilidad financiera y el incremento de la rentabilidad, que permitan el crecimiento de la empresa y así mantener su puesto en el mercado como líder y agente generador de cambio en la industria de la transformación de la madera y sus derivados.

\subsubsection{Objetivos específicos}

Dentro de los objetivos específicos de la investigación, tenemos:

- Optimizar los recursos y lograr minimizar los costos y los tiempos, obteniendo los mismos o mejores resultados de manera más eficiente.

- Alcanzar la "profesionalización" de la empresa, estableciendo procedimientos, normas y controles claros, alineados a los objetivos de la empresa, áreas y a cada puesto de trabajo.

- Buscar una estructura organizacional más adecuada, centrada en el área comercial y secundada por los servicios suplementarios y la administración interna.

- Realizar trabajos de prospección en el mercado y el rubro, estudiando tendencias en países similares al Perú, para así poder generar demanda de nuevos productos. 


\subsection{Alcance y limitaciones de la investigación:}

A fin de conseguir mayor profundidad en el trabajo, se tendrá en cuenta los siguientes alcances:

- Tiempo: la investigación se realiza teniendo en cuenta la situación de la empresa a junio del año 2013. Para efectos del análisis de indicadores, se recurrirá a información pasada de la empresa desde el 2003 hasta el año 2012, a fin de tomar los datos de años completos. No se incluirá la información del año 2013 ya que sólo se cuenta con datos de 6 meses.

- Área: el proceso a investigar es el proceso comercial, el cual incluye los pronósticos de venta, los niveles de inventario, los procesos logísticos y controles de calidad, el proceso de venta en sí y finalmente el posventa.

- Mercado: se tendrá en cuenta solo el sector de la segunda transformación de la madera y a todos los participantes de la misma (empresas comercializadoras, productivas y que brindan algún tipo de servicio).

En cuanto a las limitaciones, se tomarán en cuenta:

- La falta de información puntual del sector maderero, especialmente de la segunda transformación. Lamentablemente no se cuenta con información específica de este sector, por lo que se recurrirá a algunos de mayor tamaño (sector de manufacturas, comercio o industria).

- Al ser una empresa familiar pequeña-mediana, mucha de la información interna no es almacenada de manera adecuada, por lo que es posible que puedan existir vacíos en ciertos datos.

\subsection{Justificación de la investigación}

\subsubsection{Justificación técnica}

Técnicamente la investigación es totalmente factible. Se emplearán teorías y técnicas ya desarrolladas con éxito en industrias similares, buscando siempre la mejor adaptación de las mismas. 
Tomará tiempo ver los resultados de las acciones y técnicas implementadas, especialmente aquellas que involucren la participación de personal no debidamente calificado, pero aun así la implementación es viable.

Se buscarán las mejores alternativas de mejora, las cuales se expondrán a los jefes de área discutiendo su viabilidad, para luego ser instauradas, fomentadas y debidamente controladas.

\subsubsection{Justificación económica}

Mediante esta mejora se busca darle estabilidad, orden y controles a la empresa. Todo esto tiene como objetivo:

- Optimizar procesos y conseguir atender a más clientes y de mejor manera, dando como resultado mayor cantidad de ventas en un futuro cercano.

- Reducir los niveles de costos al mínimo necesario, consiguiendo bajar el punto de equilibrio y obteniendo así una mejor utilidad bruta.

\subsubsection{Justificación social}

Al ser uno de los objetivos del trabajo y de la empresa el profesionalizar y desarrollar la industria de la segunda transformación de la madera, el impacto social que va a generar este proceso se verá reflejado en las mejoras de las familias que estén relacionadas a la misma.

Hace unos veinte años ABC S.A.C. vendió la primera escuadradora, máquina destinada al corte de los tableros de melamine. Apostar por este tipo de maquinaria en aquella época ayudó al desarrollo de la industria y a cambiar todo lo establecido: mayor producción y muebles más baratos. El impacto lógicamente no fue solo para aquellas personas relacionadas con la industria, sino también para todos los consumidores finales.

\subsection{Hipótesis de la investigación}


Con una adecuada reestructuración del proceso comercial se conseguirán tomar decisiones más acertadas y afrontar de mejor manera la evolución del mercado y la competencia.

Asimismo, comunicar de forma adecuada la misión, visión, estrategias y objetivos de la empresa e involucrando al personal en ello, impactará de manera positiva en la moral de los empleados, acelerando el proceso de profesionalización de la empresa.

\subsection{Marco referencial de la investigación}

Dado que es reestructuración organizacional de una pequeña empresa familiar en un rubro no muy conocido, conseguir referencias iguales o muy similares, es complicado y las opciones son limitadas.

\section{Las mejores referencias encontradas son:}

- Mejora integral del Fundo San Crispin (León-Gambetta, 2011): trabajo que detalla el diagnóstico y las mejoras aplicadas en el fundo San Crispin, productor de café. Tiene un trabajo interesante en lo que refiere a indicadores de gestión y además la búsqueda del problema principal mediante diagramas causa / efecto y Pareto.

- Mejora integral de una empresa de confecciones (Caldas, 2002): presenta un organigrama similar al que se encuentra en la empresa a estudiar. Además, detalla cuales son las facultades, tareas y deberes de cada uno de los puestos.

- Mejora integral en la empresa Cartonería y Envases Piura SAC (Escalante, 2014): los problemas encontrados son similares a los de la empresa a estudiar: falta de planeamiento estratégico y control de procesos; falta de procedimientos estandarizados; desorden y poco acceso a la información; ausencia de un sistema informático, así como de presupuestos para cada área.

- Mejora en el proceso de producción de una empresa de artes gráficas (Delgado, 2013): buena justificación del trabajo, tanto técnica, económica y social. Así 
mismo, describe muy bien los productos y detalla cuales son los porcentajes de venta de cada uno y los márgenes promedio.

\subsection{Marco conceptual}

La propuesta de proyecto se basa en la situación de la empresa a junio de 2013. A pesar de tener más de 58 años de funcionamiento, el grado de profesionalismo de la empresa es mínimo, por lo que se centrará en reestructurar el proceso clave del negocio y todo lo relacionado con el mismo: ventas. Así, la propuesta va desde un nuevo organigrama, con todo lo que puede conllevar este cambio, pasando por la revisión de los pronósticos de ventas, los procesos logísticos intermedios y llegando hasta el servicio posventa y los controles de calidad y consideraciones de los clientes. 


\section{CAPÍTULO II. ANÁLISIS SITUACIONAL DE LA EMPRESA Y SELECCIÓN DEL PROCESO A SER MEJORADO}

\subsection{Análisis Externo de la Empresa}

\subsubsection{Análisis del entorno global}

A fin de tener una mejor visión del entorno de la empresa, se ha decidido analizar los siguientes factores externos:

\section{- Entorno político y legal}

La coyuntura política que vive el Perú a mediados del año 2013 no es ideal, pero es bastante buena. Se ha mantenido una misma línea política, lo que ha permitido una relativa estabilidad. Lamentablemente el país nunca se libra de una desaceleración previa a las elecciones debido al pobre nivel que muestran los candidatos, ya sea a la Presidencia u otros cargos de importancia.

Hay que tener en cuenta además que a la fecha se siguen firmando tratados de libre comercio con otros países, lo que facilita la importación, tanto a ABC S.A.C. como a potenciales competidores.

En cuanto a temas legales, debemos de mencionar ciertos aspectos que impactan en la empresa, tanto de manera positiva como negativa:

- El Perú es uno de los países que más beneficios brinda a los trabajadores. Dichos beneficios finalmente se vuelven contra los trabajadores y las empresas, ya que no permite subir los sueldos y los trabajadores, al no ver mejoras en los mismos, deciden buscar nuevas oportunidades, obligando a la empresa a recurrir nuevamente en gastos de capacitación. 
- Asimismo, hay una excesiva protección de los trabajadores en los juzgados laborales. Es muy complicado rescindir un contrato sin, probablemente, caer en algún altercado legal y hasta judicial.

- No existe tampoco una adecuada sanción contra los clientes morosos, por lo que es muy fácil aumentar la cartera de incobrables. Por ello lo ideal es siempre tener un contrato de compra-venta a fin de que ambas partes puedan resguardarse si es que alguna de ellas no cumple con lo prometido.

- A pesar de las nuevas leyes para promover la formalización de negocios y mejoras en las condiciones laborales de los trabajadores en el Perú, no se registra una mejora significativa en el porcentaje. Por el contrario, existe la sensación de que los controles por parte de las entidades del estado (Defensa Civil, municipios, SUNAT y otros) han aumentado y pareciera que se enfocan en regular a las empresas ya establecidas, dejando de lado a las informales y generando mayor competencia desleal.

Por lo expuesto y haciendo un balance entre los aspectos negativos y positivos, se concluye que el entorno político y legal no es favorable para el desarrollo de la empresa, pero sin riesgos de hacer inviable la operación de la misma.

\section{- Entorno económico}

Como ya se mencionó, el hecho de tener políticas gubernamentales relativamente similares en los últimos años ha ayudado al crecimiento del país. E1 fomento de las inversiones extrajeras, especialmente en el campo de la minería, ha logrado conseguir un crecimiento promedio de $9.5 \%$ en los últimos 8 años. Es importante mencionar que los valores de crecimiento han ido bajando en los últimos meses debido a la crisis europea y estadounidense, lo que afectó la demanda de recursos mineros y otros bienes.

En cuanto al sector de la segunda transformación de la madera, no se tienen mayor información del mismo en lo que respecta cifras. Es por ello que se ha decidido revisar 2 subsectores que están relacionados al negocio de la empresa. El primero es el sector Manufactura, del cual se espera tener una idea de cómo se han desarrollado los fabricantes de muebles. El segundo subsector es el de Construcción. Este sector está 
estrechamente ligado al del negocio, ya que mientras más construcción de viviendas $u$ oficinas, mayor será el requerimiento de muebles y por lo tanto también de bienes y servicios necesarios para fabricar los mismos.

En cuanto a la evolución del crecimiento de estos subsectores, tenemos el siguiente gráfico:

Figura 2.1

Evolución del crecimiento de los subsectores manufactura y construcción

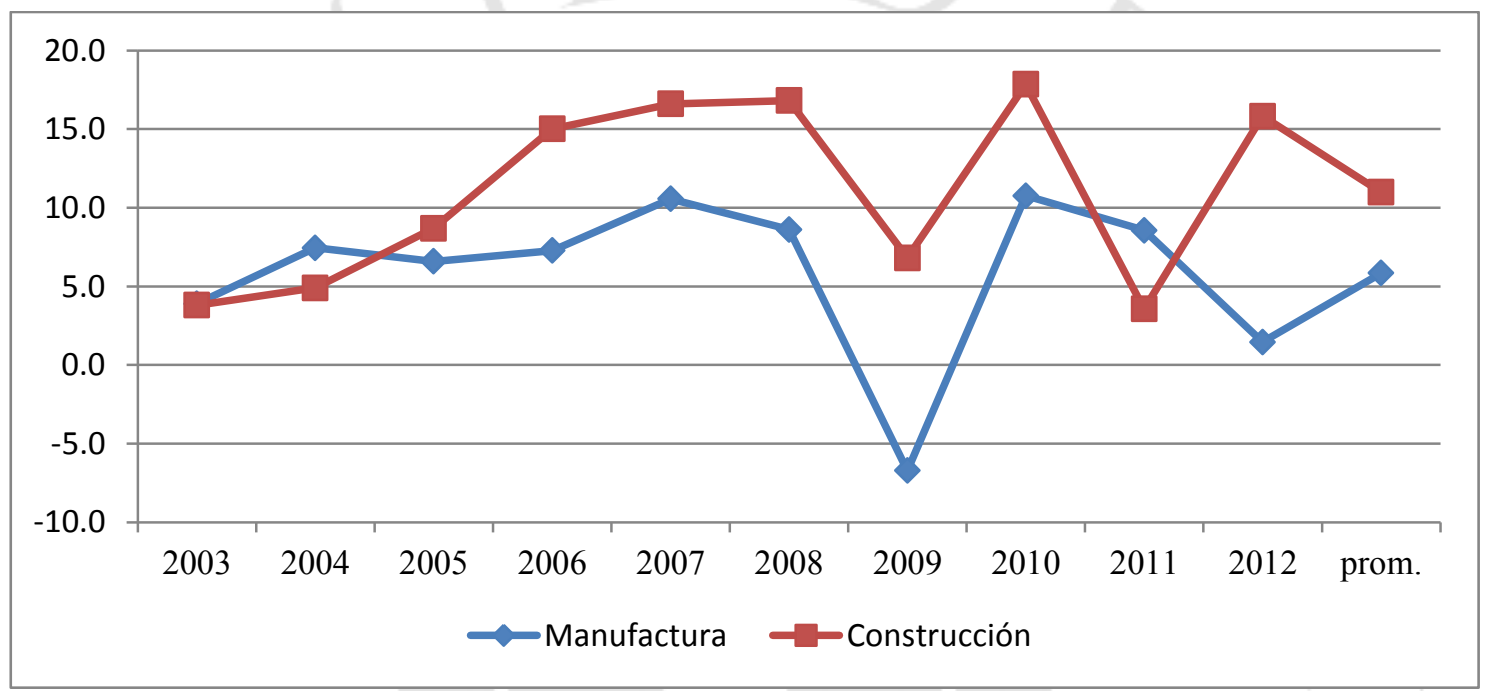

Fuente: INEI (2014)

Elaboración propia

Como se puede ver, ambos sectores tienen tendencias similares, salvo en algunos años. El sector construcción es el que registra mayor dinamismo desde el año 2003, pero lamentablemente ambos subsectores desde el 2010 tienden a la baja. Si bien es cierto que aun registran números positivos, el sector se ha contraído y todo indica que seguirá así los siguientes años.

Otro aspecto a tener en cuenta es el acelerado desarrollo que están presentando las provincias del Perú. Esto permite el crecimiento de ambos sectores, construcción y manufacturas, lo que se traduce a su vez en mayor cantidad de ventas en el sector de la segunda transformación de la madera.

Dada la situación mostrada, el entorno económico resulta favorable para $\mathrm{ABC}$ S.A.C.. 
- Entorno social

Los efectos de un fuerte crecimiento del empleo y de los ingresos han reducido los índices de pobreza en el país considerablemente en los últimos años. Se estima que en el 2013, aproximadamente medio millón de personas escaparon de la pobreza. Sin embargo, el grado de instrucción de la posible fuerza laboral para el sector manufactura no ha avanzado a la par con el crecimiento de los ingresos. Asimismo, se carece de instituciones educativas técnicas con foco en el sector y las relacionadas tienen un nivel muy básico.

Con relación a la empresa, el entorno social no tiene mucha influencia sobre los resultados de la misma, por lo cual se considera neutral.

\section{- Entorno tecnológico}

Si se compara el sector de la segunda transformación del Perú con otros de la región (Chile o Colombia), se ve claramente que el Perú está bastante atrasado respecto a ellos. La falta de profesionalismo y los bajos niveles de exigencia del mercado hacen que los productores de muebles no busquen mejoras tecnológicas para incrementar sus niveles de productividad y rendimiento.

En los últimos años, gracias a una mayor integración regional y la globalización, muchas empresas extranjeras han decidido abrir alguna sucursal en el Perú y así aprovechar al máximo su productividad. Esta competencia obligará a los productores locales a mejorar sus estándares de calidad y producción, solo posible con mejoras tecnológicas.

Es importante mencionar además que el nivel tecnológico del sector está llegando a un límite físico y que ahora se está pasando a la integración de procesos mediante programas computarizados. Son pocas las empresas a nivel mundial que pueden ofrecer una solución integral (máquinas y programas integrados).

Finalmente vale recalcar que en el Perú existe el CiteMadera (Centro de Innovación Tecnológico), entidad manejada por el Ministerio de la Producción. Su 
función es promover la innovación e impulsar la competitividad, mejorando la calidad en las diferentes etapas de transformación e industrialización de la madera; asimismo, desarrolla programas de investigación aplicada en la cadena productiva y sirve como soporte tecnológico de la producción en el sector de madera y muebles. Lamentablemente su presencia es poco conocida en el Perú (muchos de los clientes de ABC S.A.C. no lo conocen o no saben a qué se dedica).

Por lo expuesto, el entorno tecnológico es favorable para el desarrollo de $\mathrm{ABC}$ S.A.C. ya que la globalización obligará a una mejora tecnológica en la segunda transformación de la madera, siendo ABC S.A.C. quien se encuentra a la vanguardia en cuanto a la maquinaria ofrecida.

\subsubsection{Análisis del entorno competitivo}

A fin de entender el entorno competitivo de la empresa y del mercado, se utilizará el modelo de las cinco fuerzas de Porter.

- Poder de negociación de los compradores o clientes:

El poder de negociación de los clientes es alto, ya que actualmente hay en el mercado mucha competencia. Existe un alto porcentaje de clientes que deciden entrar al negocio de la segunda transformación de la madera sin conocer mucho acerca del mismo, por lo cual los argumentos de calidad de maquinaria, servicios post venta y garantía dejan de tener mucha importancia y la decisión de compra se determina por el precio y la empatía del vendedor con el comprador.

Son pocas las máquinas con grandes diferenciales técnicos, por lo que la mayoría de los productos se consideran commodities. Las exigencias técnicas de los clientes son muy elementales debido el escaso conocimiento y nivel de profesionalismo de sus negocios.

Al haber clientes con pocas exigencias técnicas, la barrera de entrada para nuevos proveedores es menor y facilita el ingreso de más participantes y una potencial guerra de precios, dándole mayor poder a los compradores. 
Lo que le quita un poco de poder a los compradores, es la lealtad a la marca. ABC S.A.C. es la empresa más reconocida a nivel nacional gracias a la calidad de productos y servicios que ofrece. La empresa cuenta con clientes muy fieles, pero, debido a la gran cantidad de oferta de otras empresas, estos deben de debatir constantemente si la fidelidad vale la pena en la situación actual del mercado.

- Poder de negociación de proveedores o vendedores:

El poder de negociación de los proveedores es bajo debido a su baja concentración, al existir muchas empresas que suministran máquinas iguales o muy similares. Si a esto le agregamos en los últimos años la posibilidad de comprar maquinaria china comparativamente más barata, los proveedores basan sus ventas en la calidad de relación que han podido entablar con el pasar de los años y en los niveles de financiamiento que puedan otorgarles a sus distribuidores.

Lo que algunas empresas extranjeras fabricantes de maquinaria han hecho en algunos países es abrir su propio canal de distribución. Sin embargo, esto solo sucede en países donde los mercados son muy grandes y atractivos, caso que no es el peruano.

- Amenazas de nuevos competidores:

La amenaza de nuevos competidores es alta dado que como ya se mencionó, las barreras de entrada en este rubro son bajas, puesto que sólo se requiere de la inversión de capital inicial. No hay regulaciones gubernamentales que limiten el ingreso de nuevas empresas al sector.

Por otro lado, el bajo conocimiento técnico de los clientes hace que este negocio esté muy sesgado por el precio, por lo que el know-how de la maquinaria y los servicios no son muy valorados y no puede ser considerado como un requerimiento para poder ingresar como un nuevo participante en el mercado. Asimismo, los clientes no incurren en costos por cambiar de proveedor, lo cual facilita el ingreso al sector. 
Además, las ferias internacionales de maquinaria son cada vez más grandes y cada vez más accesibles para potenciales competidores o, incluso, potenciales clientes finales.

- Amenaza de productos sustitutos:

La maquinaria y los insumos relacionados a la industria de la madera y específicamente para los de la segunda transformación, son muy similares entre los diferentes fabricantes y han variado poco con el pasar de los años, por lo cual la amenaza de sustitutos es baja.

En todo caso, el negocio que si se ve afectado por sustitutos es el de la segunda transformación, puesto que la venta de muebles de plástico se ha incrementado en los últimos años gracias a su menor costo con comparación con muebles de madera; lógicamente, esto afecta a ABC S.A.C. por ser proveedor de los fabricantes de muebles de madera.

- Rivalidad entre competidores.

Por lo expuesto en los puntos anteriores, se observa que la rivalidad en el mercado es muy alta, considerando la alta estandarización de productos comercializados, el nulo o mínimo costo de cambiar de proveedor por parte de los compradores y las bajas barreras tanto de entrada como de salida del sector.

Son muchos los participantes para un mercado aun chico, por lo que se espera que en los próximos años haya una fase de "depuración”, en la cual sobrevivirán aquellas empresas que tengan sus procesos ordenados, niveles de costos adecuados para sus ventas y que puedan influir en la tendencia del mercado.

A continuación revisaremos las importaciones de los principales competidores del sector: 
Tabla 2.1

Importaciones de empresas principales del sector (S/.)

\begin{tabular}{|l|r|r|r|r|}
\hline \multicolumn{1}{|c|}{ Empresa } & \multicolumn{1}{c|}{$\mathbf{2 0 0 9}$} & \multicolumn{1}{c|}{$\mathbf{2 0 1 0}$} & \multicolumn{1}{c|}{$\mathbf{2 0 1 1}$} & \multicolumn{1}{c|}{$\mathbf{2 0 1 2}$} \\
\hline ABC S.A.C & $1,090,364$ & $1,387,351$ & $1,535,681$ & $1,892,118$ \\
\hline Rep. Martin S.A.C & 276,302 & 163,972 & 463,057 & 581,384 \\
\hline Imheco & 30,765 & 73,976 & 84,653 & 401,523 \\
\hline Grupo Benaute & 0 & 10,567 & 14,792 & 299,550 \\
\hline Cimile & 112,954 & 221,346 & 194,540 & 288,198 \\
\hline Carpicentro & 0 & 245,673 & 28,518 & 286,115 \\
\hline Soluciones Modul. & 0 & 31,976 & 45,595 & 212,989 \\
\hline Vitemaq & 100,465 & 20,543 & 29,320 & 86,543 \\
\hline TLR Group & 176,510 & 265,297 & 190,668 & 3,845 \\
\hline \multicolumn{1}{|c|}{ TOTAL } & $1,789,369$ & $2,422,711$ & $2,588,835$ & $4,054,276$ \\
\hline
\end{tabular}

Fuente: SUNAT (s.f.)

Elaboración propia

Tabla 2.2

Participación en importaciones del sector

\begin{tabular}{|l|r|r|r|r|}
\hline \multicolumn{1}{|c|}{ Empresa } & $\mathbf{2 0 0 9}$ & $\mathbf{2 0 1 0}$ & $\mathbf{2 0 1 1}$ & \multicolumn{1}{c|}{$\mathbf{2 0 1 2}$} \\
\hline ABC S.A.C & $61 \%$ & $57 \%$ & $59 \%$ & $47 \%$ \\
\hline Rep. Martin S.A.C & $15 \%$ & $7 \%$ & $18 \%$ & $14 \%$ \\
\hline Imheco & $2 \%$ & $3 \%$ & $3 \%$ & $10 \%$ \\
\hline Grupo Benaute & $0 \%$ & $0 \%$ & $1 \%$ & $7 \%$ \\
\hline Cimile & $6 \%$ & $9 \%$ & $8 \%$ & $7 \%$ \\
\hline Carpicentro & $0 \%$ & $10 \%$ & $1 \%$ & $7 \%$ \\
\hline Soluciones Modul. & $0 \%$ & $1 \%$ & $2 \%$ & $5 \%$ \\
\hline Vitemaq & $6 \%$ & $1 \%$ & $1 \%$ & $2 \%$ \\
\hline TLR Group & $10 \%$ & $11 \%$ & $7 \%$ & $0 \%$ \\
\hline
\end{tabular}

Fuente: SUNAT (s.f.)

Elaboración propia

Como se observa en las tablas precedentes, el sector ha registrado un incremento en las importaciones que sin duda han afectado la participación de mercado de ABC S.A.C.; sin embargo, esta participación de importaciones no es el fiel reflejo de la participación de mercado, ya que hay empresas dentro de este grupo que tienen otras importaciones o importan maquinaria para uso propio y no exclusivamente para la venta.

A continuación se presenta una breve descripción de las principales empresas del sector: 
- Carpicentro S.A.C.: es una empresa que se dedica a la comercialización de tableros de melamine y que además, como negocio complementario, vende maquinaria. Es evidente que es un negocio complementario, ya que es poco constante en sus importaciones, ya que no registra ninguna importación en ciertos años. No debería de ser una preocupación.

- Cimile: empresa de capitales peruano - coreanos. Importaba en sus inicios maquinaria coreana de excelentes prestaciones y a precios muy competitivos. Además complementaba su oferta con políticas de crédito muy agresivas. Eventualmente fue cambiando la procedencia de sus máquinas a China y dando aún más crédito, lo que se traduce en un aumento considerable de sus importaciones en el año 2012. Según informaron, la empresa tiene muchos problemas para cobrar a sus clientes, por lo que probablemente haya una desaceleración en sus ventas en los próximos años.

- Grupo Benaute: al igual que el caso anterior, es una empresa que comercializa en su mayoría maquinaria china y da condiciones de crédito muy convenientes para sus clientes. Aun así no es tan agresivo en ese sentido como CIMILE, pero puede llegar a ser un competidor importante, especialmente si logra consolidar la empresa de manera adecuada.

- Imheco: es una empresa que busca copiar a ABC S.A.C. en casi todo. Importa maquinaria de buena calidad (europea o coreana en su mayoría) y brinda facilidades de crédito, pero no tan agresivas como en los casos anteriores. Sin lugar a duda es una empresa que podrá ser un competidor importante en un futuro.

- Representaciones Martin: es otra empresa que se dedica a la comercialización de tableros de melamine y que además, como negocio complementario, vende maquinaria. Registra picos de importaciones (año 2012 y algunos anteriores no mostrados en la tabla) básicamente porque realiza compras para su propia planta. 
- Soluciones modulares: es una empresa que importa maquinaria de Brasil de calidad media y precio acorde. Si bien es cierto que aún es pequeña en comparación a las demás, será un agente a tener en cuenta en un futuro relativamente cercano.

- TLR Group tiene la representación de una línea de maquinaria europea de reconocida trayectoria mundial. Como se observa, tuvo mejores años y actualmente está pasando por un periodo de recesión.

Como se mencionó, estas empresas son las principales del sector, pero existen muchos competidores más pequeños, por lo cual realizaremos un análisis de grupos estratégicos del sector. A fin de ubicar a las empresas del sector en un solo gráfico se ha considerado los siguientes supuestos:

- Se asume que la relación de precio - calidad es directamente proporcional, por lo que a mayor precio, mayor calidad y viceversa.

- Se considera además la cantidad de productos o servicios que se ofrece. Esto determinará el tamaño de las empresas del sector. Los productos que se ofrecen actualmente en el mercado son:

- Venta de maquinaria

- Venta de consumibles (herramientas, colas y otros renovables)

- Servicio técnico de maquinaria

- Servicio de afilado para las herramientas de corte utilizadas en la industria.

Teniendo en cuenta estos supuestos, se presenta el siguiente gráfico: 
Figura 2.2

Grupos estratégicos del sector

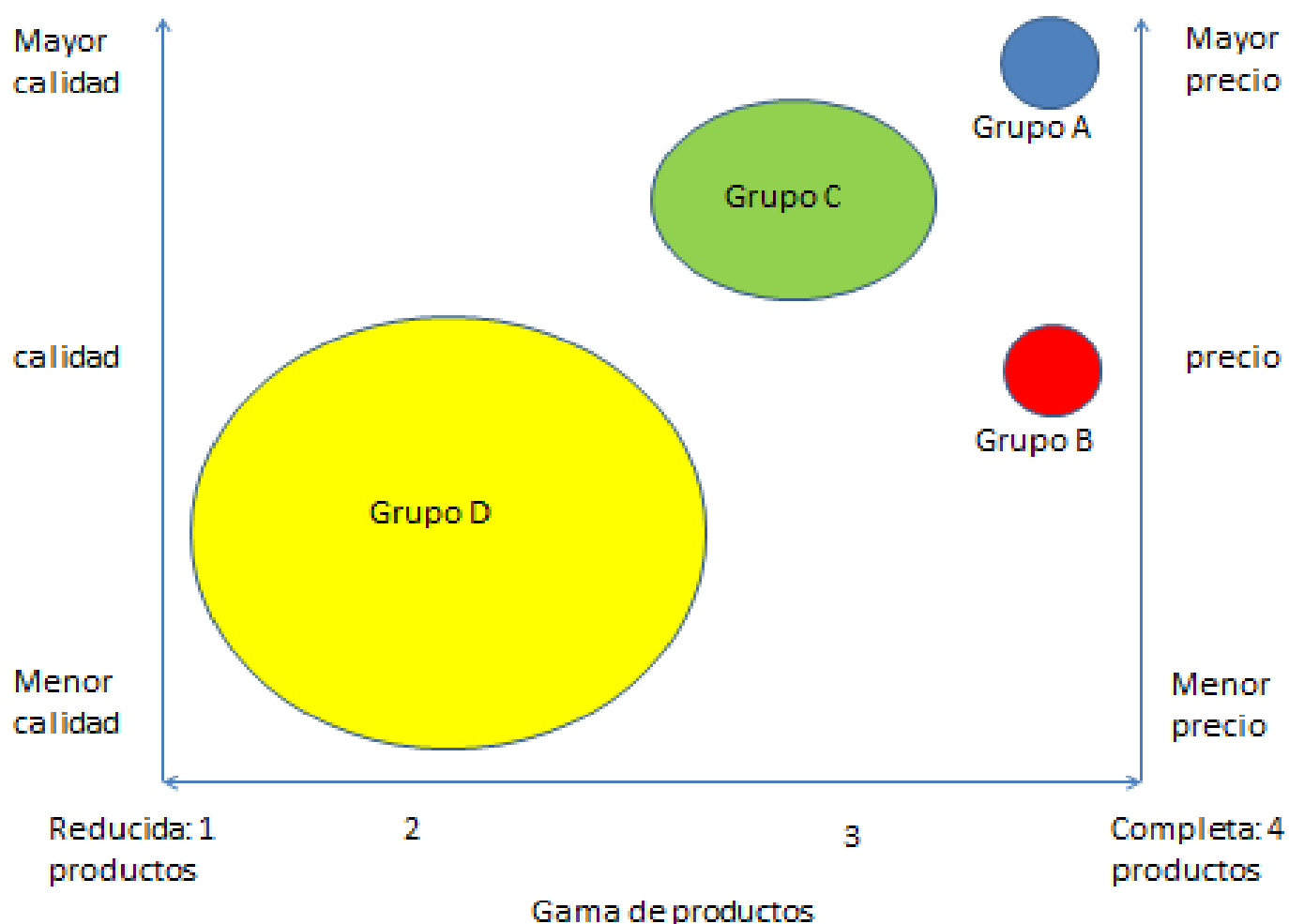

Fuente: ABC S.A.C.

Elaboración propia

En donde:

- Grupo A: son empresas que ofrecen toda la gama de productos y servicios que además son de excelente calidad y posiblemente los más caros del mercado.

- Grupo B: empresas que ofrecen toda la gama de productos y servicios, pero con precios más cómodos. Lógicamente la calidad de los bienes y servicios no son los mejores.

- Grupo C: empresas que ofrecen entre dos a tres productos y/o servicios y que tienen una buena calidad.

- Grupo D: empresas que tienen dos o menos productos y/o servicios y que al ofrecer precios muy competitivos, sacrifican la calidad de los mismos.

- Los tamaños de las circunferencias son relativos a la cantidad de participantes en cada grupo estratégico

La empresa ABC S.A.C. es el único integrante del grupo A, por lo que tiene una clara diferenciación con sus otros competidores. En el grupo B también se 
encuentra una sola empresa (Cimile). En el grupo C se encuentran la mayoría de empresas mencionadas, mientras que, en el grupo $\mathrm{D}$, son tantas y tan volátiles que es difícil identificarlas a todas.

Es importante mencionar que el mercado ha tenido un crecimiento bastante rápido en los últimos años influenciado en gran medida al crecimiento del país. Para tener una idea más clara de este desarrollo se presente el siguiente gráfico y las respectivas conclusiones:

Figura 2.3

Evolución de los grupos estratégicos del sector (2003 vs. 2013)

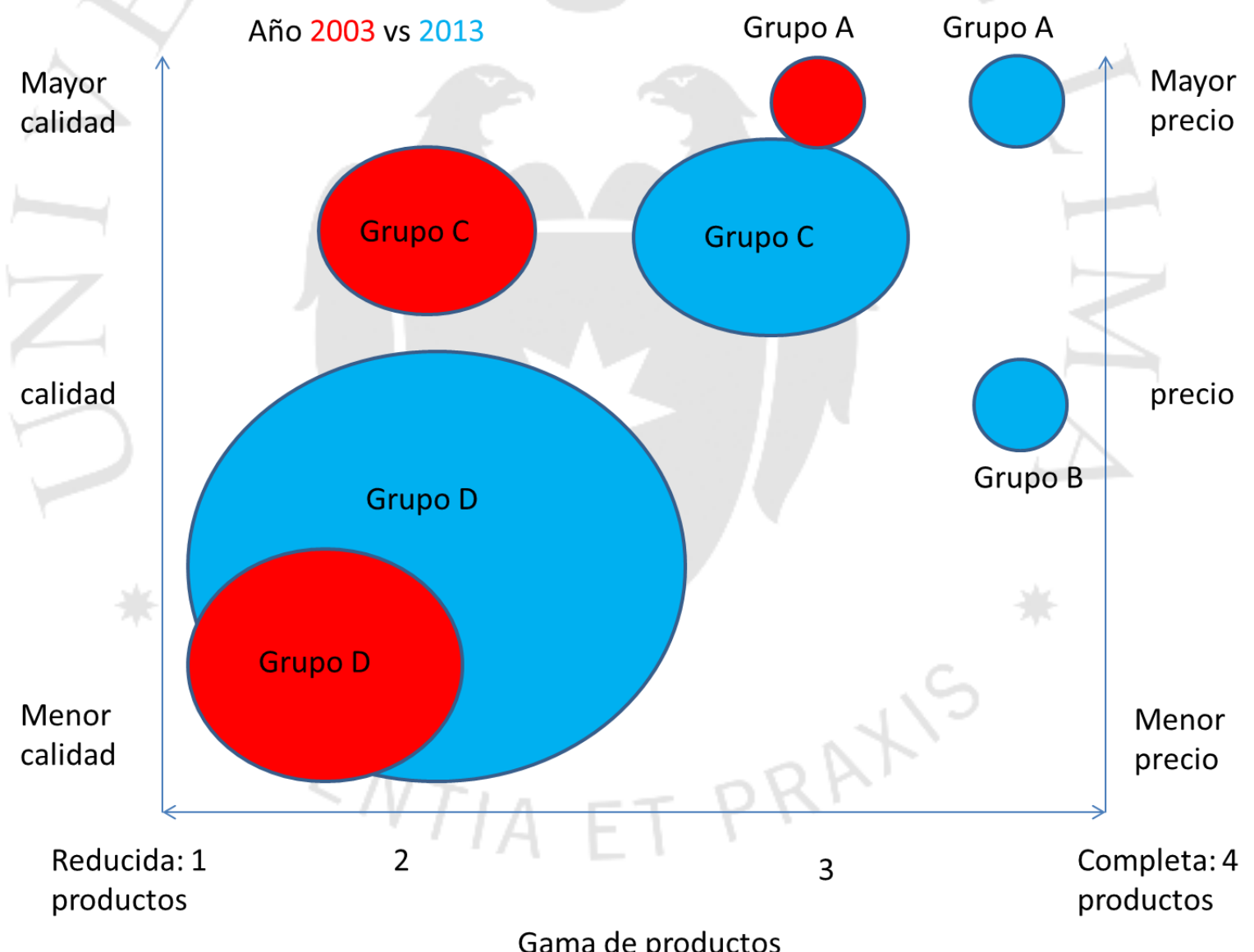

Fuente: ABC S.A.C.

Elaboración propia 
- Sin lugar a duda la competencia en el sector aumentó en los últimos años, especialmente en el grupo D (un solo producto de mala calidad o los que brindan un solo servicio y de mala calidad). Esto se debe principalmente a la facilidad con que se pueden importar bienes desde el extranjero (especialmente China) y las oportunidades que ven algunos emprendedores en negocios con bajas barreras de entrada.

- Asimismo el crecimiento del grupo C y la aparición del grupo B ratifican este incremento en la competencia del sector.

- El grupo A (ABC S.A.C.), aumenta su gama de productos de tres a cuatro. La empresa, luego de la compra de DEF S.A.C., empresa que se dedica a brindar servicio de afilado a las herramientas del sector, obtuvo una nueva diferenciación con respecto a sus competidores.

- Los competidores del grupo C, los que mantienen una buena calidad, también ampliaron sus negocios adquiriendo nuevos productos.

\subsubsection{Identificación y evaluación de las oportunidades y amenazas del} entorno

Teniendo en cuenta los factores externos revisados y con la finalidad de presentar una conclusión adecuada, a continuación se presenta la matriz de evaluación de factores externos (EFE), la cual califica con cuanta eficacia responden las estrategias actuales de la empresa a cada factor externo: 
Tabla 2.3

Matriz EFE

\begin{tabular}{|c|c|c|c|c|c|}
\hline \multicolumn{2}{|c|}{ Oportunidades } & Problema & Peso & Calificación & Peso ponderado \\
\hline 1 & $\begin{array}{l}\text { Posibilidad de contacto con } \\
\text { nuevos y buenos proveedores }\end{array}$ & Pasivo & 0.06 & 2 & 0.11 \\
\hline 2 & $\begin{array}{l}\text { Relativa estabilidad económica } \\
\text { del país }\end{array}$ & Activo & 0.09 & 2 & 0.17 \\
\hline 3 & $\begin{array}{l}\text { Desarrollo de provincias } \\
\text { acelerado }\end{array}$ & Activo & 0.09 & 3 & 0.26 \\
\hline 4 & $\begin{array}{l}\text { Crecimiento del sector } \\
\text { inmobiliario }\end{array}$ & Pasivo & 0.06 & 3 & 0.17 \\
\hline 5 & $\begin{array}{l}\text { Posibilidad de creación de } \\
\text { escuelas/capacitaciones }\end{array}$ & Crítico & 0.11 & 3 & 0.34 \\
\hline \multicolumn{2}{|c|}{ Amenazas } & Problema & Peso & Calificación & Peso ponderado \\
\hline 6 & Poca oferta de personal calificado & Activo & 0.09 & 1 & 0.09 \\
\hline 7 & $\begin{array}{l}\text { Pobre desarrollo tecnológico y } \\
\text { profesionalismo del sector } \\
\text { industrial maderero }\end{array}$ & Crítico & 0.11 & 2 & 0.23 \\
\hline 8 & $\begin{array}{l}\text { Pocos clientes dispuestos a pagar } \\
\text { por un buen servicio/producto }\end{array}$ & Crítico & 0.11 & 2 & 0.23 \\
\hline 9 & $\begin{array}{l}\text { Bajas barreras de entrada para } \\
\text { otros competidores }\end{array}$ & Crítico & 0.11 & 2 & 0.23 \\
\hline 10 & Pocos controles gubernamentales & Activo & 0.09 & 1 & 0.09 \\
\hline 11 & $\begin{array}{l}\text { Muchos pequeños competidores } \\
\text { con ventaja de precios contra el } \\
\text { líder }\end{array}$ & Pasivo & 0.06 & 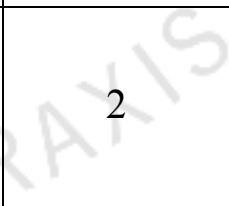 & 0.11 \\
\hline 12 & $\begin{array}{l}\text { Cambio de gobierno año } 2016 \text { y } \\
\text { posible desaceleración económica }\end{array}$ & Indiferente & 0.02 & 1 & 0.02 \\
\hline \multicolumn{3}{|c|}{ Total: } & 1.00 & & 2.05 \\
\hline
\end{tabular}

Fuente: Propia

Elaboración propia

Luego de analizar la matriz, se llega a las siguientes conclusiones: 
- El promedio ponderado de los factores externos de 2.05 indica que la empresa no está tomando buenas decisiones para aminorar las amenazas y aprovechar las oportunidades.

- El entorno externo de la empresa es ligeramente favorable al desarrollo del negocio (las oportunidades con un promedio ponderado de 1.06 es mayor que las amenazas con 1.00). Sin embargo, la diferencia es mínima, por lo que la situación puede cambiar en poco tiempo y es posible que se tengan que tomar medidas a corto y mediano plazo para afrontar cualquier problema futuro.

- La empresa puede aprovechar el pobre desarrollo tecnológico de la industria para crear escuelas o centros de capacitación y así intentar cambiar la idiosincrasia del sector y de los clientes en lo que refiere a productos de mala calidad y baja productividad, pero de precio económico.

- La empresa debe de delinear claros procesos y funciones de los trabajadores y ofrecerles recompensas por sus logros, a fin de conseguir mayor compromisos de los mismos y evitar la fuga de talento y posibles futuros competidores.

\subsection{Análisis Interno de la Empresa}

\subsubsection{Análisis del direccionamiento estratégico: visión, misión y objetivos organizacionales.}

Como ya se mencionó, ABC S.A.C. pasó por algunos cambios a nivel de Directorio y Gerencial, los cuales influenciaron, sobre todo, en la misión de la empresa. Para el año 2010, antes de la formación del Directorio, la misión de la empresa era:

"Brindar soluciones integrales a la industria maderera peruana para hacerla más competitiva y eficiente, y pueda enfrentar con éxito el reto de la globalización."

Luego de la formación del Directorio, la misión se simplificó:

"Ser un factor relevante para el desarrollo de las Empresas del sector Madera y Tableros." 
Este cambio sugerido por el Directorio en su momento fue acertado. La misión debe de describir la razón por la cual existe la empresa ("ser un factor relevante para el desarrollo") y debe de enfocarse en las necesidades del cliente ("empresas del sector madera y tableros").

En cuanto a la visión, la cual data de inicios de la década pasada y se ha mantenido igual en los últimos años, es la siguiente:

"Ser un factor relevante de desarrollo de la industria maderera, ofreciendo soluciones dirigidas al uso eficiente de los recursos madereros en el Perú"

En sí la visión de la empresa cumple con casi todos elementos, salvo con delimitar el marco competitivo. La empresa se fundó hace aproximadamente 60 años y hace más de 40 años se centra en la venta de soluciones para la industria de la segunda transformación de la madera.

En ambos casos, tanto misión como visión, tienen un estilo formal de redacción, el cual es el indicado para una empresa que quiere que la reconozcan por su presencia, seriedad y trascendencia en el mercado.

En el caso de los objetivos organizacionales, la empresa no registra nada por escrito. Esto es una clara muestra de que la comunicación interna y la estructura organizacional no son de las mejores. Los empleados creen saber cuáles son los objetivos de la empresa, cuando en realidad esto no sucede, y cada uno de ellos busca sus propios objetivos y metas, dejando de lado los intereses los de la empresa.

Por otro lado, la empresa si desarrollo y comunicó los valores de la organización, los cuales son:

1. Equidad: Creemos que el éxito mutuo depende de la confianza y lealtad que tengamos entre los socios, con nuestro personal, con nuestros aliados y proveedores, clientes y en general con la comunidad de la que formamos parte. 
2. Innovación y profesionalismo: Tenemos el deber de innovar $y$ mejorar continuamente, logrando la total satisfacción de nuestros clientes, a través de nuevas ideas y una mayor eficiencia en nuestro servicio al cliente.

3. Priorización del capital humano: Nuestro principal recurso será nuestro capital humano, siendo la empresa responsable de su personal. Debemos respetar su dignidad y reconocer su mérito, y nos comprometemos a apoyarlos en su búsqueda de desarrollo.

4. Honestidad: Creemos en los valores de la honestidad, responsabilidad, y trabajo en equipo como base de la organización, velando siempre por el desarrollo adecuado de la empresa y aceptando críticas al desempeño de la organización.

5. Rentabilidad: La rentabilidad económica y social es la única manera de garantizar nuestra supervivencia a largo plazo.

De alguna manera estos valores se acercan a delinear los objetivos de la empresa, pero carecen de ciertas características con las que los objetivos deben contar, como por ejemplo:

- Deben ser específicos

- $\quad$ Deben ser medibles

- $\quad$ Deben ser alcanzables

- $\quad$ Deben ser realistas

- $\quad$ Deben desarrollarse en un tiempo definido.

Los valores pueden dar una idea de lo que busca la empresa, pero no llegan a ser metas medibles y alcanzables en un tiempo determinado; se tiene una idea general de lo que son las metas, pero no un plan de acción para concretarlas.

Asimismo para complementar el análisis del direccionamiento estratégico, se presenta el modelo de negocio Canvas de ABC S.A.C.: 
Figura 2.4

Modelo de negocio Canvas

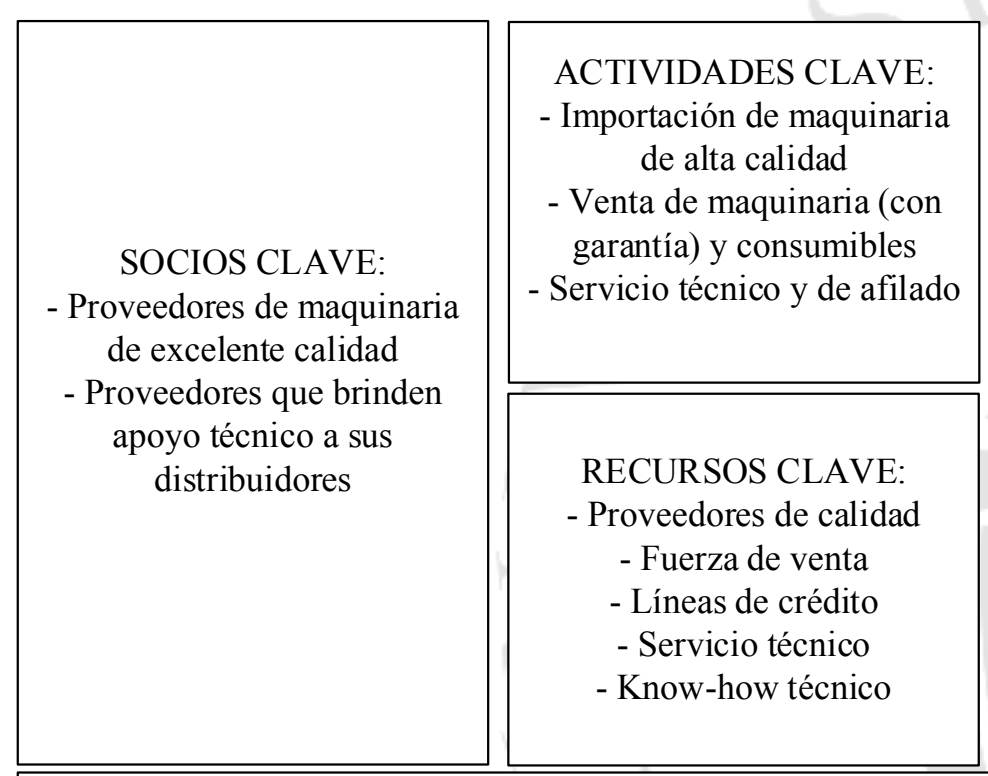

\section{ESTRUCTURA DE COSTOS:}

- Maquinaria y consumibles a vender

- Personal de ventas, administrativo y técnico

- Impuestos

\begin{tabular}{|c|c|c|}
\hline \multirow{2}{*}{$\begin{array}{l}\text { PROPUESTA DE VALOR: } \\
\text { - Productos de calidad } \\
\text { - Servicio técnico } \\
\text { - Productos en stock }\end{array}$} & $\begin{array}{l}\text { RELACIÓN CON } \\
\text { CLIENTES: } \\
\text { - Visitas de vendedores } \\
\text { - Invitaciones a ferias } \\
\text { - Comunicación de } \\
\text { promociones }\end{array}$ & $\begin{array}{l}\text { SEGMENTO DE MERCADO } \\
\text { - todos a nivel nacional: } \\
\text { - Emprendedores y pequeños } \\
\text { carpinteros: gran cantidad, } \\
\text { pero compras de bajo volumen } \\
\text { - Empresas medianas: mayor } \\
\text { poder adquisitivo y más }\end{array}$ \\
\hline & $\begin{array}{c}\text { CANALES: } \\
\text { - Venta directa en dos locales } \\
\text { comerciales } \\
\text { - Vendedores maquinaria a } \\
\text { nivel nacional por zonas (3) } \\
\text { - Vendedores consumibles a } \\
\text { nivel nacional por zonas (3) }\end{array}$ & $\begin{array}{c}\text { - Empresas grandes: pocas en } \\
\text { el sector y las referentes en el } \\
\text { mercado. } \\
\text { - Clientes corporativos: alto } \\
\text { poder adquisitivo y capacidad } \\
\text { de negociación. } \\
\text { - Licitaciones: en su mayoría } \\
\text { encargadas por el estado. }\end{array}$ \\
\hline
\end{tabular}

\section{FUENTE DE INGRESO:}

- Venta de maquinaria, consumibles, servicio técnico y servicio de afilado

- Pagos en efectivo, tarjeta de crédito, cheque o transferencia bancaria.

- Venta contado

- Venta a crédito sin una política clara (financiamiento de hasta 2 años e iniciales menores a $30 \%$ en algunos casos)

- Se planea conseguir una entidad financiera que ayude a los clientes en su financiamiento.

Fuente: ABC S.A.C.

Elaboración propia 


\subsubsection{Análisis de la estructura organizacional}

Para analizar de manera adecuada la organización y la estructura organizacional de la empresa al momento de la investigación, se presentará el organigrama de la empresa y las funciones que tiene cada elemento del mismo:

Figura 2.5

Organigrama

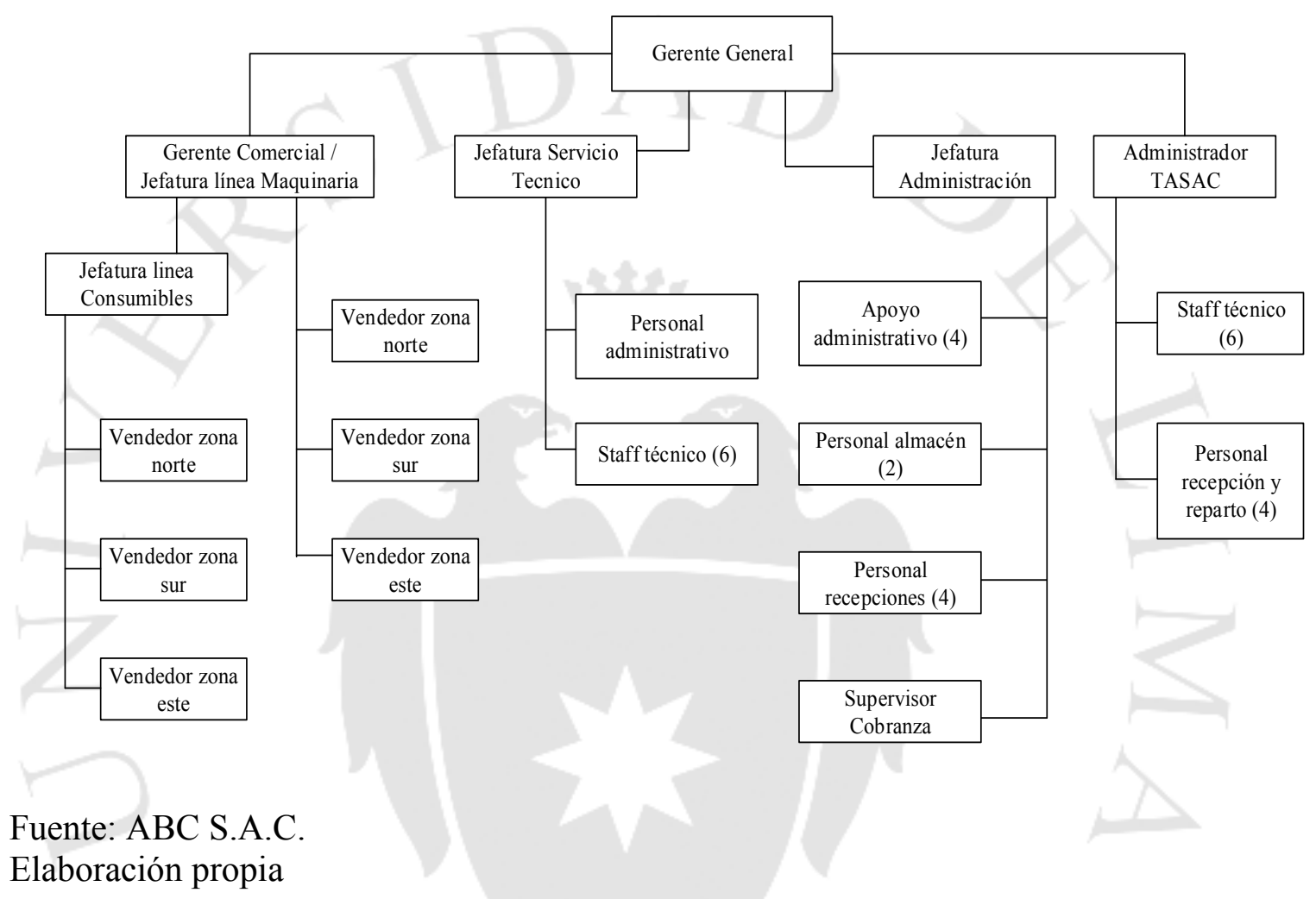

Como ya se mencionó, las funciones del personal no están definidas con claridad. No se cuenta con ningún documento oficial en donde se detalle cuáles son las tareas y objetivos de cada puesto según organigrama. Es por ello que se procedió a entrevistar tanto al Gerente General como a las diferentes gerencias y jefaturas para poder delinear las funciones de cada área:

- $\quad$ Gerente Comercial / línea maquinaria

La gerencia comercial se encarga directamente de las ventas de maquinaria, pero también tiene bajo su responsabilidad la jefatura comercial de consumibles para el reporte a la gerencia general. Dentro de las principales funciones de esta gerencia tenemos: 
- Establecer y controlar precios de venta y márgenes de los productos y servicios

- Elaborar el presupuesto de ventas de maquinaria y velar por su cumplimiento.

- $\quad$ Supervisar y dirigir los equipos de venta de la línea maquinaria

- Establecer cuotas de venta y cronograma de visitas de los vendedores

- Verificar cumplimiento de cuotas

- Controlar niveles de inventario y control de los mismos

- $\quad$ Preparar argumentos de venta y entregarlos a los equipos de venta

- Buscar nuevos proveedores.

- Realizar y/o participar en eventos comerciales (ferias y promociones).

- Gestionar pedidos a proveedores, así como los niveles de stock mínimos y de seguridad.

- Coordinar con Servicio Técnico la necesidad de repuestos y accesorios

- Calcular las capacidades de producción de la maquinaria a solicitar

Coordinar con los proveedores el diseño de máquinas para el mercado nacional

Jefatura Comercial / línea consumibles

Dado el crecimiento que tuvo el negocio de consumibles en los últimos años, se creó una jefatura bajo la gerencia comercial para controlar la gestión de ventas de esta línea. A continuación se muestran las principales funciones de esta jefatura:

- Controlar los márgenes de los productos y servicios ofrecidos

- $\quad$ Supervisar y dirigir los equipos de venta de la línea consumibles

- Establecer cuotas de venta y cronograma de visitas de los vendedores

- Verificar cumplimiento de cuotas

- Coordinar con la Gerencia Comercial la realización de eventos comerciales (ferias y promociones).

- Gestionar los pedidos a proveedores, así como los niveles de stock mínimos y de seguridad.

- Preparar argumentos de venta y entregarlos a los equipos de venta

- Buscar nuevos proveedores

- Jefatura de Servicio Técnico 
Esta jefatura está a cargo del servicio de mantenimiento preventivo y reactivo a la maquinaria vendida por la empresa a sus clientes. Sus principales funciones son:

- Dar respuesta oportuna a los requerimientos de los clientes a través del staff técnico

- Solucionar todo problema técnico que pueda haber con todas las máquinas vendidas por $\mathrm{ABC}$ S.A.C.

- Supervisar las labores de los técnicos de ABC S.A.C. y todo aquel que se subcontrate para labores específicas.

- Controlar los niveles de stock de maquinaria y repuestos.

- Mantener la sala de exhibición y sus componentes en perfecto estado y funcionando.

- Desarrollar nuevas oportunidades de negocio.

- Estudiar constantemente la demanda y actividad de los competidores.

Mantener stocks de seguridad de mercadería a su cargo.

- Desarrollar al personal a cargo.

Visitar a clientes claves (Lima y provincias).

\section{Jefatura Administrativa}

Se encarga de la gestión financiera y contable de la empresa, así como del bienestar del personal. Dentro de las principales funciones de esta jefatura se pueden mencionar:

- Controlar cajas chica propia y de las áreas de ventas y servicio técnico.

- Controlar y apoyar a la empresa encargada de la contabilidad

- Gestionar el pago de planillas

- Actualizar las líneas de crédito por cliente

- Gestionar herramientas y servicios de uso cotidiano que permiten el funcionamiento de la empresa (equipos de cómputo, telefonía móvil, luz, agua, etc.)

- Registrar comprobantes de compra para elaboración de balances e impuestos

- Gestionar las importaciones y exportaciones con los proveedores, agencias de trasporte y agentes de aduanas

- Elaborar los estados financieros de la empresa

- Calcular y liquidar los impuestos de ley 
- Coordinar gestión de pagos y manejo de cuentas con sectoristas de bancos.

- Supervisor cobranzas

Este puesto debe velar por tener al día las cobranzas y aprobar los créditos de acuerdo a los niveles autorizados por la gerencia general. Sus funciones son:

- Aprobar las solicitudes de créditos del área de ventas

- Gestionar el cobro de deudas con los clientes, evitando su vencimiento

- Mantener en niveles mínimos las deudas vencidas

- Emitir reportes de cobranzas, periódicamente y a solicitud de la gerencia general

- Registrar cobranzas en el sistema.

- Analizar la cartera morosa.

- Realizar seguimiento a las letras por cobrar

- Coordinar con la fuerza de ventas y facturación

Administrador DEF S.A.C.

Este puesto tiene a su cargo la administración general y contacto principal entre DEF S.A.C. y la Gerencia de ABC S.A.C.. Dentro de sus funciones están:

- Velar por la atención adecuada y puntual de los clientes

Supervisar el despacho y la recepción de productos.

- $\quad$ Mantener niveles de stock adecuados de repuestos y suministros

- Manejar caja chica para gastos varios

- Controlar cuentas por pagar y cobrar

- Controlar las líneas de crédito

\subsubsection{Identificación y descripción general de los procesos claves}

Para la descripción de los procesos claves de la empresa, a continuación se presenta el mapa de procesos, en el cual se revisan los procesos estratégicos, procesos de realización y finalmente procesos de soporte de la organización: 
Figura 2.6

Mapa de procesos

\section{Procesos Estratégicos}

\begin{tabular}{|c|c|}
\hline $\begin{array}{c}\text { Definición de } \\
\text { objetivos y } \\
\text { metas }\end{array}$ & $\begin{array}{c}\text { Establecimiento } \\
\text { de políticas } \\
\text { comerciales }\end{array}$ \\
\hline
\end{tabular}

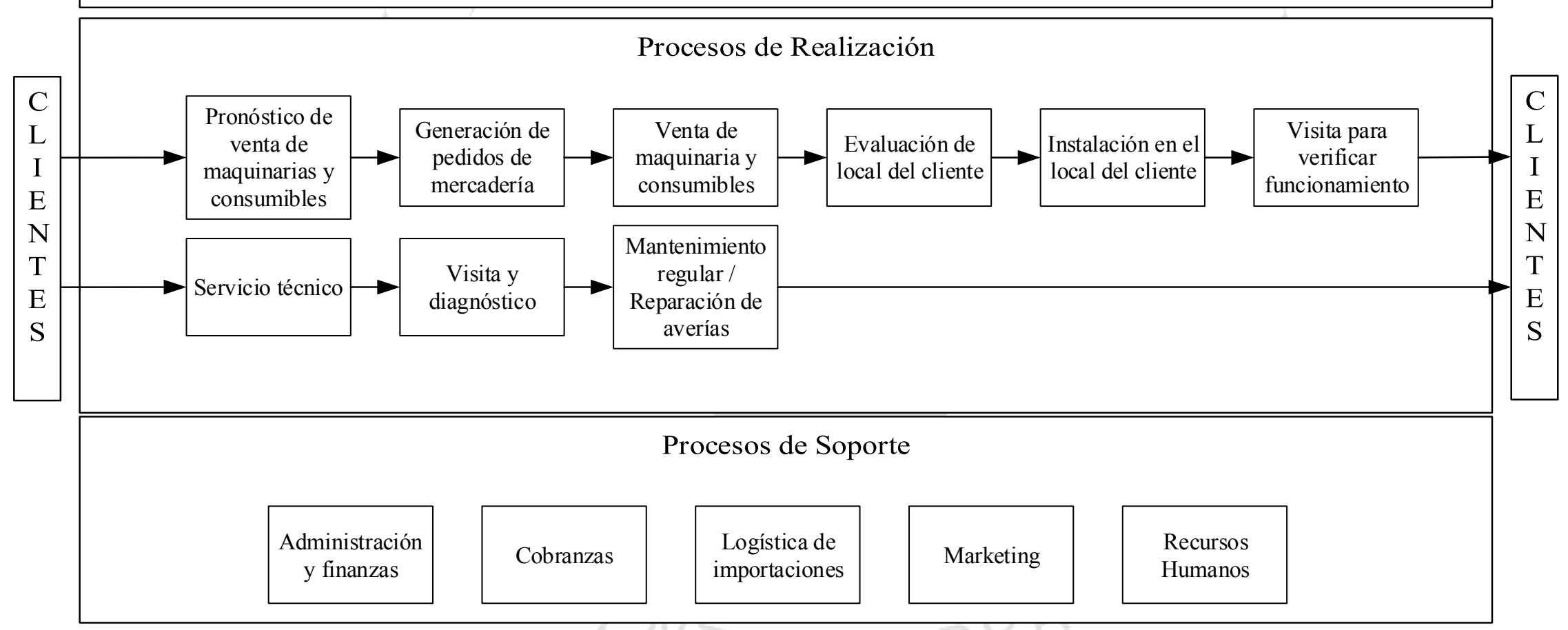

Fuente: ABC S.A.C.

Elaboración propia 
A continuación se presenta una breve descripción de las actividades mencionadas en el mapa de procesos:

Procesos estratégicos:

- Definición de objetivos y metas: se realiza entre el Gerente General y los jefes de área. En este proceso se fijan los objetivos organizacionales, así como también las metas de ventas y de rentabilidad de la empresa.

- $\quad$ Establecimiento de políticas comerciales: este proceso se refiere a la política de compras y ventas, en la cual se revisan los términos en los que se desarrollan ambos procesos, a fin de estar alineados con los objetivos y la estrategia de la empresa. En este proceso participan tanto el gerente general como los jefes de área.

Innovación y desarrollo: es un proceso deficiente en la empresa, ya que se no existen estudios de mercado que busquen identificar nuevas necesidades del mercado que permitan innovar con la importación de nueva maquinaria. Normalmente se importa una nueva máquina sin una mayor investigación, por lo cual no se tiene mucho éxito y por ello la empresa no apuesta mucho por importar maquinaria innovadora.

Procesos de realización:

- Venta de maquinaria y consumibles: el proceso de ventas inicia con la definición de las especificaciones de la maquinaria a solicitar, en base a los requerimientos del mercado local, con lo cual se pasa a definir el pronóstico para realizar la compra de maquinaria y consumibles. Definidos los pronósticos, se realizan los pedidos de mercadería y luego se procede con la ejecución de la venta a los clientes, para lo cual los vendedores cuentan con cuotas de ventas establecidas y utilizan una poderosa herramienta comercial como es el crédito. Cerrada una venta e ingresado el pedido, se coordina la visita del staff técnico para revisar el lugar donde se instalará la máquina, para posteriormente proceder con la instalación propiamente dicha, para lo cual se programa el despacho de la maquinaria hacia el local del cliente. Instalada la máquina 
de acuerdo al requerimiento del cliente, este proceso termina con una visita de validación de la garantía, la cual se realiza a los 30 días de instalada la máquina.

- Servicio Técnico: la empresa ofrece el servicio técnico de mantenimiento a la maquinaria vendida como parte de la garantía y también como un servicio adicional luego del vencimiento de la misma. Los requerimientos de servicio técnico se realizan a través de los vendedores o los clientes se comunican directamente con la empresa para solicitarlo. En este proceso una persona del staff técnico debe acercarse a realizar una revisión de la maquinaria y dar un diagnóstico para su posterior cotización. Si el cliente acepta la propuesta, el técnico realiza la reparación en el local del cliente.

Procesos de soporte:

- Administración y finanzas: como se mencionó en las funciones del área, este proceso consiste en la gestión financiera y contable de la empresa. En este proceso existen problemas reflejados en la mala situación financiera de la empresa, debido principalmente a un exceso de endeudamiento bancario y con proveedores, así como un crecimiento excesivo de gastos administrativos que reducen demasiado el margen de la empresa.

- Cobranzas: este proceso consta de dos partes, la primera es autorizar el otorgamiento de créditos a clientes por propuesta de ventas y la segunda es mantener al mínimo las deudas vencidas, apoyados en la gestión de ventas. Lamentablemente el proceso no ha funcionado de manera adecuada, ya que se asignaron demasiados créditos para impulsar las ventas y las cuentas por cobrar se dispararon, quitándole liquidez a la empresa y aumentando el nivel de endeudamiento.

- Logística de importación: este proceso está a cargo también del área administrativa, la cual se encarga de la compra y los trámites de importación de la maquinaria para 
venta. Este proceso se desarrolla con normalidad, no existiendo muchos inconvenientes asociados al mismo.

- Marketing: la empresa no cuenta con un área de Marketing propiamente dicha, por lo cual la responsabilidad de estas acciones recae sobre el gerente comercial. Las acciones de marketing se limitan a la participación en ferias especializadas de maquinaria para la segunda transformación de madera, en las cuales la presencia de la empresa es de lo más resaltante.

- Gestión de Recursos Humanos: no existe un área de recursos humanos propiamente dicha y es el área de administración la encargada de la gestión de planillas. Asimismo el área de ventas gestiona la capacitación del propio personal en cuanto a técnicas de negociación y gestión de ventas, así como también en aspectos técnicos de la maquinaria necesarios para poder venderla.

\subsubsection{Análisis de los indicadores generales de desempeño de los procesos claves \\ Para el análisis de indicadores generales nos enfocaremos en los} principales procesos de la empresa: administración y finanzas, ventas y servicio-técnico. Para ello, consideramos también como premisa que el objetivo principal de este trabajo es el de garantizar la estabilidad financiera y el incremento de la rentabilidad mediante una reestructuración del proceso principal de la empresa, que son las ventas.

En base a los balances y resultados de la empresa, se procede a preparar cuadros comparativos para ver la evolución de los indicadores por proceso. Lamentablemente la empresa no ha guardado un registro confiable de información, por lo que en algunos casos no se podrá determinar el indicador o se tomará en cuenta la información de primera mano que se pueda conseguir en la empresa mediante una entrevista al personal clave.

Indicadores del proceso de Administración y Finanzas:

Para la revisión de este proceso, tendremos en cuenta los principales indicadores de liquidez, solvencia y rentabilidad, los cuales se presentan en la siguiente tabla: 
Tabla 2.4

Indicadores de administración y finanzas

\begin{tabular}{|c|c|c|c|c|c|c|c|c|c|c|}
\hline Indicadores financieros & 2003 & 2004 & 2005 & 2006 & 2007 & 2008 & 2009 & 2010 & 2011 & 2012 \\
\hline Activo Cor & 676,454 & 921,677 & $2,118,610$ & $2,460,936$ & $2,224,524$ & $3,651,189$ & $4,843,613$ & $6,348,882$ & $7,873,596$ & $7,638,377$ \\
\hline Pasivo Cor & 414,984 & 403,875 & $1,139,347$ & 579,982 & $1,134,157$ & & & & & \\
\hline Razón co & & 2.28 & 1.86 & 4.24 & 1.96 & \begin{tabular}{|l|}
1.94 \\
\end{tabular} & 1.91 & & & 1.13 \\
\hline Invent & 483,676 & 587,749 & 511,628 & $1,470,275$ & $1,355,835$ & $1,563,399$ & $2,328,013$ & $2,408,652$ & $2,792,801$ & $4,687,839$ \\
\hline & 0.46 & & & & & & & & & \\
\hline Activo & 1,266 & 1,939 & $2,898,217$ & 3,018 & 3,276 , & $5,166,369$ & $6,081,066$ & & & \\
\hline Pasi & 871 & & $1,437,263$ & 1,356 & 1,545 , & 2,708 & 2,766 & & & \\
\hline Patrir & & & $1,460,954$ & $1,662,603$ & $1,730,360$ & $2,457,942$ & $3,314,966$ & & & $2,702,497$ \\
\hline imiento / Activo & 0.69 & 0.43 & 0.50 & 0.45 & 0.47 & \begin{tabular}{|l|}
0.52 \\
\end{tabular} & 0.45 & 0.49 & 0.68 & 0.73 \\
\hline Im. / Patrimonio & 2.20 & & 0.98 & & 0.89 & 1.10 & \begin{tabular}{|l|l}
0.83 \\
\end{tabular} & 0.97 & & 2.72 \\
\hline Ventas T & $1,739,504$ & $3,362,370$ & $4,372,302$ & $3,961,943$ & $4,732,940$ & $7,296,368$ & $8,243,777$ & $11,150,101$ & $10,081,141$ & $9,738,372$ \\
\hline Utilide & & & & & & & & & & \\
\hline Rentabilidad / Patrimonio & 0.06 & & & & & & 0.30 & 0.23 & 0.04 & 0.04 \\
\hline Rentabilidad / Activo Total & & & & & & & 0.16 & & .01 & 0.01 \\
\hline Rentabilidad Neta / Ventas & 0.01 & 0.10 & 0.16 & 0.15 & 0.09 & 0.11 & 0.12 & 0.08 & 0.01 & 0.01 \\
\hline Endeudamier & & 0 & 186,140 & 99,608 & 100,029 & 682,504 & 532,592 & $1,660,332$ & $3,645,777$ & $4,323,627$ \\
\hline & & 403,875 & 953,207 & & $1,034,128$ & $1,141,364$ & $1,988,068$ & $1,773,783$ & 684,706 & $2,454,814$ \\
\hline Gastos administrativos & 352,611 & 522,509 & 534,050 & 435,236 & 463,947 & 466,865 & 476,414 & $1,097,990$ & $1,157,229$ & $1,152,481$ \\
\hline EBITDA & 62,668 & 465,387 & 905,852 & 604,251 & 778,196 & $1,144,333$ & $1,429,915$ & $1,366,255$ & 59,279 & $-627,534$ \\
\hline
\end{tabular}

Fuente: ABC S.A.C.

Elaboración propia 
En base al cuadro anterior, procedemos a estudiar cada indicador con sus respectivos resultados y evoluciones:

Figura 2.7

Indicadores de liquidez

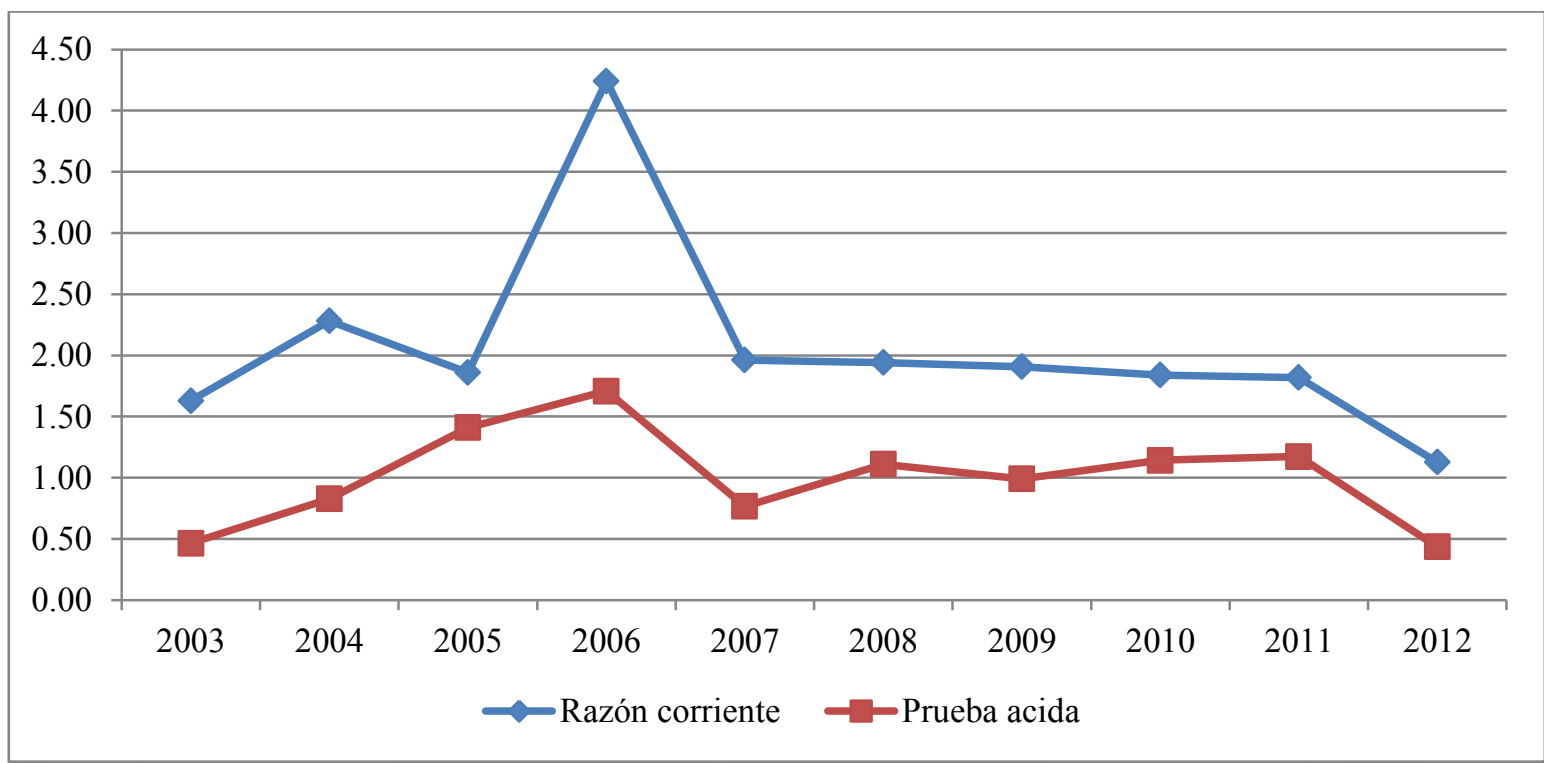

Fuente: ABC S.A.C.

Elaboración propia

Como se observa, la razón corriente disminuye año a año desde el 2004 de una manera leve (en el año 2006 escapa de la tendencia y no se tomará en cuenta). En los años de crecimiento de la empresa se contaba con suficiente liquidez como para solventar las deudas a corto plazo. Desde el 2007 hasta el 2011 se mantiene gracias a un incremento de las ventas, pero luego de que estas comienzan a disminuir y los compromisos crediticios aumentaron, la razón corriente disminuyó considerablemente. Es así que la empresa afronta claramente un problema de liquidez.

La prueba acida confirma la conclusión obtenida por la razón corriente, además de agregar otro factor clave: la empresa cada vez tiene menos activos corrientes de fácil realización para solventar las deudas. Es decir, la empresa tiene un problema de liquidez y además es posible que no tenga mercadería de fácil venta para poder mejorar la situación. 
Figura 2.8

Indicadores de Solvencia

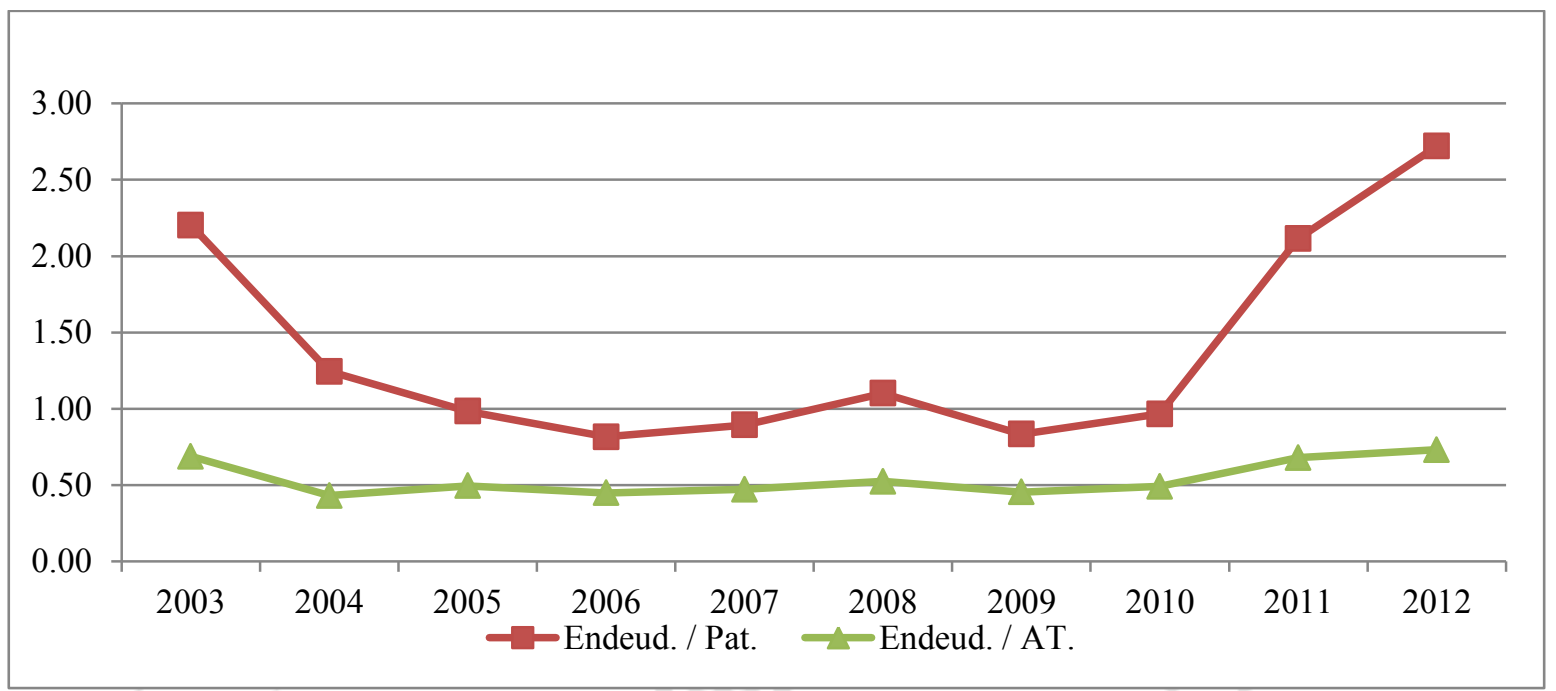

Fuente: ABC S.A.C.

Elaboración propia

En lo que respecta a indicadores de solvencia, en la figura 2.8 se observa que el endeudamiento sobre el patrimonio sólo ha aumentado en los últimos años, debido a que el nivel de deuda financiera se ha incrementado a niveles demasiado altos. A finales del año 2012, las deudas de la empresa casi triplican los recursos propios. Por otro lado, el endeudamiento sobre el activo se ha disparado en los últimos tres años alcanzando un nivel de $73 \%$, lo que significa que este porcentaje de los activos de la empresa se encuentra sostenido en acreedores y sólo un $27 \%$ en recursos propios, lo cual es una situación bastante riesgosa. 
Figura 2.9

Endeudamiento

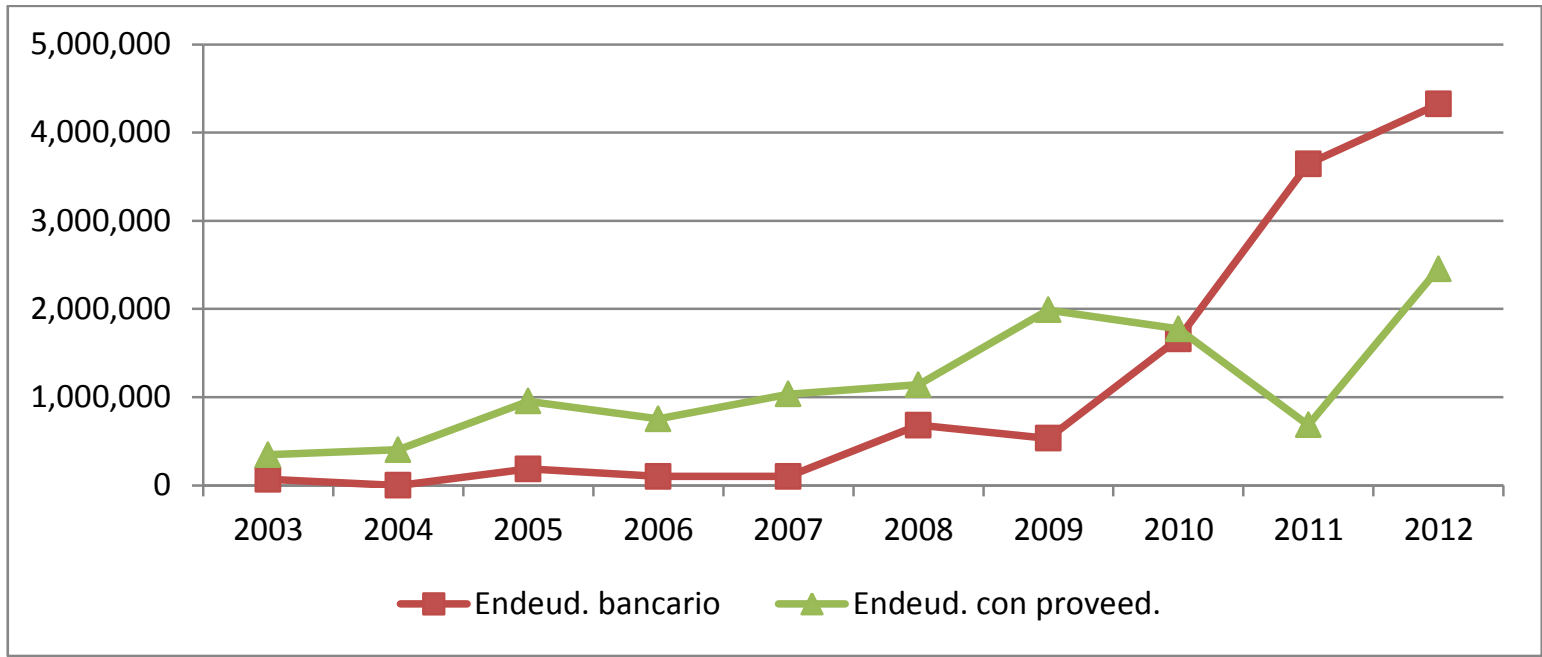

Fuente: ABC S.A.C.

Elaboración propia

Como se observa en la figura 2.9, el endeudamiento bancario se incrementó considerablemente desde el año 2009, lo que indica que la empresa ha estado soportando la operación a través de financiamiento, confirmando así los resultados del análisis de solvencia. Cabe destacar que la empresa ya ha realizado gestiones con los bancos para reprogramar cronogramas de pagos, a fines de poder para afrontar la crisis financiera por la que atraviesa. Por otro lado, el endeudamiento con proveedores casi se ha duplicado en la segunda mitad del periodo de análisis; considerando que las ventas prácticamente se han duplicado en este mismo periodo, se mantiene la misma relación de los últimos 10 años. 
Figura 2.10

Utilidad neta (S/.)

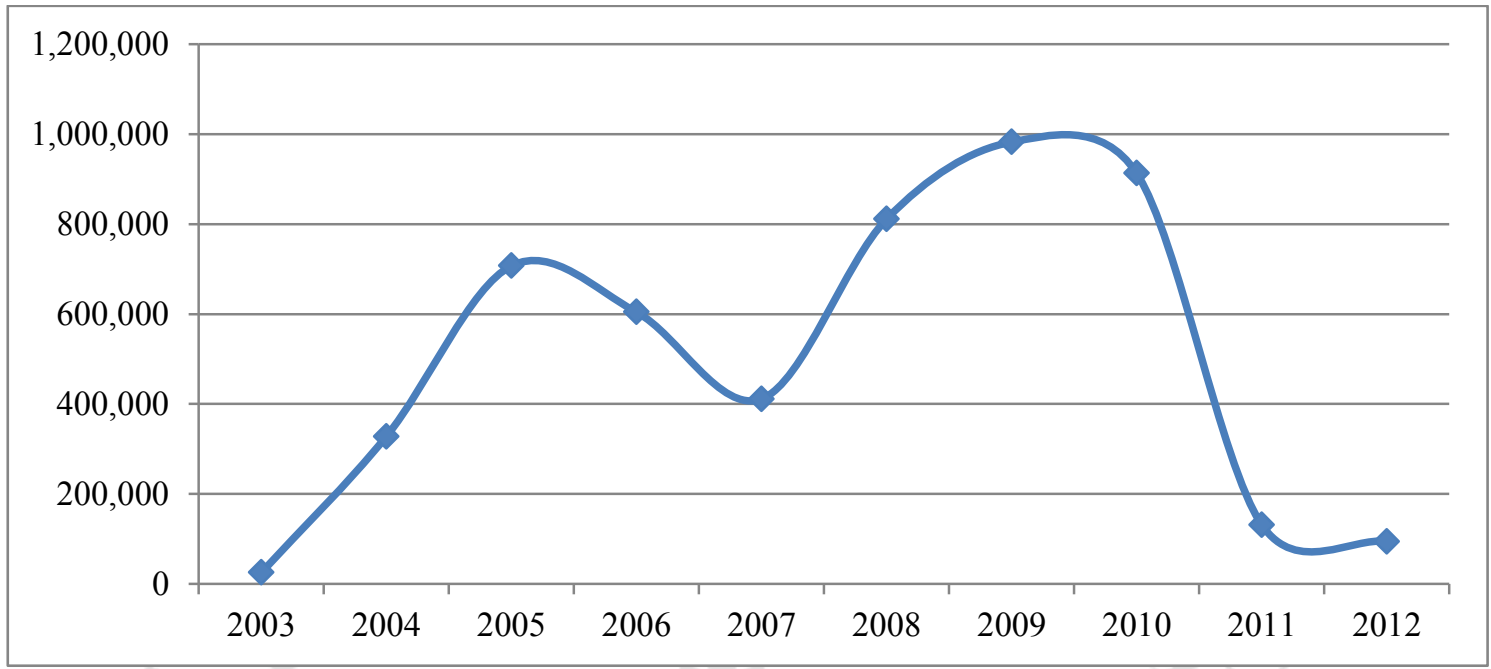

Fuente: ABC S.A.C.

Elaboración propia

Con respecto a la rentabilidad del negocio, podemos observar que la utilidad neta ha tenido un marcado declive en los últimos 2 años, con una reducción superior al $85 \%$ del 2010 al 2011, y de $28 \%$ del 2011 al 2012. Este declive se debe principalmente a menores ventas en los últimos años y al aumento de costos de ventas, gastos administrativos y gastos de ventas. Cabe destacar que en el año 2012 la utilidad operativa llega a ser negativa, pero la utilidad neta termina siendo positiva gracias a que se recibieron altos ingresos financieros. Sin embargo, esto denota un serio problema puesto que la operación en si misma ha generado pérdidas en el último año. 
Figura 2.11

Indicadores de Rentabilidad

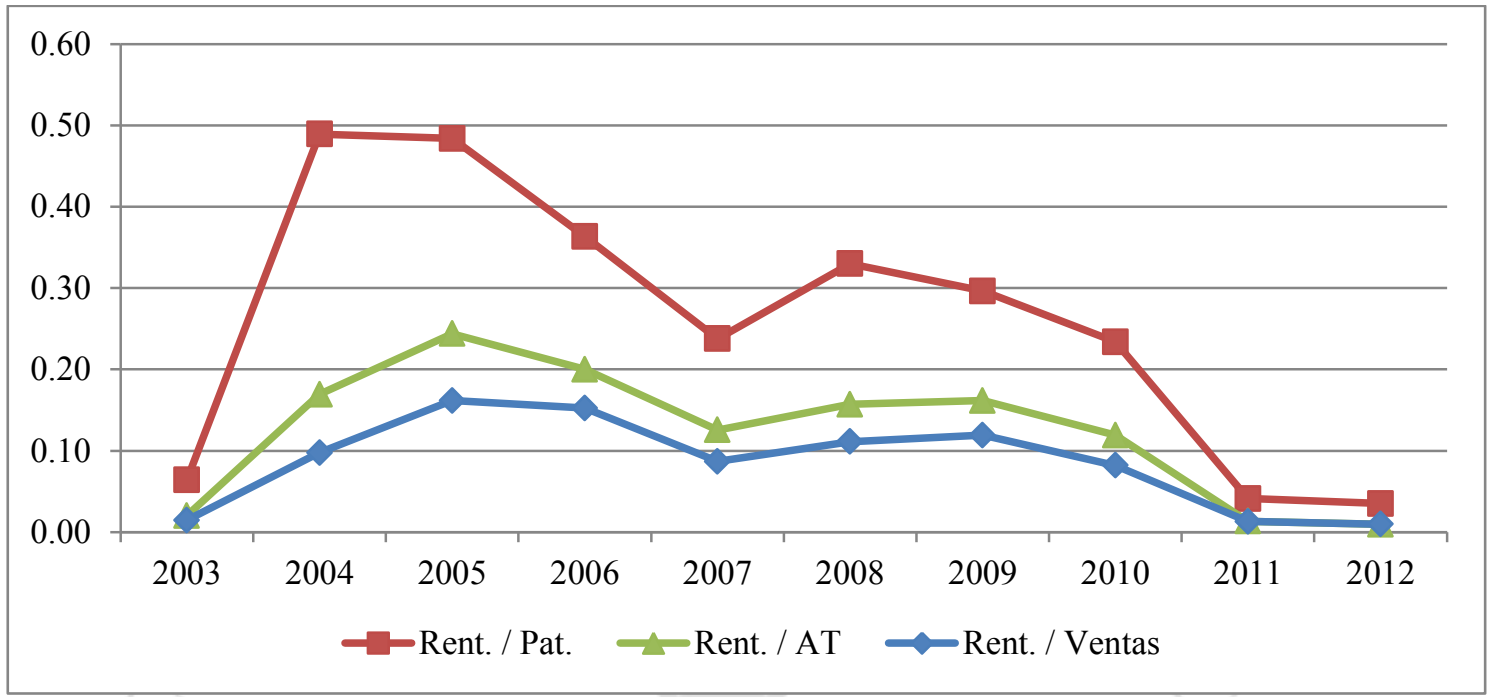

Fuente: ABC S.A.C.

Elaboración propia

Los indicadores de rentabilidad muestran una clara tendencia a la baja desde el año 2009, debido a los bajos niveles de utilidad neta, situación que se torna crítica en el año 2012 con la utilidad más baja de los últimos 9 años. Del gráfico de rentabilidad, podemos concluir que la inversión de los socios cada año es menos rentable, que los activos tienden a no generar utilidad y que las ventas no son suficientes para contrarrestar la crisis financiera de la empresa.

Figura 2.12

Gastos Administrativos vs. EBITDA

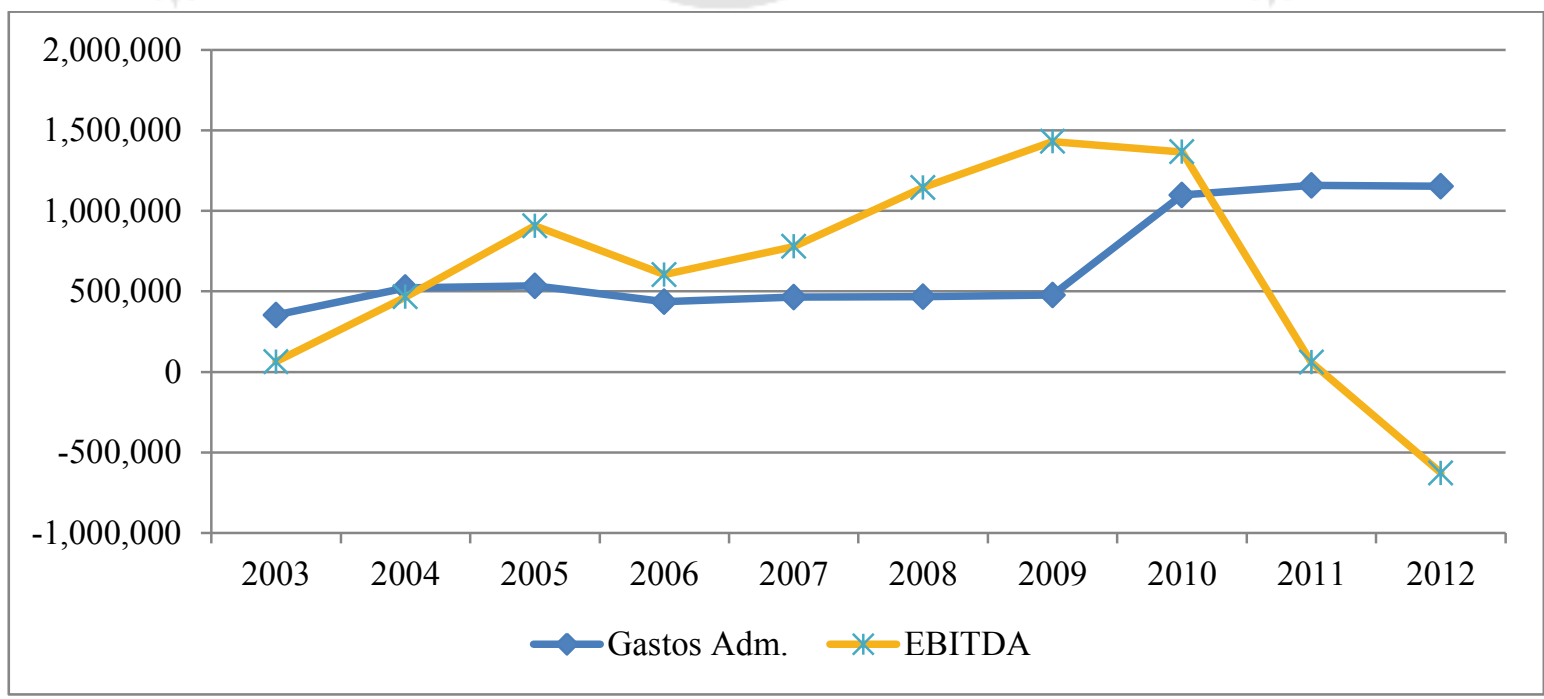

Fuente: ABC S.A.C.

Elaboración propia 
En la figura 2.12 se aprecia que los resultados del indicador EBITDA son los esperados. Desde el 2010 solo ha disminuido, llegando a tener utilidad operativa negativa en el 2012, lo cual deja a la empresa en una situación crítica para negociar las renovaciones de crédito con los financistas. Asimismo podemos observar que los gastos administrativos prácticamente se duplicaron entre el 2009 y 2010, lo cual no hace más que empeorar la situación del EBITDA. La empresa tiene gastos demasiado altos para el nivel de venta que maneja, por lo cual es necesario sincerar la estructura administrativa y buscar eficiencias que permitan recortar gastos.

Como conclusión del análisis de indicadores del proceso de administración y finanzas, se observa que la empresa pasa por una situación financiera realmente crítica, considerando la baja liquidez, el alto nivel de endeudamiento y sobre todo la baja rentabilidad del negocio, con lo cual se está llegando inclusive a un resultado negativo de la operación al momento del análisis. Asimismo el nivel de gastos administrativos se ha incrementado demasiado, sin tener relación con el incremento en el nivel de ventas, lo cual afecta directamente a la operación.

Indicadores del proceso de Venta de Maquinaria y Consumibles:

Para la revisión de este proceso, se presenta un análisis general de las ventas registradas, las cuentas por cobrar y la rotación de inventarios. Consideramos estos dos últimos indicadores como parte del proceso de ventas ya que dependen en gran medida de las acciones del área comercial. Para realizar ventas de manera responsable, son los vendedores quienes proponen otorgar el crédito a un cliente considerando su situación económica, y son ellos mismos quienes, al tener una relación más cercana con los clientes, deben asegurar que estos cumplan con sus pagos de acuerdo a las condiciones acordadas, y así mantener bajo control las cuentas por cobrar. Por otro lado, la rotación de inventarios también depende en gran medida de la gestión de ventas, ya que es un indicador afectado directamente por el pronóstico de ventas (calculado por el área comercial) y por el nivel de ventas. 
Tabla 2.5

Ventas de maquinaria y consumibles (S/.)

\begin{tabular}{|l|r|r|r|}
\hline Año & $\begin{array}{c}\text { Ventas } \\
\text { maquinarias }\end{array}$ & $\begin{array}{c}\text { Ventas } \\
\text { consumibles }\end{array}$ & Total S/. \\
\hline $\mathbf{2 0 0 3}$ & $1,304,628$ & 347,901 & $1,652,529$ \\
\hline $\mathbf{2 0 0 4}$ & $2,521,778$ & 672,474 & $3,194,252$ \\
\hline $\mathbf{2 0 0 5}$ & $3,279,227$ & 787,014 & $4,066,241$ \\
\hline $\mathbf{2 0 0 6}$ & $2,971,457$ & 713,150 & $3,684,607$ \\
\hline $\mathbf{2 0 0 7}$ & $3,549,705$ & 709,941 & $4,259,646$ \\
\hline $\mathbf{2 0 0 8}$ & $5,472,276$ & $1,094,455$ & $6,566,731$ \\
\hline $\mathbf{2 0 0 9}$ & $6,182,833$ & $1,030,472$ & $7,213,305$ \\
\hline $\mathbf{2 0 1 0}$ & $8,362,576$ & $1,393,763$ & $9,756,338$ \\
\hline $\mathbf{2 0 1 1}$ & $7,560,856$ & $1,209,737$ & $8,770,593$ \\
\hline $\mathbf{2 0 1 2}$ & $7,303,779$ & $1,168,605$ & $8,472,384$ \\
\hline
\end{tabular}

Fuente: ABC S.A.C.

Elaboración propia

Figura 2.13

Ventas registradas $(\mathrm{S} /$.

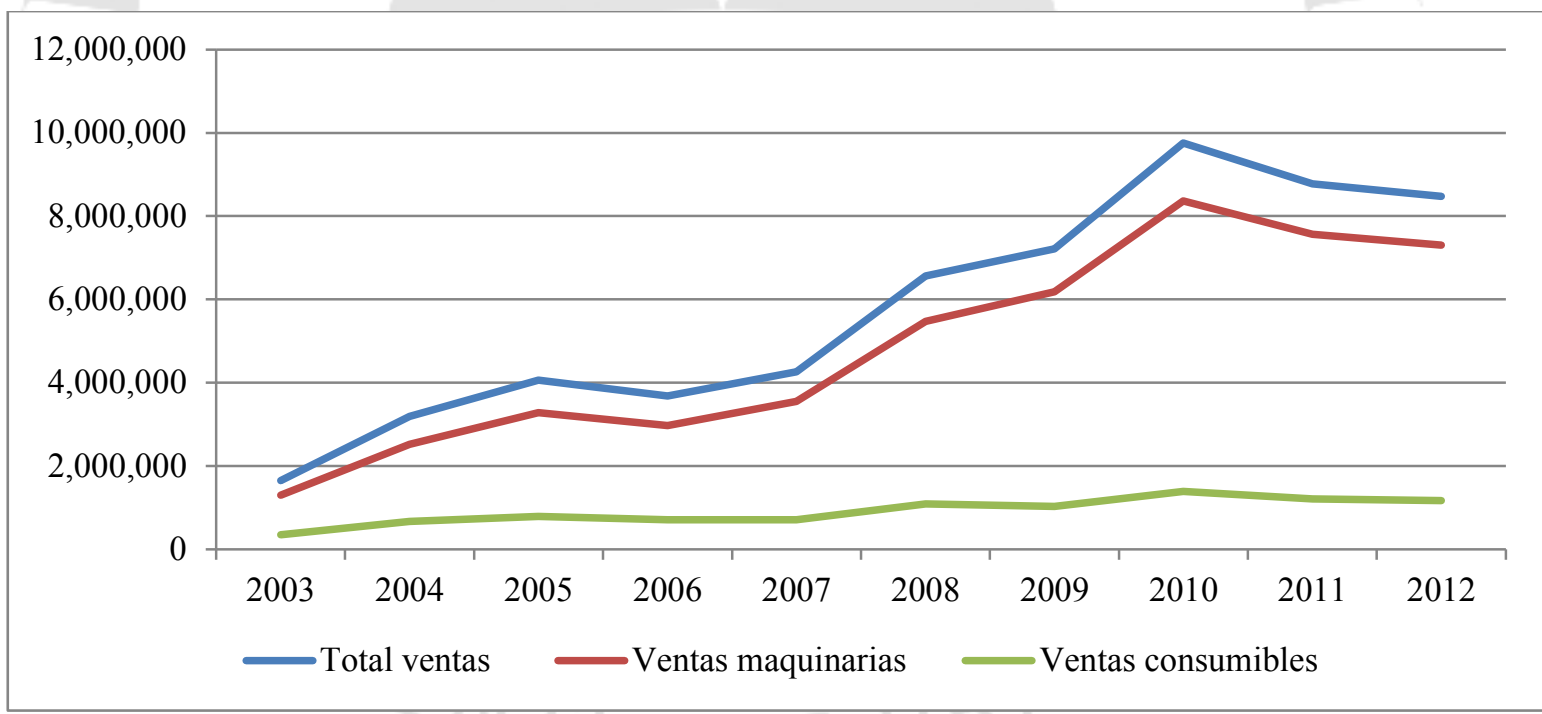

Fuente: ABC S.A.C.

Elaboración propia

Como se observa, las ventas registradas en este proceso siguen la tendencia de la venta de maquinaria, por tratarse de la línea de negocio principal de ABC S.A.C., que aporta el $75 \%$ de las ventas totales de la empresa. El crecimiento de ventas entre el 2003 y el 2010 fue considerable, pero sostenido en endeudamiento y en créditos otorgados de manera irresponsable, lo cual explica en gran medida los altos niveles de las cuentas por cobrar y pagar. Lamentablemente a partir del 2011, por una coyuntura 
del mercado, las ventas cayeron poniendo a la empresa en una situación muy vulnerable por su baja liquidez y las obligaciones que tiene con terceros.

En cuanto a la venta de consumibles se puede observar que los niveles de venta tuvieron un crecimiento importante hasta el año 2010 y luego se han mantenido relativamente en un mismo nivel; esto significa que a pesar de que el parque de maquinaria en el mercado ha crecido, las ventas no han aumentado, lo cual puede deberse a un aumento en la oferta, así como también de una falta de capacidad y proyección de esta línea de negocio que no es la principal para ABC S.A.C..

Tabla 2.6

Nivel de cuentas por cobrar

\begin{tabular}{|c|c|c|}
\hline Año & S/. & Variación \% \\
\hline 2003 & 24,701 & - \\
\hline 2004 & 283,593 & $1048 \%$ \\
\hline 2005 & 961,168 & $239 \%$ \\
\hline 2006 & 323,590 & $-66 \%$ \\
\hline 2007 & 234,278 & $-28 \%$ \\
\hline 2008 & $1,019,940$ & $335 \%$ \\
\hline 2009 & $2,022,030$ & $98 \%$ \\
\hline 2010 & $3,038,213$ & $50 \%$ \\
\hline 2011 & $4,238,095$ & $39 \%$ \\
\hline 2012 & $2,407,572$ & $-43 \%$ \\
\hline
\end{tabular}

Fuente: ABC S.A.C.

Elaboración propia 
Figura 2.14

Nivel de cuentas por cobrar

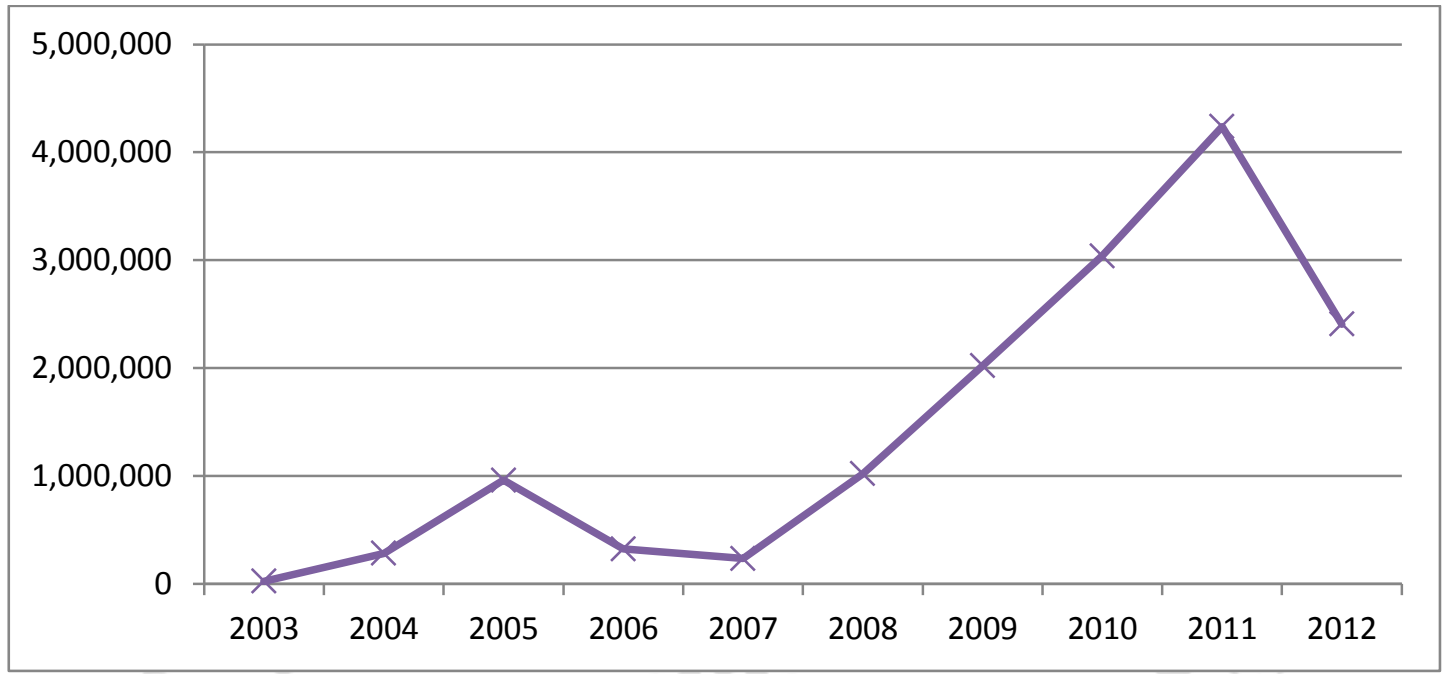

Fuente: ABC S.A.C.

Elaboración propia

Con respecto a las cuentas por cobrar, se observa un incremento significativo a partir del año 2008, en el cual se logra un pico de ventas. Todo indica que el incremento de las ventas se debió a una política muy agresiva de financiamiento directo a los clientes. Si bien es cierto que ha bajado considerablemente en el último año, el nivel aún es muy elevado. Considerando los altos niveles de deuda financiera y que cada vez hay menos liquidez según la prueba acida, urge contar con una nueva política de venta al crédito y un mayor involucramiento del área comercial para la cobranza, a fines de mejorar la situación de este indicador. 
Tabla 2.7

Rotación de Inventarios

\begin{tabular}{|l|r|r|c|}
\hline Año & $\begin{array}{c}\text { Costo de } \\
\text { Ventas (CV) }\end{array}$ & $\begin{array}{c}\text { Inventario } \\
\text { Promedio (I) }\end{array}$ & $\begin{array}{c}\text { Rotación de } \\
\text { Inventarios (CV/I) }\end{array}$ \\
\hline $\mathbf{2 0 0 3}$ & $1,055,380$ & 483,676 & 2.18 \\
\hline $\mathbf{2 0 0 4}$ & $2,213,220$ & 535,713 & 4.13 \\
\hline $\mathbf{2 0 0 5}$ & $2,444,948$ & 549,689 & 4.45 \\
\hline $\mathbf{2 0 0 6}$ & $1,985,257$ & 990,952 & 2.00 \\
\hline $\mathbf{2 0 0 7}$ & $2,854,560$ & $1,413,055$ & 2.02 \\
\hline $\mathbf{2 0 0 8}$ & $4,764,023$ & $1,459,617$ & 3.26 \\
\hline $\mathbf{2 0 0 9}$ & $5,073,180$ & $1,945,706$ & 2.61 \\
\hline $\mathbf{2 0 1 0}$ & $6,886,574$ & $2,368,333$ & 2.91 \\
\hline $\mathbf{2 0 1 1}$ & $6,695,264$ & $2,600,727$ & 2.57 \\
\hline $\mathbf{2 0 1 2}$ & $6,940,886$ & $3,740,320$ & 1.86 \\
\hline
\end{tabular}

Fuente: ABC S.A.C.

Elaboración propia

Figura 2.15

Rotación de inventarios

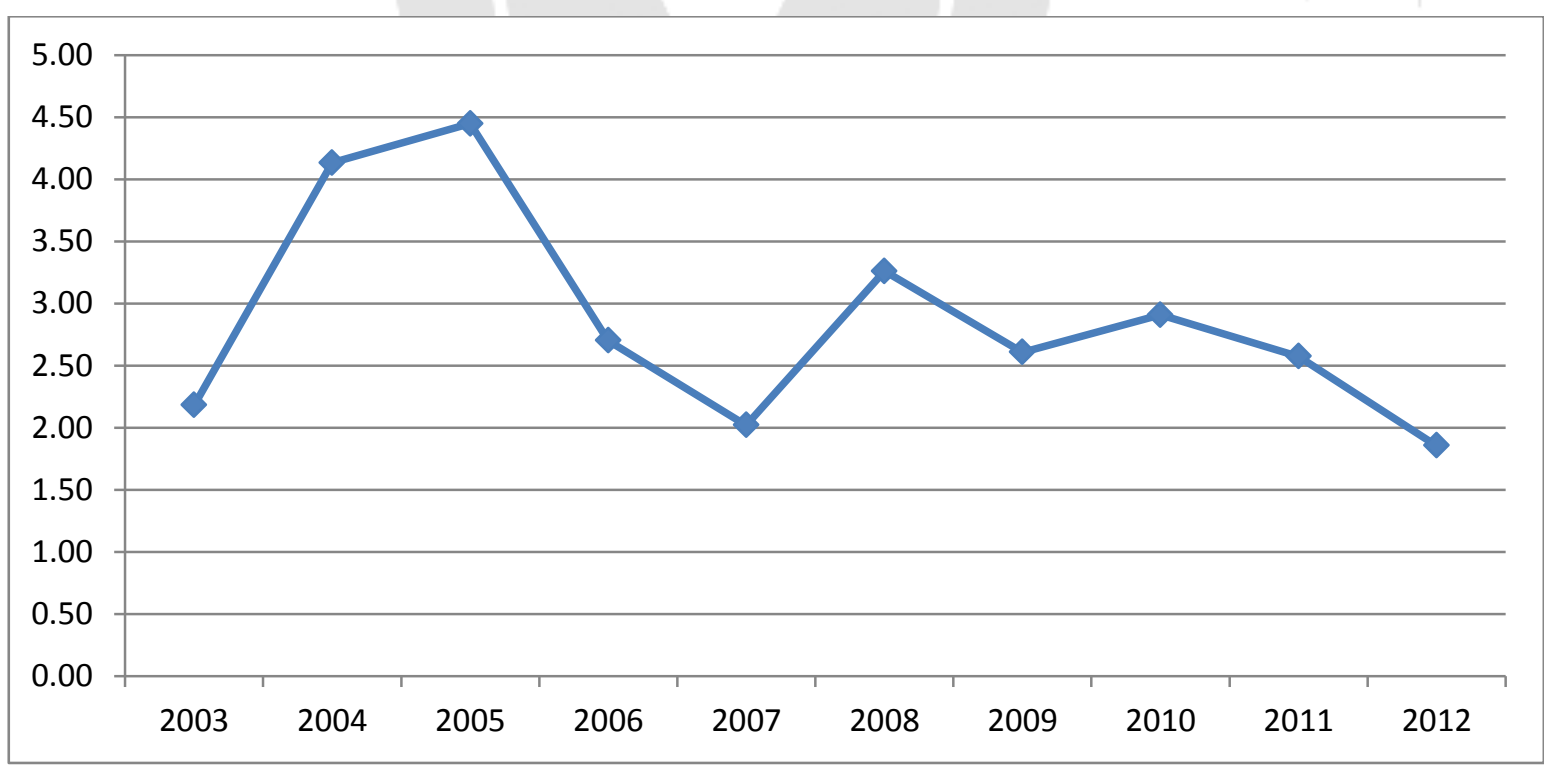

Fuente: ABC S.A.C.

Elaboración propia

La rotación de inventarios, como se observa en la gráfica, es cada vez menor.

En el 2005 llegó a su mejor punto con una rotación de inventarios cada dos meses y 
medio aproximadamente. Luego esta cifra no hizo más que empeorar hasta llegar a una rotación de 6 meses. El promedio de la rotación de inventarios entre el año 2003 y mediados del 2013 es de 1.86 veces al año. Sin lugar a duda hubo una mala gestión en el pronóstico de ventas para los pedidos de mercadería.

\section{Indicadores del proceso de Servicio Técnico:}

En el caso de este proceso de realización, se cuenta con el indicador de ventas del servicio de mantenimiento regular y de reparación de averías; lamentablemente no existe mucho control en este proceso, lo cual dificulta la obtención de información.

Tabla 2.8

Ventas de Servicio Técnico

\begin{tabular}{|c|r|c|}
\hline Año & $\begin{array}{c}\text { Ventas servicio } \\
\text { técnico }\end{array}$ & $\begin{array}{c}\text { Variación } \\
\%\end{array}$ \\
\hline 2003 & 86,975 & \\
\hline 2004 & 168,119 & $93 \%$ \\
\hline 2005 & 306,061 & $82 \%$ \\
\hline 2006 & 277,336 & $-9 \%$ \\
\hline 2007 & 473,294 & $71 \%$ \\
\hline 2008 & 729,637 & $54 \%$ \\
\hline 2009 & $1,030,472$ & $41 \%$ \\
\hline 2010 & $1,393,763$ & $35 \%$ \\
\hline 2011 & $1,310,548$ & $-6 \%$ \\
\hline 2012 & $1,265,988$ & $-3 \%$ \\
\hline
\end{tabular}

Fuente: ABC S.A.C.

Elaboración propia 
Figura 2.16

Ventas de servicio técnico

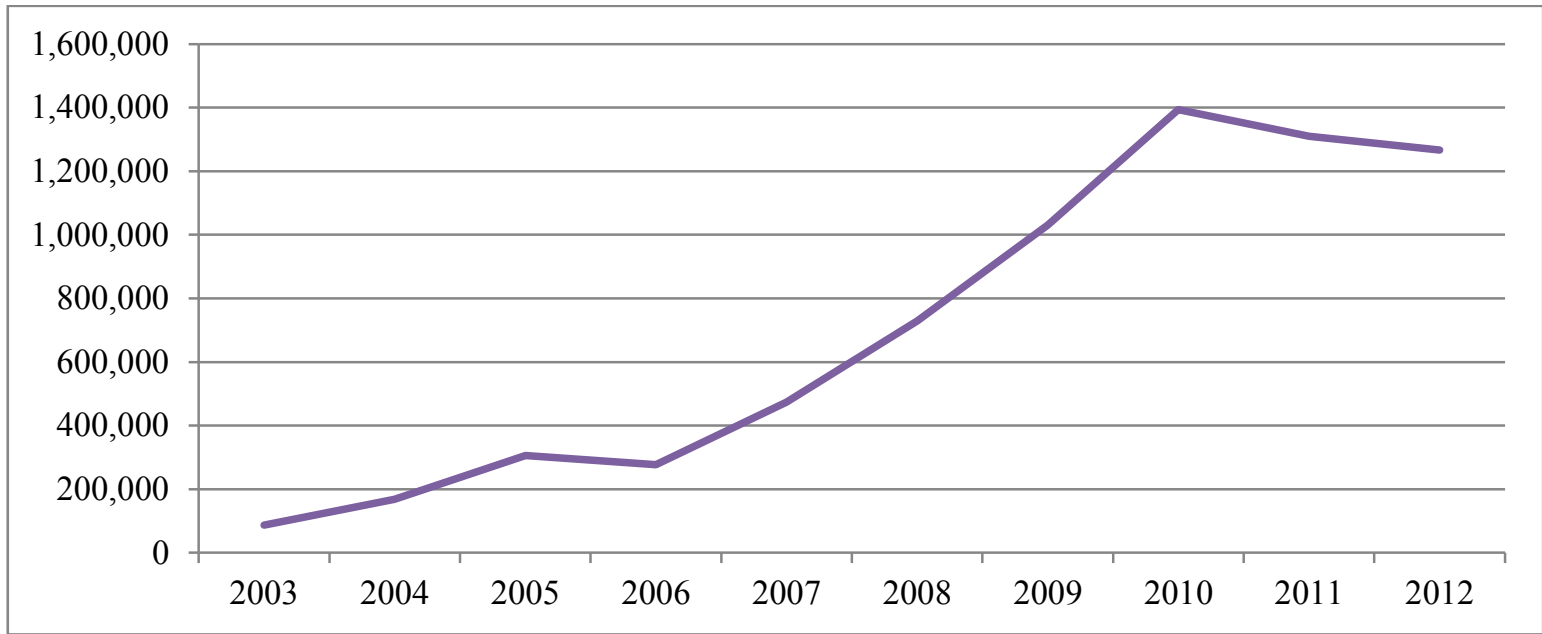

Fuente: ABC S.A.C.

Elaboración propia

Como se observa en el indicador, las ventas de este servicio empiezan un despegue pronunciado en el año 2007, manteniendo 4 años de un crecimiento bastante importante, pero que decae en los últimos 2 años, como consecuencia del mal manejo que se tuvo en la empresa y que como se mencionó anteriormente, no es el foco de la empresa. Pero si bien no es el rubro principal para ABC S.A.C., este negocio tiene potencial para crecer, ya que mientras aumente el parque de maquinaria, hay más posibilidades de brindar el servicio, inclusive para máquinas vendidas por otras empresas.

Por otro lado, se realizó la consulta al jefe de servicio técnico acerca de la cantidad de servicios con reclamos, es decir, que el servicio no fue bien ejecutado y se tuvo que volver a realizar. Dado que no llevan un control de estos incidentes, la estimación que nos brindó el jefe del área es que menos del 10\% de servicios brindados requieren este retrabajo.

\subsubsection{Determinación de posibles oportunidades de mejora}

A continuación se presentan los problemas encontrados en cada proceso tras el análisis realizado de los mismos: 
Administración y finanzas:

- $\quad$ Poca comunicación con otras áreas

- $\quad$ Poca generación de información de soporte.

- $\quad$ Poco control de gastos

- $\quad$ Falta de políticas financieras que regulen el nivel de endeudamiento.

- $\quad$ Tasa de efectividad de cobranzas muy baja.

- $\quad$ Registro de cobranzas y morosos poco claro y no actualizado.

- $\quad$ Entrega de reportes e información poco claros.

Ventas:

- $\quad$ Poca información y manejo de la misma

- $\quad$ Poco control sobre los vendedores asignados

- $\quad$ Falta de estrategia comercial clara: promoción, marketing, descuentos, etc.

- $\quad$ Incumplimiento de las cuotas de ventas

- $\quad$ Poco control de los gastos y costos asociados a las ventas

- $\quad$ Falta de seguimiento a la cartera de principales cuentas por cobrar.

- Poca comunicación y coordinación con otras áreas.

Servicio Técnico:

- $\quad$ Falta de programación de los servicios técnicos

- $\quad$ Poco control sobre los técnicos asignados

- $\quad$ Falta de control sobre los costos y gastos asociados

- Falta de capacitaciones internas y conocimientos no homogéneos.

- Poca comunicación y coordinación con otras áreas.

Tras el análisis de los mencionados problemas así como también de los indicadores y gráficos del punto anterior, podemos encontrar las siguientes oportunidades de mejora:

- Los niveles de endeudamiento financiero son críticos y esto se debe básicamente a un trabajo deficiente de las cobranzas, a políticas inadecuadas de ventas (excesivo financiamiento directo a los clientes por parte de la empresa) y a un exceso de 
endeudamiento para seguir operando de la misma manera. Es necesario mejorar estos temas para iniciar la recuperación financiera.

- No hubo trabajo de planeamiento estratégico y por lo tanto no se pudo prever la desaceleración en el 2011 ni las medidas para afrontarla. Bajaron las ventas, pero no los costos de las mismas. En vez de reorganizar los procesos y la organización, se buscó mayor financiamiento. Se requiere entonces un mejor enfoque de los procesos estratégicos.

- Lamentablemente no se tienen muchos indicadores de gestión de ventas, lo cual no permite una mejor evaluación de la gestión del personal, que a su vez permitiría enfocar mejor los temas a mejorar.

- La rotación de inventarios es muy baja y se debe básicamente a la poca planificación en el pronóstico de ventas y la inexistencia de estudios de mercado previos a las compras (es posible que muchos de los activos importados nunca se llegaron a vender, ya que el mercado no los necesitaba). Se requiere un mejor cálculo de pronósticos y mayor investigación de las necesidades del mercado.

\subsubsection{Identificación y evaluación de las fortalezas y debilidades de la empresa}

Teniendo en cuenta la revisión realizada de los procesos internos y sus indicadores de gestión, y con la finalidad de presentar una conclusión adecuada, a continuación se presenta la matriz de evaluación de factores internos (EFI): 
Tabla 2.9

\section{Matriz EFI}

\begin{tabular}{|c|c|c|c|c|c|}
\hline \multicolumn{2}{|r|}{ Fortalezas } & Problema & Peso & Calificación & Peso ponderado \\
\hline 1 & Mayor conocimiento técnico del mercado & activo & 0.08 & 3 & 0.24 \\
\hline 2 & Amplia cobertura geográfica & activo & 0.08 & 4 & 0.32 \\
\hline 3 & $\begin{array}{l}\text { Representante de marcas reconocidas } \\
\text { mundialmente y buena relación con ellos }\end{array}$ & pasivo & 0.05 & 4 & 0.2 \\
\hline 4 & $\begin{array}{l}\text { Local propio, bien ubicado y presencia } \\
\text { reconocida }\end{array}$ & activo & 0.08 & 3 & 0.24 \\
\hline 5 & $\begin{array}{l}\text { Buena relación con los clientes } \\
\text { representativos/clave }\end{array}$ & pasivo & 0.05 & 3 & 0.15 \\
\hline & Debilidades & Problema & Peso & Calificación & Peso ponderado \\
\hline 6 & Bajo compromiso del personal & critico & 0.05 & 2 & 0.1 \\
\hline 7 & Estructura con costos fijos muy altos & pasivo & 0.08 & 2 & 0.16 \\
\hline 8 & $\begin{array}{l}\text { Falta de definición y control de } \\
\text { procedimientos internos }\end{array}$ & critico & 0.11 & 2 & 0.22 \\
\hline 9 & Falta de un manual de funciones & activo & 0.08 & 2 & 0.16 \\
\hline 10 & Personal poco preparado & critico & 0.08 & 2 & 0.16 \\
\hline 11 & $\begin{array}{l}\text { Alto endeudamiento bancario y con } \\
\text { proveedores }\end{array}$ & pasivo & 0.11 & 1 & 0.11 \\
\hline 12 & $\begin{array}{l}\text { Cuentas por cobrar muy altas y con poco } \\
\text { seguimiento }\end{array}$ & indiferente & 0.11 & 1 & 0.11 \\
\hline 13 & Deficiente gestión de recursos humanos & critico & 0.03 & 2 & 0.06 \\
\hline 14 & $\begin{array}{l}\text { Falta de planes de marketing y promoción } \\
\text { de productos }\end{array}$ & indiferente & 0.03 & 2 & 0.06 \\
\hline 15 & Falta de control de indicadores de gestión & activo & 0.08 & 2 & 0.16 \\
\hline & Total: & & 1 & & 2.45 \\
\hline
\end{tabular}

Fuente: ABC S.A.C.

Elaboración propia

Luego de analizar la matriz EFI se llegan a las siguientes conclusiones:

- $\quad$ El promedio ponderado es de 2.45 , lo cual sitúa a la empresa cerca del promedio pero con tendencia a tener debilidad en su administración estratégica interna.

- $\quad$ El promedio ponderado de las debilidades (1.3) es mayor que el de la fortalezas (1.15), por lo que es posible que no se estén aprovechando todas las oportunidades externas debido a una deficiente organización y planificación de actividades, un mal manejo de recursos y decisiones erradas tomadas por la gerencia general. 
- $\quad$ La empresa puede aprovechar el pobre desarrollo tecnológico de la industria para crear escuelas o centros de capacitación y así ver de cambiar la idiosincrasia del sector y de los clientes en lo que refiere a productos de mala calidad y baja productividad, pero de precio económico.

- $\quad$ La empresa debe delinear claros procesos y funciones de los trabajadores y ofrecerles recompensas por sus logros, a fin de conseguir mayor compromisos de los mismos y evitar la fuga de talento y posibles futuros competidores.

- $\quad$ La empresa debe tomar medidas inmediatas para atacar sus problemas más serios como son el alto nivel de endeudamiento y de cuentas por cobrar, a fin de ganar solvencia y liquidez.

\subsubsection{Selección del sistema o proceso a mejorar}

Realizado el diagnóstico y con conocimiento de la problemática, se procederá con la selección del proceso a mejorar, para lo cual se utilizará el método de ranking de factores. Para la utilización de esta herramienta, primero se definirán los factores o criterios claves para la selección, luego se calificará cada proceso y finalmente se seleccionará uno para su mejora.

A continuación se presentan los factores o criterios de selección:

A) Indicadores a mejorar: la mejora en el proceso a calificar tendrá impacto sobre determinados indicadores que pueden ser muy o poco relevantes para el objetivo de la investigación, que es mejorar la rentabilidad. Dada su importancia, a este factor se le otorgará un peso de $35 \%$.

B) Complejidad del proceso: basándonos en la operatividad de cada proceso, serán calificados con respecto al grado de complejidad para la ejecución de una mejora. El peso otorgado a este factor es de $20 \%$.

C) Disponibilidad de información: dado que la empresa no lleva un control adecuado de indicadores, se complica la obtención de información para realizar el diagnóstico y con ello identificar problemas y oportunidades de mejora. Este factor tendrá un peso de $20 \%$.

D) Interés del investigador: se tendrá en cuenta este criterio adicional para calificar a los procesos de acuerdo al interés, experiencia y objetivos de quienes realizan la investigación. Este factor tendrá un peso de $25 \%$. 
Definidos los pesos por cada criterio, se proceden a evaluar los procesos claves de la empresa:

- Administración y finanzas: mejorar este proceso tiene una alta influencia en indicadores ya que mejores políticas y procesos internos ayudarán a reducir el endeudamiento, tener una mejor liquidez y reducir gastos administrativos, con una consiguiente mejora en el resultado. La complejidad del proceso es media, ya que se puede controlar directamente en las instalaciones de la empresa, y la disponibilidad de información es buena ya que se obtiene principalmente de los estados financieros; sin embargo, el interés de los investigadores es bajo por su poca orientación a las finanzas.

- Ventas: una mejora del proceso de ventas debe tener como consecuencia un incremento en los ingresos, lo cual suma directamente a la mejora de la rentabilidad. Asimismo, una reducción en gastos de ventas aporta en este objetivo. Sin embargo, es un proceso de alta complejidad ya que la venta depende de la capacidad del vendedor y su relación con el cliente, lo cual es difícil de controlar. Este proceso es de interés de los investigadores debido a su experiencia en temas comerciales.

Servicio Técnico: incrementar las ventas de servicio técnico tendría un impacto relativamente en los resultados de la empresa, ya que en el último año representó el $13 \%$ de los ingresos. El proceso tiene una complejidad media, ya que responde a las necesidades de los clientes y el control puede ser un poco complicado porque el trabajo se realiza fuera de la empresa, por lo cual no se cuenta con mucha información para calcular indicadores del mismo. Finalmente, el poco conocimiento de los investigadores sobre temas técnicos hace que su interés en mejorar este proceso sea bajo.

En base a lo mencionado, se presenta el ranking de factores: 
Tabla 2.10

Ranking de factores para selección de proceso a mejorar

\begin{tabular}{|c|c|c|c|c|c|c|c|}
\hline \multirow{2}{*}{ Factor } & \multirow{2}{*}{ Peso } & \multicolumn{2}{c|}{ Admin. y finanzas } & \multicolumn{2}{c|}{ Ventas } & \multicolumn{2}{c|}{ Servicio Técnico } \\
\cline { 3 - 8 } & Calif. & Puntaje & Calif. & Puntaje & Calif. & Puntaje \\
\hline $\begin{array}{c}\text { Indicadores a } \\
\text { mejorar }\end{array}$ & 35.00 & 4 & 140.00 & 4 & 140.00 & 2 & 70.00 \\
\hline $\begin{array}{c}\text { Complejidad del } \\
\text { proceso }\end{array}$ & 20.00 & 3 & 60.00 & 2 & 40.00 & 4 & 80.00 \\
\hline $\begin{array}{c}\text { Disponibilidad de } \\
\text { información }\end{array}$ & 20.00 & 4 & 80.00 & 3 & 60.00 & 2 & 40.00 \\
\hline $\begin{array}{c}\text { Interés del } \\
\text { investigador }\end{array}$ & 25.00 & 2 & 50.00 & 4 & 100.00 & 2 & 50.00 \\
\hline TOTAL & 100.00 & & $\mathbf{3 3 0 . 0 0}$ & & $\mathbf{3 4 0 . 0 0}$ & & $\mathbf{2 4 0 . 0 0}$ \\
\hline
\end{tabular}

Elaboración propia

Con el resultado del ranking de factores, seleccionaremos el proceso de ventas para la implementación de la mejora. Luego del diagnóstico presentado en este capítulo, se estima que una reorganización para la mejora del proceso de ventas podría ser de gran ayuda para la empresa. El proceso de ventas incluirá:

- Las políticas crediticias a los clientes: cuáles son los requisitos y cuáles son las condiciones de la empresa para brindar un crédito a un cliente.

- Métodos de pronóstico de ventas y estudio de requerimientos de mercado.

- Adecuados procesos logísticos de pedidos de mercadería. Se trabajará con los pronósticos de ventas y las necesidades del mercado.

- Mejorar el sistema de cobranzas

- Mejorar la información del área comercial a fin de determinar la eficiencia de los vendedores y la participación de la competencia. 


\section{CAPÍTULO III. DIAGNÓSTICO DEL PROCESO OBJETO DE ESTUDIO}

\subsection{Análisis del proceso objeto de estudio}

\subsubsection{Caracterización detallada del proceso objeto de estudio}

Habiendo definido que el proceso a ser mejorado es el de ventas y considerando que $\mathrm{ABC}$ S.A.C. registra su mayor ingreso por venta de maquinaria, contando además con diferentes servicios que dan soporte a estas ventas, el proceso objeto de estudio es el de ventas de maquinaria importada.

El proceso de ventas inicia con el pronóstico de ventas de maquinaria para todo el año. Para poder elaborar un pronóstico de ventas del año la empresa se basa en las ventas históricas del negocio (especialmente las del año previo) y tienen en consideración, de una manera muy ligera, la coyuntura externa. El pronóstico de ventas es muy pobre y normalmente se ha caracterizado por no tener mucho sustento. Como ya se mencionó, no se detallan las consideraciones externas ni tampoco se especifica cuáles serán las actividades para conseguir dichas ventas (ferias, campañas, ofertas, prospección detallada de posibles negocios, etc.). El pronóstico del año no se verifica ni se valida una segunda o tercera vez en el año, por lo que si hay algún suceso importante, este solo es considerado por las personas involucradas (vendedores, gerencia comercial y gerencia general).

Seguidamente con este pronóstico de ventas se pasa a la logística de entrada. Se planifica con los proveedores un aproximado del requerimiento de insumos a lo largo del año. Para ello se tiene en cuenta el nivel de inventario actual y los tiempos de fabricación y traslado (entre 60 y 90 días en la mayoría de los casos). Lógicamente, al no tener una validación de pronóstico, las fechas de pedidos casi siempre cambian, generando nuevas coordinaciones, roturas de stock (retrasos) o bodegas llenas (adelantos). Una vez realizado el pedido y coordinado el despacho, se espera la 
mercadería, y luego de los respectivos procesos de desaduanaje, se ingresan los productos al almacén.

En paralelo se van trabajando las ventas a clientes. Se trata de manejar una prospección, pero no se lleva un buen control de la misma. No se cuenta con un sistema que soporte el avance de objetivos de venta ni el control de créditos otorgados, sino que se utiliza una hoja de cálculo y las actualizaciones por parte del personal de ventas no siempre se dan a tiempo. Es importante mencionar que esta falta de actualizaciones, combinada con la falta de certeza en la llegada de los productos, hacen que las condiciones de venta varíen dependiendo de los niveles de stock: si hay demasiados productos se busca tener promociones o dar mayores descuentos; si hay pocos productos se pierden ventas por falta de entrega al cliente. En ambos casos la empresa se ve perjudicada.

El vendedor realiza la negociación para cerrar la venta, llegando a un acuerdo del precio y las condiciones comerciales, entre las cuales se encuentra el crédito. Una vez efectuada la venta, se procede a la logística de salida, es decir, el despacho de la máquina. Se revisa la máquina a despachar, verificando que tenga todos los implementos y que no presente una falla evidente, dado que la maquinaria no se arma ni se enciende hasta llegar al local del cliente. Luego se coordina con el área de servicio técnico y el cliente la fecha de instalación y despacho. Previo a esta fecha el equipo técnico de ABC S.A.C. realiza una visita al local del cliente y se verifica que tenga todos los implementos necesarios para poder recibir la maquinaria y ponerla en marcha (espacio libre, carga eléctrica, iluminación, un piso adecuado, etc.). Si se cumplen todos los requerimientos se procede a despachar la máquina junto con los documentos contables y administrativos (guías y facturas). En caso que el cliente no cuente con las condiciones mínimas, el equipo no se instala y, muchas veces, ni siquiera se despacha.

Finalmente, se procede con la instalación de la máquina. Una vez instalada y probada, junto con el visto bueno del cliente, empiezan a correr 30 días, luego de los cuales se realiza una visita de validación de garantía. En esta visita se busca verificar que se mantienen las condiciones en las cuales se instaló la máquina y por lo tanto la garantía sigue siendo válida. En caso que el cliente haya movido la máquina, recableado o ejecutado alguna otra actividad que la pueda poner en riesgo, la garantía se suspende. 
A pesar de ser una excelente iniciativa, esta visita rara vez se cumple a tiempo, si es que se cumple.

A continuación se presentan el diagrama de bloques de este proceso:

Figura 3.1

Diagrama de bloques del proceso de venta de maquinaria

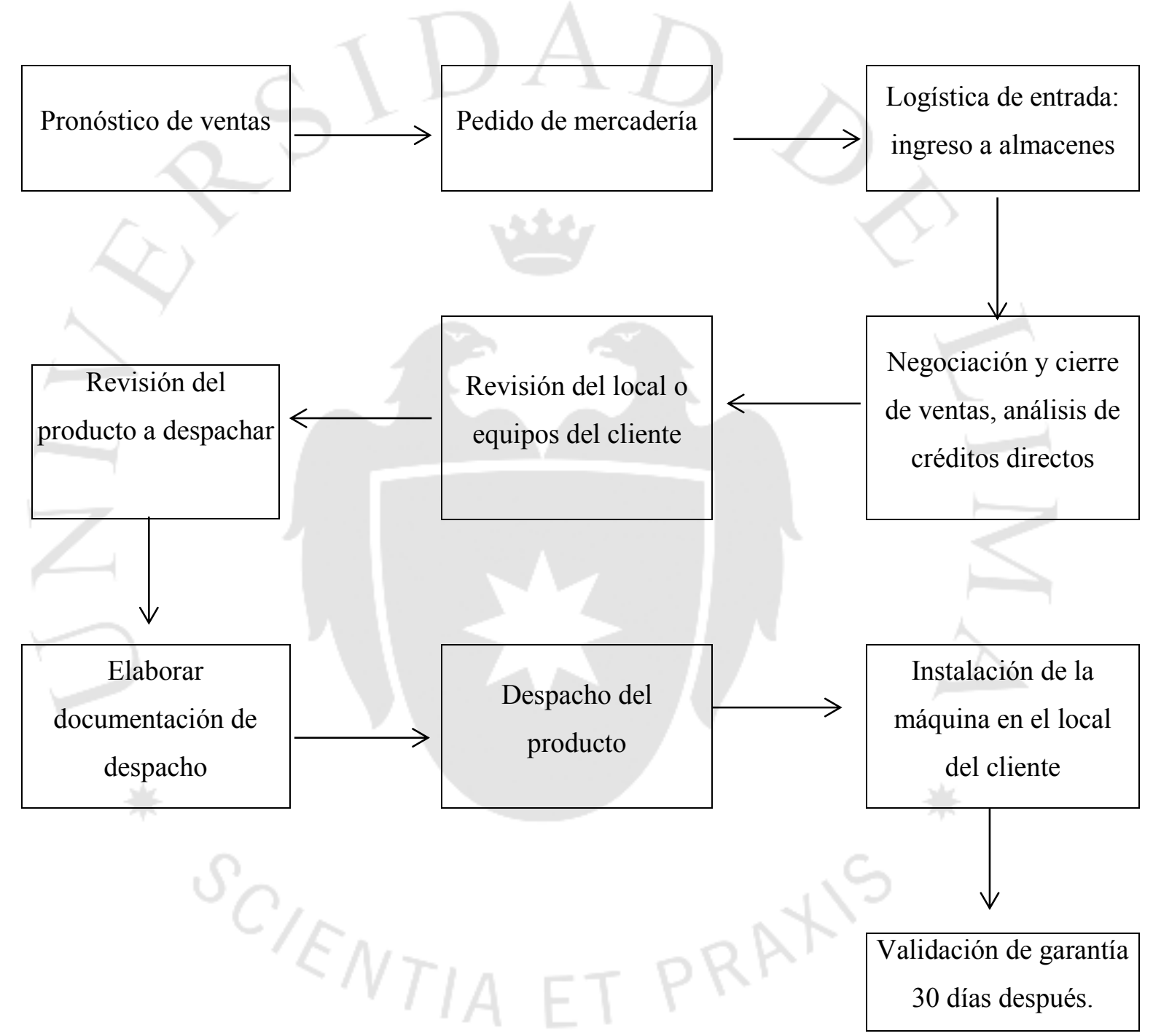

Fuente ABC S.A.C.

Elaboración propia

\subsubsection{Análisis de los indicadores específicos de desempeño del sistema o proceso}

A fines de realizar un diagnóstico del proceso seleccionado, se revisarán los indicadores específicos del proceso de venta de maquinarias. 
Lamentablemente no se cuenta con mucha información específica debido a que la empresa no maneja un sistema para el control de indicadores. El análisis a realizar estará centrado en revisar principalmente indicadores de volumen de ventas, inventarios, gastos de ventas y cuentas por cobrar.

- Rotación de Inventarios: Costo de ventas / Inventario promedio (maquinaria)

Tabla 3.1

Rotación de Inventarios

\begin{tabular}{|l|r|r|c|}
\hline Año & $\begin{array}{c}\text { Costo de } \\
\text { Ventas (CV) }\end{array}$ & $\begin{array}{c}\text { Inventario } \\
\text { Promedio (I) }\end{array}$ & $\begin{array}{c}\text { Rotación de } \\
\text { Inventarios (CV/I) }\end{array}$ \\
\hline $\mathbf{2 0 0 3}$ & 791,535 & 386,941 & 2.05 \\
\hline $\mathbf{2 0 0 4}$ & $1,659,915$ & 470,199 & 3.53 \\
\hline $\mathbf{2 0 0 5}$ & $1,833,711$ & 409,302 & 4.48 \\
\hline $\mathbf{2 0 0 6}$ & $1,488,943$ & $1,249,734$ & 1.19 \\
\hline $\mathbf{2 0 0 7}$ & $2,140,920$ & $1,152,460$ & 1.86 \\
\hline $\mathbf{2 0 0 8}$ & $3,573,017$ & $1,328,889$ & 2.69 \\
\hline $\mathbf{2 0 0 9}$ & $3,804,885$ & $1,978,811$ & 1.92 \\
\hline $\mathbf{2 0 1 0}$ & $5,164,931$ & $2,047,354$ & 2.52 \\
\hline $\mathbf{2 0 1 1}$ & $5,021,448$ & $2,234,241$ & 2.25 \\
\hline $\mathbf{2 0 1 2}$ & $5,205,665$ & $3,750,271$ & 1.39 \\
\hline
\end{tabular}

Fuente ABC S.A.C.

Elaboración propia 
Figura 3.2

Rotación de inventarios

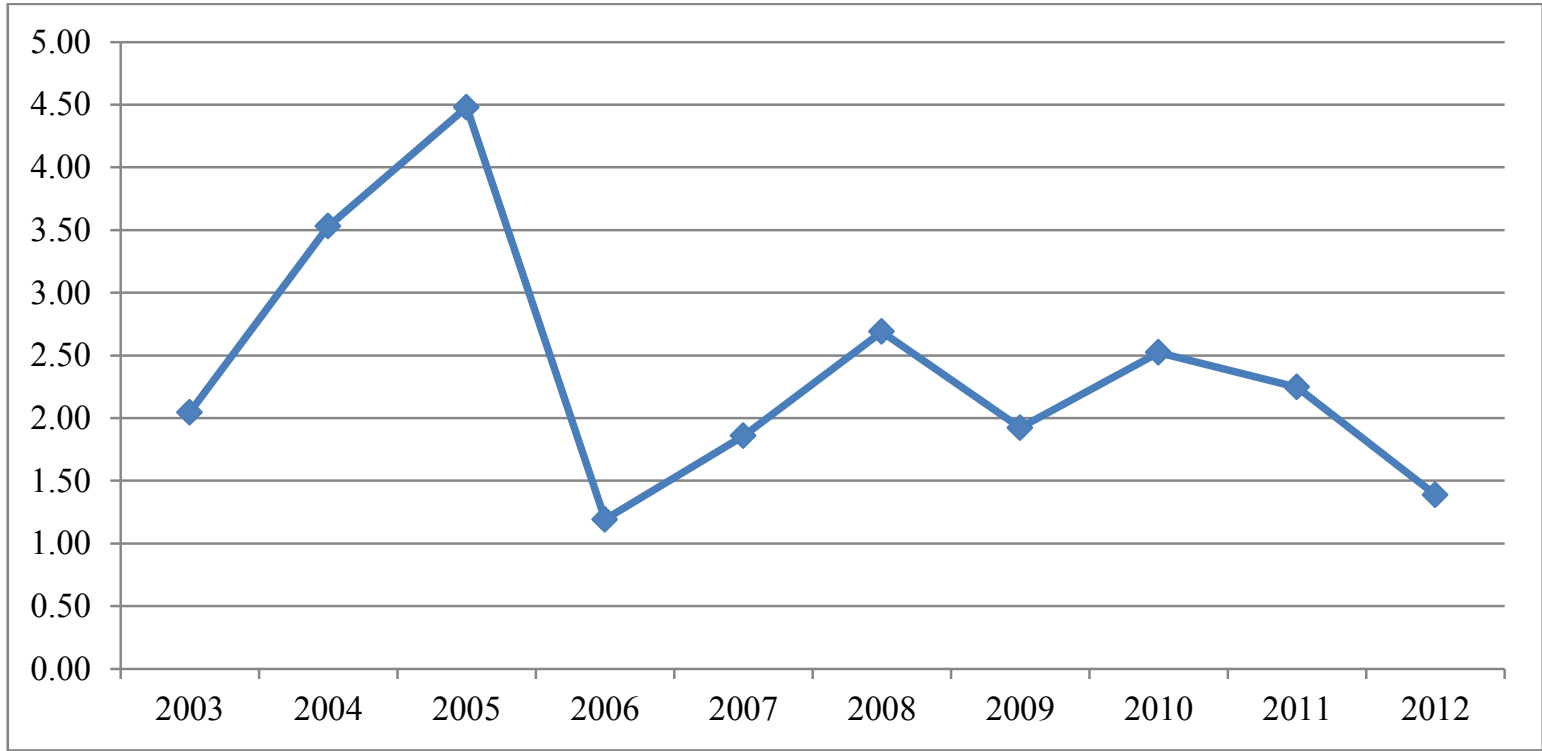

Fuente ABC S.A.C.

Elaboración propia

En el gráfico podemos observar que una tendencia fluctuante entre los años 2003 y 2010, y hacia adelante la tendencia se vuelve negativa. La rotación de inventarios de maquinaria alcanza su mejor nivel en el año 2005 con un valor de 4.5 veces por año (es decir, cada 2 meses y medio), descendiendo hasta casi 2.5 en el 2010 y por debajo de 1.5 en los últimos periodos evaluados. La gráfica tiene una tendencia similar al indicador general de rotación de inventarios, debido al peso que tiene la maquinaria en los costos de ventas y en el inventario. Sin embargo, las diferencias están en que la rotación de máquinas es más lenta que la de consumibles y al mismo tiempo los inventarios de maquinaria son más costosos que los de consumibles. Es claro que este indicador se ve afectado por el alto nivel de las existencias promedio de maquinarias, lo cual se debe principalmente a un inadecuado pronóstico de ventas por máquina y a que no hay una planificación estratégica de compras que permita tener un nivel de inventarios promedio adecuado. Ambos problemas afectan directamente a las ventas, ya que hay sobre stock de algunas máquinas mientras que no se tiene stock de otras que podrían colocarse.

- Efectividad de ventas

La efectividad de ventas será medida como la relación entre el número de ventas facturadas y cotizaciones emitidas de maquinaria; lamentablemente la empresa 
no cuenta con un registro unificado y ordenado de las cotizaciones emitidas. Gracias a las entrevistas llevadas a cabo a los vendedores de manera individual, se pudo estimar que las ventas cerradas representan aproximadamente el $37 \%$ de las cotizaciones emitidas en el último año. Además, se estima que este porcentaje se ha mantenido igual en años previos, ya que si bien los vendedores han ganado más experiencia y por lo tanto conocen más las máquinas y tienen mayor capacidad de cerrar ventas, cada vez hay mayor competencia y los clientes tienen más opciones de donde elegir.

- Devoluciones de producto

La empresa no cuenta con información histórica sobre incidentes con la maquinaria vendida, ya que los casos en los que el producto vendido ha resultado averiado o defectuoso han sido mínimos. De acuerdo a lo manifestado por el Gerente General, este tipo de situaciones se registra con una periodicidad menor a un incidente anual, lo que significa que el indicador es menor a $1 \%$.

- Total de ventas registradas de maquinaria

Tabla 3.2

Venta de maquinaria

\begin{tabular}{|c|c|c|}
\hline Año & $\begin{array}{c}\text { Ventas } \\
\text { Maquinaria (S/.) }\end{array}$ & $\begin{array}{c}\text { Variación } \\
\%\end{array}$ \\
\hline $\mathbf{2 0 0 3}$ & $1,304,628$ & - \\
\hline $\mathbf{2 0 0 4}$ & $2,521,778$ & $93 \%$ \\
\hline $\mathbf{2 0 0 5}$ & $3,279,227$ & $30 \%$ \\
\hline $\mathbf{2 0 0 6}$ & $2,971,457$ & $-9 \%$ \\
\hline $\mathbf{2 0 0 7}$ & $3,549,705$ & $19 \%$ \\
\hline $\mathbf{2 0 0 8}$ & $5,472,276$ & $54 \%$ \\
\hline $\mathbf{2 0 0 9}$ & $6,182,833$ & $13 \%$ \\
\hline $\mathbf{2 0 1 0}$ & $8,362,576$ & $35 \%$ \\
\hline $\mathbf{2 0 1 1}$ & $7,560,856$ & $-10 \%$ \\
\hline $\mathbf{2 0 1 2}$ & $7,303,779$ & $-3 \%$ \\
\hline
\end{tabular}

Fuente ABC S.A.C.

Elaboración propia 
Figura 3.3

Venta de maquinaria

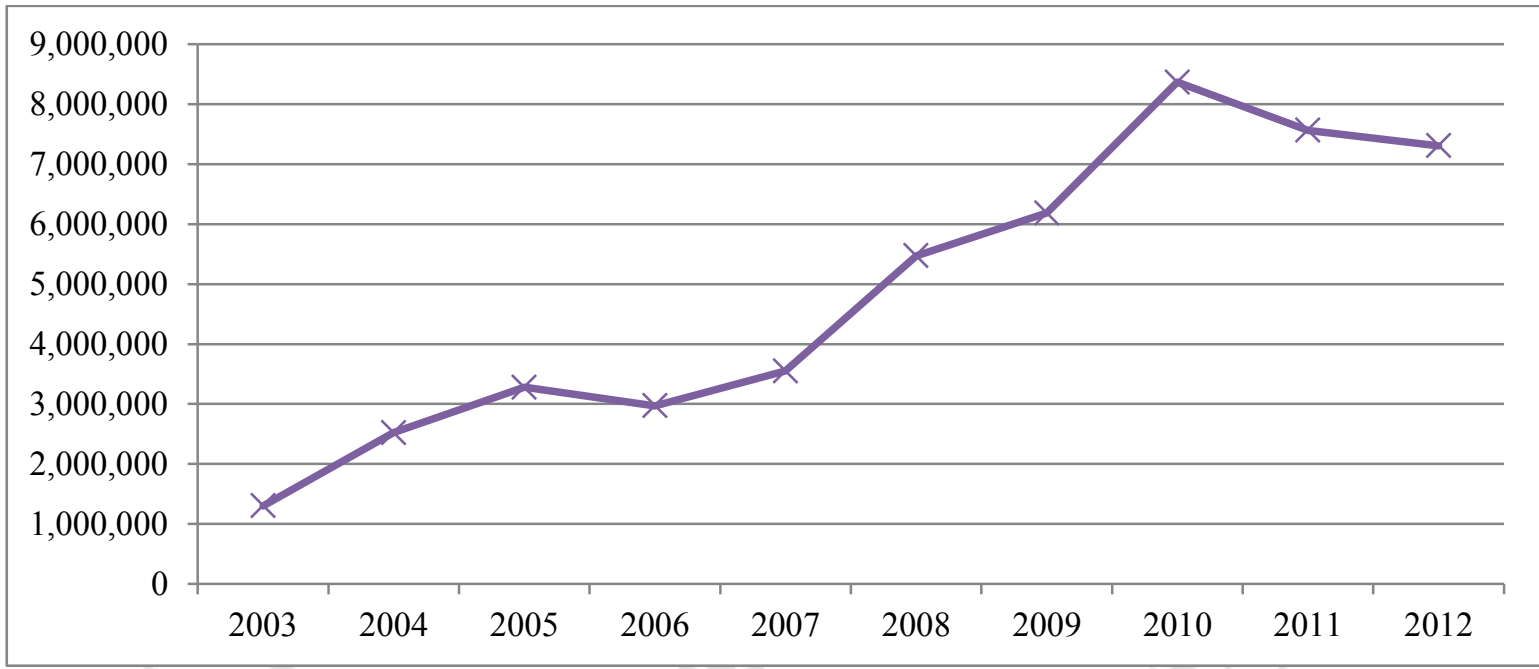

Fuente ABC S.A.C.

Elaboración propia

En la figura 3.3 podemos observar la evolución de las ventas de maquinaria, en la cual hay un crecimiento continuo entre los años 2007 y 2010, registrando el mayor incremento porcentual en el año 2008 y el pico de ventas en el año 2010. Sin embargo en los últimos dos años las ventas han decrecido, lo cual complica la situación considerando la situación financiera en la que se encuentra la empresa. Si bien se pronostica una leve mejoría para los siguientes años, esta no será suficiente para dar un llegar a un resultado positivo del negocio.

- Número de clientes

La empresa no cuenta con un registro histórico del número de clientes, por lo cual no se cuenta con mucha información histórica al respecto. Sin embargo, se cuenta con información de los últimos tres años:

Tabla 3.3

Número de clientes

\begin{tabular}{|c|r|c|}
\hline Año & Nro. de clientes & Variación \% \\
\hline 2010 & 2,336 & - \\
\hline 2011 & 2,435 & $4 \%$ \\
\hline 2012 & 1,470 & $-40 \%$ \\
\hline
\end{tabular}

Fuente ABC S.A.C.

Elaboración propia 
Como se aprecia en el cuadro, no hubo una mayor variación entre los años 2010 y 2011, pero si hay una gran disminución hacia el año 2012. Esto se debe a que se realizó un sinceramiento del padrón de clientes, eliminando a una gran cantidad de clientes que ya no existían o que habían cambiado de rubro y por tanto ya no eran del interés de la empresa. En adelante se requiere llevar un mejor control del padrón, a fines de tomar las mejores decisiones con respecto a las zonas de ventas y al número de vendedores necesarios para atenderlas.

- Costo y Gasto de Ventas

Para revisar estos indicadores, procederemos a analizar la relación entre costos y gastos de ventas sobre las ventas de maquinaria:

Tabla 3.4

Costos/Gastos de Ventas vs. Ventas

\begin{tabular}{|c|c|c|c|c|c|}
\hline $\mathbf{A n ̃ o}$ & $\begin{array}{c}\text { Venta } \\
\text { Maquinaria } \\
(\mathbf{S} / .)\end{array}$ & $\begin{array}{c}\text { Costo de } \\
\text { Ventas } \\
(\mathbf{S} / .)\end{array}$ & $\begin{array}{c}\text { Costo de } \\
\text { ventas vs. } \\
\text { Ventas }\end{array}$ & $\begin{array}{c}\text { Gastos de } \\
\text { Ventas } \\
(\mathbf{S} / .)\end{array}$ & $\begin{array}{c}\text { Gastos de } \\
\text { ventas vs. } \\
\text { Ventas }\end{array}$ \\
\hline $\mathbf{2 0 0 3}$ & $1,304,628$ & 791,535 & 0.61 & 241,961 & 0.19 \\
\hline $\mathbf{2 0 0 4}$ & $2,521,778$ & $1,659,915$ & 0.66 & 235,129 & 0.09 \\
\hline $\mathbf{2 0 0 5}$ & $3,279,227$ & $1,833,711$ & 0.56 & 438,707 & 0.13 \\
\hline $\mathbf{2 0 0 6}$ & $2,971,457$ & $1,488,943$ & 0.50 & 478,607 & 0.16 \\
\hline $\mathbf{2 0 0 7}$ & $3,549,705$ & $2,140,920$ & 0.60 & 572,613 & 0.16 \\
\hline $\mathbf{2 0 0 8}$ & $5,472,276$ & $3,573,017$ & 0.65 & 829,032 & 0.15 \\
\hline $\mathbf{2 0 0 9}$ & $6,182,833$ & $3,804,885$ & 0.62 & $1,137,843$ & 0.18 \\
\hline $\mathbf{2 0 1 0}$ & $8,362,576$ & $5,164,931$ & 0.62 & $1,619,354$ & 0.19 \\
\hline $\mathbf{2 0 1 1}$ & $7,560,856$ & $5,021,448$ & 0.66 & $1,952,432$ & 0.26 \\
\hline $\mathbf{2 0 1 2}$ & $7,303,779$ & $5,205,665$ & 0.71 & $2,045,285$ & 0.28 \\
\hline
\end{tabular}

Fuente ABC S.A.C.

Elaboración propia 
Figura 3.4

Costos/Gastos de Ventas vs. Ventas

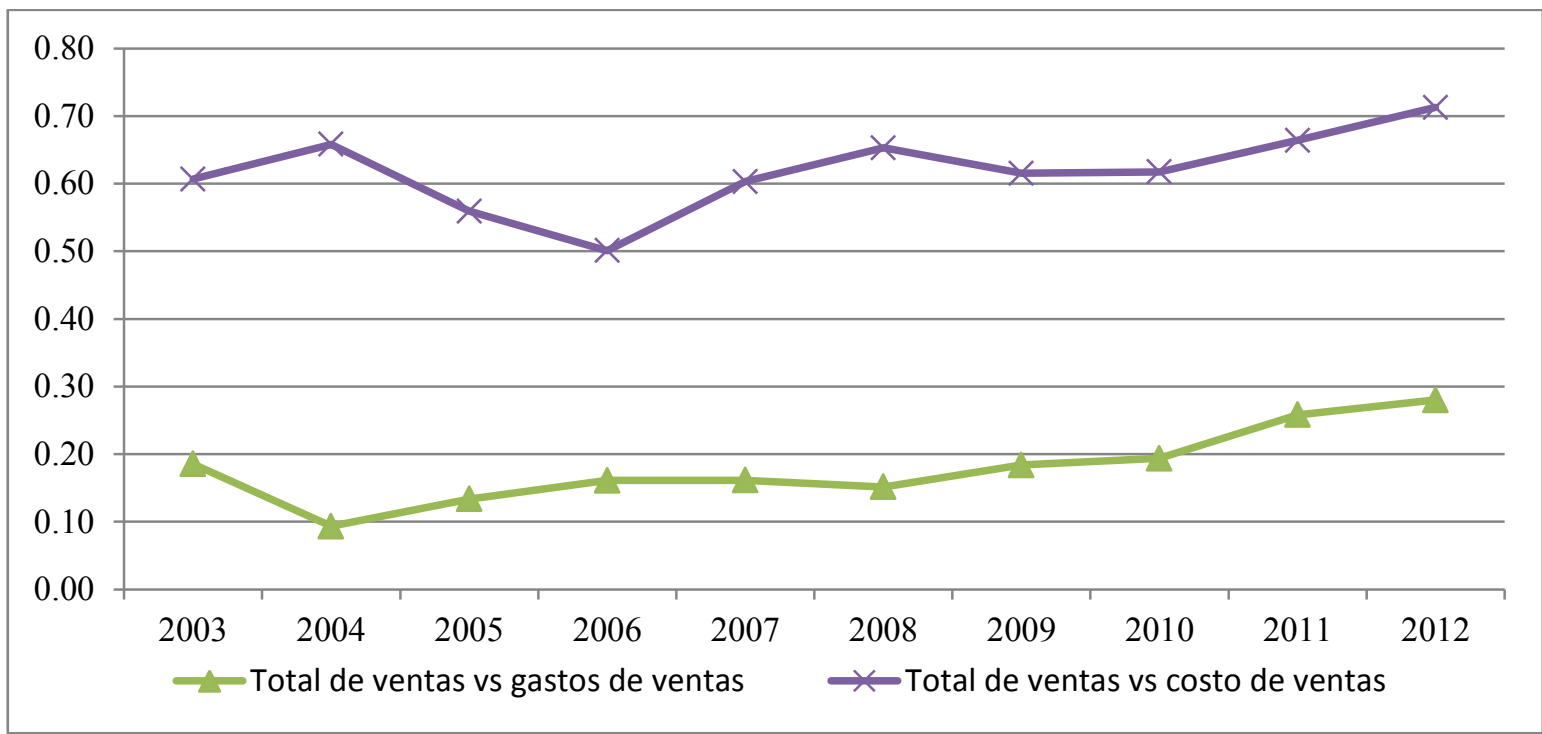

Fuente ABC S.A.C.

Elaboración propia

En la figura 3.5 se observa una clara tendencia al alza de la relación que existe entre los costos de venta versus las ventas. Si bien es cierto que en los años 2005 y 2006 hay una caída pronunciada, la curva es ascendente en casi todo momento, lo que se traduce en una clara disminución del margen debido un aumento de los costos de maquinaria sin el respectivo incremento en los precios de venta. El factor principal que ha influido en el alza de este indicador es la competencia en el sector. Al haber mayor cantidad de participantes en el sector, la empresa se ve en la obligación de ajustar sus precios de venta a fin de mantenerse competitiva. Asimismo, según información de la Gerencia, casi todos los años los proveedores incrementan sus precios debido a las tasas de inflación de cada país, siendo que este incremento muchas veces no se refleja en la lista de precios final de $\mathrm{ABC}$ S.A.C., debido a que la empresa prefiere reducir sus márgenes y mantenerse competitiva a subir sus precios. Es importante mencionar que el ingreso al mercado de maquinaria proveniente de China, considerablemente más barata, acelera esta reducción de márgenes.

De manera similar, la relación de los gastos de ventas sobre ventas mantiene una tendencia al alza de manera sostenida desde el año 2004. Esto se debe principalmente a que la empresa responde al incremento de la demanda haciendo crecer la organización, entre otras medidas, con lo cual espera dar respuesta a las necesidades 
de sus clientes existentes y potenciales. En los primeros años, con el incremento de las ventas, parece ser una medida adecuada pero, cuando estas dejan de crecer, los gastos ya no son justificados. La Gerencia consideró en su momento aumentar la presencia en el mercado a fin de mejorar las ventas (desde el año 2010), medida que no fue la indicada al no traer mejores resultados.

Para un mejor entendimiento, revisaremos en detalle el incremento en los gastos de ventas haciendo una comparación entre los años 2010 y 2012, revisando para cada año la relación entre las cuentas de gastos y las ventas:

Tabla 3.5

Gastos de ventas 2010 vs. 2012 (S/.)

\begin{tabular}{|l|r|c|r|c|c|}
\hline \multicolumn{1}{|c|}{ Cuenta } & $\begin{array}{r}\text { Año } \\
\mathbf{2 0 1 0}\end{array}$ & $\begin{array}{c}\text { \% del } \\
\text { gasto } \\
\text { sobre } \\
\text { ventas }\end{array}$ & $\begin{array}{c}\text { Año } \\
\mathbf{2 0 1 2}\end{array}$ & $\begin{array}{c}\text { \% del } \\
\text { gasto } \\
\text { sobre } \\
\text { ventas }\end{array}$ & $\begin{array}{c}\text { Variación } \\
\text { del \%o }\end{array}$ \\
\hline Ventas & $\mathbf{8 , 3 6 2 , 5 7 6}$ & - & $\mathbf{7 , 3 0 3 , 7 7 9}$ & - & - \\
\hline Planilla total & 860,121 & $10.3 \%$ & $1,233,479$ & $16.9 \%$ & $6.6 \%$ \\
\hline Gastos de viaje & 257,815 & $3.1 \%$ & 330,073 & $4.5 \%$ & $1.4 \%$ \\
\hline Gastos de distribución & 244,568 & $2.9 \%$ & 190,665 & $2.6 \%$ & $-0.3 \%$ \\
\hline Equipos & 45,586 & $0.5 \%$ & 90,985 & $1.2 \%$ & $0.7 \%$ \\
\hline Capacitación & 5,714 & $0.1 \%$ & 9,981 & $0.1 \%$ & $0.1 \%$ \\
\hline Publicidad & 9,305 & $0.1 \%$ & 22,956 & $0.3 \%$ & $0.2 \%$ \\
\hline Otros servicios de terceros & 150,959 & $1.8 \%$ & 99,324 & $1.4 \%$ & $-0.4 \%$ \\
\hline Otros & 45,286 & $0.5 \%$ & 67,822 & $0.9 \%$ & $0.4 \%$ \\
\hline Total gastos de ventas & $\mathbf{1 , 6 1 9 , 3 5 4}$ & $\mathbf{1 9 . 4 \%}$ & $\mathbf{2 , 0 4 5 , 2 8 5}$ & $\mathbf{2 8 . 0 \%}$ & $\mathbf{8 . 6 \%}$ \\
\hline
\end{tabular}

Fuente ABC S.A.C.

Elaboración propia

Como se observa en el cuadro, hubo un incremento excesivo en los gastos de ventas, lo cual no corresponde con el nivel de ventas que inclusive disminuye. Esto denota que el manejo de gastos de ventas no ha sido bien llevado y que no hay un control estricto del mismo. La cuenta donde se registra un mayor incremento porcentual es la de planillas, por lo cual se requiere una revisión de la estructura de la organización para buscar eficiencias y reducir este gasto que para la situación de la empresa es excesivo. Por otro lado, vale destacar que también hubo un aumento considerable de gastos de viaje, debido al poco control que existe sobre los mismos. En cuanto a los 
gastos de capacitación y publicidad, si bien aumentan en porcentaje, siguen siendo una parte mínima de la composición del gasto, lo cual muestra el poco interés que ha tenido la empresa en ambos rubros.

- Rotación de Cuentas por cobrar: Ventas / Cuentas por cobrar

Tabla 3.6

Rotación de cuentas por cobrar

\begin{tabular}{|l|c|c|c|c|}
\hline Año & Venta Maquinaria (S/.) & Cuentas por Cobrar & Rotación & Días \\
\hline $\mathbf{2 0 0 4}$ & $2,521,778$ & 255,234 & 9.9 & 36.9 \\
\hline $\mathbf{2 0 0 5}$ & $3,279,227$ & 865,051 & 3.8 & 96.3 \\
\hline $\mathbf{2 0 0 6}$ & $2,971,457$ & 291,231 & 10.2 & 35.8 \\
\hline $\mathbf{2 0 0 7}$ & $3,549,705$ & 210,850 & 16.8 & 21.7 \\
\hline $\mathbf{2 0 0 8}$ & $5,472,276$ & 917,946 & 6.0 & 61.2 \\
\hline $\mathbf{2 0 0 9}$ & $6,182,833$ & $1,819,827$ & 3.4 & 107.4 \\
\hline $\mathbf{2 0 1 0}$ & $8,362,576$ & $2,734,392$ & 3.1 & 119.3 \\
\hline $\mathbf{2 0 1 1}$ & $7,560,856$ & $3,814,286$ & 2.0 & 184.1 \\
\hline $\mathbf{2 0 1 2}$ & $7,303,779$ & $2,166,815$ & 3.4 & 108.3 \\
\hline
\end{tabular}

Fuente ABC S.A.C.

Elaboración propia

Figura 3.5

Rotación de cuentas por cobrar y días de crédito

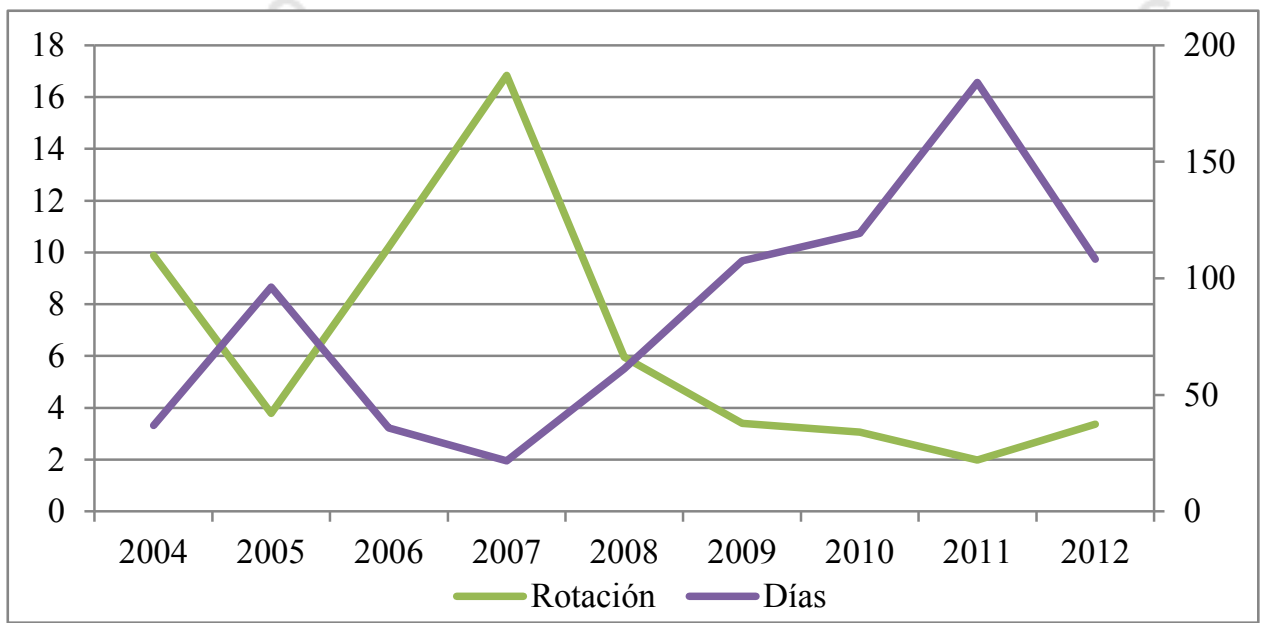

Fuente ABC S.A.C.

Elaboración propia 
Las cuentas por cobrar se consideran un indicador compartido entre ventas y cobranzas, ya que es responsabilidad del área comercial proponer la asignación de créditos a los clientes y posteriormente manejar la relación comercial de manera que se controle constantemente que el cliente esté al día con el pago de sus deudas. Como se observa en la tabla 3.6, el nivel de cuentas por cobrar se incrementó considerablemente a partir del año 2009, puesto que el incremento de ventas era sostenido en el crédito otorgado a clientes. Es así que en el año 2011 alcanza su nivel más alto, debido a que el año anterior hubo demasiada venta al crédito que no fue recuperada a tiempo y que en algunos casos nunca se recuperaron, debido a una irresponsable asignación de créditos por parte del área comercial. La rotación de cuentas llegó a 2 veces por año, lo que significa que la empresa recuperaba el crédito entregado al mercado cada 6 meses. En los siguientes años se ha ido bajando el nivel de cuentas por cobrar, pero aún es demasiado alto y con más de 100 días de crédito al mercado, lo que se ve reflejado en la baja liquidez con la que cuenta la empresa actualmente. La empresa debe tomar medidas que controlen mejor el otorgamiento de créditos, así como también la cobranza de los mismos.

Como conclusión del análisis de indicadores del proceso de ventas de maquinaria, se obtienen cuatro problemas principales dentro del mismo:

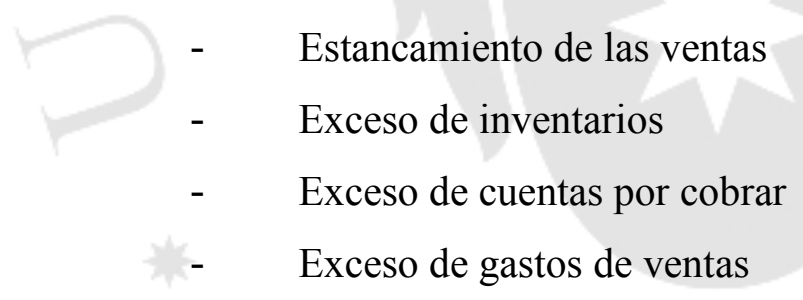

\subsection{Determinación de las causas raíz de los problemas hallados}

Luego de analizar los diferentes indicadores se procede a determinar las causas principales de estos resultados. Para ello se utilizarán dos métodos. El primero de ellos es el diagrama Causa-Efecto y el segundo es la metodología de diagnóstico de J. P. Thibaut.

Para elaborar el diagrama Causa-Efecto se determina en primer lugar el problema que se pretende resolver. Como se revisó en el capítulo 2, el problema principal de la empresa es su baja rentabilidad, por lo cual esta investigación busca 
mejorar la rentabilidad de la empresa mediante la mejora en el proceso de ventas y así conseguir la estabilidad financiera.

Seguidamente se identifican las principales categorías dentro de las cuales se podrían calificar las causas de dicho problema. Para este caso en particular las categorías son:

- Personal

- Procedimientos

- Planeación estratégica

- Recursos (know-how, personal, proveedores, infraestructura física, etc.)

- Competencia

Finalmente se procede a identificar las causas raíz en dichas categorías. Estas por lo general son aspectos específicos de cada categoría (posiblemente haya más de una causa en cada categoría), los cuales generan el problema. Para este caso en particular podemos encontrar las siguientes causas dentro de cada categoría:

\section{Personal}

- Malos procesos de contratación llevaron a tener personal relacionado al proceso de ventas muy poco preparado para las funciones que realizan.

- La falta de capacitación interna, especialmente a los vendedores, hacen que se requiera mucho tiempo en capacitar de manera adecuada a una persona, por lo que toma mucho tiempo hasta que dicha persona alcance un rendimiento óptimo.

- La falta de visión general de negocio y de metas claramente definidas en el área de ventas, genera que los trabajadores se sientan poco comprometidos con la empresa.

Procedimientos

- La falta de procedimientos de ventas y la ausencia de un sistema de indicadores no permite mejorar el nivel de ventas con respecto a los dos últimos años.

- Falta de control en la asignación de créditos así como el poco seguimiento en las cobranzas llevaron a tener niveles de cuentas por cobrar demasiados altos para la empresa.

- La falta de controles logísticos evitó que se emitiera una alerta de los altos niveles de inventario que se tenía en ciertos productos. 


\section{Planeamiento estratégico}

- Al no tener una estrategia clara de ventas y de cómo aplicarla para cada producto, se generó un aumento de stock de productos de poca rotación (no se conocía el impacto que podría tener en el mercado). Esto resultó a su vez altos niveles de cuentas por pagar, ya sea a proveedores o a entidades bancarias.

- La ausencia de indicadores de gestión y la respectiva comparación de estos con años anteriores evitaron que la empresa logre aprender de gestiones pasadas.

- La falta de una estrategia general y de una posición autocrítica evitó que la empresa pueda ver que mantiene una estructura con costos fijos demasiados altos.

\section{Recursos}

- Se tiene un local propio y muy bien ubicado, cuyo alto valor comercial relajó la presión de los socios por resultados comerciales, al sentir un respaldo en el valor del inmueble.

- Buena presencia en el mercado y claro liderazgo ocasionó que la gerencia general se descuide en la toma rápida de decisiones y en la implementación de campañas comerciales, al considerar a la empresa como "el referente del sector".

- Se tiene el mayor conocimiento técnico del sector, pero no se aprovecha al máximo: no se resguarda, no se reparte al personal de manera adecuada y tampoco se promociona a la empresa con ese argumento hacia los clientes.

\section{Competencia}

- Malas políticas de retención ocasionan fuga de talentos, lo que probablemente resulte finalmente en un nuevo competidor. La Gerencia nos indica que por lo menos siete ex-trabajadores de ABC S.A.C. han decidido abrir su propio negocio, todos compitiendo con la empresa, ya sea en la venta de maquinaria, consumibles o servicio técnico. Asimismo, hay otra importante cantidad de personas que trabajaron en ABC S.A.C. y que actualmente están laborando en empresas competidoras.

- Falta de inteligencia comercial evitó tener una mejor lectura de lo que hacen los competidores, especialmente con maquinaria más económica. 
A continuación se presenta el diagrama Causa-Efecto elaborado con estas consideraciones. 
Figura 3.6

Diagrama de Causa-Efecto del problema "Baja Rentabilidad"

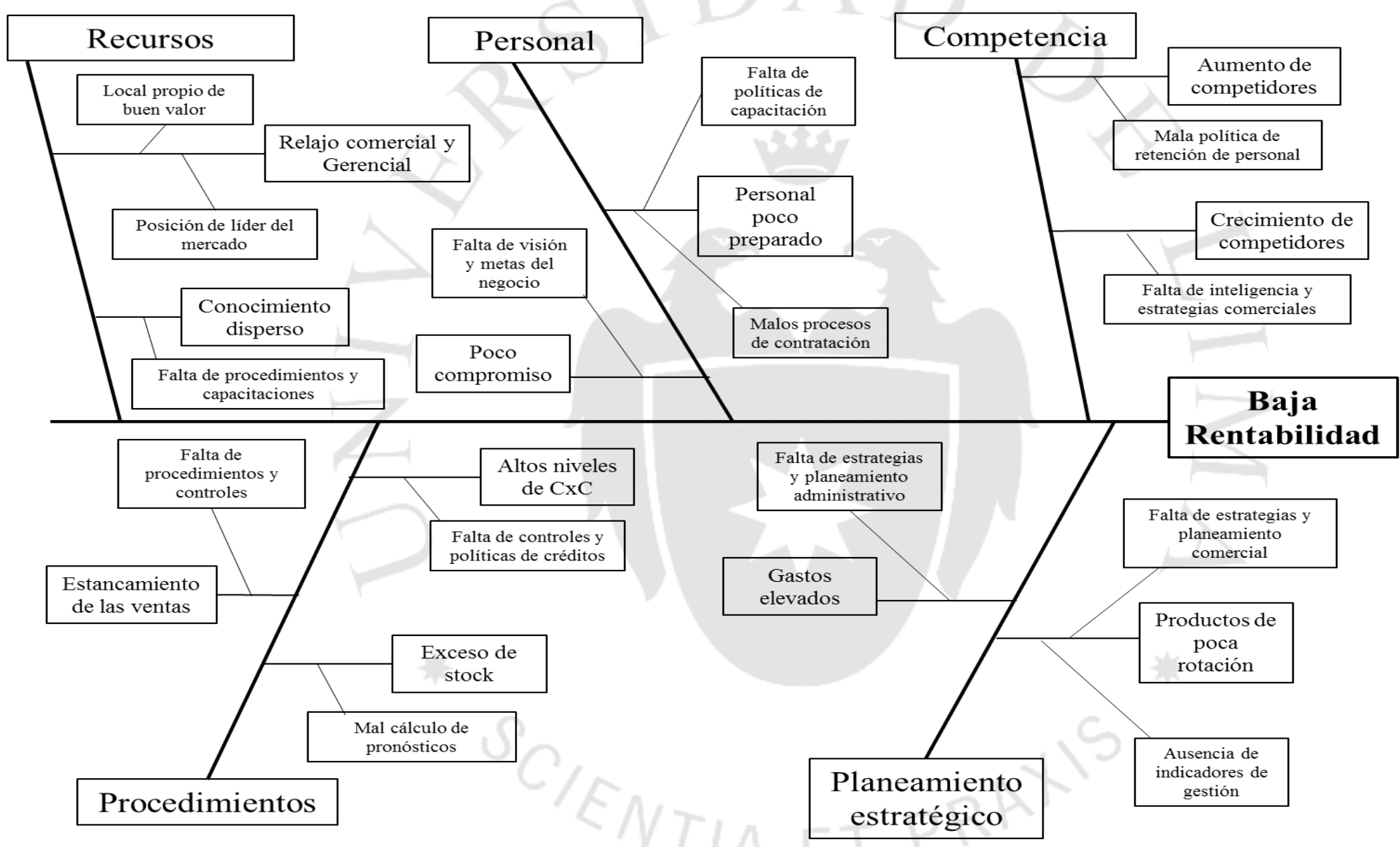

Elaboración propia 
Asimismo, de manera complementaria y para profundizar en el análisis de la problemática, se presenta el análisis de diagnóstico comercial siguiendo a la metodología de Jean Pierre Thibaut (Thibaut, 1994). Dicho análisis se realiza de acuerdo a la siguiente estructura teórica:

- Análisis de resultados

- Estudio de la política comercial

- Revisión de medios y organización

- Análisis de métodos de gestión

- Estudio de interacciones con el entorno

- Planteamiento de problemática y causa raíz.

Luego de estudiar esta estructura e aplicarla a nuestro proceso objeto de estudio, se presentan los resultados de cada etapa del proceso:

\section{Análisis de resultados}

Consiste en comparar el crecimiento del negocio mediante el uso de ciertos indicadores de gestión. Sin lugar a duda la cantidad de indicadores que se pueden usar son muchos, pero lamentablemente la falta de información histórica por parte de la empresa limita la exposición de un gran número de los mismos. El análisis de los resultados del negocio está detallado en el punto 3.1.2.

\section{Estudio de la política comercial}

En lo que concierne a las políticas comerciales, la empresa no cuenta con un plan de marketing claramente definido. La Gerencia General, con ayuda de la Gerencia Comercial, se encarga de determinar los productos a vender, los precios de venta y los respectivos márgenes, dependiendo de si se trata de un cliente final o de un distribuidor, y esto se traduce en un tarifario que maneja el área comercial y de facturación. Es por ello que cada situación de venta se puede manejar como un caso individual, lo que hace el proceso de venta más lento. Sin lugar a duda algunos productos ameritarán tener este tratamiento, pero hay otros (los más vendidos) que deberían de manejarse con una política clara de precios, descuentos y créditos.

En lo que respecta a políticas de productos, la empresa tampoco tiene claro cuáles serán sus planes de introducción o retiro de productos. Dependiendo de las 
oportunidades que detecta o las que aprovechó la competencia, la empresa decide importar un nuevo producto o retirarlo. Se podría decir que la empresa tiene una posición muy cómoda y que no tiene mayor apremio por mejorar la política de productos que maneja actualmente. Hay poca orientación a la mejora y a la introducción de nuevos productos. Si bien es cierto que la Gerencia General indica que se ha intentado introducir nuevos productos, lo cierto es que se ha realizado de manera incorrecta, sin estudios del mercado o del producto a profundidad, sin campañas de lanzamiento y sin un plan estratégico para el producto.

La política de precios es una de las más controladas por la empresa y, por lo tanto, donde las características están más claras. La empresa intenta manejar los precios de mejor manera y trata de restarle importancia, buscando otros argumentos como la calidad o el servicio. Lamentablemente el mercado no tiene la misma perspectiva.

En cuanto a las políticas de plaza, la empresa mantiene un status quo de años. Cuenta con dos locales en Lima y en alguna oportunidad ha intentado conseguir un distribuidor en provincia sin mayor éxito. Dichos intentos se han realizado sin un estudio de mercado previo y sin contar con un plan claramente definido. Es claro que la empresa no le da la importancia del caso a la distribución y a como esta podría ampliar el volumen de ventas si es que se logra conseguir distribuidores serios y confiables.

Finalmente, en cuanto a promociones, la empresa carece de planes promocionales claramente definidos. Estas se dan principalmente cuando la Gerencia General, muchas veces por consejo o requerimientos de la Gerencia Comercial, determina su lanzamiento a fines de levantar las ventas. Sin lugar a duda es uno de los factores más pobremente desarrollados en la empresa.

\section{Revisión de medios y organización}

A fin de tener una mejor idea de los diferentes medios con los que cuenta la organización, se realizó un cuestionario a la Gerencia General. A continuación se muestra las conclusiones obtenidas luego de la entrevista.

Medios Materiales: 
Sin lugar a duda la empresa busca, con muchas falencias, darle todos los medios a sus colaboradores para que se sientan cómodos y puedan trabajar de la mejor manera. Por ejemplo, el área de ventas cuenta con un espacio dedicado a ellos, pero está muy apartado (otra edificación) de las demás áreas (como la administrativa, la de servicio técnico o incluso de la Gerencia General), por lo que las coordinaciones entre las mismas siempre toman más tiempo del necesario. Si a esto se le agrega el hecho de que prácticamente no existe manejo del área de soporte tecnológico, resulta casi imposible que la información se maneje de manera adecuada. No solo las áreas están separadas físicamente, sino que también están separadas en lo que respecta a la información que manejan.

Finalmente, no se cuenta con presupuesto asignado a ningún área ni tampoco hay planes de desarrollo para ninguna de las mismas, por lo que no se puede llevar casi ningún tipo de control de evolución de las mismas.

Medios humanos:

Lamentablemente la empresa no cuenta con perfiles de puestos claramente definidos, por lo que muchas de sus contrataciones se efectúan mediante referidos que podrían o no ajustarse a los verdaderos requerimientos del puesto. Por ejemplo el caso de los vendedores. La empresa básicamente ascendió a vendedores a diferentes personas (desde técnicos del área de Servicio Técnico hasta a un encargado de reparto de documentos) sin ningún criterio más que el de la motivación del personal por percibir mejores ingresos. Esto sin lugar a duda hace que sea difícil evaluar el grado de motivación y compromiso del personal para con la empresa.

Organización del área:

La planificación estratégica es mínima en la empresa, y por ende, en el área comercial. Básicamente se trabaja para cubrir las necesidades del día a día, lo que se traduce en ineficiencia en los procesos y en los recursos económicos y tiempo. Si bien existen objetivos generales y, según la empresa, de largo plazo (un año), no se cuentan con objetivos inmediatos o de plazos más cortos. El personal sabe qué es lo que tiene que conseguir, pero no sabe cómo conseguirlo, ya que no tienen mayor orientación ni guía. 
La Gerencia Comercial intenta reunirse semanalmente con los vendedores a fin de hacerles un seguimiento a los avances de la cuota, pero en estas reuniones no se definen las próximas visitas a realizar en las siguientes semanas. No se cuenta con un plan de visitas a futuro ni se brindan las herramientas necesarias para que lo puedan efectuar.

Del mismo modo, la Gerencia General exige resultados a la Gerencia Comercial, pero no indica pautas a seguir para conseguirlos. Si bien es cierto que la Gerencia General no va a realizar el trabajo de la Gerencia Comercial, tampoco existe la exigencia debida para que la gerencia comercial efectúe un plan estratégico, un plan de marketing, un verdadero diagnóstico de ventas, un manejo de presupuestos o incluso la supervisión de la fuerza de ventas.

\section{Análisis de métodos de gestión}

Al igual que en casos anteriores, se procede a separar los diferentes medios de gestión en subcategorías. Con la ayuda de algunas preguntas claves para las Gerencias de la empresa y utilizando información complementaria (reportes de resultados y resultados de auditorías) conseguimos las siguientes conclusiones:

\section{Gestión de Mercado:}

Muy pobre gestión de mercado por parte de la empresa. No se cuentan con procesos claros de recopilación de información o manejo de la misma, ya sea de clientes o de proveedores. Si bien es cierto que semanalmente el equipo de ventas (Gerencia y vendedores) procura reunirse para discutir los avances de cuotas y noticias del mercado acerca de la competencia y de los clientes, estas reuniones no siempre se llevan a cabo. En caso se den, la información que se recolecta no se guarda ni comparte con otros interesados.

Al no tener un registro de datos e información, es muy difícil poder analizar cuantitativa o cualitativamente a los clientes o a los competidores, por lo que no se tiene una evolución clara de los mismos. En este aspecto, la información obtenida por la empresa depende principalmente de la experiencia y la memoria de sus trabajadores. 
La falta de información tampoco permite tener indicadores de gestión claramente definidos, por lo que no se tiene claro cuál es el desempeño de los vendedores, de los clientes o de la competencia. Se trabaja a ciegas y especulando que las decisiones que se toman son las mejores para ese momento.

Gestión de productos:

Al igual que el caso anterior, la gestión de productos es también muy pobre. La gerencia se sostiene en la excusa del poco desarrollo del sector y desestima la importancia de la gestión de producto. La empresa participa en ferias internacionales y evalúa, de manera subjetiva, las mejoras o lanzamientos de nuevas máquinas o consumibles, dejando de evaluar de manera estratégica la evolución de sus líneas actuales.

Asimismo, no se recopila información de fallos, reclamación o devoluciones, por lo que la información de los productos actuales que se tiene es muy subjetiva y depende de la persona que la brinda.

Gestión de precios:

La empresa gestiona relativamente bien sus precios de venta, si es que se compara con los casos anteriores. La lista de precios de maquinaria se actualiza una vez al año (básicamente por temas de alzas en los precios de los proveedores) y se entrega a los vendedores. Asimismo, si los precios se modificaron, se ingresan en el sistema de facturación, por lo que las facturas tienen el mismo precio de venta que las órdenes de pedido. En el caso de los consumibles la situación es otra ya que al tener una gran cantidad de productos, muchos precios de venta no se han actualizado en relación a sus costos, por lo que no se tiene plena confianza de que los márgenes se mantienen.

Gestión de canales:

En los últimos años la empresa buscó mejorar la gestión de canales enviando a sus proveedores, una vez al año, la lista de las compras de todo el año. De esta manera se buscó una mejor planificación de pedidos, el cual ayudaría a la empresa y a sus proveedores. Lamentablemente la planeación de la demanda no siempre fue buena y esta planificación no se llega a cumplir en su plenitud. 
La empresa se encarga de la distribución de toda la mercadería, por lo que tiene total control de la misma. Lamentablemente, como en casos anteriores, no se aprovecha esta situación para manejar indicadores de rendimiento o un mejor control de gastos. Se trabaja en base a la experiencia y a la rutina.

Finalmente lo que refiere a la planificación de la demanda, la empresa utiliza las cifras de años pasados, combinada con información que puedan dar los vendedores, para determinar la misma y la respectiva cuota a cada vendedor. Esta cuota de venta no se vuelve a revisar sino hasta fin de año, en el caso de maquinaria. En cuanto a los consumibles, se revisa mensualmente, pero el cumplimiento o incumplimiento de la misma no genera ninguna consecuencia sobre el vendedor.

Gestión de promoción:

El tema de la promoción es algo que se maneja muy poco y mal. La empresa no cuenta con políticas claras de presupuestos de promoción ni lanzamiento de campañas. Así mismo, cuando se efectúa una nueva promoción, no se mide el impacto de la misma sobre las ventas y por lo tanto no se puede llegar a la conclusión de si efectivamente la promoción fue buena o si simplemente se vendió con menos margen.

La Gerencia de la empresa justifica esta falta de gestión de promoción indicando que no son productos de consumo masivo y por lo tanto idear promociones es complicado y fuera de lugar.

\section{Estudio de interacciones con el entorno}

Proceso financiero:

En el caso de una empresa comercializadora, el proceso financiero es clave y por ello ambos, tanto ventas como finanzas, deben de ser revisados y coordinados con mucho cuidado. Las ventas, y especialmente los términos de pagos, afectan de manera directa a las finanzas de la empresa.

Puntualmente el caso de ABC S.A.C., el área de ventas perdió total relación con el área financiera en los años 2009 y 2010 y parte del 2011. Si bien es cierto que las ventas se elevaron en esos años, también lo hicieron las deudas por pagar, los créditos y las cuentas por cobrar, así como los niveles de existencias; es decir, que se rompió el 
equilibrio, importando más de lo que se podía vender. En los siguientes años la empresa logró conseguir nuevamente ese equilibrio pero a costa de aumentar sus líneas de crédito de manera muy peligrosa, poniendo en riesgo el patrimonio de los socios.

Proceso de la cadena de suministro:

En lo que respecta a la cercanía entre el proceso comercial y la cadena de suministro, ambos están relativamente bien coordinados. Si bien es cierto que se registraron roturas de stock, especialmente en lo que respecta a los consumibles, la empresa mantiene un stock bastante adecuado de maquinarias, lo que permite atender casi siempre a tiempo a sus clientes. Se tiene claro cuáles son las máquinas con mayor demanda y se procura siempre estar abastecido de las mismas. Si bien es cierto que se planifican con un año de antelación las órdenes de compra, estas casi nunca se cumplen y la empresa siempre está pendiente de su stock y en realizar los pedidos a tiempo.

En cuanto a consumibles, como ya se mencionó, la situación es distinta. Las roturas de stock son frecuentes y esto dificulta la labor comercial, especialmente la fidelización de los clientes.

\section{Presentación de problemática y causa raíz}

Como conclusión del diagnóstico realizado, se obtienen cuatro problemas principales que afectan al área comercial, sobre los cuales se presentan a continuación los diagramas de causa raíz. 


\section{Figura 3.7}

Diagrama de causas raíz del problema "Estancamiento de las ventas de maquinaria"

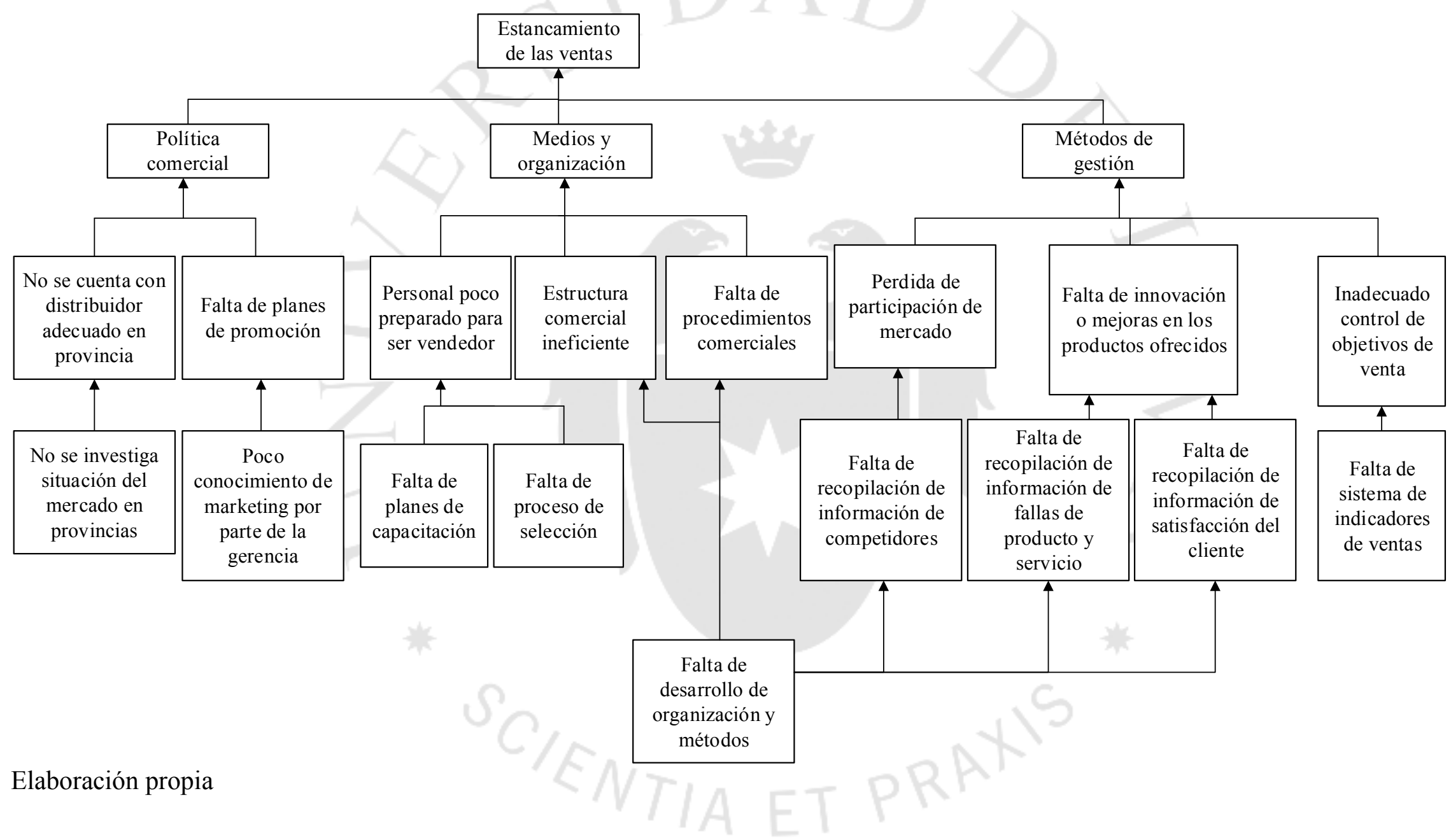


Figura 3.8

Diagrama de causas raíz del problema "Exceso de Inventarios"

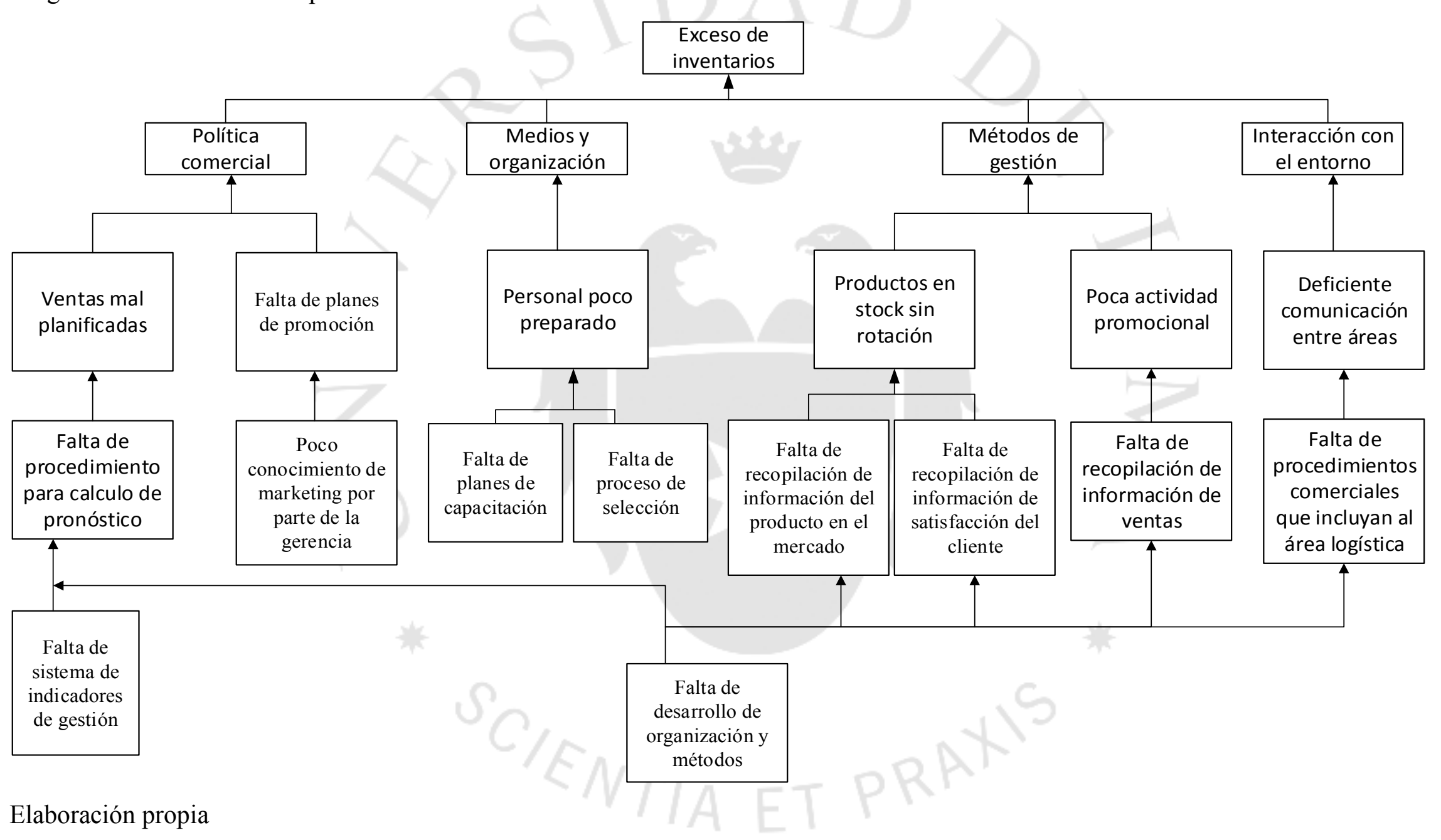


Figura 3.9

Diagrama de causas raíz del problema "Cuentas por cobrar en exceso"

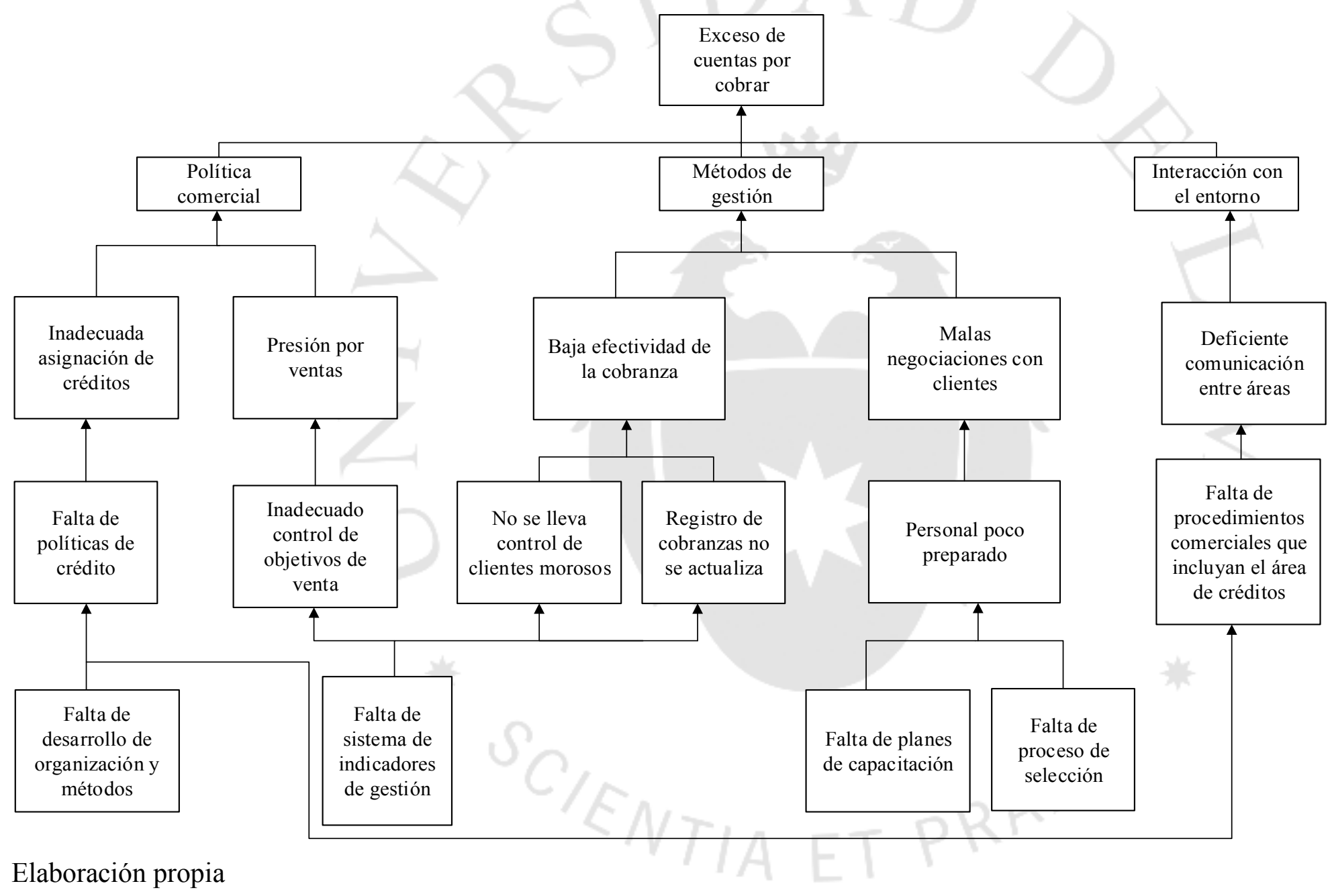


Figura 3.10

Diagrama de causas raíz del problema "Exceso gasto de ventas"

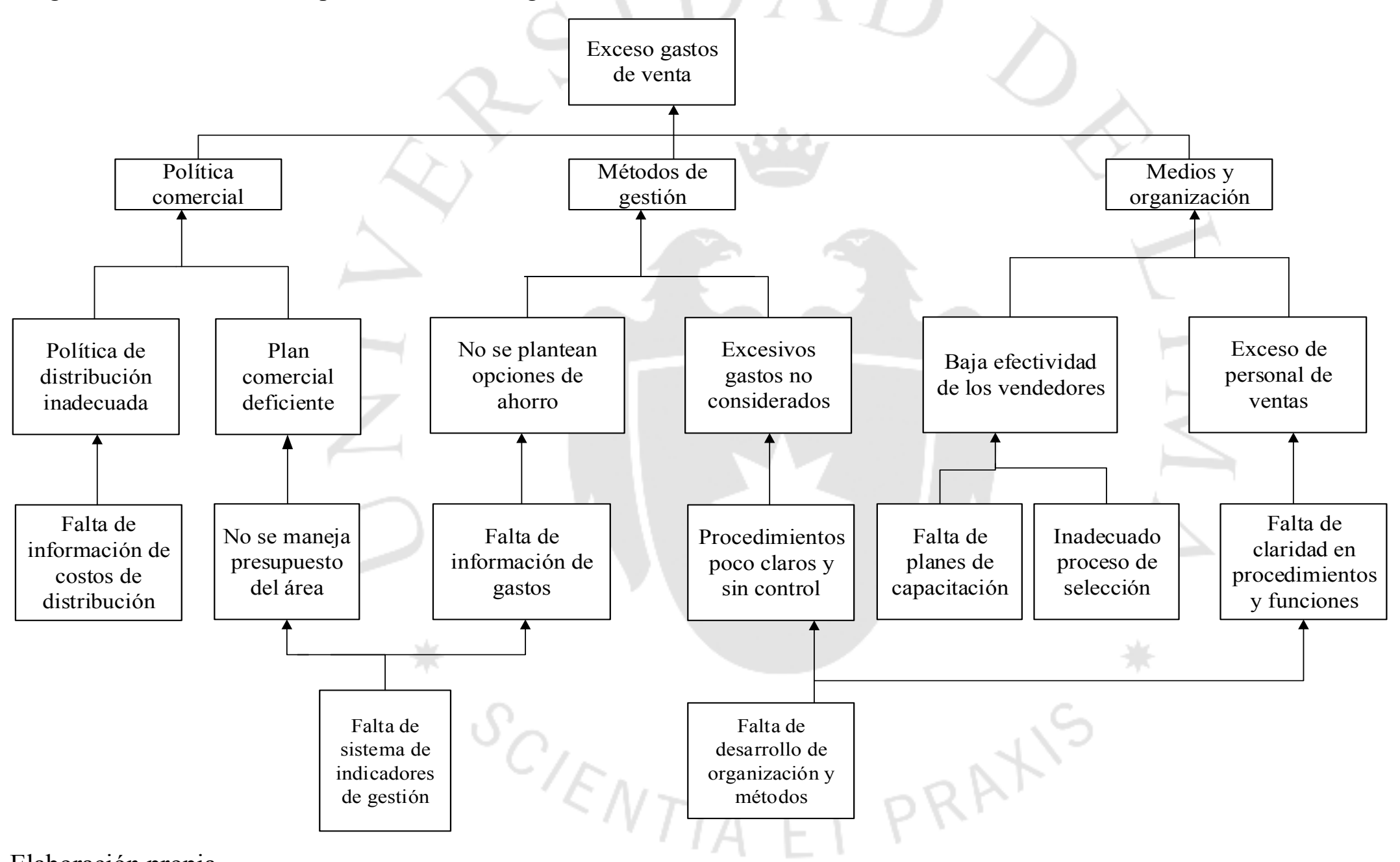

Elaboración propia 
Conocidas las causas raíz de los problemas, se agruparán de acuerdo a su similitud y se procederá a realizar una clasificación $\mathrm{ABC}$ de las mismas a través de una matriz de enfrentamiento, de manera que se pueda obtener una jerarquización que pueda ser utilizada al momento del planteamiento y selección de alternativas de solución en el siguiente capítulo.

Causas Raíz:

A) Falta de desarrollo de organización y métodos comerciales

B) Falta de un sistema de indicadores de gestión.

C) Falta de información del mercado de distribución

D) Falta de planes de capacitación

E) Falta de proceso de selección de personal

F) Poco conocimiento de la gerencia sobre estrategias de marketing y ventas

Tabla 3.7

Matriz de enfrentamiento de causas raíz

\begin{tabular}{|c|c|c|c|c|c|c|c|c|}
\hline Causa & A & B & C & D & E & F & Conteo & Peso \\
\hline A & - & 1 & 1 & 1 & 1 & 1 & 5 & $31 \%$ \\
\hline B & 0 & - & 1 & 1 & 1 & 1 & 4 & $25 \%$ \\
\hline C & 0 & 0 & - & 0 & 0 & 1 & 1 & $6 \%$ \\
\hline D & 0 & 0 & 1 & - & 1 & 1 & 3 & $19 \%$ \\
\hline E & 0 & 0 & 1 & 1 & - & 0 & 2 & $13 \%$ \\
\hline F & 0 & 0 & 0 & 0 & 1 & - & 1 & $6 \%$ \\
\hline TOTAL & \multicolumn{10}{|c|}{} \\
\hline
\end{tabular}

Elaboración propia

De esta manera procedemos a clasificar las causas raíz de acuerdo a su importancia: 
Tabla 3.8

Clasificación $\mathrm{ABC}$ de causas raíz

\begin{tabular}{|l|c|c|c|}
\hline \multicolumn{1}{|c|}{ Causa raíz } & Peso & Peso acum. & Tipo \\
\hline $\begin{array}{l}\text { A) Falta de desarrollo de organización y métodos } \\
\text { comerciales }\end{array}$ & $31 \%$ & $31 \%$ & A \\
\hline B) Falta de un sistema de indicadores de gestión & $25 \%$ & $56 \%$ & A \\
\hline D) Falta de planes de capacitación & $19 \%$ & $75 \%$ & B \\
\hline E) Falta de proceso de selección de personal & $13 \%$ & $88 \%$ & B \\
\hline $\begin{array}{l}\text { F) Poco conocimiento de la gerencia sobre estrategias de } \\
\text { marketing y ventas }\end{array}$ & $6 \%$ & $94 \%$ & C \\
\hline C) Falta de información del mercado de distribución & $6 \%$ & $100 \%$ & C \\
\hline
\end{tabular}

\section{Elaboración propia}




\section{CAPÍTULO IV. DETERMINACIÓN DE LA PROPUESTA DE SOLUCIÓN}

\subsection{Planteamiento de alternativas de solución a la problemática encontrada}

Según los problemas encontrados en el capítulo anterior, se plantean las siguientes soluciones al proceso de ventas, las cuales podrían mejorar los indicadores y darle mayor estabilidad financiera a la empresa.

Alternativa 1: Creación de un área de recursos humanos.

Una de las alternativas de solución podría ser instaurar un área de recursos humanos en la empresa, la cual deberá de contar con personal lo suficientemente calificado para elaborar procesos de contratación adecuados, plantear líneas de carrera a los trabajadores con los respectivos incentivos y la planificación de las capacitaciones del personal nuevo y actual.

- Objetivo: Contar con procesos de selección de personal que permitan la contratación de colaboradores que cuenten con un perfil acorde con las funciones que realizarán. Asimismo mejorar el compromiso del personal con la empresa, asegurando su motivación para crecer profesionalmente.

- Causas raíz a solucionar:

- Falta de proceso de selección de personal (B)

- Actividades: para la implementación de esta propuesta se requiere:

- Definir las funciones del área

- Definir la estructura organizacional

- Definir perfil de personal requerido

- Proceso de selección del personal

Alternativa 2: Implementación de un programa de capacitación 
Esta alternativa implica un adecuado proceso de entrenamiento al personal involucrado en el proceso comercial, enfocado en las actividades que le corresponde realizar a cada área puede significar mejores resultados comerciales en menor tiempo, mejorando el nivel de ventas de la empresa.

- Objetivo: Mejorar el desempeño del personal, que a su vez se traduzca en una mejora de los resultados comerciales: mejora del nivel de ventas, reducción de cuentas por cobrar, reducir niveles actuales de inventario.

- Causas raíz a solucionar:

- Falta de desarrollo de organización y métodos comerciales (A)

- Falta de planes de capacitación (B)

- Poco conocimiento de la gerencia sobre estrategias de marketing y ventas $(\mathrm{C})$

- Actividades: para la implementación de esta propuesta se requiere:

- Definir temas de capacitación

- Definir participantes y expositores

- Preparación de material y recursos necesarios

○ Definir proceso de evaluación

- Elaborar un cronograma que no afecte la operación

\section{Alternativa 3: Reconformación del área de ventas}

Una alternativa más radical podría ser la de cambiar gran parte del equipo de ventas, incluyendo a la gerencia. Si bien es cierto que se podría perder gran parte de la información comercial que aún no se tiene correctamente almacenada, contratar un personal más preparado técnica y teóricamente puede ser de gran ayuda para la empresa y la reestructuración del área comercial. Esto implicaría también desarrollar un proceso de selección para el personal que se va a contratar.

- Objetivo: Contar con el personal idóneo para la gestión de ventas, con el consecuente incremento de ventas, mejora en las condiciones comerciales y una reducción de los gastos involucrados en el proceso comercial.

- Causas raíz a solucionar:

- Falta de desarrollo de organización y métodos (A)

- Falta de planes de capacitación (B) 
- Falta de proceso de selección de personal (B)

- Poco conocimiento de la gerencia sobre estrategias de marketing y ventas $(\mathrm{C})$

- Actividades: para la implementación de esta propuesta se requiere:

- Definir perfil de personal requerido

- Proceso de selección de personal

- Inducción del nuevo equipo a sus puestos

\section{Alternativa 4: Implementación de un sistema de indicadores de gestión}

Otra alternativa es la de implementación de un adecuado sistema de control de las diferentes gerencias, el cual debe de contemplar metas a corto plazo, indicadores de gestión, revisión de estrategias de mediano y largo plazo. Se debe de indicar además la frecuencia con la cual se deben de revisar cada meta y quien es el responsable de la misma y de la revisión. De esta manera las diferentes gerencias del negocio, especialmente la comercial, podrán contar con cifras comparativas y verificar si es que los resultados que se están midiendo son los esperados o no. Esto ayudará a mantener controlados los niveles de cuentas por pagar, las cuentas por cobrar, las ventas, los niveles de inventarios, los costos y gastos de ventas entre otros.

- Objetivo: Contar con información actualizada que permita realizar seguimiento a indicadores claves definidos que aseguren el correcto desempeño del área y permitan alcanzar las metas y tomar decisiones de corto o mediano plazo para implementar nuevas estrategias de negocio.

- Causas raíz a solucionar:

- Falta de un sistema de indicadores de gestión (A)

- Actividades: para la implementación de esta propuesta se requiere:
- Definir herramienta de control
- Establecer los indicadores a medir por área
- Definir las metas por indicador
- Elaborar el proceso de ingreso y actualización de información
- Elaborar reportes con el respectivo proceso de despliegue

\section{Alternativa 5: Implementación de soluciones informáticas integrales}


La compra de un sistema CRM que se pueda integrar al actual sistema de inventarios que tiene la empresa o incluso, la adquisición de un nuevo sistema ERP que reemplace al actual y que sea más potente puede ser una alternativa interesante que podría modernizar a la empresa y facilitaría la obtención de información y el manejo de la misma.

- Objetivo: Tener acceso a la información para una mejor toma de decisiones que mejoren el desempeño del negocio

- Causas raíz a solucionar:

- Falta de un sistema de indicadores de gestión (A)

- Actividades: para la implementación de esta propuesta se requiere:

○ Definir información a ingresar

- Definir sistema de información a utilizar

- Búsqueda y selección de proveedor de sistemas de información

- Implementación de software

\section{Alternativa 6: Creación de procedimientos del proceso de ventas}

Dado que por su situación actual, la empresa no está en condiciones de crear un área de organización y métodos, se propone como proyecto de mejora la creación de procedimientos para el proceso de ventas. Estos procedimientos deben de considerar desde la planificación de pedidos hasta el sistema de cobranzas, pasando por la evaluación crediticia del cliente, el cierre de ventas y creación de documentos de despacho, así como también labores de investigación comercial por parte del equipo de ventas en el mercado. Si los procedimientos son claros se mantendrá mejor control sobre todo el proceso, lo que generaría mayor control en las acciones comerciales actuales y evitará problemas futuros (por ejemplo cuentas por cobrar elevadas). Estos procedimientos a su vez permitirán definir las funciones de las áreas relacionadas al proceso de ventas y reestructurar la organización de la gerencia comercial.

- Objetivo: Tener procedimientos claros, ordenados y documentados, que permitan un mejor desempeño del proceso comercial, con el consiguiente impacto en resultados de ventas y demás subprocesos (logística, créditos, etc.)

- Causas raíz a solucionar:

- Falta de desarrollo de organización y métodos comerciales (A) 
○ Falta de información del mercado de distribución (C)

- Actividades: para la implementación de esta propuesta se requiere:

- Organizar el equipo de trabajo

○ Revisión del diagnóstico de la empresa

- Elaboración de propuesta de procedimientos

- Elaboración del manual de procedimientos y manual de funciones

○ Despliegue a la organización

\section{Alternativa 7: Creación de un área de prospección tecnológica}

Finalmente, otra posible solución comercial es la de realizar trabajos de prospección tecnológica a cargo de las gerencias y/o los socios de la empresa. De esta manera se podría prever las tendencias del mercado y conseguir mayor cantidad de lanzamientos de productos nuevos exitosos, lo que significa un aumento en las ventas con mejor margen.

- Objetivo: Mantener a la empresa a la vanguardia de la tecnología de la maquinaria ofrecida, manteniendo así la sólida posición de líder del mercado en innovación.

- Causas raíz a solucionar:

- Poco conocimiento de la gerencia sobre estrategias de marketing y ventas $(\mathrm{C})$

- Actividades: para la implementación de esta propuesta se requiere:

- Definir la estrategia de prospección

- Definir las funciones del área

○ Definir estructura organizacional

\subsection{Selección de alternativas de solución}

\subsubsection{Determinación y ponderación de criterios evaluación de las alternativas}

A fin de determinar la mejor de las alternativas de solución presentadas líneas arriba, se exponen los criterios y la ponderación de los mismos. 
Los criterios que se tomarán en cuenta son:

- Tiempo requerido para implementar la solución:

Considera el tiempo necesario para implementar de manera exitosa y de forma completa la solución. Dada la situación económica en la que se encuentra el negocio, el tiempo es un factor determinante para la elección de las mejoras a implementar, ya que mientras más pronto se implemente una solución, más rápido se verá reflejado su impacto en los resultados.

- Costo requerido para implementar la solución:

Al igual que el caso anterior, el factor de costo es determinante. La empresa tiene una delicada situación financiera y adquirir nuevas deudas puede ser complicado y peligroso. Cada nuevo costo y gasto puede modificar de manera negativa los balances de resultados y la imagen que se tiene con los principales prestamistas de la empresa: los bancos. Perder las líneas de crédito de la empresa en este momento puede tener consecuencias nefastas.

- Causas raíz que mejora la solución:

Cada solución apunta a solucionar la problemática encontrada en el diagnóstico del proceso de ventas, atacando las causas raíz que la generan. Teniendo en cuenta la clasificación $\mathrm{ABC}$ de las causas raíz mostrada en el capítulo anterior, se calificará cada solución de acuerdo a la cantidad de causas que soluciona y a la importancia de cada una de ellas (A, B o C).

- Impacto de la solución en la empresa:

Se refiere al impacto que tendrá la solución, considerando no sólo el área comercial, sino también los otros procesos de la empresa, así como también los resultados del negocio. Considerando que una empresa está conformada por diferentes áreas y que la interacción entre estas determina el nivel de eficiencia global de la empresa, tener procesos claros que involucren de manera adecuada a cada área es clave. Es por ello que una solución debe de contemplar no solo el impacto en un área específica, sino también en toda la empresa, en los resultados del negocio y en la motivación que puede tener en todos los trabajadores.

- Nivel de urgencia de implementación de la solución: 
Dada la criticidad de la situación financiera en la que se encuentra la empresa, con niveles de endeudamiento y cuentas por cobrar demasiados elevados que la dejan en una posición muy vulnerable ante cualquier eventualidad que pueda tener el mercado, se define como criterio la urgencia de implementación de la solución, el cual evaluará las soluciones en base a las necesidades más inmediatas que tenga la empresa.

Expuestos todos los criterios de para evaluar las distintas posibilidades de solución, se pasa a determinar la importancia de dichos criterios mediante una matriz de enfrentamiento:

Factores:

$\mathrm{A}=$ Tiempo requerido para implementar la solución

$\mathrm{B}=$ Costo requerido para implementar la solución

$\mathrm{C}=$ Causas raíz que mejora la solución

$\mathrm{D}=$ Impacto de la solución en la empresa

$\mathrm{E}=$ Nivel de urgencia de implementación de la solución

Tabla 4.1

Matriz de Enfrentamiento de Factores

\begin{tabular}{|c|c|c|c|c|c|c|c|}
\hline Factor & $\mathrm{A}$ & $\mathrm{B}$ & $\mathrm{C}$ & $\mathrm{D}$ & $\mathrm{E}$ & Conteo & Peso \\
\hline $\mathrm{A}$ & - & 1 & 0 & 0 & 1 & 2 & 13.33 \\
\hline $\mathrm{B}$ & 1 & - & 0 & 1 & 1 & 3 & 20.00 \\
\hline $\mathrm{C}$ & 1 & 1 & - & 1 & 1 & 4 & 26.67 \\
\hline $\mathrm{D}$ & 1 & 1 & 0 & - & 1 & 3 & 20.00 \\
\hline E & 1 & 1 & 0 & 1 & - & 3 & 20.00 \\
\hline TOTAL & \multicolumn{7}{|l}{} \\
\hline
\end{tabular}

Elaboración propia

Luego de ejecutado el Ranking de Factores se determina que el criterio principal a tener en cuenta para determinar qué solución es la adecuada es el de causas raíz a mejorar, seguido del costo, el impacto y la urgencia de implementación de la solución. Finalmente el tiempo de implementación es el factor con menos peso que el resto, pero que no deja de ser importante en cuanto a su peso. 


\subsubsection{Evaluación cualitativa y cuantitativa de alternativas de solución}

Una vez determinado cuales son los criterios más importantes y cuales los menos importantes, se pasa a evaluar estos criterios con las alternativas de solución propuestas. Para ello se asigna una calificación de las mismas de la siguiente manera:

$\begin{array}{lll}\text { Indiferente } & : & 0 \\ \text { Regular } & : & 1 \\ \text { Bueno } & : & 2 \\ \text { Muy bueno } & : & 3 \\ \text { Excelente } & : & 4\end{array}$


Tabla 4.2

Ranking de Factores

\begin{tabular}{|c|c|c|c|c|c|c|c|c|c|c|c|c|c|c|c|}
\cline { 2 - 17 } \multicolumn{1}{c|}{} & \multicolumn{2}{c|}{ Alternativa 1 } & \multicolumn{2}{c|}{ Alternativa 2 } & \multicolumn{2}{c|}{ Alternativa 3 } & \multicolumn{2}{c|}{ Alternativa 4 } & \multicolumn{2}{c|}{ Alternativa 5 } & \multicolumn{2}{c|}{ Alternativa 6 } & \multicolumn{2}{c|}{ Alternativa 7 } \\
\hline FACTOR & Peso & Calific. & Punt. & Calific. & Punt. & Calific. & Punt. & Calific. & Punt. & Calific. & Punt. & Calific. & Punt. & Calific. & Punt. \\
\hline A & 13.33 & 2 & 26.7 & 2 & 26.7 & 1 & 13.3 & 3 & 40.0 & 2 & 26.7 & 3 & 40.0 & 2 & 26.7 \\
\hline B & 20.00 & 3 & 60.0 & 3 & 60.0 & 1 & 20.0 & 4 & 80.0 & 1 & 20.0 & 4 & 80.0 & 3 & 60.0 \\
\hline C & 26.67 & 1 & 26.7 & 3 & 80.0 & 1 & 26.7 & 3 & 80.0 & 3 & 80.0 & 4 & 106.7 & 2 & 53.3 \\
\hline D & 20.00 & 2 & 40.0 & 3 & 60.0 & 2 & 40.0 & 4 & 80.0 & 3 & 60.0 & 4 & 80.0 & 2 & 40.0 \\
\hline E & 20.00 & 1 & 20.0 & 4 & 80.0 & 2 & 40.0 & 4 & 80.0 & 2 & 40.0 & 4 & 80.0 & 3 & 60.0 \\
\hline TOTAL & 100 & & $\mathbf{1 7 3 . 3}$ & & $\mathbf{3 0 6 . 7}$ & & $\mathbf{1 4 0 . 0}$ & & $\mathbf{3 6 0 . 0}$ & & $\mathbf{2 2 6 . 7}$ & & $\mathbf{3 8 6 . 7}$ & & $\mathbf{2 4 0 . 0}$ \\
\hline
\end{tabular}

Elaboración propia

Ordenando las alternativas tenemos:

Alternativa 6: Creación de procedimientos del proceso de ventas -386.7

Alternativa 4: Implementación de un sistema de indicadores de gestión - 360.0

Alternativa 2: Implementación de un programa de capacitación - 306.7

Alternativa 7: Creación de un área de prospección tecnológica - 240.0

Alternativa 5: Implementación de soluciones informáticas integrales - 226.7

Alternativa 1: Creación de un área de recursos humanos. - 173.3

Alternativa 3: Reconformación del área de ventas - 140.0 


\subsubsection{Priorización y programación de soluciones seleccionadas}

Como se observa en la tabla anterior, la alternativa con mayor puntaje y, por lo tanto, la mejor alternativa es la número seis: creación de procedimientos. Seguidamente encontramos los planes de capacitación y muy cerca de ella la creación de un sistema de indicadores de gestión. Dado que estas tres alternativas son también las que obtienen un mejor puntaje en la urgencia de implementación, son las que seleccionaremos para implementar en ABC S.A.C.

En cuanto a las otras alternativas, si bien todas tendrían un impacto interesante en el negocio, en este momento no son prioritarias dada la situación crítica en la que se encuentra la empresa y la necesidad de generar resultados positivos a la brevedad para no ahondar la crisis.

Es así que la programación de actividades se dará como se presenta a continuación:

Paso 1: Implementación de un sistema de indicadores de gestión

El primer paso debe ser definir los indicadores de gestión que se controlaran, ya que para el desarrollo de procedimientos se debe incluir la recolección de datos necesarios generar dichos indicadores. Para esta tarea la Gerencia General debe definir con los jefes de área cuales son los indicadores a medir, a fines de poder evaluar su desempeño. Posteriormente, estos indicadores deben ser validados por los socios.

Paso 2: Creación de procedimientos del proceso de ventas

La Gerencia General debe de liderar este siguiente paso y, junto con la gerencia comercial, debe de organizar las reuniones necesarias para comenzar a crear los procedimientos que garanticen el correcto funcionamiento del área. Deben de ser pasos a seguir lógicos y bien especificados, que no dejen opción a duda o ambigüedades, quedando un registro por escrito a fin de que cada paso se vuelva una obligación para la persona involucrada. Este proyecto debe terminar con la creación de un manual de procedimientos y funciones.

Paso 3: Implementación de planes de capacitación 
Definidos los procedimientos y funciones, se puede empezar con un plan de capacitaciones a la fuerza de ventas y de manera complementaria se podrían organizar capacitaciones sobre los procesos complementarios a los de la venta: logística, almacén, post venta, etc. La Gerencia podría determinar los cronogramas y los temas a tratar y asignar a un encargado para cada uno. Este encargado tendría la función de preparar la documentación, hacer la presentación e incluso evaluar a los participantes.

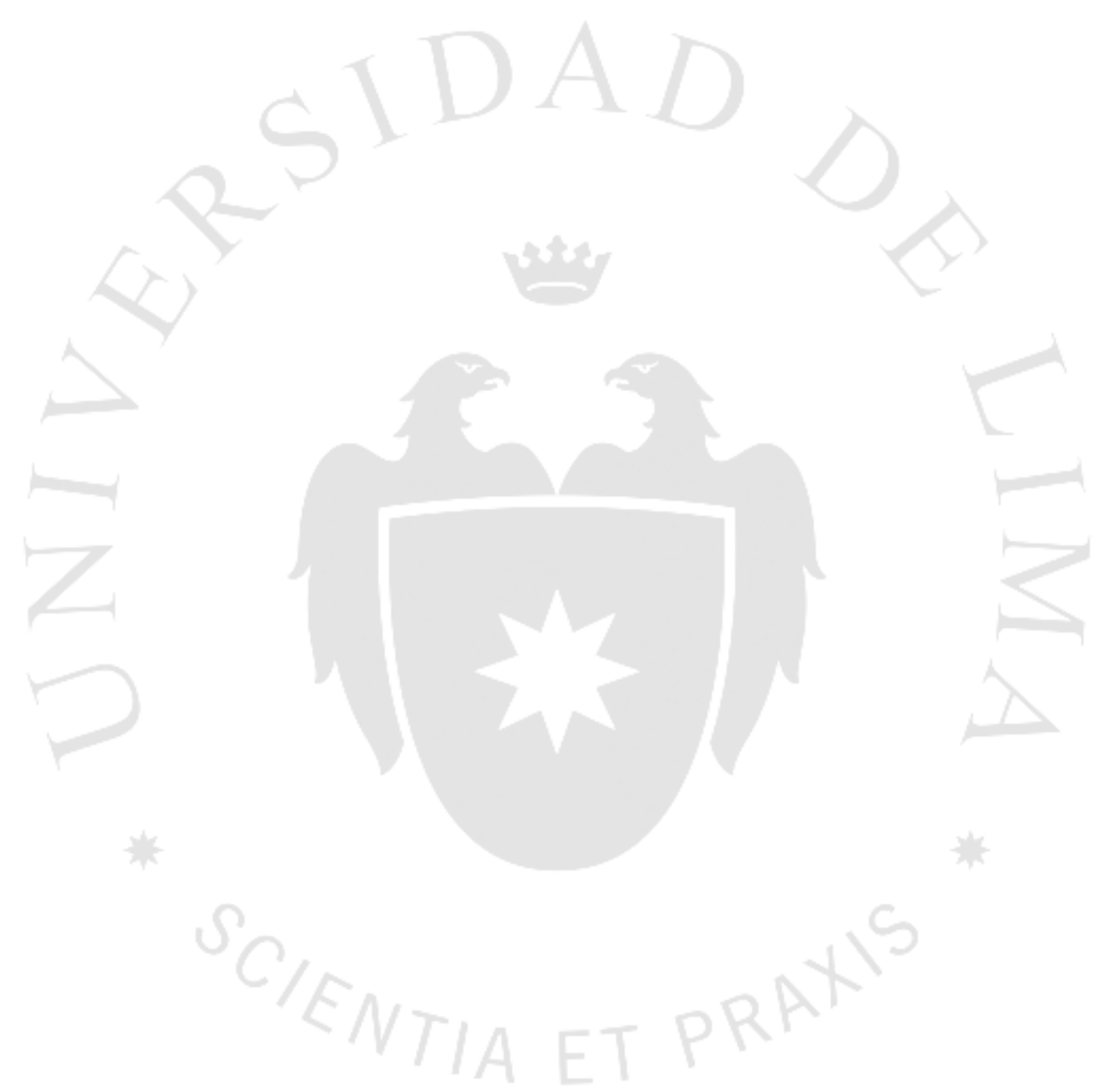




\section{CAPÍTULO V. DESARROLLO Y PLANIFICACIÓN DE LAS SOLUCIONES}

\subsection{Ingeniería de la solución}

Seleccionadas las alternativas de solución con mayor puntaje se procede a plantear los proyectos de solución para cada una de ellas, el cual seguirá la siguiente estructura:

- Marco teórico

- Objetivo

- Entregable

- Personal involucrado

- Recursos necesarios

- Actividades

A) Implementación de un sistema de indicadores de gestión

\section{Marco teórico:}

Para la implementación de un sistema de indicadores de gestión, la propuesta es utilizar un cuadro de mando integral (CMI). Esta herramienta es un sistema de administración que traduce la estrategia y la visión de una organización, en un conjunto de indicadores que proporcionan la estructura necesaria para un sistema de gestión estratégico. El CMI sugiere que veamos a la organización desde cuatro perspectivas, cada una de las cuales debe responder a una pregunta determinada:

- Financiera: ¿Cómo nos vemos a los ojos de los accionistas?

- Del cliente: ¿Cómo nos ven los clientes?

- Interna del Negocio: ¿En qué debemos sobresalir?

- Desarrollo y Aprendizaje: ¿Podemos continuar mejorando y creando valor?

El CMI es por lo tanto un sistema de gestión estratégica de la empresa, que consiste en:

- Formular una estrategia consistente y transparente.

- Comunicar la estrategia a través de la organización. 
- Coordinar los objetivos de las diversas unidades organizacionales.

- Conectar los objetivos con la planificación financiera y presupuestaria.

- Identificar y coordinar las iniciativas estratégicas.

- Medir de un modo sistemático la realización, proponiendo acciones correctivas oportunas.

Objetivos:

La implementación de un cuadro de mando integral tiene por objetivo controlar los indicadores claves para el desempeño del negocio, de manera que la situación crítica en la que se encuentra ABC S.A.C. no se agrave y los resultados de la operación empiecen a recuperarse. Así tenemos:

- Control de los principales indicadores financieros: liquidez, solvencia y rendimiento

- Control sobre los objetivos de ventas, que permita tomar correcciones sobre la marcha en caso no se alcancen los objetivos o sea necesario redefinirlos para generar más ingresos.

- Involucramiento a todo nivel del personal, ya que habrán indicadores para los distintos niveles de la organización

- Medición adecuada del desempeño de los trabajadores

Personal involucrado:

- Gerencia general

- Gerencia comercial

- Fuerza de ventas

- Encargado de almacén

- Apoyo administrativo

- Recepciones

- Supervisor de cobranza

- Administrador de DEF S.A.C.

- Jefatura de servicio técnico

- Staff técnico

$\underline{\text { Recursos necesarios: }}$ 
La empresa cuenta con todos los recursos necesarios para reformular los procesos, entre los cuales destacamos:

- Sistema de contabilidad y control de inventarios existente: Siigo.

- Software existente, especialmente Microsoft Excel y Word.

- Horas hombre del personal involucrado.

- Sala de reunión equipada (pizarras, proyector, PC)

- Información histórica del negocio (ventas, niveles de inventario, cantidad de vendedores, etc.)

- Información de dominio público (registros de importaciones)

Actividades:

Paso 1: Formación de equipo de trabajo

La implementación de un cuando de mando integral requiere el compromiso y trabajo de los líderes de las diferentes áreas involucradas, en este caso es la gerencia comercial, la jefatura técnica, la jefatura de administración y la administración de DEF S.A.C., ya que cada área debe generar sus propios indicadores y colocar sus objetivos, los cuales deben ser revisados y validados por la gerencia general. Asimismo se requerirá que una persona del área administrativa se encargue del seguimiento y la actualización del cuadro integrado de mando, a fin de contar con información actualizada en todo momento.

Paso 2: Revisión interna de indicadores

Cada jefe de área revisará con su equipo los indicadores que a monitorear, revisarán su valor actual y definirán sus respectivas metas internas. Con la retroalimentación de los equipos, los jefes de área procederán al desarrollo de la herramienta

Paso 3: Desarrollo del cuadro de mando integral

El primer paso para el desarrollo del cuadro de mando integral consiste en el desarrollo del mapa estratégico. En este mapa se definen en un primer nivel cuales son las variables a controlar desde las cuatro perspectivas mencionadas. Posteriormente en 
un segundo nivel, se profundizará sobre las variables del proceso de ventas, ya que es el proceso objeto de mejora.

A continuación se presenta el mapa estratégico para la posterior elaboración del cuadro de mando integral:

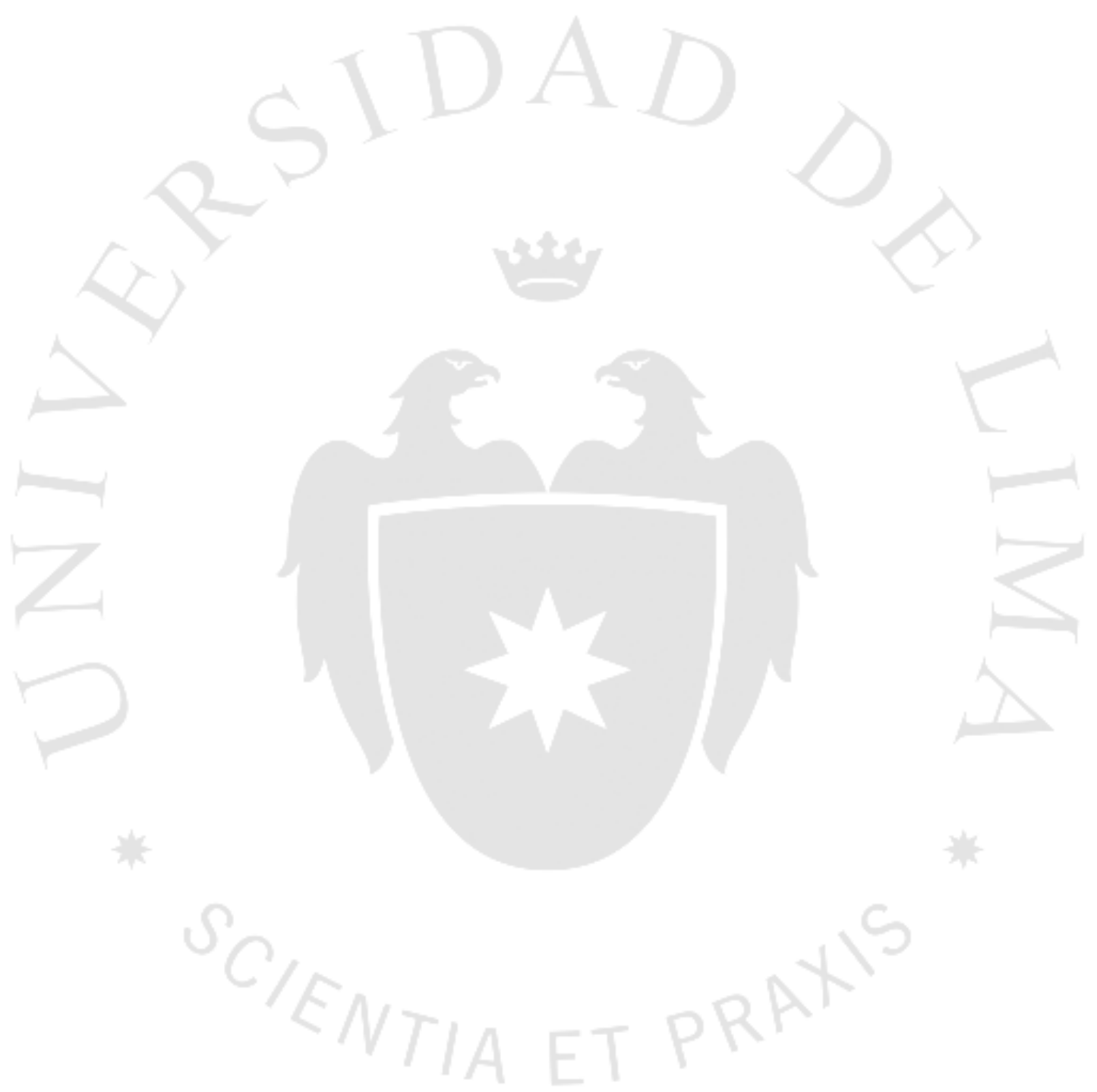




\section{Figura 5.1}

Mapa estratégico

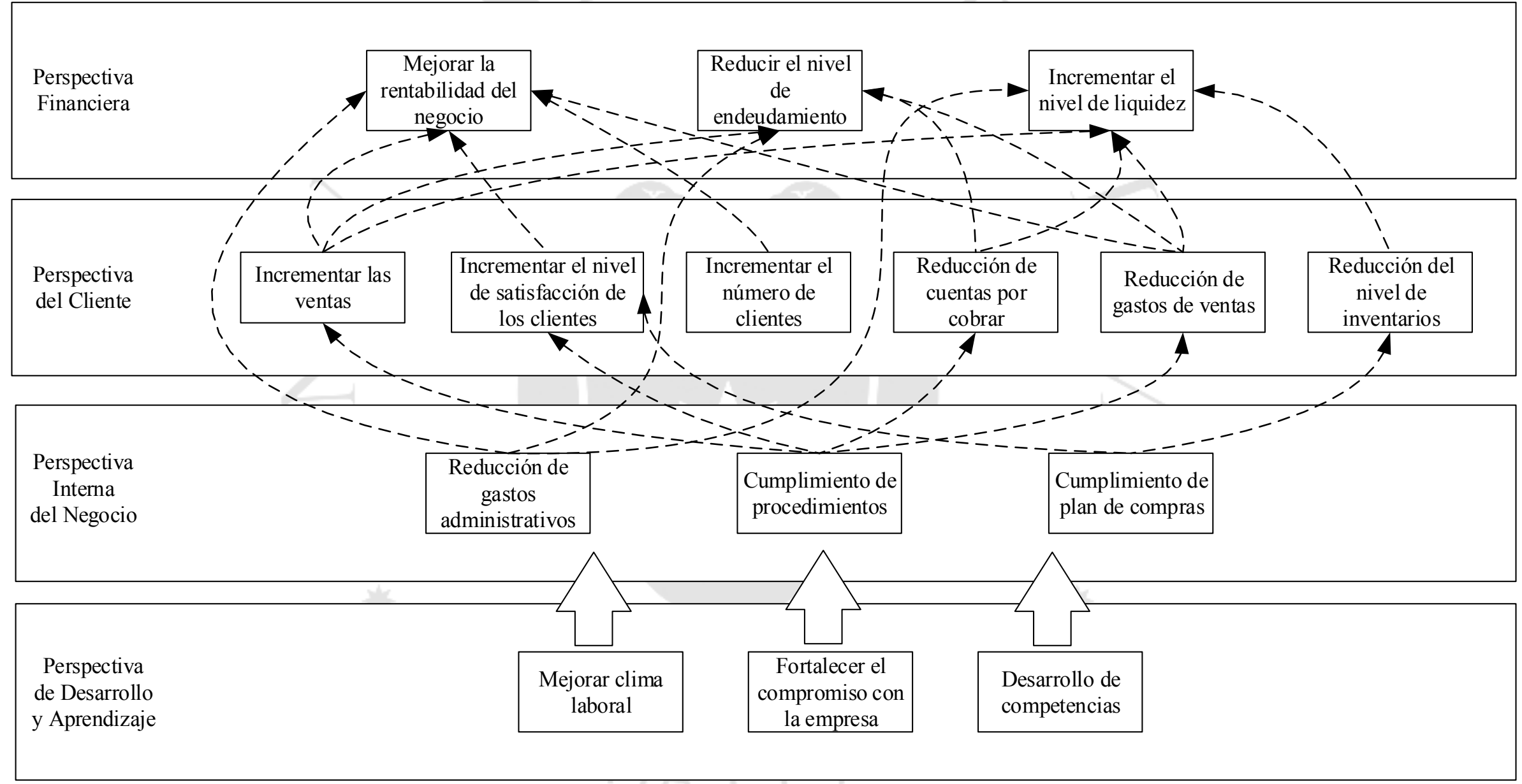


Definidos el mapa estratégico y sus relaciones, procederemos a definir los indicadores que servirán de guía para alcanzar los objetivos de acuerdo a cada perspectiva de análisis. Cada indicador debe tener una meta alcanzable y un responsable asignado de acuerdo al área a la que corresponde el indicador. Si se trata de indicadores generales que corresponden a todas las áreas, el responsable será la Gerencia General, que lógicamente cuenta con el soporte de todos los jefes de área para cumplir con las metas.

Para realizar un correcto monitoreo del avance en las metas, es necesario que una persona de apoyo administrativo se encargue de consolidar la información y actualizarla mes a mes, de manera que pueda estar a disposición de la Gerencia General y los jefes de área en el momento en que se requiera. Asimismo, los pasos para la obtención y entrega de la información que alimenta el cuadro de mando integral se detallarán como parte de la siguiente solución a desarrollar que es la creación de procedimientos comerciales.

A continuación se muestra a detalle el cuadro de mando integral desarrollado: 
Tabla 5.1

Cuadro de Mando Integral

\begin{tabular}{|c|c|c|c|c|c|}
\hline Perspectiva & Objetivos & Indicador & Valor actual & Meta & Responsable \\
\hline \multirow{7}{*}{ Financiera } & \multirow{3}{*}{ Mejorar rentabilidad del negocio } & Utilidad Neta / Ventas & 0.01 & 0.15 & Gerente General \\
\hline & & Utilidad Neta / Patrimonio & 0.04 & 0.3 & Gerente General \\
\hline & & Utilidad Neta / Activos & 0.01 & 0.2 & Gerente General \\
\hline & \multirow{2}{*}{ Reducir nivel de endeudamiento } & Pasivo Total / Patrimonio & 2.72 & 1 & Jefe Administración \\
\hline & & Pasivo Total / Activo Total & 0.73 & 0.5 & Jefe Administración \\
\hline & \multirow{2}{*}{ Incrementar nivel de liquidez } & Activo Cor. / Pasivo Cor. & 1.13 & 2 & Jefe Administración \\
\hline & & $\frac{\text { (Activo Cor. - Inventarios) }}{\text { Pasivo Cor. }}$ & 0.44 & 1.7 & Jefe Administración \\
\hline \multirow{10}{*}{ Cliente } & \multirow{4}{*}{ Incrementar las ventas } & $\frac{\text { Ventas totales - Ventas PY }}{\text { Ventas PY }}$ & $-3.4 \%$ & $10 \%$ & Gerente Comercial \\
\hline & & $\frac{\text { Ventas Maq. - Ventas Maq. PY }}{\text { Ventas Maq. PY }}$ & $-3.4 \%$ & $10 \%$ & Gerente Comercial \\
\hline & & $\frac{\text { Ventas Cons. - Ventas Cons. PY }}{\text { Ventas Cons. PY }}$ & $-3.4 \%$ & $10 \%$ & Gerente Comercial \\
\hline & & $\frac{\text { Ventas Serv. Tec. - Ventas Serv. Tec. PY }}{\text { Ventas Serv. Tec. PY }}$ & $-3.4 \%$ & $10 \%$ & Gerente Comercial \\
\hline & Incrementar nivel de satisfacción del cliente & $\%$ de clientes satisfechos & - & $90 \%$ & Gerente Comercial \\
\hline & Incrementar el número de clientes & $\frac{\# \text { de clientes act. - \# de clientes ant. }}{\# \text { de clientes ant. }}$ & - & $5 \%$ & Gerente Comercial \\
\hline & \multirow{2}{*}{ Reducción de cuentas por cobrar } & Ventas / Cuentas por cobrar & 3.4 & 10 & G. Comer. / J. Admin. \\
\hline & & Días de crédito & 108 & 35 & G. Comer. / J. Admin. \\
\hline & Reducción del gasto de ventas & Gastos de Ventas / Ventas & 0.28 & 0.2 & Gerente Comercial \\
\hline & Reducción del nivel de inventarios & Costo de ventas / Inventarios & 1.86 & 4 & G. Comer. / J. Admin. \\
\hline \multirow{3}{*}{ Interna } & Reducción de gastos administrativos & Ventas / Gastos Adm. & 0.15 & 0.1 & Jefe Administración \\
\hline & Cumplimiento de procedimientos & $\%$ de cumplimiento & S & $90 \%$ & Gerente General \\
\hline & Cumplimiento del plan de compras & Compras reales / compras planeadas & 3 & $90 \%$ & Jefe Administración \\
\hline \multirow{3}{*}{$\begin{array}{l}\text { Desarrollo y } \\
\text { aprendizaje }\end{array}$} & Mejora del clima laboral & $\%$ de satisfacción laboral & - & $90 \%$ & Gerente General \\
\hline & Fortalecer compromiso con la empresa & $\%$ de empleados comprometidos & - & $90 \%$ & Gerente General \\
\hline & Desarrollo de competencias & Evaluación de capacitaciones & - & $80 \%$ & Gerente General \\
\hline
\end{tabular}




\section{B) Creación de procedimientos del proceso de ventas}

\section{Marco teórico:}

El manual de procedimientos es un documento que contiene toda la información necesaria para describir las actividades y así delimitar las funciones que deben de seguir todos los involucrados de un área específica y otras relacionadas.

Estos manuales cuentan con información general y otra más específica, como ejemplos de autorizaciones o formularios, recursos físicos y de personal, que ayuden a especificar el correcto desarrollo de las actividades dentro de la empresa.

Asimismo, los manuales de procedimientos y de funciones facilitan las labores de control y evaluación interna de los procesos, especialmente aquella que relaciona la parte administrativa de los mismos.

\section{Objetivo:}

Los objetivos inmediatos que se busca con esta solución son:

Ahorro de tiempo: al tener un proceso más claro para todos los empleados, se logrará tener mayor eficiencia en las tareas. Habrán responsables y ellos tendrán tareas determinadas que realizar, ya no hay excusas.

- Reducción de costos: menos errores y reducción en los tiempos equivale a tener menos costos organizacionales.

- Reducción de personal: al tener una estructura más ordenada y dinámica, se podrán disponer o liberar recursos de personal.

- Mejor manejo de la información: nuevos y ordenados procesos permitirá conseguir y almacenar más información, dando soporte a otras iniciativas, como lo es el manejo de indicadores.

- Mejorar nivel de servicio: mejor atención adelantándonos a las necesidades del cliente.

\section{Entregables:}

- Nuevo diagrama de proceso: se replanteará el actual y se buscarán mejoras en el mismo, a fin de tener procesos y una organización más dinámica y controlada. 
- Nuevo organigrama: el nuevo diagrama de proceso supondrá algunos cambios en la estructura organizacional de la empresa, los cuales se reflejarán en un nuevo organigrama.

- Nuevas funciones de los responsables: para que este nuevo proceso y organigrama tengan éxito se deberán de replantear las funciones de las gerencias y jefaturas.

Personal involucrado:

El personal involucrado en la creación de los procesos de ventas es:

- Gerencia general

- Gerencia comercial

- Fuerza de ventas

- Encargado de almacén

- Apoyo administrativo

- Recepciones

- Supervisor de cobranza

- Administrador de DEF S.A.C.

- Jefatura de servicio técnico

- Staff técnico

Recursos necesarios:

Como se puede observar, las soluciones con mayor puntaje son aquellas que no involucran un gasto adicional para el negocio. Es por ello que la empresa ya cuenta con todos los recursos necesarios para reformular los procesos, entre los cuales destacamos:

- Sistema de contabilidad y control de inventarios existente: Siigo.

- Software existente, especialmente Microsoft Excel y Word.

- Horas hombre del personal involucrado.

- Sala de reunión equipada (pizarras, proyector, PC)

- Información histórica del negocio (ventas, niveles de inventario, cantidad de vendedores, etc.)

- Información de dominio público (registros de importaciones)

Actividades:

Paso 1: Conformación del equipo de trabajo 
El primer paso de todo gran cambio es comunicar e involucrar a los participantes del mismo. La Gerencia General debe conseguir el compromiso de los líderes de las diferentes áreas involucradas, en este caso es la gerencia comercial, la jefatura técnica, la jefatura de administración y la administración de DEF S.A.C. y debe de hacerlos participes del plan, asignando las tareas y responsabilidades, indicando claramente las metas y el tiempo del cual disponen.

Será la Gerencia General la que coordine con cada jefatura y gerencia la organización de cada capacitación y serán estas jefaturas y gerencias de segundo nivel las que preparen y dicten las capacitaciones a sus subalternos. Lógicamente ellos podrán contar con el apoyo de colaboradores al momento de crear el material didáctico.

Asimismo se debe de buscar la retroalimentación de los involucrados, ya que son ellos los que probablemente tengan mayor conocimiento de las labores diarias que realizan ellos mismos y sus subalternos. Esta retroalimentación además sirve para conocer en mayor detalle los procesos actuales y dan la posibilidad de partir con algunas ideas y experiencias previas.

Paso 2: Revisión del diagnóstico del proceso actual

Con el equipo de trabajo principal y secundario formado, se pasa a revisar el proceso actual de ventas (revisar capítulo 3) y se determina sus falencias y cuáles podrían ser sus mejoras, las cuales detallaremos en los siguientes pasos. Es importante mencionar que el proceso de ventas mostrado en el capítulo 3 se tomará como estructura principal y sobre él se harán las mejores necesarias. De esta forma además logramos que los cambios no sean muy bruscos y así más fáciles de implementar en la empresa.

Paso 3: Planteamiento de la nueva propuesta

Para el desarrollo de la propuesta del nuevo proceso de ventas, dividiremos el mismo en 4 subprocesos en el siguiente orden:

- Pronóstico de ventas 
- Pedido de mercadería

- Recepción de mercadería

- Cierre de venta

- Despacho de producto

A continuación se desarrollará cada subproceso:

- Pronóstico de Ventas

El pronóstico de ventas se realiza actualmente recurriendo a las ventas históricas y, en menor medida, a la coyuntura externa. Este pronóstico de ventas sirve para marcar una pauta de lo que se podría esperar en todo el año.

Dado que conseguir mayor información del mercado puede llegar a ser algo costoso y puede tomar mucho tiempo (contratar un estudio de mercado), no se cambiará los métodos de predicción actuales por el momento. Lo que se buscará es conseguir mayor detalle en el sistema actual y elaborar sistemas de registro para futuros análisis.

Para ello la proyección de ventas deberá de ser mensual y detallada, como se muestra en el siguiente formato: 
Tabla 5.2

Modelo cuadro proyección de ventas

\begin{tabular}{|c|c|c|c|c|c|c|c|c|c|c|c|c|c|c|c|c|c|c|c|c|c|c|c|c|c|c|c|c|c|c|c|}
\hline \multirow{3}{*}{\multicolumn{2}{|c|}{ Pronóstico de ventas }} & \multicolumn{7}{|c|}{ Trimestre 1} & \multicolumn{7}{|c|}{ Trimestre 2} & \multicolumn{7}{|c|}{ Trimestre 3} & \multicolumn{7}{|c|}{ Trimestre 4} & & \\
\hline & & \multicolumn{2}{|c|}{ Mes 1} & \multicolumn{2}{|c|}{ Mes 2} & \multicolumn{2}{|c|}{ Mes 3} & \multirow{2}{*}{\begin{tabular}{|c|}
$\begin{array}{c}\text { Total } \\
\text { trim. } \\
1\end{array}$ \\
S/. \\
\end{tabular}} & \multicolumn{2}{|c|}{ Mes 4} & \multicolumn{2}{|c|}{ Mes 5} & \multicolumn{2}{|c|}{ Mes 6} & \multirow{2}{*}{\begin{tabular}{|c|}
$\begin{array}{c}\text { Total } \\
\text { trim. } \\
\mathbf{2}\end{array}$ \\
$\mathrm{S} /$ \\
\end{tabular}} & \multicolumn{2}{|c|}{ Mes 7} & \multicolumn{2}{|c|}{ Mes 8} & \multicolumn{2}{|c|}{ Mes 9} & \multirow{2}{*}{\begin{tabular}{|c|}
$\begin{array}{c}\text { Total } \\
\text { trim. } \\
\mathbf{3}\end{array}$ \\
$\mathrm{S} / \mathrm{.}$ \\
\end{tabular}} & \multicolumn{2}{|c|}{ Mes 10} & \multicolumn{2}{|c|}{ Mes 11} & \multicolumn{2}{|c|}{ Mes 12} & \multirow{2}{*}{\begin{tabular}{|c|}
$\begin{array}{c}\text { Total } \\
\text { trim. } \\
\mathbf{4}\end{array}$ \\
S/. \\
\end{tabular}} & \multicolumn{2}{|c|}{ Total } \\
\hline & & Cant. & $\mathrm{S} /$. & Cant. & $\mathrm{S} /$. & Cant. & $\mathrm{S} /$. & & Cant. & $\mathrm{S} /$. & Cant. & $\mathrm{S} /$. & Cant. & $\mathrm{S} /$. & & Cant. & $\mathrm{S} /$. & Cant. & S/. & Cant. & $\mathrm{S} /$. & & Cant. & $\mathrm{S} /$. & Cant. & $\mathrm{S} /$. & Cant. & $\mathrm{S} /$. & & Cant. & $\mathrm{S} /$. \\
\hline \multirow{8}{*}{$\begin{array}{l}-\overrightarrow{0} \\
\stackrel{0}{0} \\
\frac{0}{0} \\
\frac{0}{0}\end{array}$} & Escuadradoras & & & $A$ & & & & & & & & $\mathrm{a}$ & & & $a_{-1}$ & & & & & & & - & & & & & & & & & \\
\hline & Enchapadora & & & 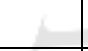 & & - & & & & & & 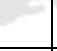 & & & -4 & $\mathrm{t}$ & & & & & & & & & & & & & & & \\
\hline & Cortadora vertical & & & & & & & & & & & & & & 7 & t & & & & & & - & & & & & & & & & \\
\hline & Solución integral & & & He & & & & & & & & & & & & & & & & & & -1 & 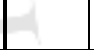 & & & & & & & & \\
\hline & Maq. para madera & & & & & & & & & & & & & & & 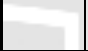 & & & & & & & & & & & & & & & \\
\hline & Herramientas & & & 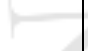 & $Y$ & & & & & & & & & & & & & & & & & & 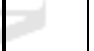 & & & & & & & & \\
\hline & Cola & & & 2 & & & & & & & & & & & & & & & & & & & & & & & & & & & \\
\hline & Otros: & & & & & & & & & & & & & & & & & & & & & & $\gamma$ & & & & & & & & \\
\hline \multirow{8}{*}{ 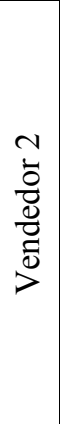 } & Escuadradoras & & & $y=$ & & & & & D & & & & & & 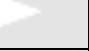 & & & 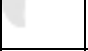 & & & & & & & & & & & & & \\
\hline & Enchapadora & & & & & 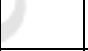 & & & & & & & 1 & 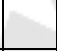 & & & 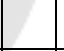 & & & & + & $\sqrt{7}$ & & & & & & & & & \\
\hline & Cortadora vertical & & & $Y$ & & & & & & & & & & & & V & & & & & & & & & & & & & & & \\
\hline & Solución integral & & & & & & & & & & & & & & & & & & & & & & & & & & & & & & \\
\hline & Maq. para madera & & & & & +4 & & & & & & . & & & & & & & & & + & & & & & & & & & & \\
\hline & Herramientas & & & & & & & & & & & & & & & & & & & & & & & & & & & & & & \\
\hline & Cola & & & & & & & 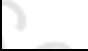 & & & & & & & & & & & & $\mathrm{n}$ & & & & & & & & & & & \\
\hline & Otros: & & & & & & & ( & & & & & & & & & & $\nabla$ & 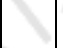 & & & & & & & & & & & & \\
\hline
\end{tabular}


Este cuadro se deberá revisar todos los meses y verificar el estado del pronóstico de ventas en relación a las ventas actuales. La Gerencia Comercial deberá de realizar por lo menos un control una vez al mes a todos sus vendedores y la Gerencia General deberá de verificar el avance trimestralmente cuando menos. Esta tabla y sus respectivos avances trimestrales deberán de ser guardados en el servidor de la empresa, de tal manera que puedan ser accesibles para el futuro a la Gerencia Comercial y Gerencia General.

Del mismo modo se buscará analizar a la competencia y su actividad de ventas. Para ello la Gerencia General deberá de asignar la responsabilidad de verificar una vez al mes las importaciones realizadas por la competencia al personal de apoyo administrativo. Esta persona deberá de controlar a los competidores más cercanos (los que más importan) mensualmente y a los demás cada trimestre. Esta información deberá de ser registrada en una tabla para ser desplegada a la Gerencia General y a la Gerencia Comercial; asimismo, debe guardarse el registro en el servidor de la empresa, de tal manera que pueda ser utilizada en un futuro por las áreas involucradas. Esta información ayudará a tener una idea del tamaño del mercado, de manera que sirva de base para el cálculo de los pronósticos de crecimiento y de ventas para los siguientes periodos.

- Pedido de mercadería

Como ya se mencionó, el pedido de mercadería anual se efectúa dependiendo del pronóstico anual de ventas. Al implementar una tabla de control mensual y trimestral se buscará conseguir mayor precisión en las ventas y por lo tanto también en los pedidos. Si se logra esto se podrían consolidar los pedidos de mercadería por países y en contenedores más grandes, logrando reducir los costos de venta.

Una medida que puede garantizar el control de los pedidos y el nivel de stock es la implementación de un formato de pedido, el cual, antes de ser remitido al proveedor, deberá de contar con doble firma. Una de estas firmas deberá de ser de la gerencia comercial (encargado de verificar los niveles de stock y ventas antes de corroborar el pedido realizado por adelantado al proveedor) y la otra de la gerencia 
general. Este mismo sistema se podría aplicar para el área de servicio técnico y los pedidos de repuestos.

Una vez conseguida la doble firma este formato pasa al área administrativa, quien se encarga de las coordinaciones de embarque y despacho de la mercadería y su respectiva llegada al puerto de destino final.

Asimismo se debe considerar contar con stock de seguridad para cada producto. Para ello se aplica la siguiente formula:

(Plazo máximo de entrega de producto - Plazo de entrega normal de producto) $x$

\section{Demanda media del producto}

Esta fórmula debe de ser revisada una vez al año en los productos de mayor rotación y en los cuales los vendedores consideren que podría haber un aumento considerable de la demanda. Para ello se deberá organizar una reunión, la cual será dirigida por la Gerencia Comercial y se buscará la retroalimentación de los vendedores. En los demás productos el plazo puede ser mayor. El encargado de realizar este control es el encargado del almacén y deberá de ingresar esta cifra en el software contable y de control de stock con el que cuenta la empresa actualmente. De esta manera se tendrá mayor control sobre la cantidad de productos que se almacenan, los que están por llegar y despachar, evitando roturas de stock o demasiados productos en el almacén.

- Recepción de mercadería

La logística de entrada es uno de los procedimientos más claros y que mejor funciona. Al estar a cargo de una sola área (la parte administrativa se encarga de coordinar las fechas de embarque, despacho y llegada de la mercadería al puerto y al local), las tareas son claras y precisas. Lo que se debe de mejorar es la comunicación de dichas órdenes a los demás interesados, en este caso la fuerza de venta y su respectiva gerencia. Para ello se puede crear una tabla que permita el acceso a los interesados, pero no la edición y en la cual se muestre el stock actual, el stock de seguridad y las próximas reposiciones, indicando cantidad de productos a reponer y la fecha estimada de llegada. Esta tabla deberá de ser actualizada cada vez que un producto está próximo 
a llegar al stock de seguridad, de tal manera que el área de ventas pueda saber con certeza de cuantos productos puede disponer para una entrega inmediata.

Sin lugar a duda la mejor manera de manipular este tipo de información es mediante un ERP, pero esta inversión es demasiada elevada para la empresa actualmente y su implementación puede tomar más tiempo del que se tiene para conseguir resultados positivos.

- Cierre de venta

Para el seguimiento y cierre de las ventas se requerirá de un mayor compromiso y trabajo por parte de la fuerza de venta y su respectiva gerencia. Ellos deberán de tener reuniones semanales en las cuales deberán de comentar sus prospectos de ventas y actualizarlos. Si bien lo ideal para realizar este control sería contar con un sistema automatizado, por el momento no es factible que la empresa adquiera uno. Por ello, se plantea la utilización del siguiente formato de seguimiento: 


\section{Tabla 5.3}

Propuesta de modelo de seguimiento de ventas

\begin{tabular}{|c|c|c|c|c|c|c|c|c|c|c|}
\hline \multicolumn{11}{|c|}{ Vendedor: } \\
\hline $\mathrm{N}^{\circ}$ & Nombre cliente & $\begin{array}{l}\text { Cliente } \\
\text { nuevo? }\end{array}$ & Distrito & $\begin{array}{l}\text { Fecha de } \\
\text { visita }\end{array}$ & $\begin{array}{l}\text { Producto(s) } \\
\text { cotizado(s) }\end{array}$ & $\begin{array}{l}\text { Precio } \\
\text { cotizado }\end{array}$ & $\begin{array}{c}\text { Condiciones } \\
\text { de venta }\end{array}$ & $\begin{array}{l}\text { Fecha aprox. } \\
\text { de compra }\end{array}$ & $\begin{array}{c}\text { Probabilidad } \\
\text { de cierre }\end{array}$ & Observaciones \\
\hline 1 & & & & & 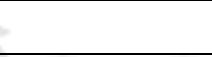 & 8 & & 2 & & \\
\hline \multicolumn{11}{|l|}{2} \\
\hline \multicolumn{11}{|l|}{3} \\
\hline 4 & & 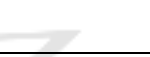 & & & & & & 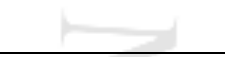 & & \\
\hline 5 & & 8 & 8 & & & & 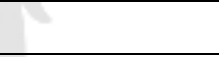 & 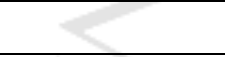 & & \\
\hline 6 & & . & & & 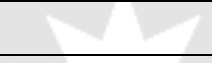 & & & +2 & & \\
\hline 7 & & - & & & 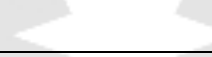 & & & 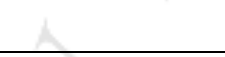 & & \\
\hline \multicolumn{11}{|l|}{8} \\
\hline 9 & & $x$ & & & & & & & & \\
\hline \multicolumn{11}{|l|}{10} \\
\hline \multicolumn{11}{|l|}{11} \\
\hline \multicolumn{11}{|c|}{ 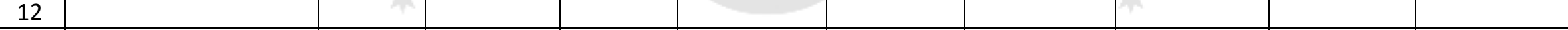 } \\
\hline \multicolumn{11}{|l|}{13} \\
\hline 14 & & & 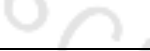 & & & & $1 \otimes 3$ & & & \\
\hline
\end{tabular}

Elaboración propia 
Este formato de seguimiento podría contener mayor cantidad de información, especialmente aquella relacionada a los datos del cliente, como información de contacto, pero se ha estimado que esto hará más tediosa la carga de trabajo de los vendedores y hará más difícil el cumplimiento del llenado de este cuadro.

En lo que respecta a las condiciones de venta, hay una en especial en la cual la empresa debe de prestar atención y se trata de las condiciones crediticias. Como ya se observó, los niveles de cuentas por cobrar son extremadamente altos y esto se debe básicamente a dos factores: condiciones de crédito demasiadas generosas y de fácil obtención y un mal manejo de la cartera de cuentas por cobrar.

Dadas estas circunstancias se busca controlar los créditos. Cualquier vendedor que decida solicitar un crédito para su cliente debe de conocer que la empresa solo financiará, como máximo y en casos excepcionales, el 50\% del valor del negocio. El vendedor deberá de comunicar a la gerencia comercial que su cliente está interesado en solicitar un crédito y si la gerencia da el visto bueno, se le comunicará al encargado de las cobranzas que desean un estudio del cliente. Para ello se recurrirá a dos fuentes, historial crediticio del cliente con la empresa e historial del cliente según Infocorp ${ }^{1}$. El vendedor debe de entregar al encargado de cobranzas el nombre del representante legal y DNI y el nombre de la empresa y RUC para su respectiva verificación. Si alguno de estos dos filtros no arroja buenos resultados se le negará el crédito. De tener buenos resultados, la gerencia general es la que tiene la última palabra y decidirá si entregar el crédito, cambiar las condiciones planteadas por el cliente o negarlo.

En caso que se brinde el crédito, el cliente deberá de firmar y devolver las letras por adelantado y así mismo un contrato mediante el cual autoriza a la empresa ABC S.A.C. la recuperación del bien vendido si es que se incurre en un atraso en los pagos. Para que estas medidas no desalienten la venta, la empresa buscará brindar otras ventajas a sus clientes a parte del crédito, el cual representa, en ese momento, una clara amenaza a la estabilidad del negocio.

1 Infocorp proporciona un reporte de crédito de las personas o empresas con quien se va a hacer negocio y si está en capacidad de realizar transacciones comerciales. 
De cerrarse la venta con alguna condición crediticia, las condiciones, las letras y el contrato ya estarán en manos del encargado de cobranza, quien deberá de ingresar a este nuevo cliente en su base de datos. El encargado de cobranzas deberá de agendar las fechas de vencimiento de las respectivas letras con los datos del cliente en un calendario. Asimismo deberá de mantener un documento que permita una rápida actualización de las cuentas por cobrar, separando claramente las que están al día, las que están en mora de 30 días, las que tienen más de 60 días de atraso y las que tienen más de 90 días. Si el monto adeudado es considerable y vale la pena, la empresa podrá tomar acciones legales que permitan la recuperación del bien vendido. Importante mencionar que el vendedor tendrá que apoyar a la labor de cobranza, ya que al fin y al cabo, es él el que mantiene mayor contacto con el cliente.

- Despacho de productos

Luego de aprobada la venta, la empresa cuenta con una serie de procedimientos y formatos bastante claros y lógicos para llevar a cabo el despacho de productos. Sin embargo, este subproceso tiene dos falencias; la primera es la disciplina al momento de aplicarlos y la segunda, el almacenamiento de la información recolectada. Para solucionar el primer problema, las gerencias deben de ser más estrictas con sus subalternos y deben de fomentar que se sigan los procedimientos y se llenen los formularios requeridos, alimentándolos con recompensas o sanciones según estipulen. Para el segundo problema, se debe llevar a cabo una recopilación de los pormenores que se encuentran al momento de ejecutar las actividades establecidas, de tal manera que esta información pueda ser utilizada por la empresa para mejorar diferentes aspectos del negocio.

A continuación se presentan las actividades que se deben realizar para este subproceso:

- Revisión del producto antes del despacho: el encargado de almacén deberá revisar minuciosamente el producto para verificar que no tengan ningún defecto al momento de entregarse. De encontrarse alguna falla, se debe documentar cual es el error encontrado, a fin de que se puedan mostrar evidencias contundentes a los proveedores. Con esas cifras la empresa puede evaluar la calidad del proveedor (cuantos errores encuentra en los despachos) y qué decisión tomar al 
respecto de ellos. La revisión no debe de acabar en el llenado de la ficha, sino que deben de ser ingresada en un sistema que permita futuras estadísticas y estas quizás en mejores condiciones comerciales con los proveedores. Actualmente la empresa ya cuenta con una ficha (ver Anexo $\mathrm{N}^{\circ} 1$ ), pero no hay mayor trabajo de almacenamiento ni análisis de dicha información, lo cual debe ser reforzado por la jefatura administrativa para que se cumpla.

- Visita de validación del local y equipamiento del cliente: el equipo técnico de ABC S.A.C. realizará una visita al local del cliente para verificar que cuente con las condiciones necesarias para recibir y poner en marcha la maquinaria (espacio, carga eléctrica, iluminación, piso adecuado, pozo a tierra, etc.). Verificadas las condiciones, se procede a llenar el formato de validación (ver Anexo $\mathrm{N}^{\circ}$ 2). La información obtenida en el formato, por cuenta del vendedor encargado, debe de ser ingresada a una base de datos, de tal manera que la empresa pueda determinar, por ejemplo, cual es el faltante más común en los locales de los clientes. Esto podrá generar ahorro de tiempo, reducción de costos e incluso nuevas oportunidades comerciales.

- Instalación de la maquinaria: con la verificación realizada, el jefe de servicio técnico procede a coordinar con el cliente la instalación, la cual es llevada a cabo a continuación por parte del staff técnico. Realizada la instalación, el encargado debe proceder a capacitar al personal del cliente en el uso de la maquinaria, entregando el respectivo manual de funcionamiento y las herramientas e implementos incluidos con la maquinaria. Finalizada la capacitación, se procederá con el llenado de la ficha de instalación (ver Anexo $\mathrm{N}^{\circ}$ ), la cual debe entregarse posteriormente al área de administración para su respectivo registro. La empresa debe de aspirar a tener una hoja clínica de cada máquina vendida, de tal manera que esta pueda ser consultada o incluso vendida en un futuro. El vendedor deberá realizar una visita al cliente, ya sea durante la instalación de la máquina o al día siguiente. Con ello se busca que la presencia del vendedor sea constante y así pueda entablar una mejor relación con sus clientes. 
- Validación de garantía: transcurridos 30 días desde la instalación, el jefe de servicio técnico debe coordinar con el cliente una visita de validación de garantía. Para ello un miembro del staff técnico verificará en el local del cliente que se mantienen las condiciones en las que se instaló la maquinaria. En el caso en que las condiciones hayan variado de manera en que pongan en riesgo el estado de la maquinaria, la garantía se suspende. La información conseguida en estas visitas debe de ser registrada en la ficha de instalación y almacenada de forma adecuada, de tal manera que permita conseguir beneficios para la empresa. En esta visita el técnico estará acompañado del vendedor, siguiendo la idea de reforzar la relación entre cliente y vendedor. Asimismo, como cierre de esta actividad se deberá realizar una encuesta de satisfacción del cliente, en la cual el cliente evaluará algunos aspectos del servicio que ABC S.A.C. le ha prestado hasta el momento. La encuesta, que será llevada a cabo por vía telefónica por una persona del área administrativa, deberá de ser corta y servirá para conseguir mayor cantidad de información sobre la perspectiva del cliente hacia los productos y servicios que la empresa ofrece. La evaluación se realizará asignando puntajes del 1 al 5, siendo 5 el de mejor apreciación por parte del cliente. A continuación se presenta el formato a utilizar: 
Tabla 5.4

Formato de encuesta de satisfacción del cliente

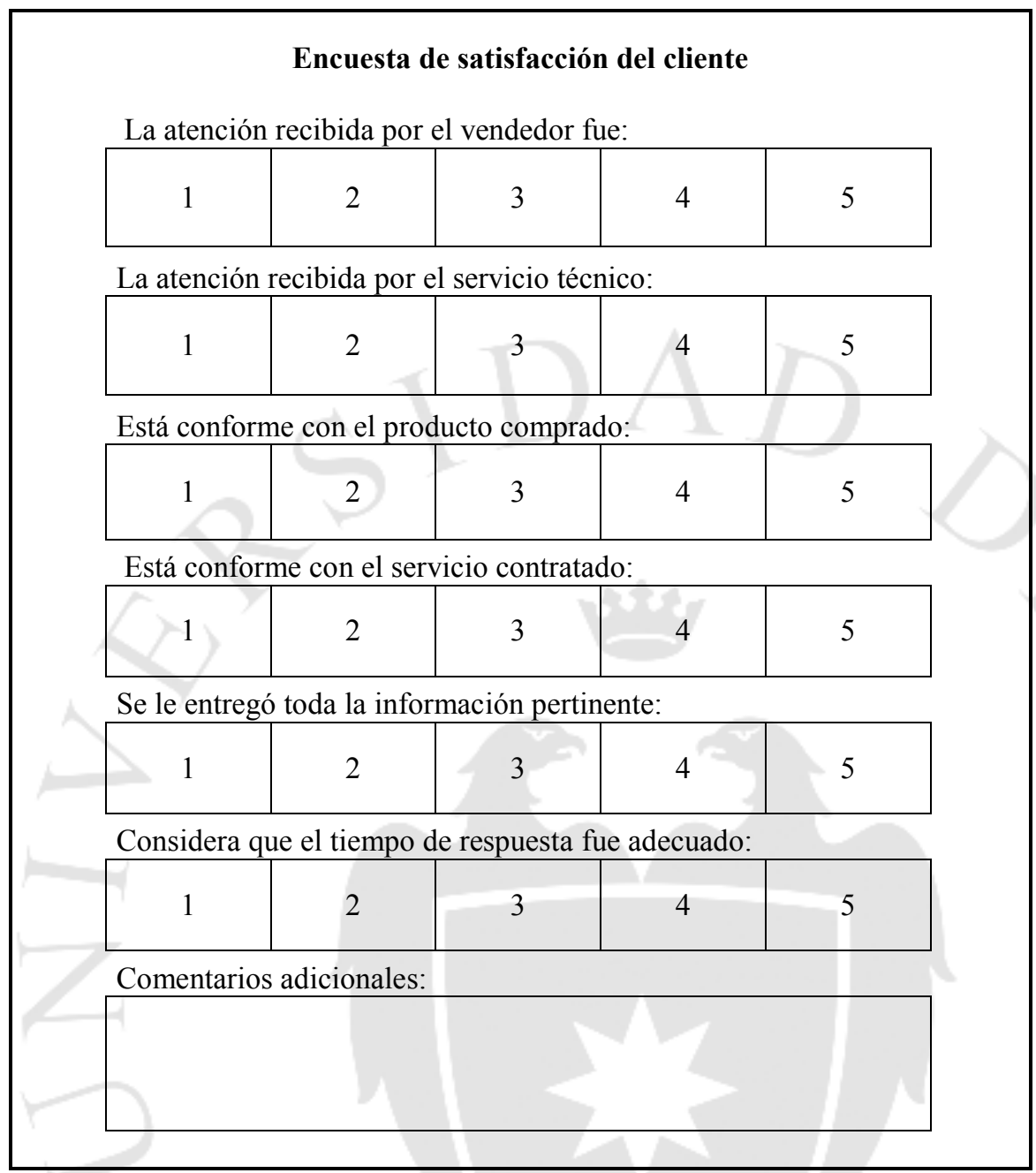

Elaboración propia

A continuación se muestra el diagrama de flujo del nuevo proceso de venta de maquinaria. Tal como se ha desarrollado, el diagrama se subdivide en subprocesos que se presentan seguidamente en diagramas aparte. 
Figura 5.2

Diagrama de flujo del nuevo proceso de venta de maquinaria

Diagrama de flujo principal del proceso de ventas

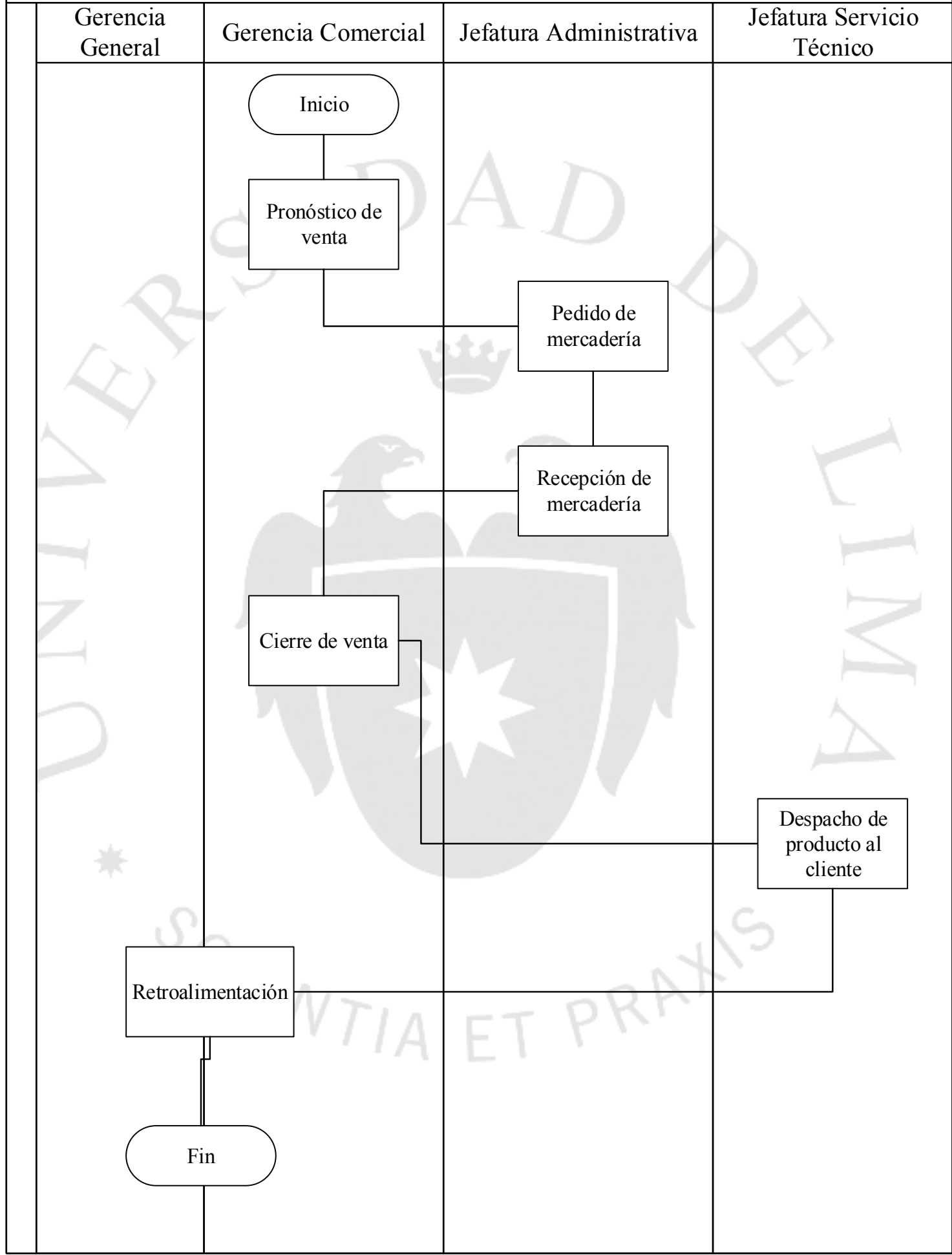

Elaboración propia 
Figura 5.3

Diagrama de flujo del nuevo subproceso "pronóstico de ventas"

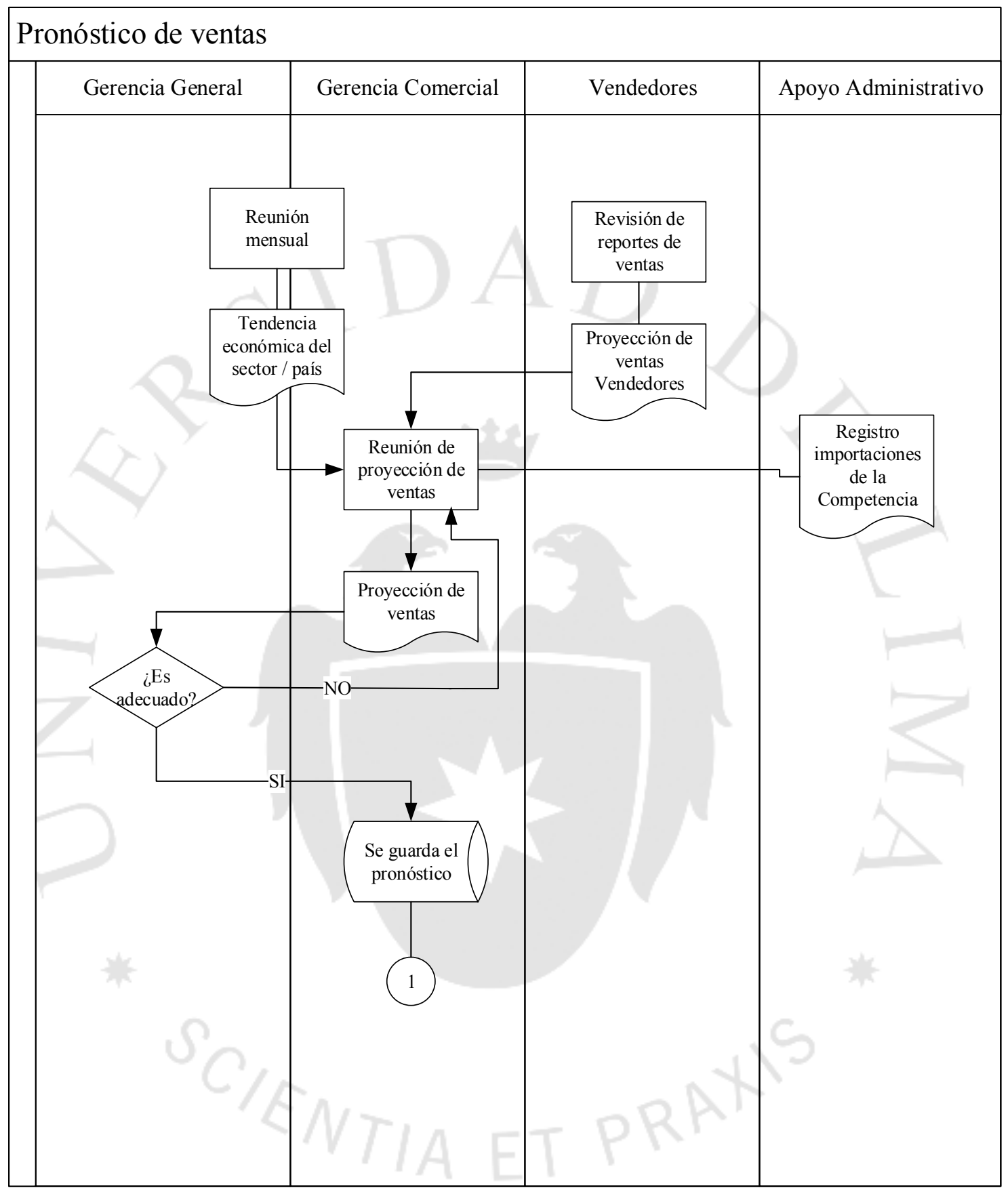

Elaboración propia 
Figura 5.4

Diagrama de flujo del nuevo subproceso "pedido de mercadería"

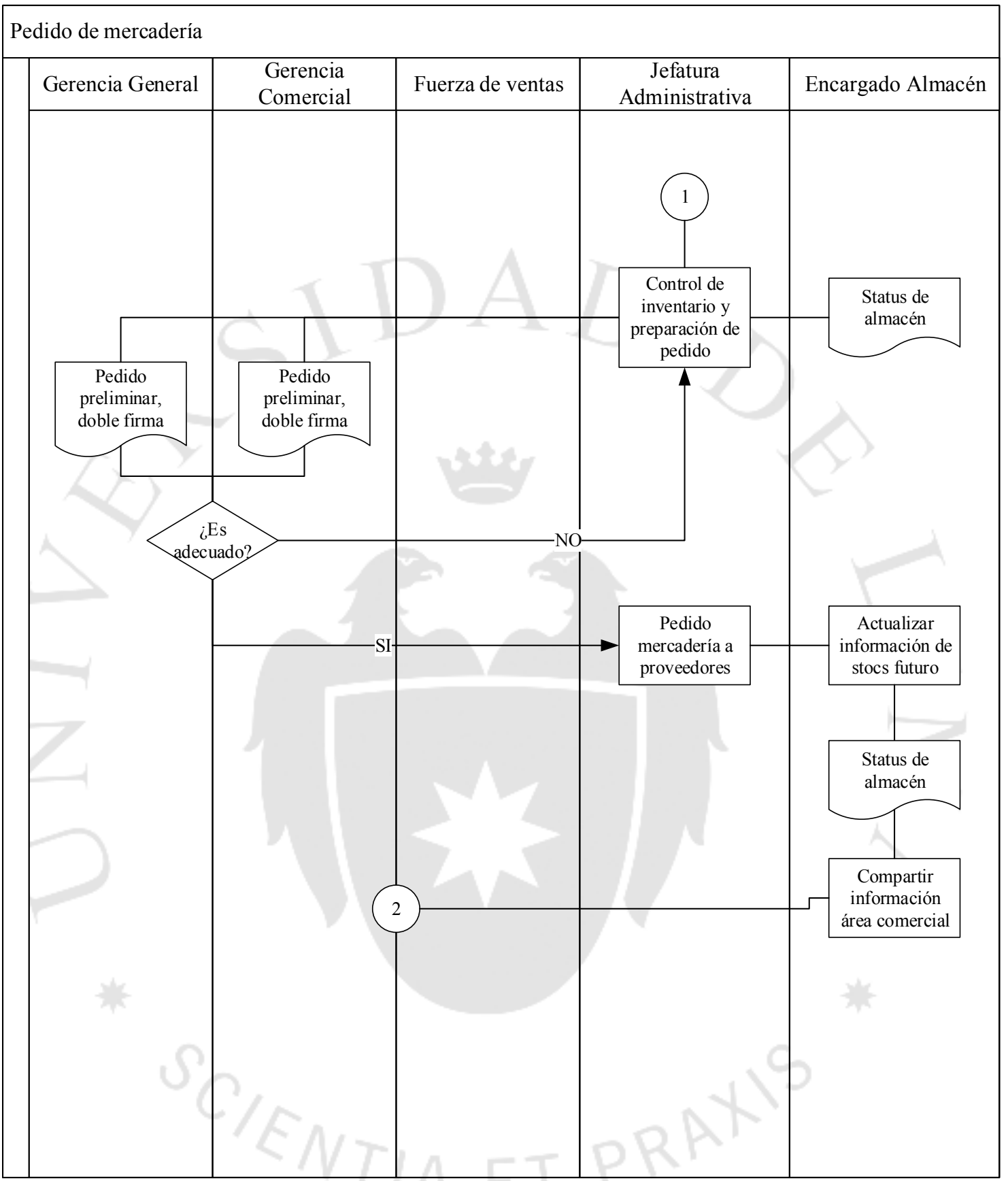

Elaboración propia 
Figura 5.5

Diagrama de flujo del nuevo subproceso "cierre de venta"

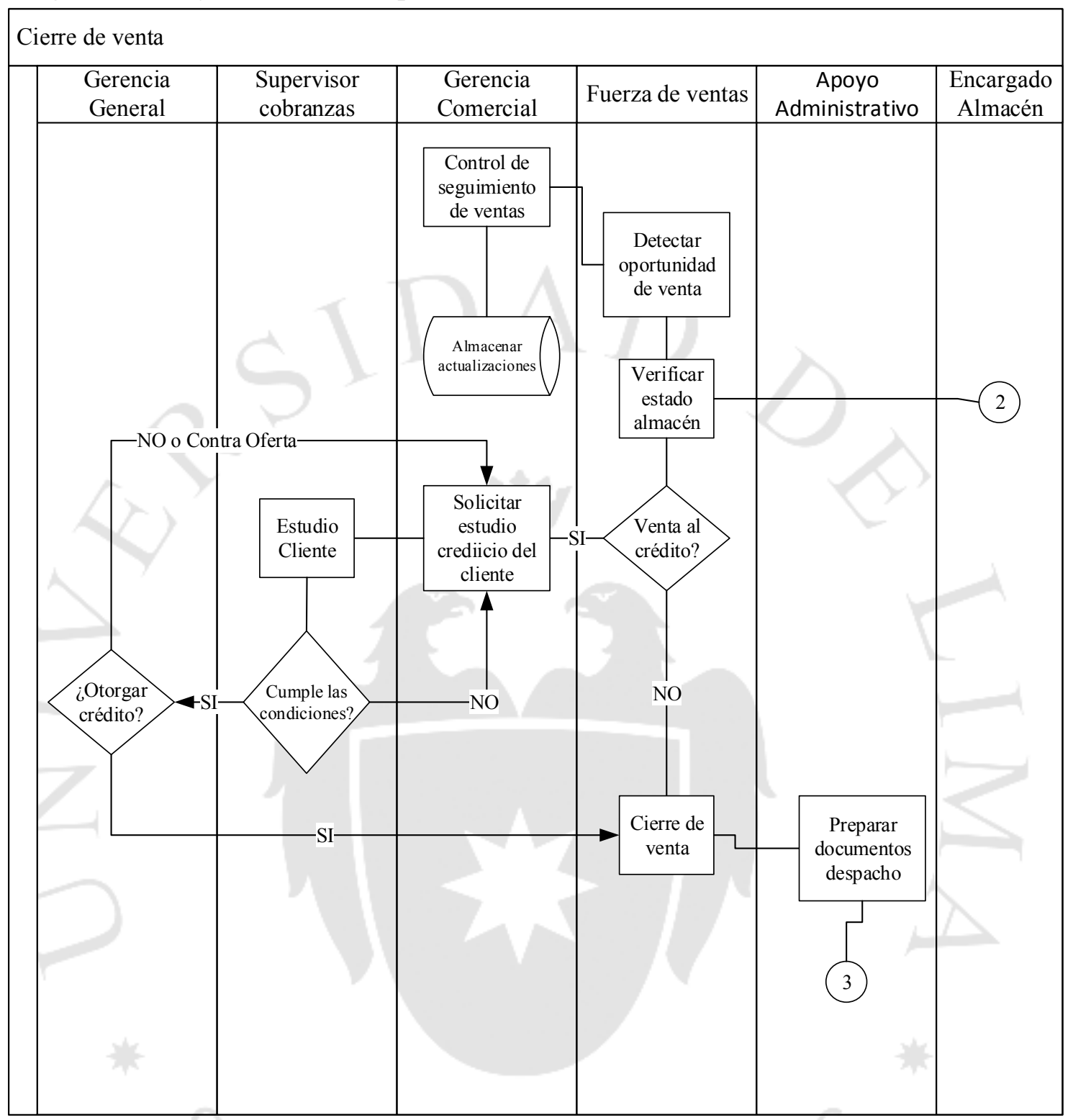

Elaboración propia 
Figura 5.6

Diagrama de flujo del nuevo subproceso "despacho de producto"

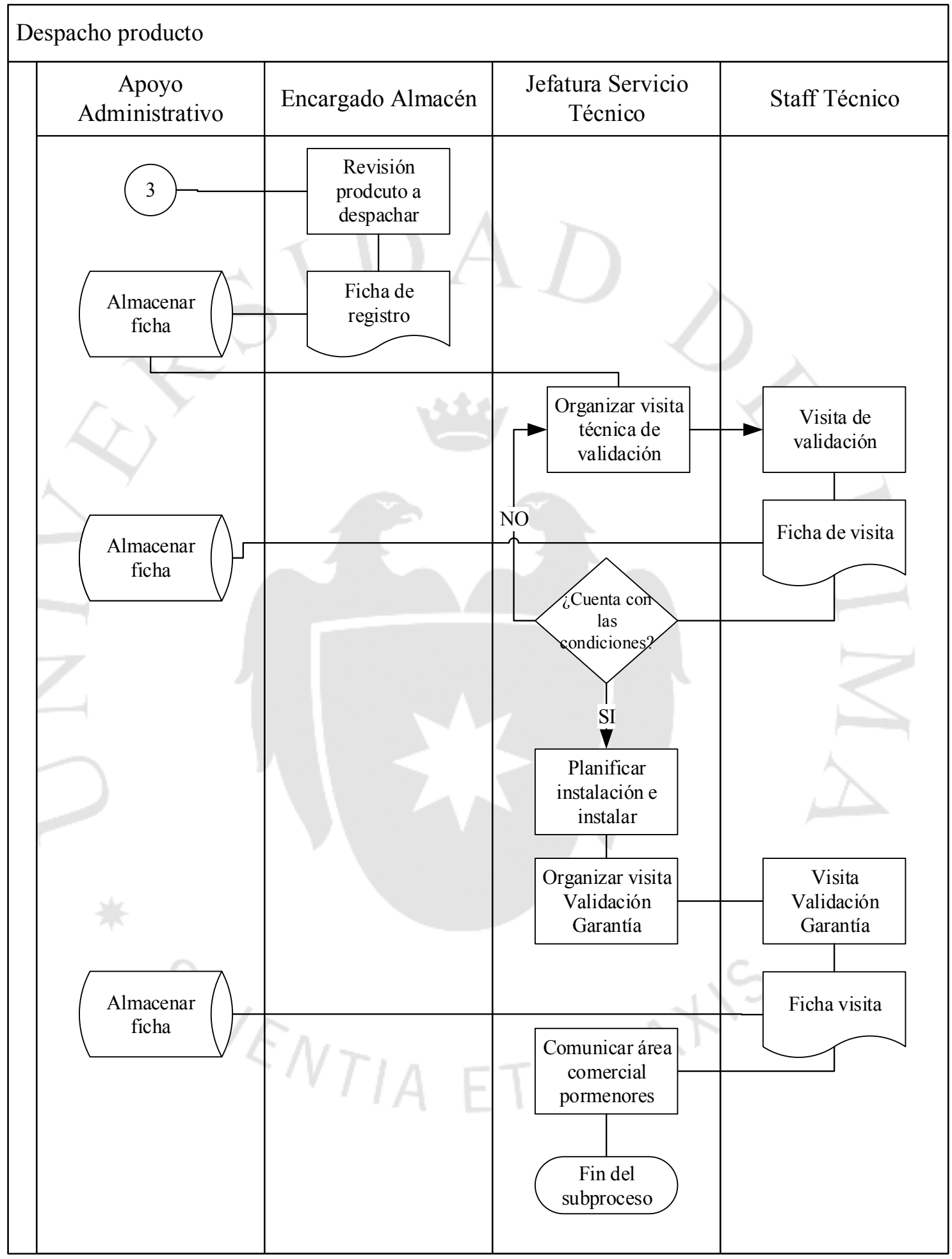

Elaboración propia 
De manera complementaria y con el objetivo de obtener información adicional que pueda ser utilizada por el área comercial, se propone que tanto el staff técnico de ABC S.A.C como el de DEF S.A.C. recopilen información de los clientes al momento de brindar sus servicios. Para ello se propone lo siguiente:

- Staff técnico: los técnicos por lo general consiguen información a la cual los vendedores muchas veces no pueden acceder, especialmente aquella relacionada a la competencia: calidad de las máquinas de la competencia, percepción del cliente acerca de la competencia y sus productos. Toda esta información debe de ser transmitida a la gerencia comercial y a la jefatura técnica para que se almacene y se le dé un uso pertinente. Para la primera parte se propone el siguiente formato, el cual es muy simple y no debería de complicar al staff técnico en el llenado del mismo.

\section{Tabla 5.5}

Formato recopilación de información de la competencia

\section{INFORMACIÓN DE LA COMPETENCIA}

Técnico:

Tipo de maquina:

Cliente / Empresa:

Marca:

Fecha y hora de visita:

Modelo:

Favor califique según crea, siendo 1 el de menor puntaje y 5 el de mayor puntaje

1 - Calidad de la máquina según su criterio

\begin{tabular}{|l|l|l|l|l|}
\hline 1 & 2 & 3 & 4 & 5 \\
\hline
\end{tabular}

2 - Calidad de la máquina según criterio del operario

\begin{tabular}{|l|l|l|l|l|}
\hline 1 & 2 & 3 & 4 & 5 \\
\hline
\end{tabular}

3 - Calidad de la máquina según criterio del dueño

\begin{tabular}{|l|l|l|l|l|}
1 & 2 & 3 & 4 & 5 \\
\hline
\end{tabular}

4 - Comentarios adicionales:

Elaboración propia 
- Personal DEF S.A.C.: al brindar un servicio complementario a los que da directamente la empresa ABC S.A.C. y al tener un contacto casi diario con los clientes, el personal de DEF S.A.C. tiene información de primera mano y casi al momento del requerimiento, por lo que puede ser muy útil para el área comercial y técnica de ABC S.A.C.. Nuevamente, con la idea de facilitar el trabajo del personal de DEF S.A.C. y que no se sientas abrumados por una nueva tarea, se presenta el siguiente modelo de formato:

Tabla 5.6

Formato para recopilación DEF S.A.C.

\begin{tabular}{|c|c|c|c|}
\hline \multicolumn{4}{|c|}{ Información del cliente } \\
\hline \multicolumn{4}{|l|}{ Informante: } \\
\hline \multicolumn{4}{|c|}{ Cliente/Empresa: } \\
\hline \multicolumn{4}{|c|}{ Fecha y hora de visita: } \\
\hline \multicolumn{4}{|c|}{1 - Atención solicitada } \\
\hline Maquinaria & Herramientas & Cola & Serv. Tecnico \\
\hline & jeja & & tunidad \\
\hline \multicolumn{4}{|c|}{2 - Detalle de producto o servicio } \\
\hline Producto: & & \multicolumn{2}{|l|}{$\begin{array}{l}\text { Marca: } \\
\text { Modelo: }\end{array}$} \\
\hline \multicolumn{4}{|l|}{ Cantidad: } \\
\hline \multicolumn{4}{|c|}{3 - Comentarios adicionales } \\
\hline
\end{tabular}

Elaboración propia

Este formato será entregado al encargado del reparto de las herramientas que tiene en su ruta a ABC S.A.C.. Estos formatos serán entregados en la recepción de ABC S.A.C. y seguidamente se entregarán al área correspondiente, de tal manera que puedan tener la información incluso antes de que el cliente se comunique con ABC S.A.C.. Este nivel de servicio sin lugar a duda marcará una brecha entre este negocio y sus competidores. 
Recolectada la información, esta deberá de ser almacenada en hojas de cálculo por un encargado de soporte administrativo, para que luego sea revisada y estudiada de la mejor manera por parte del Gerente Comercial y su equipo.

Con el nuevo proceso de ventas desarrollado, a continuación se presenta la propuesta de organigrama funcional para poder hacer frente a los nuevos procedimientos. El cambio más importante es que se eliminó la Jefatura Comercial de consumibles y todos los vendedores pasan a estar bajo la Gerencia Comercial.

Con ello se da otro cambio importante ya que se elimina la diferenciación entre vendedores de maquinaria y consumible, pasando a tener vendedores de ambas líneas. Asimismo, se plantea la reducción de un vendedor ya que el nivel de ventas actual se ha podido manejar con un vendedor menos anteriormente. Este cambio y el anterior significarían un ahorro de $12 \%$ en la planilla del personal de ventas. 
Figura 5.7

Nuevo organigrama propuesto

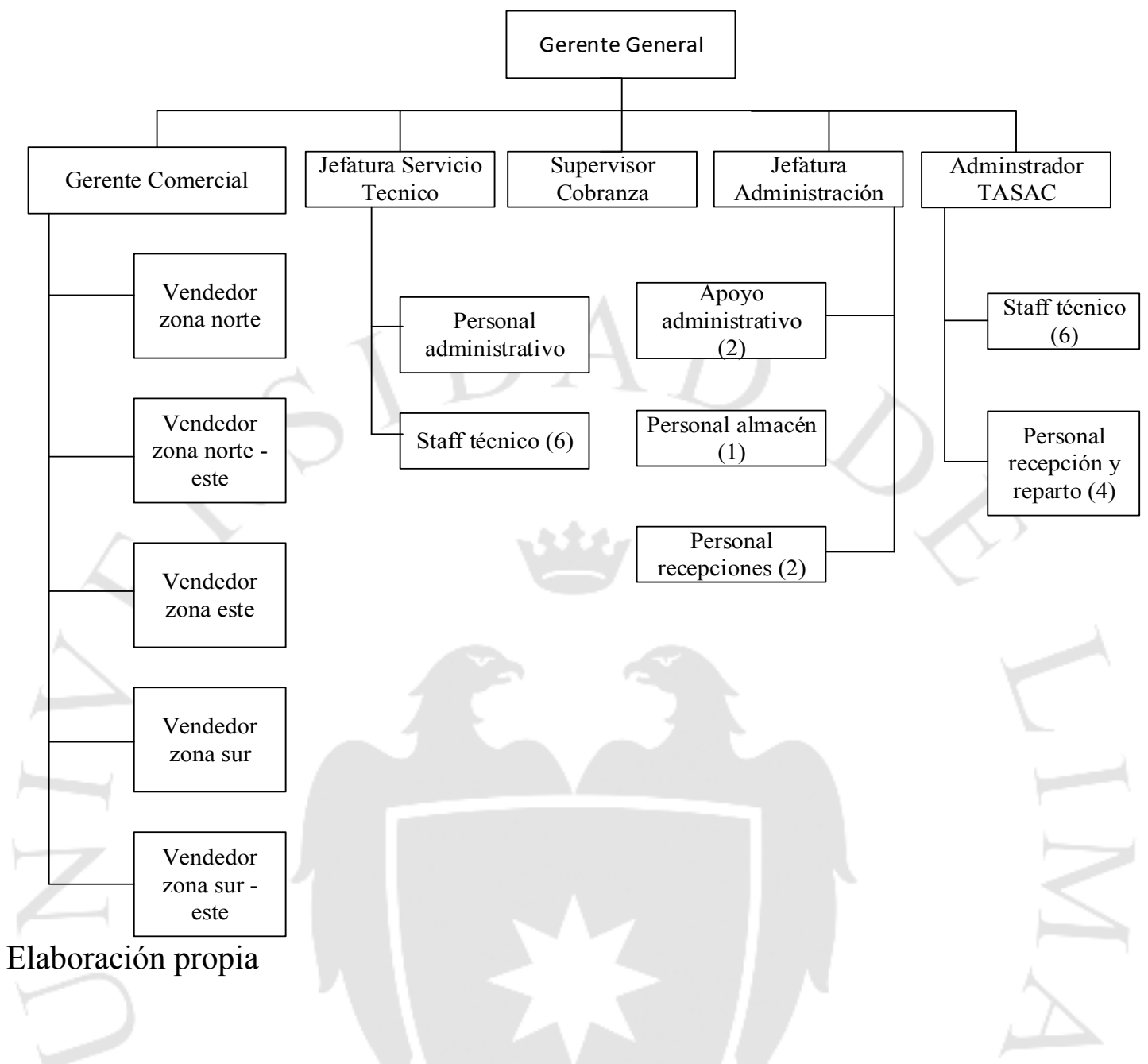

Por otro lado, al tener nuevos procesos y organigrama, es necesario revisar las funciones de los trabajadores involucrados y los respectivos perfiles que cada puesto exigirá. A continuación se muestran las nuevas descripciones de puestos de trabajo: 
Tabla 5.7

Descripción del nuevo perfil del puesto Gerente General

\begin{tabular}{|c|c|}
\hline DESCRIPCIÓN DEL PU & STO DE TRABAJO: \\
\hline \multicolumn{2}{|l|}{ TITULAR: } \\
\hline DEPARTAMENTO: & Gerencia General \\
\hline ÁREA: & Gestión \\
\hline RANGO DE PUESTO: & Gerente \\
\hline SUPERIOR: & Junta de socios - directorio de la empresa \\
\hline SUBORDINADOS: & $\begin{array}{l}\text { Gerencia Comercial, Jefatura administrativa, Jefatura de Servicio } \\
\text { Técnico, Administrador de DEF SAC. }\end{array}$ \\
\hline OBJETIVOS: & $\begin{array}{l}\text { El Gerente General será el líder para la implementación de las } \\
\text { soluciones planteadas y además tendrá a su cargo la supervisión de } \\
\text { presupuestos, planes, funciones y objetivos de todas las otras } \\
\text { jefaturas y gerencias a su cargo }\end{array}$ \\
\hline \multirow[t]{6}{*}{ TAREAS: } & $\begin{array}{l}\text { Apoyo comercial con clientes corporativos y claves para la empresa } \\
\text { Apoyo en la elaboración de políticas y eventos comerciales. } \\
\text { Encargado del manejo financiero de la empresa }\end{array}$ \\
\hline & $\begin{array}{l}\text { Verificación de los márgenes de los productos y servicios y } \\
\text { establecer, de ser necesario, nuevos márgenes y precios de venta. }\end{array}$ \\
\hline & Responsable de la aprobación de créditos. \\
\hline & Trato con proveedores. \\
\hline & Supervisor de Recursos Humanos \\
\hline & $\begin{array}{l}\text { Control de los indicadores establecidos por los socios de la empresa } \\
\text { y velar por conseguir los niveles adecuados. }\end{array}$ \\
\hline \multirow{4}{*}{$\begin{array}{l}\text { ATRIBUCIONES: } \\
\text { RESPONSABILIDADES: }\end{array}$} & Representación legal del negocio frente a cualquier proceso legal \\
\hline & Conseguir mayor rentabilidad en el negocio \\
\hline & Conseguir una utilidad positiva creciente \\
\hline & Velar por mantener mantenerse como líder absoluto del mercado \\
\hline \multirow[t]{3}{*}{ REQUISITOS: } & $\begin{array}{l}\text { Mínimo graduado universitario de carrera ingeniería industrial, } \\
\text { economía o administración, de preferencia con algún tipo de MBA o } \\
\text { especialización en manejo comercial u operaciones }\end{array}$ \\
\hline & $\begin{array}{l}\text { Experiencia laboral de } 10 \text { años y por lo menos } 5 \text { en el sector de } \\
\text { maquinaria industrial y servicios. }\end{array}$ \\
\hline & $\begin{array}{l}\text { Competencias técnicas: Office avanzado. Ingles a nivel intermedio. } \\
\text { Conocimiento y manejo de algún ERP y/o CRM. }\end{array}$ \\
\hline $\begin{array}{l}\text { ELEMENTOS DE } \\
\text { JUICIO: }\end{array}$ & $\begin{array}{l}\text { Líder, proactivo, organizado, perspectiva estratégica, capacidad para } \\
\text { trabajar en equipo. }\end{array}$ \\
\hline
\end{tabular}

Elaboración propia 
Tabla 5.8

Descripción del nuevo perfil del puesto Gerente Comercial

\begin{tabular}{|c|c|}
\hline \multicolumn{2}{|c|}{ DESCRIPCIÓN DEL PUESTO DE TRABAJO: } \\
\hline \multicolumn{2}{|c|}{ TITULAR: } \\
\hline DEPARTAMENTO: & Comercial \\
\hline ÁREA: & Gestión \\
\hline RANGO DE PUESTO: & Gerente \\
\hline SUPERIOR: & Gerente General \\
\hline SUBORDINADOS: & Fuerza de ventas, recepciones \\
\hline OBJETIVOS: & $\begin{array}{l}\text { La gerencia comercial se encargará directamente de las ventas de } \\
\text { maquinaria y de los consumibles }\end{array}$ \\
\hline \multirow[t]{11}{*}{ TAREAS: } & $\begin{array}{l}\text { Establecer y controlar precios de venta y márgenes de los productos } \\
\text { Preocuparse de conseguir información del sector }\end{array}$ \\
\hline & $\begin{array}{l}\text { Elaborar el presupuesto de ventas de maquinaria y consumibles y velar } \\
\text { por su cumplimiento }\end{array}$ \\
\hline & $\begin{array}{l}\text { Supervisar y dirigir los equipos de venta de la línea maquinaria y de } \\
\text { consumibles. }\end{array}$ \\
\hline & Establecer cuotas de venta y cronograma de visitas de los vendedores \\
\hline & $\begin{array}{l}\text { Verificar cumplimiento de cuotas y de controlar ingreso de información } \\
\text { en semanal del seguimiento de visitas. }\end{array}$ \\
\hline & Controlar niveles de inventario y control de los mismos \\
\hline & Preparar argumentos de venta y entregarlos a los equipos de venta \\
\hline & $\begin{array}{l}\text { Realizar y/o participar en eventos comerciales (ferias y promociones). } \\
\text { Coordinar con los proveedores el diseño de máquinas para el mercado } \\
\text { nacional }\end{array}$ \\
\hline & Supervisar que las ventas a crédito se mantengan al mínimo. \\
\hline & Elaborar y efectuar los planes de capacitación \\
\hline & $\begin{array}{l}\text { Adecuado almacenamiento de la información de mercado proporcionada } \\
\text { por los vendedores, el staff técnico, el apoyo administrativo y el } \\
\text { personal de reparto de DEF SAC }\end{array}$ \\
\hline \multirow{3}{*}{$\begin{array}{l}\text { ATRIBUCIONES: } \\
\text { RESPONSABILIDADES: }\end{array}$} & Representación comercial del negocio frente a posibles negocios \\
\hline & Aumentar el nivel de ventas de las distintas líneas de negocio. \\
\hline & Respetar los presupuestos de venta asignados. \\
\hline \multirow[t]{3}{*}{ REQUISITOS: } & $\begin{array}{l}\text { Mínimo graduado universitario de la carrera ingeniería industrial, } \\
\text { administración o marketing, de preferencia con algún tipo de MBA o } \\
\text { especialización en manejo comercial. }\end{array}$ \\
\hline & $\begin{array}{l}\text { Experiencia laboral de } 8 \text { años en el área comercial, por lo menos } 5 \text { en el } \\
\text { sector de maquinaria industrial y servicios y por lo menos } 2 \text { en el sector. }\end{array}$ \\
\hline & $\begin{array}{l}\text { Competencias técnicas: Office avanzado. Ingles a nivel intermedio. De } \\
\text { preferencia conocimiento y manejo de algún CRM }\end{array}$ \\
\hline $\begin{array}{l}\text { ELEMENTOS DE } \\
\text { JUICIO: }\end{array}$ & $\begin{array}{l}\text { Líder, proactivo, organizado, capacidad para trabajar en equipo, trabajo } \\
\text { bajo presión. }\end{array}$ \\
\hline
\end{tabular}

Elaboración propia 
Tabla 5.9

Descripción del nuevo perfil del puesto Vendedor

\begin{tabular}{|c|c|}
\hline \multicolumn{2}{|c|}{ DESCRIPCIÓN DE PUESTO DE TRABAJO: } \\
\hline $\begin{array}{l}\text { TITULAR: } \\
\text { DEPARTAMENTO: } \\
\text { ÁREA: } \\
\text { RANGO DE PUESTO: } \\
\text { SUPERIOR: } \\
\text { SUBORDINADOS: } \\
\end{array}$ & $\begin{array}{l}\text { Comercial } \\
\text { Ventas } \\
\text { Vendedor } \\
\text { Gerente Comercial } \\
\text { - }\end{array}$ \\
\hline OBJETIVOS: & $\begin{array}{l}\text { Cumplir con las cuotas de ventas asignadas por la Gerencia } \\
\text { Comercial y representar a la empresa de manera adecuada, } \\
\text { demostrando profesionalismo y buena actitud hacia los clientes. }\end{array}$ \\
\hline \multirow[t]{6}{*}{ TAREAS: } & $\begin{array}{l}\text { Cumplir con la cuota de ventas, tanto en unidades como en soles. } \\
\text { Conocimiento completo y actualizado de líneas de productos, } \\
\text { precios, promociones, políticas y procedimientos. }\end{array}$ \\
\hline & $\begin{array}{l}\text { Informar constantemente sobre la competencia (productos, } \\
\text { precios, promociones, etc.). }\end{array}$ \\
\hline & $\begin{array}{l}\text { Incrementar la cartera de clientes existentes en sus zonas de } \\
\text { trabajo, maximizando la distribución (clientes nuevos y/o } \\
\text { recuperados), y exhibición de nuestros productos. } \\
\text { Cumplir con visitas programadas, generando una } \\
\text { retroalimentación de los clientes. } \\
\text { Cumplir con los reportes solicitados por la Gerencia Comercial. } \\
\text { Hacer seguimiento constante a sus clientes (servicio pre y post } \\
\text { venta). } \\
\text { Asistir a juntas, reuniones, convenciones y exhibiciones indicadas } \\
\text { por la Gerencia Comercial }\end{array}$ \\
\hline & $\begin{array}{l}\text { Mantener en estricta confidencialidad y reserva toda información } \\
\text { entregada por la empresa }\end{array}$ \\
\hline & $\begin{array}{l}\text { Registrar diariamente las visitas y/o llamadas realizadas en sus } \\
\text { reportes }\end{array}$ \\
\hline & Apoyar en la gestión de las cobranzas. \\
\hline $\begin{array}{l}\text { ATRIBUCIONES: } \\
\text { RESPONSABILIDADES: }\end{array}$ & $\begin{array}{l}\text { Representación comercial del negocio frente a posibles negocios } \\
\text { Aumentar el nivel de ventas de las distintas líneas de negocio. } \\
\text { Cumplir con las cuotas de venta asignados. }\end{array}$ \\
\hline \multirow[t]{3}{*}{ REQUISITOS: } & $\begin{array}{l}\text { Mínimo estudios técnicos relacionados a la industria (mecánica, } \\
\text { electrónica, etc) con interés por el área comercial y/o con un } \\
\text { estudio relacionado al área comercial con interés por el sector. }\end{array}$ \\
\hline & $\begin{array}{l}\text { Experiencia laboral de } 3 \text { años en el área comercial, por lo menos } \\
1 \text { en el sector de maquinaria industrial y servicios. }\end{array}$ \\
\hline & $\begin{array}{l}\text { Competencias técnicas: Office intermedio. Ingles a nivel } \\
\text { intermedio. De preferencia conocimiento y manejo de algún } \\
\text { CRM }\end{array}$ \\
\hline $\begin{array}{l}\text { ELEMENTOS DE } \\
\text { JUICIO: }\end{array}$ & $\begin{array}{l}\text { Orientación al cliente, proactivo, organizado, capacidad para } \\
\text { trabajar en equipo, trabajo bajo presión, manejo de conflictos }\end{array}$ \\
\hline
\end{tabular}

Elaboración propia 
Tabla 5.10

Descripción del nuevo perfil del puesto Jefe de Servicio Técnico

\begin{tabular}{|c|c|}
\hline DESCRIPCIÓN DE PUE & Jefe de Servicio Técnico \\
\hline TITULAR: & \\
\hline DEPARTAMENTO: & Servicio Técnico \\
\hline ÁREA: & Gestión \\
\hline RANGO DE PUESTO: & Jefe \\
\hline SUPERIOR: & Gerente General \\
\hline SUBORDINADOS: & Staff técnico \\
\hline OBJETIVOS: & $\begin{array}{l}\text { Esta jefatura está a cargo del servicio de mantenimiento } \\
\text { preventivo y reactivo a la maquinaria vendida por la empresa a } \\
\text { sus clientes }\end{array}$ \\
\hline TAREAS: & $\begin{array}{l}\text { Dar respuesta oportuna a los requerimientos de los clientes a } \\
\text { través del staff técnico }\end{array}$ \\
\hline & $\begin{array}{l}\text { Solucionar todo problema técnico que pueda haber con todas las } \\
\text { máquinas vendidas por } \mathrm{ABC}\end{array}$ \\
\hline & $\begin{array}{l}\text { Supervisar las labores de los técnicos de } \mathrm{ABC} \text { y todo aquel que se } \\
\text { subcontrate para labores específicas }\end{array}$ \\
\hline & $\begin{array}{l}\text { Controlar los niveles de stock de maquinaria y repuestos, } \\
\text { manteniendo los stock de seguridad. Hacer los pedidos necesarios. }\end{array}$ \\
\hline & $\begin{array}{l}\text { Mantener la sala de exhibición y sus componentes en perfecto } \\
\text { estado y funcionando. }\end{array}$ \\
\hline & Desarrollar nuevas oportunidades de negocio \\
\hline & $\begin{array}{l}\text { Estudiar constantemente la demanda y actividad de los } \\
\text { competidores }\end{array}$ \\
\hline & Elaborar y efectuar los planes de capacitación \\
\hline & Visitar a clientes claves (Lima y provincias). \\
\hline & $\begin{array}{l}\text { Supervisión y planificación de revisión de maquinaria y locales } \\
\text { del cliente. }\end{array}$ \\
\hline & $\begin{array}{l}\text { Adecuado almacenamiento de la información de los clientes } \\
\text { proporcionada por el staff técnico. }\end{array}$ \\
\hline ATRIBUCIONES: & Representación técnico del negocio frente a los clientes \\
\hline RESPONSABILIDADES: & Aumentar el nivel de ventas de la línea de servicios \\
\hline & Respetar los presupuestos de venta asignados. \\
\hline REQUISITOS: & $\begin{array}{l}\text { Mínimo técnico mecánico o electrico, de preferencia con algún } \\
\text { tipo especialización o diplomado relacionado a operaciones o } \\
\text { servicios }\end{array}$ \\
\hline & $\begin{array}{l}\text { Experiencia laboral de } 5 \text { años y por lo menos } 3 \text { en el sector de } \\
\text { maquinaria industrial y servicios. }\end{array}$ \\
\hline & $\begin{array}{l}\text { Competencias técnicas: Office Office intermedio. Ingles a nivel } \\
\text { intermedio }\end{array}$ \\
\hline $\begin{array}{l}\text { ELEMENTOS DE } \\
\text { JUICIO: }\end{array}$ & $\begin{array}{l}\text { Líder, proactivo, organizado, capacidad para trabajar en equipo, } \\
\text { trabajo bajo presión. }\end{array}$ \\
\hline
\end{tabular}

Elaboración propia 
Tabla 5.11

Descripción del nuevo perfil del puesto Jefe Administrativo

\begin{tabular}{|c|c|}
\hline DESCRIPCIÓN DE PUES & TO DE TRABAJO: \\
\hline TITULAR: & \\
\hline DEPARTAMENTO: & Administración \\
\hline ÁREA: & Gestión \\
\hline RANGO DE PUESTO: & Jefe \\
\hline SUPERIOR: & Gerente General \\
\hline SUBORDINADOS: & Recepciones, asistentes administrativos, personal almacén. \\
\hline OBJETIVOS: & $\begin{array}{l}\text { Se encarga de la gestión financiera y contable de la empresa, así } \\
\text { como del bienestar del personal y la logística de los pedidos de } \\
\text { productos }\end{array}$ \\
\hline TAREAS: & $\begin{array}{l}\text { Controlar cajas chica propia y de las áreas de ventas y servicio } \\
\text { técnico. }\end{array}$ \\
\hline & Controlar y apoyar a la empresa encargada de la contabilidad \\
\hline & Controlar y actualizar las líneas de crédito por cliente \\
\hline & $\begin{array}{l}\text { Gestionar herramientas y servicios de uso cotidiano que permiten } \\
\text { el funcionamiento de la empresa (equipos de cómputo, telefonía } \\
\text { móvil, luz, agua, etc.) }\end{array}$ \\
\hline & $\begin{array}{l}\text { Registrar comprobantes de compra para elaboración de balances e } \\
\text { impuestos }\end{array}$ \\
\hline & $\begin{array}{l}\text { Gestionar las importaciones y exportaciones con los proveedores, } \\
\text { agencias de trasporte y agentes de aduanas }\end{array}$ \\
\hline & Elaborar los estados financieros de la empresa \\
\hline & Calcular y liquidar los impuestos de ley \\
\hline & $\begin{array}{l}\text { Coordinar gestión de pagos y manejo de cuentas con sectoristas } \\
\text { de bancos. }\end{array}$ \\
\hline & Elaborar y efectuar los planes de capacitación \\
\hline ATRIBUCIONES: & Representación técnico del negocio frente a los clientes \\
\hline RESPONSABILIDADES: & Aumentar el nivel de ventas de la línea de servicios \\
\hline & Respetar los presupuestos de venta asignados. \\
\hline REQUISITOS: & $\begin{array}{l}\text { Mínimo técnico - universitario carrera contabilidad o } \\
\text { administración, de preferencia con algún tipo especialización o } \\
\text { diplomado relacionado a operaciones o administración. servicios }\end{array}$ \\
\hline & $\begin{array}{l}\text { Experiencia laboral de } 5 \text { años manejando el área contable o } \\
\text { administrativa. }\end{array}$ \\
\hline & $\begin{array}{l}\text { Competencias técnicas: Office avanzado. Ingles a nivel } \\
\text { intermedio. Manejo de algún ERP. }\end{array}$ \\
\hline $\begin{array}{l}\text { ELEMENTOS DE } \\
\text { JUICIO: }\end{array}$ & tivo, organizado, trabajo bajo presión. \\
\hline
\end{tabular}

Elaboración propia 
Tabla 5.12

Descripción del nuevo perfil del puesto Supervisor de cobranzas

\begin{tabular}{|c|c|}
\hline \multicolumn{2}{|c|}{ DESCRIPCIÓN DE PUESTO DE TRABAJO: } \\
\hline $\begin{array}{l}\text { TITULAR: } \\
\text { DEPARTAMENTO: } \\
\text { ÁREA: } \\
\text { RANGO DE PUESTO: } \\
\text { SUPERIOR: } \\
\text { SUBORDINADOS: }\end{array}$ & $\begin{array}{l}\text { Administración } \\
\text { Supervisión } \\
\text { Supervisor } \\
\text { Gerente General } \\
\text { - }\end{array}$ \\
\hline OBJETIVOS: & $\begin{array}{l}\text { Este puesto debe velar por tener al día las cobranzas y aprobar los } \\
\text { créditos de acuerdo a los niveles autorizados por la gerencia } \\
\text { general. }\end{array}$ \\
\hline TAREAS: & $\begin{array}{l}\text { Aprobar las solicitudes de créditos del área de ventas } \\
\text { Gestionar el cobro de deudas con los clientes, evitando su } \\
\text { vencimiento } \\
\text { Mantener en niveles mínimos las deudas vencidas } \\
\text { Emitir reportes de cobranzas, periódicamente y a solicitud de la } \\
\text { gerencia general } \\
\text { Registrar cobranzas en el sistema. } \\
\text { Analizar la cartera morosa. } \\
\text { Realizar seguimiento a las letras por cobrar } \\
\text { Coordinar con la fuerza de ventas y facturación }\end{array}$ \\
\hline $\begin{array}{l}\text { ATRIBUCIONES: } \\
\text { RESPONSABILIDADES: }\end{array}$ & $\begin{array}{l}\text { Representación técnico del negocio frente a los clientes } \\
\text { Aumentar el nivel de ventas de la línea de servicios } \\
\text { Respetar los presupuestos de venta asignados. }\end{array}$ \\
\hline REQUISITOS: & $\begin{array}{l}\text { De preferencia con un grado técnico } \\
\text { Experiencia laboral de por lo menos } 3 \text { en el sector administrativo } \\
\text { y por lo menos } 1 \text { año en sector de cobranzas. } \\
\text { Competencias técnicas: Office intermedio }\end{array}$ \\
\hline $\begin{array}{l}\text { ELEMENTOS DE } \\
\text { JUICIO: }\end{array}$ & Proactivo, organizado, trabajo bajo presión, perseverante. \\
\hline
\end{tabular}

Elaboración propia 
Tabla 5.13

Descripción del nuevo perfil del puesto Administrador DEF S.A.C.

\begin{tabular}{|c|c|}
\hline DESCRIPCIÓN DE PU & Administrador DEF S.A.C. \\
\hline $\begin{array}{l}\text { TITULAR: } \\
\text { DEPARTAMENTO: } \\
\text { ÁREA: } \\
\text { RANGO DE PUESTO: } \\
\text { SUPERIOR: } \\
\text { SUBORDINADOS: }\end{array}$ & $\begin{array}{l}\text { Administración } \\
\text { Gestión } \\
\text { Administrador } \\
\text { Gerente General } \\
\text { Recepción DEF, técnicos, personal de reparto. }\end{array}$ \\
\hline OBJETIVOS: & $\begin{array}{l}\text { Este puesto tiene a su cargo la administración general y contacto } \\
\text { principal entre DEF S.A.C. y la Gerencia de ABC S.A.C. }\end{array}$ \\
\hline TAREAS: & $\begin{array}{l}\text { Velar por la atención adecuada y puntual de los clientes } \\
\text { Supervisar el despacho y la recepción de productos. } \\
\text { Mantener niveles de stock adecuados de repuestos y suministros } \\
\text { Manejar caja chica para gastos varios } \\
\text { Controlar cuentas por pagar y cobrar } \\
\text { Controlar las líneas de crédito } \\
\text { Elaborar y efectuar los planes de capacitación }\end{array}$ \\
\hline $\begin{array}{l}\text { ATRIBUCIONES: } \\
\text { RESPONSABILIDADES: }\end{array}$ & $\begin{array}{l}\text { Representación técnico del negocio frente a los clientes } \\
\text { Aumentar el nivel de ventas de la línea de servicios } \\
\text { Respetar los presupuestos de venta asignados. }\end{array}$ \\
\hline REQUISITOS: & $\begin{array}{l}\text { Mínimo técnico contable o administrador, de preferencia con } \\
\text { algún tipo especialización o diplomado relacionado a operaciones } \\
\text { o servicios. } \\
\text { Experiencia laboral de } 5 \text { años en el área administrativa. } \\
\text { Competencias técnicas: Office intermedio }\end{array}$ \\
\hline $\begin{array}{l}\text { ELEMENTOS DE } \\
\text { JUICIO: }\end{array}$ & vo, organizado, trabajo bajo presión. \\
\hline
\end{tabular}

Elaboración propia

Finalmente con la información desarrollada, se debe proceder con la elaboración e impresión del manual de funciones para vendedores, el cual servirá también para la capacitación del personal nuevo cuando se requiera. Para la elaboración de este manual la empresa deberá de tomar en consideración:

1. Información general del negocio: historia, misión, visión y valores.

2. Información de su actividad de mercado y los productos ofrecidos.

3. Detalle del organigrama, las funciones del personal y de los procedimientos actuales del negocio, cómo funciona el área de ventas y como se relaciona con las otras áreas. 
4. Información acerca del compromiso de la empresa para con sus empleados: planes de capacitación, beneficios, etc.

5. Reglamento interno general del negocio.

Este manual puede ser muy útil para todos los trabajadores, nuevos $\mathrm{y}$ existentes, ya que servirá como recordatorio y guía ante cualquier duda o eventualidad. Es importante mencionar que dicho manual tiene que ser continuamente actualizado cada vez que haya algún cambio organizacional o estratégico en el negocio y debe de cuidarse la confidencialidad de dicha guía, de manera que no termine en manos de la competencia.

\section{C) Implementación de un programa de capacitación}

\section{Marco teórico:}

Las capacitaciones son una de las mejores maneras de lograr un cambio positivo en una organización. Mediante ella se busca mejorar el presente y construir un mejor futuro para los negocios, además de contribuir con el desarrollo del personal y profesional de los individuos que forman parte de la empresa.

Una adecuada capacitación puede aumentar la productividad de los empleados y la rentabilidad de la organización. Asimismo se reduce la necesidad de supervisión y facilita que el personal se identifique con la empresa.

\section{Objetivo:}

Los objetivos que se buscan con la implementación de planes de capacitación son:

- Aumentar las ventas de la empresa: vendedores más preparados contarán con mayor cantidad de argumentos para cerrar una venta frente a la competencia.

- Aumentar y mejorar la recolección y manejo de la información: si el objetivo de la empresa es conseguir más y mejor información, debe de capacitar a las personas que la recolectan.

- Conseguir mayor eficiencia en el proceso de venta - back office y por lo tanto mejor servicio al cliente.

\section{Entregables:}

Cada proceso de capacitación tendrá una sumilla resumen, la cual indicará:

- El tema a tratar 
- Los logros que se quieren conseguir

- Cantidad de horas requeridas

- Encargado de la exposición

- Cantidad de participantes y cargos.

$\underline{\text { Personal involucrado: }}$

- Gerencia general

- Gerencia comercial

- Fuerza de ventas

- Encargado de almacén

- Apoyo administrativo

- Jefatura administrativa

- Recepciones

- Administrador de DEF S.A.C.

- Personal de reparto de DEF S.A.C.

- Staff técnico, incluyendo a la jefatura del área.

\section{Recursos necesarios:}

De igual manera que en el caso anterior, la empresa buscará recursos propios para llevar a cabo los cambios y soluciones que se plantean. Ente estos recursos destacamos los siguientes en relación a los planes de capacitación a efectuarse al personal relacionado al proceso de ventas:

- Sistema de contabilidad y control de inventarios existente: Siigo.

- Software existente, especialmente Microsoft Excel, Word y Power Point.

- Horas hombre del personal involucrado.

- Sala de reunión equipada (pizarras, proyector, PC)

- Bibliografía de fácil comprensión y de temas relacionados al proceso de ventas

- Material pedagógico, didáctico o de apoyo.

Actividades:

Todo objetivo debe de ser alcanzable y es por ello que la intensión es la de no abarcar demasiado en el tema de capacitaciones. En un primer momento las 
capacitaciones estarán destinadas, en este orden prioritario, a la fuerza de ventas, al área logística y al staff técnico de ABC S.A.C. y de DEF S.A.C..

a) Fuerza de ventas:

La fuerza de venta está conformada por todos aquellos vendedores, de maquinaria, consumibles o servicios, que tienen trato directo con el cliente. Así mismo se considera a la Gerencia Comercial como parte de la fuerza de ventas e incluso a la Gerencia General.

Los temas en los cuales se les capacitará son:

- Secuencia de la venta: búsqueda y calificación de prospectos, preparación para la visita, la visita, presentación y demostración y finalmente el seguimiento.

- Especificaciones de productos y servicios ofrecidos y la respectiva comparación con los principales competidores y sus respectivos productos y servicios.

- Trato al cliente y manejo de situaciones difíciles

- Desarrollo de competencias personales, automotivación y liderazgo

b) Área logística:

El área logística está conformada por el personal a cargo del almacén, las recepciones de los locales, el apoyo administrativo y su respectiva jefatura. Los temas en los cuales se les capacitarán son:

- Organización del almacén y uso del programa contable y de almacenaje con el que cuenta la empresa actualmente (Siigo), logrando así una mejor y más rápida atención a los clientes.

c) Staff técnico y personal de reparto de DEF S.A.C.:

La capacitación a este grupo de personas es puntual y está destinada a todos aquellos colaboradores que visitan el local del cliente para un determinado fin, que no necesariamente sean las ventas. Ellos son los técnicos de ABC S.A.C. que realizan una visita técnica, la respectiva jefatura, los encargados de DEF S.A.C. de la entrega y recojo de la mercadería e incluso a los vendedores.. 
El tema en el cual se les capacitará está relacionado a la recopilación de información relevante acerca del cliente, la cual puede incluir:

- Información cuantitativa importante: cuántas máquinas tiene, de que tipo son (marca, modelo), qué consumibles usa, cuántos empleados tiene, etc.

- Información cualitativa importante: básicamente juicios de valor del visitante respecto a los procesos e ideas del cliente: tiene mucho o poco trabajo, está contento con sus máquinas, consumibles y servicios, etc.

Definidos los temas y los participantes de las capacitaciones, se observa que la variedad es amplia, tanto en temas como en participantes. A fin de simplificar el plan y mantener una línea de trabajo unificada, se considerarán las siguientes observaciones como preceptos básicos al momento de diseñar las capacitaciones:

A. El momento:

Es importante que los intereses del aprendizaje no choquen con otros intereses de la organización. Es usual que la capacitación se lleve a cabo en horas de trabajo útiles para los empleados y que ellos, debido a esta capacitación, no pueda atender otras tareas solicitadas por sus jefes inmediatos. Esta situación es desfavorable tanto para el que recibe la capacitación como para la organización (por ejemplo, si se dicta una capacitación a la fuerza de ventas en horas de trabajo y suena el teléfono de uno de los vendedores, la organización podría perder una venta si es que no se contesta o el vendedor podría perder parte de la capacitación si es que contesta).

Para solucionar este conflicto se recomienda organizar las capacitaciones luego del horario de trabajo regular. Sin lugar a duda esto puede afectar los ánimos y la motivación del personal. Para ello la empresa deberá de preparar de manera adecuada la capacitación, de tal manera que no sea percibida como una obligación que les resta tiempo de descanso, sino como una actividad que fortalecerá su crecimiento profesional. Asimismo se debe ofrecer un refrigerio acorde con las preferencias del personal.

\section{B. Lenguaje:}


El lenguaje debe de ser simple y coloquial, pero a la vez debe de procurar utilizar la terminología técnica adecuada. Al ser una capacitación interna, la cual será dictada también por personal propio de la empresa, se cuenta con la ventaja de conocer a la audiencia y sus formas de comunicación, además de sus puntos débiles y fuertes. El facilitador debe de conseguir una comunicación efectiva y procurar introducir, poco a poco, una terminología adecuada.

\section{Material:}

Todo material entregado al personal debe ser claro, sencillo y didáctico. Nuevamente, aprovechando que el encargado de dar la capacitación tiene la ventaja de conocer muy bien a la audiencia, puede elaborar el material de manera que se entienda con claridad, haciendo especial énfasis en los puntos débiles y pasando de manera más superficial los puntos en los que se tiene buen conocimiento y desempeño.

La presentación debe de ser clara y debe de contemplar todos los aspectos importantes. Para ello es recomendable que pase por una serie de revisiones por parte de las Gerencias y Jefaturas, de tal manera que pueda ser lo más precisa y directa posible.

D. Técnica de aprendizaje y capacitación:

La capacitación debe manejarse como un taller. Considerando que las personas tienen diferentes habilidades de aprendizaje (algunos aprenden más con la lectura, otros escuchando, etc.), la capacitación debe de contemplar todas en la medida de lo posible. Es por ello que la secuencia de la capacitación debe de ser la siguiente:

- Entrega de material a presentar a fin de que los participantes puedan leerlo con anterioridad.

- Capacitación "en clase", la cual consiste en explicar el material previamente entregado y resolver cualquier duda que pueda surgir. En esta etapa es importante las comparaciones (de preferencia con productos de la competencia) y los ejemplos. 
- Capacitación “en campo". Se buscará realizar demostraciones de los productos y servicios explicados. Los participantes incluso deben de tener la opción de, por ejemplo, operar una de las máquinas.

- Repaso individual. Terminada la etapa de explicaciones y demostraciones, los participantes deberán de pasar por una evaluación de salida. Para ello contarán con unos días para repasar lo aprendido.

- Evaluación final, la cual será preparada por el facilitador y será tomada de forma individual. Esta evaluación debe de ser tomada en serio por los participantes y es por ello que se deben de guardar en cada archivo del personal calificado. En un futuro estas evaluaciones deben de ser sustento para un ascenso o para un despido del trabajador en cuestión.

Además se plantea de realizar una capacitación en cadena. Esto significa que los que reciben la capacitación serán los que la impartan en un futuro. Por ejemplo, el Gerente General le dará a la Gerencia Comercial una capacitación, o mejor dicho una breve directriz de cómo debería ser el curso que dictará la Gerencia Comercial a continuación (es importante mencionar que esta directriz no se presupuestará, ya que no significa mayor utilización de tiempo o materiales). Con esta directriz la Gerencia Comercial prepara el material y seguidamente realizará la capacitación a su Fuerza de Venta. El vendedor que obtenga la mejor evaluación será el encargado de dar la capacitación a los encargados de las recepciones. Para ello podrá reutilizar el material que preparó la Gerencia Comercial. De esta manera se asegura el aprendizaje replicando lo aprendido. Es importante mencionar que estas capacitaciones deben de contar con la supervisión inmediata del grado inmediatamente superior. Así, siguiendo con el ejemplo, cuando el asignado de la Fuerza de Venta esté dictando la capacitación a los encargados de las recepciones, es necesario que el Gerente Comercial esté presente y supervisando la entrega de conocimientos, por lo menos en algún momento de la capacitación.

\section{E. Evaluación:}

El proceso de capacitación a los empleados debe de contemplar, como ya se mencionó, una etapa de evaluación. La empresa debe de poder saber si es que este proceso de capacitación genera resultados positivos o negativos y en cuanto tiempo. 
Una manera de evaluar los resultados en un periodo de tiempo corto es utilizando pruebas luego de cada proceso de capacitación. Estas pruebas evaluarán lo que se ha enseñado y pretenden evidenciar el nivel de compromiso de los empleados en el periodo de capacitación. Incluso, se debería de tomar una prueba de entrada a cada participante a fin de evidenciar que tanto saben del tema antes y después.

Otra manera de evaluar los resultados, esta vez en un periodo de tiempo más largo, es implementando indicadores de éxito relacionados a este proceso puntual. Para ello se proponen los siguientes indicadores:

- Evolución de las ventas: comparar como varían las ventas luego de la capacitación. Es importante mencionar que este cambio posiblemente no sea inmediato y que las capacitaciones tendrán que ser reiteradas a fin de tener mejores resultados.

- Evolución de la cantidad de quejas de los clientes.

- Evolución de la cantidad de roturas de stock y la rotación del inventario.

- Evolución de la cantidad de información conseguida por personal que no es de ventas.

Finalmente la empresa debe de realizar una última evaluación y es con respecto a la capacitación en sí. Debe de realizar una encuesta de salida a los participantes a fin de tener una retroalimentación. Las preguntas no deben de ser muchas y lo ideal es que con ellas se pueda tener una evaluación del proceso precisa. Se sugieren:

- Califique del 1 al 5, siendo 1 el puntaje más bajo y 5 el mayor,

○ qué le pareció la capacitación en general

- que le pareció el facilitador

○ que le pareció el material entregado y mostrado

- Considera que la capacitación fue muy larga: SI / NO

- Qué fue lo que más le gusto:

- Que fue lo que menos le gusto:

- Comentario adicional:

F. Motivación y proyección: 
Como ya se mencionó, motivar a los empleados es clave para que este proceso de capacitaciones resulte y tenga el éxito esperado. Es por ello que se plantean las siguientes opciones para motivar a los empleados:

- Tener buenos resultados en las evaluaciones y por lo tanto también en su desarrollo como profesional puede ayudarlos a conseguir mayores responsabilidades y mejores condiciones salariales.

- Tener buenos resultados en las evaluaciones y también en su desarrollo profesional puede llevarlos a que la empresa les auspicie una nueva capacitación de su interés y dictada por terceros (por ejemplo cursos de inglés o diplomados).

Una vez detallado las consideraciones necesarias para elaborar los planes de capacitación, se desarrollarán las sumillas para cada uno de los cursos a impartir a cada área. Estas sumillas se pueden revisar en el Anexo $\mathrm{N}^{\circ} 4$.

Finalmente y de manera complementaria, a continuación se presenta el modelo de negocio Canvas correspondiente, tomando en cuenta las tres propuestas de solución desarrolladas: 
Figura 5.8

Nuevo modelo de negocio Canvas

\begin{tabular}{|c|c|c|c|c|}
\hline \multirow{3}{*}{$\begin{array}{c}\text { SOCIOS CLAVE: } \\
\text { - Proveedores de } \\
\text { maquinaria de excelente } \\
\text { calidad } \\
\text { - Proveedores que brinden } \\
\text { apoyo técnico a sus } \\
\text { distribuidores } \\
\text { - Entidades financieras }\end{array}$} & $\begin{array}{c}\text { ACTIVIDADES CLAVE: } \\
\text { - Proyección de ventas para } \\
\text { evitar roturas de stock } \\
\text { - Venta consultiva de maquinaria } \\
\text { (con garantía) y consumibles } \\
\text { - Venta del mejor servicio } \\
\text { técnico y de afilado } \\
\text { - Control de indicadores de }\end{array}$ & \multirow{3}{*}{$\begin{array}{l}\text { PROPUESTA DE VALOR: } \\
\text { - Productos de calidad } \\
\text { - Servicio técnico calificado } \\
\text { - Venta consultiva a cargo de } \\
\text { vendedores preparados } \\
\text { - Mayor disponibilidad de } \\
\text { productos en stock }\end{array}$} & $\begin{array}{l}\text { RELACIÓN CON CLIENTES: } \\
\text { - Visitas de vendedores con } \\
\text { mayor programación } \\
\text { - Invitaciones a ferias } \\
\text { - Comunicación de } \\
\text { promociones de una manera } \\
\text { más efectiva } \\
\text { - Eventual área de marketing }\end{array}$ & \multirow{3}{*}{$\begin{array}{c}\text { SEGMENTO DE MERCADO - } \\
\text { todo a nivel naciona: } \\
\text { - Emprendedores y pequeños } \\
\text { carpinteros: gran cantidad, } \\
\text { pero compras de bajo } \\
\text { volumen } \\
\text { - Empresas medianas: mayor } \\
\text { poder adquisitivo y más } \\
\text { constituidas. } \\
\text { - Empresas grandes: pocas en } \\
\text { el sector y las referentes en el } \\
\text { mercado. } \\
\text { - Clientes corporativos: alto } \\
\text { poder adquisitivo y capacidad } \\
\text { de negociación. } \\
\text { - Licitaciones: en su mayoría } \\
\text { encargadas por el estado. }\end{array}$} \\
\hline & servicio & & & \\
\hline & $\begin{array}{c}\text { RECURSOS CLAVE: } \\
\text { - Proveedores de calidad } \\
\text { - Fuerza de venta capacitada } \\
\text { - Líneas de crédito controladas } \\
\text { - Servicio técnico capacitado } \\
\text { - Knowhow técnico compartido } \\
\text { entre colaboradores } \\
\end{array}$ & & $\begin{array}{c}\text { CANALES: } \\
\text { - Venta directa en dos locales } \\
\text { comerciales } \\
\text { - Vendedores maquinaria y } \\
\text { consumibles (5) a nivel } \\
\text { nacional y por zonas }\end{array}$ & \\
\hline \multicolumn{2}{|c|}{$\begin{array}{c}\text { ESTRUCTURA DE COSTOS: } \\
\text { - Maquinaria y consumibles a vender } \\
\text { - Personal de ventas, administrativo y técnico } \\
\text { - Impuestos } \\
\text { - Recursos de marketing } \\
\text { - Planes de capacitación }\end{array}$} & \multicolumn{3}{|c|}{$\begin{array}{l}\text { FUENTE DE INGRESO: } \\
\text { - Venta de maquinaria, consumibles, servicio técnico y servicio de afilado. } \\
\text { - Pagos en efectivo, tarjeta de crédito, cheque o transferencia bancaria. } \\
\text { - Venta contado } \\
\text { - Venta a crédito con una política clara (por lo menos } 50 \% \text { de adelanto y } \\
\text { como máximo } 6 \text { letras). } \\
\text { - Conseguir una entidad financiera que ayude a los clientes en su } \\
\text { financiamiento. }\end{array}$} \\
\hline
\end{tabular}




\subsection{Planificación de la implementación de la solución}

\subsubsection{Determinación de objetivos y metas}

La implementación de estas 3 propuestas de manera simultánea puede traer inmediatos beneficios, de diferentes tipos, a la empresa. Si bien es cierto que determinar un número exacto es casi imposible y mucho tendrá que ver la voluntad de la empresa para conseguir los resultados, a continuación se exponen los resultados que se esperarían para fines del año 2013.

Aumento de las ventas:

En un primer momento el manejo de la información del mercado y el control sobre los encargados de las ventas podrán generar un impacto en el número de las ventas. Más adelante la capacitación de los vendedores, el manejo de la información interna y el tener procesos claramente establecidos, que permitan reducir tiempos de respuesta al cliente, serán determinantes para mantener los buenos resultados conseguidos en una primera instancia. Si bien es difícil determinar un porcentaje de aumento de las ventas, tanto el gerente general como comercial estiman que aplicando las soluciones planteadas, para fines del 2013 se podrá lograr aumentar el nivel de ventas registrado en el año 2012 en un 5\% (alrededor de los diez millones de nuevos soles). Para el siguiente año el objetivo sería más ambicioso ( $10 \%$ de crecimiento) por cuanto las soluciones implementadas deben traer mejores resultados. Esto significaría un gran logro para el negocio, especialmente si se considera la complicada coyuntura interna, la tendencia a la baja en la economía nacional y los nuevos controles internos que podrían desacelerar la venta en un primer momento de adaptación.

Mejora cartera cuentas por cobrar:

El hecho de poder contar con un proceso de ventas que establece claramente los procedimientos y las normas, una fuerza de ventas que entienda la importancia de mantener las cuentas por cobrar controladas mediante estos procesos y además gerencias y jefaturas comprometidas con el cumplimiento de los indicadores, permitirán, en un primer momento, no seguir aumentando de manera irresponsable las cuentas por cobrar. Más adelante esta cartera debería de tender a la baja y se espera que 
para fines del año 2013 se consiga tener un número inferior a los dos millones de nuevos soles.

Reducir niveles de mercadería:

Aumentar las ventas permitirá reducir los niveles de existencias, pero es importante que la empresa no sea víctima del pánico de posibles roturas de stock y no vuelva a tener los 3.2 millones de soles en mercadería registrados a mediados del año 2013. El hecho de plantear un adecuado proceso de ventas, que involucre los procedimientos de proyección y pedidos de mercadería, así como controles de productos y cifras mediante los indicadores, permitirá tener una logística adecuada y reducir este monto. La reducción en un primer momento dependerá de cómo evolucionen las ventas y es posible que para fines del año 2014 se consiga tener en stock 2.5 millones de soles en mercadería y que esta siga reduciéndose.

Reducir cantidad de empleados:

Procesos claros, metas claramente establecidas y controladas y un adecuado manejo de la información permitirá que la empresa pueda prescindir de algunos colaboradores que representan un alto porcentaje de los gastos de venta de la empresa. Para fines de 2013 se cree que estos nuevos procedimientos y reorganización organizacional pueden reducir hasta en $12 \%$ la planilla actual.

Reducción de gastos de venta y administrativos:

Mejores procesos logísticos, procedimientos claros y personal más preparado permite reducir la cantidad de errores relacionados a la venta y a las labores que lo respaldan administrativamente. La gerencia general estima que con una adecuada implementación de estos cambios y con un control exhaustivo, se podría alcanzar una meta de reducción de gastos de hasta un 30\% para fines del año 2014, en comparación con el año 2012. Para fines del año 2013 se debería de notar alguna mejora, por lo cual la meta será sólo de reducir en \% contra el año anterior.

Reducción de costos de venta:

Si se logra implementar un proceso de venta adecuado, en el cual se afinen los pronósticos de ventas, se podría optimizar los pedidos a los proveedores. De ser el caso, se podrían unificar algunos requerimientos que vengan del mismo país o de algún cercano, consiguiendo mejores costos de importación (traslados, desaduanaje, etc.). 
Actualmente el costo de venta representa, en promedio de los últimos 10 años, un $63 \%$. Estas mejoras deberían de significar una mejora en ese porcentaje en un periodo de tiempo medio. En un periodo más corto, digamos fines del año 2014, se debería de aspirar a tener un valor porcentual por debajo de ese promedio del $63 \%$.

\subsubsection{Elaboración del presupuesto general requerido para la ejecución de la solución}

Los principales costos que tendría que afrontar la empresa son dos. El primero de ello es el costo del trabajo elaborado por los consultores de este proyecto. $\mathrm{Si}$ se considera que la empresa tiene más de 60 años de funcionamiento y que en ese tiempo nunca ha logrado formular elementos básicos en sus procesos o que no cuenta con un sistema de recolección de información y análisis de la misma, es poco probable que el actual equipo de trabajo tenga la disciplina adecuada para llevar a cabo cualquier cambio. El trabajo de diagnóstico, planteamiento de soluciones adecuadas y reales e incluso el seguimiento de implementación de estas, son una suma de actividades que la empresa debería de evaluar contratar. En otras palabras, este costo se ocuparía de plantear los nuevos procesos e indicadores y entregar todo lo necesario para que puedan ser aplicados como una nueva función de los trabajadores de ABC S.A.C..

El otro costo en el cual la empresa incurrirá son los costos de oportunidad de su personal al momento de implementar los planes de capacitación. El equipo de ABC S.A.C. es el más preparado para ejecutar estas capacitaciones, por lo que el Gerente General y las demás Jefaturas y gerencias destinarán tiempo de trabajo en la implementación, el cual tiene un valor para la organización. Por ejemplo, el Gerente Comercial requerirá de cierta cantidad de horas para preparar una capacitación a su fuerza de ventas, para el dictado de la misma y la supervisión futura.

A continuación se muestran las tablas con el presupuesto requerido por la empresa para cubrir estos dos costos: 
Tabla 5.14

Presupuesto de la consultoría

\begin{tabular}{|l|c|c|}
\hline \multicolumn{1}{|c|}{ Concepto } & $\begin{array}{c}\text { Plazo } \\
\text { proyecto }\end{array}$ & Costo S/. \\
\hline Diagnóstico & 4 semanas & $3,000.00$ \\
\hline Planteamiento de soluciones adecuadas & 2 semanas & $3,000.00$ \\
\hline Seguimiento, asesoría para la implementación & 18 semanas & $10,000.00$ \\
\hline \multicolumn{1}{|c|}{ TOTAL } & $\mathbf{2 4}$ & $\mathbf{1 6 , 0 0 0 . 0 0}$ \\
\hline
\end{tabular}

Elaboración propia

Tabla 5.15

Presupuesto de horas-hombre por capacitación

\begin{tabular}{|c|c|c|c|c|c|c|c|}
\hline Puesto & Cantidad & \begin{tabular}{|l|} 
Sueldo prom. \\
mensual $(\mathrm{S} /)$.
\end{tabular} & $\begin{array}{c}\text { Costo } \\
\text { H-H }\end{array}$ & Tarea & $\begin{array}{c}\text { Cant. De } \\
\text { veces }\end{array}$ & \begin{tabular}{|l|} 
Cant. horas \\
requeridas
\end{tabular} & $\begin{array}{c}\text { Costo tarea } \\
(\mathrm{S} / .)\end{array}$ \\
\hline Gerencia Comercial & 1 & $6,000.00$ & 33.33 & $\begin{array}{l}\text { Preparación curso A1 } \\
\text { Dictado Curso A1 } \\
\text { Supervisión curso A1 } \\
\text { Preparación curso A2 } \\
\text { Dictado curso A2 } \\
\text { Supervisión curso A2 } \\
\text { Preparación curso A3 } \\
\text { Dictado curso A3 } \\
\text { Supervisión curso A3 } \\
\text { Apoyo dictado curso C1 } \\
\text { Apoyo dictado curso C2 }\end{array}$ & $\begin{array}{c}10 \\
10 \\
10 \\
1 \\
1 \\
10 \\
1 \\
1 \\
10 \\
1 \\
1 \\
\end{array}$ & \begin{tabular}{|l|}
3.00 \\
3.50 \\
1.17 \\
3.00 \\
3.00 \\
1.00 \\
3.00 \\
3.00 \\
1.00 \\
1.25 \\
1.25 \\
\end{tabular} & \begin{tabular}{|c|}
$1,000.00$ \\
$1,166.67$ \\
388.89 \\
100.00 \\
100.00 \\
333.33 \\
100.00 \\
100.00 \\
333.33 \\
41.67 \\
41.67 \\
\end{tabular} \\
\hline Vendedor & 5 & $\begin{array}{l}2,345.00 \\
2,345.00\end{array}$ & $\begin{array}{l}13.03 \\
13.03\end{array}$ & $\begin{array}{c}\text { Curso A1 } \\
\text { Curso A2 } \\
\text { Curso A3 } \\
\text { Dictado curso A1 } \\
\text { Dictado curso A2 } \\
\text { Dictado curso A3 } \\
\end{array}$ & $\begin{array}{c}10 \\
1 \\
1 \\
10 \\
1 \\
1 \\
\end{array}$ & $\begin{array}{l}3.50 \\
3.00 \\
3.00 \\
3.50 \\
3.00 \\
3.00 \\
\end{array}$ & $\begin{array}{c}2,279.86 \\
195.42 \\
195.42 \\
455.97 \\
39.08 \\
39.08 \\
\end{array}$ \\
\hline Jefatura Servicio Técnicd & 1 & $3,600.00$ & 20.00 & $\begin{array}{c}\text { Preparación curso C1 } \\
\text { Dictado curso C1 } \\
\text { Preparación curso C2 } \\
\text { Dictado curso C2 }\end{array}$ & $\begin{array}{l}1 \\
1 \\
1 \\
1\end{array}$ & $\begin{array}{l}2.00 \\
2.50 \\
2.00 \\
2.50\end{array}$ & $\begin{array}{l}40.00 \\
50.00 \\
40.00 \\
50.00\end{array}$ \\
\hline Tecnicos & $\begin{array}{l}6 \\
1 \\
\end{array}$ & $\begin{array}{l}1,650.00 \\
1,650.00 \\
\end{array}$ & $\begin{array}{l}9.17 \\
9.17 \\
\end{array}$ & $\begin{array}{c}\text { Curso C1 } \\
\text { Curso C2 } \\
\text { Apoyo Curso A1 } \\
\end{array}$ & $\begin{array}{c}1 \\
1 \\
10 \\
\end{array}$ & $\begin{array}{l}2.50 \\
2.50 \\
0.75 \\
\end{array}$ & $\begin{array}{c}137.50 \\
137.50 \\
68.75 \\
\end{array}$ \\
\hline Jefatura Administrativa & 1 & $3,500.00$ & 19.44 & $\begin{array}{c}\text { Preparación curso B1 } \\
\text { Curso B1 }\end{array}$ & $\begin{array}{l}1 \\
1\end{array}$ & $\begin{array}{l}2.00 \\
3.00\end{array}$ & $\begin{array}{l}38.89 \\
58.33\end{array}$ \\
\hline $\begin{array}{l}\text { Personal administrativo } \\
\text { Recepciones }\end{array}$ & $\begin{array}{l}5 \\
3\end{array}$ & $\begin{array}{l}1,700.00 \\
1,700.00\end{array}$ & $\begin{array}{l}9.44 \\
9.44\end{array}$ & $\begin{array}{l}\text { Curso B1 } \\
\text { Curso A1 } \\
\text { Curso A2 } \\
\text { Curso A3 } \\
\end{array}$ & $\begin{array}{c}1 \\
10 \\
1 \\
1\end{array}$ & $\begin{array}{l}3.00 \\
3.50 \\
3.00 \\
3.00\end{array}$ & $\begin{array}{c}141.67 \\
991.67 \\
85.00 \\
85.00 \\
\end{array}$ \\
\hline $\begin{array}{l}\text { Administrador TASAC } \\
\text { Personal reparto TASAC }\end{array}$ & $\begin{array}{l}1 \\
2\end{array}$ & $\begin{array}{l}1,700.00 \\
1,000.00\end{array}$ & $\begin{array}{l}9.44 \\
5.56\end{array}$ & $\begin{array}{l}\text { Curso B1 } \\
\text { Curso C1 } \\
\text { Curso C2 }\end{array}$ & $\begin{array}{l}1 \\
1 \\
1\end{array}$ & $\begin{array}{l}3.00 \\
2.50 \\
2.50\end{array}$ & $\begin{array}{l}28.33 \\
27.78 \\
27.78\end{array}$ \\
\hline \multicolumn{7}{|c|}{ TOTAL } & $8,918.58$ \\
\hline
\end{tabular}

Elaboración propia 
Tabla 5.16

Presupuesto de recursos para capacitaciones

\begin{tabular}{|c|c|c|c|}
\hline Cursos & Cantidad & Material & $\begin{array}{c}\text { Costo } \\
\text { (S/.) }\end{array}$ \\
\hline Curso A1 & 10 & $\begin{array}{c}\text { Copias y demás } \\
\text { materiales de exposición }\end{array}$ & 100.00 \\
\hline Curso A2 & 1 & $\begin{array}{c}\text { Copias y demás } \\
\text { materiales de exposición }\end{array}$ & 10.00 \\
\hline Curso A3 & 1 & $\begin{array}{c}\text { Copias y demás } \\
\text { materiales de exposición }\end{array}$ & 10.00 \\
\hline Curso B1 & 1 & $\begin{array}{c}\text { Copias y demás } \\
\text { materiales de exposición }\end{array}$ & 10.00 \\
\hline Curso C1 & 1 & $\begin{array}{c}\text { Copias y demás } \\
\text { materiales de exposición }\end{array}$ & 10.00 \\
\hline Curso C2 & 1 & $\begin{array}{c}\text { Copias y demás } \\
\text { materiales de exposición }\end{array}$ & 10.00 \\
\hline \multicolumn{4}{|c|}{ TOTAL } \\
\hline
\end{tabular}

Elaboración propia

Tabla 5.17

Presupuesto de liquidación de personal de ventas

\begin{tabular}{|c|c|l|}
\hline Cargo & $\begin{array}{c}\text { Monto liquidación } \\
\text { (S/.) }\end{array}$ & \multicolumn{1}{c|}{ Observación } \\
\hline Jefatura Consumibles & 0.00 & $\begin{array}{l}\text { Con contrato a plazo fijo, no se } \\
\text { renovará }\end{array}$ \\
\hline Vendedor Consumibles & $20,560.00$ & 8 años de trabajo \\
\hline TOTAL & $\mathbf{2 0 , 5 6 0 . 0 0}$ & \\
\hline
\end{tabular}

\section{Elaboración propia}

Sumando la inversión requerida en las cuatro tablas se llega a una inversión total de $\mathrm{S} / .45,628.58$

\subsubsection{Cronograma de implementación de la solución}

A continuación se muestra el cronograma de ejecución de las alternativas de solución. Es importante mencionar que no sé están especificando las tareas de seguimiento de implementación en lo que respecta a procedimientos ni tampoco la recolección de datos en lo referente a indicadores de gestión.

Así mismo en lo que respecta a las capacitaciones técnicas, solo se está indicando las dos primeras capacitaciones, pero se entiende que las demás mantendrán la misma secuencia y cronograma. La Gerencia Comercial deberá de precisar las fechas en que se ejecutarán. 
Figura 5.9

Diagrama de Gantt para la implementación de las soluciones

\begin{tabular}{|c|c|c|c|c|c|c|c|c|c|c|c|c|c|c|c|c|c|c|c|c|c|c|c|c|c|c|c|c|}
\hline \multirow[t]{2}{*}{ Id } & \multirow[t]{2}{*}{ Nombre de tarea } & \multirow[t]{2}{*}{ Duración } & \multirow{2}{*}{\multicolumn{2}{|c|}{ Comienzo Fin }} & \multicolumn{10}{|c|}{04 ago '13 } & \multicolumn{7}{|c|}{11 ago '13 } & \multicolumn{7}{|c|}{18 ago '13 } \\
\hline & & & & & J & $\mathbf{v}$ & $S$ & D & L & $\mathbf{M}$ & $\mathbf{x}$ & J & $\mathbf{v}$ & $S$ & D & $\mathbf{L}$ & $\mathbf{M}$ & $\mathbf{X}$ & J & v & $\mathrm{S}$ & D & L & $\mathbf{M}$ & $\mathbf{x}$ & J & $\mathbf{v}$ & $\mathrm{S}$ \\
\hline 1 & $\begin{array}{l}\text { Implementación de sistema de } \\
\text { indicadores }\end{array}$ & 4 días & $\begin{array}{l}\text { jue } \\
01 / 08 / 13\end{array}$ & $\operatorname{mar}_{06 / 08 / 13}$ & & & & & & & & & & & & & & & & & & & & & & & & \\
\hline 2 & $\begin{array}{l}\text { Revisión interna de diagnóstico en } \\
\text { cada área y planteamiento de } \\
\text { indicadores y metas }\end{array}$ & 2 dias & $\begin{array}{l}\text { jue } \\
01 / 08 / 13\end{array}$ & $\begin{array}{l}\text { vie } \\
02 / 08 / 13\end{array}$ & & & & & & & & & & & & & & & & & & & & & & & & \\
\hline 3 & $\begin{array}{l}\text { Revisión de la GerenciaGeneral con } \\
\text { jefes de áreay aprobación de }\end{array}$ & 1 dia & $\begin{array}{l}\operatorname{lun} \\
05 / 08 / 13\end{array}$ & $\operatorname{lun}_{05 / 08 / 13}$ & & & & & & & & & & & & & & & & & & & & & & & & \\
\hline 4 & $\begin{array}{l}\text { Comunicación de nuevos indicadores } \\
\text { a demás gerencias y jefaturas }\end{array}$ & s 1 dia & $\begin{array}{l}\operatorname{mar} \\
06 / 08 / 13\end{array}$ & $\begin{array}{l}\operatorname{mar} \\
06 / 08 / 13\end{array}$ & & & & & & & & & & & & & & & & & & & & & & & & \\
\hline 5 & $\begin{array}{l}\text { Capacitación de personal a cargo de } \\
\text { alimentar de información el cuadro } \\
\text { de mando integral }\end{array}$ & 1 dia & $\begin{array}{l}\operatorname{mar} \\
06 / 08 / 13\end{array}$ & $\begin{array}{l}\operatorname{mar} \\
06 / 08 / 13\end{array}$ & & & & & & है & & & & & & & & & & & & & & & & & & \\
\hline 6 & $\begin{array}{l}\text { Creación de procedimientos del } \\
\text { proceso de ventas }\end{array}$ & 32 días & $\begin{array}{l}\text { mié } \\
\mathbf{0 7 / 0 8 / 1 3}\end{array}$ & $\begin{array}{l}\text { jue } \\
\text { 19/09/13 }\end{array}$ & & & & & & & & & & & & & & & & & & & & & & & & \\
\hline 7 & $\begin{array}{l}\text { Formulación equipos proceso de } \\
\text { pronóstico y comunicación de plan }\end{array}$ & 1 dia & $\begin{array}{l}\text { mié } \\
07 / 08 / 13\end{array}$ & $\begin{array}{l}\text { mié } \\
07 / 08 / 13\end{array}$ & & & & & & & & & & & & & & & & & & & & & & & & \\
\hline 8 & Revisión proceso de pronóstico & 2 dias & jue 08/08/ & / vie 09/08 & & & & & & & & & & & & & & & & & & & & & & & & \\
\hline 9 & $\begin{array}{l}\text { Planteamiento de proceso ideal de } \\
\text { pronóstico }\end{array}$ & 4 dias & $\begin{array}{l}\operatorname{lum} \\
12 / 08 / 13\end{array}$ & $\begin{array}{l}\text { jue } \\
15 / 08 / 13\end{array}$ & & & & & & & & & & & & & & & & & & & & & & & & \\
\hline 10 & $\begin{array}{l}\text { Comunicación del nuevo proceso de } \\
\text { pronóstico }\end{array}$ & 1 dia & $\begin{array}{l}\text { vie } \\
16 / 08 / 13\end{array}$ & $\begin{array}{l}\text { vie } \\
16 / 08 / 13\end{array}$ & & & & & & & & & & & & & & & & & & & & & & & & \\
\hline 11 & $\begin{array}{l}\text { Implementar nuevo proceso de } \\
\text { pronóstico }\end{array}$ & 5 dias & $\begin{array}{l}\operatorname{lum} \\
19 / 08 / 13\end{array}$ & $\begin{array}{l}\text { vie } \\
23 / 08 / 13\end{array}$ & & & & & & & & & & & & & & & & & & & & & & & & \\
\hline
\end{tabular}

Elaboración propia 
Figura 5.10

Continuación del diagrama de Gantt para la implementación de las soluciones (I)

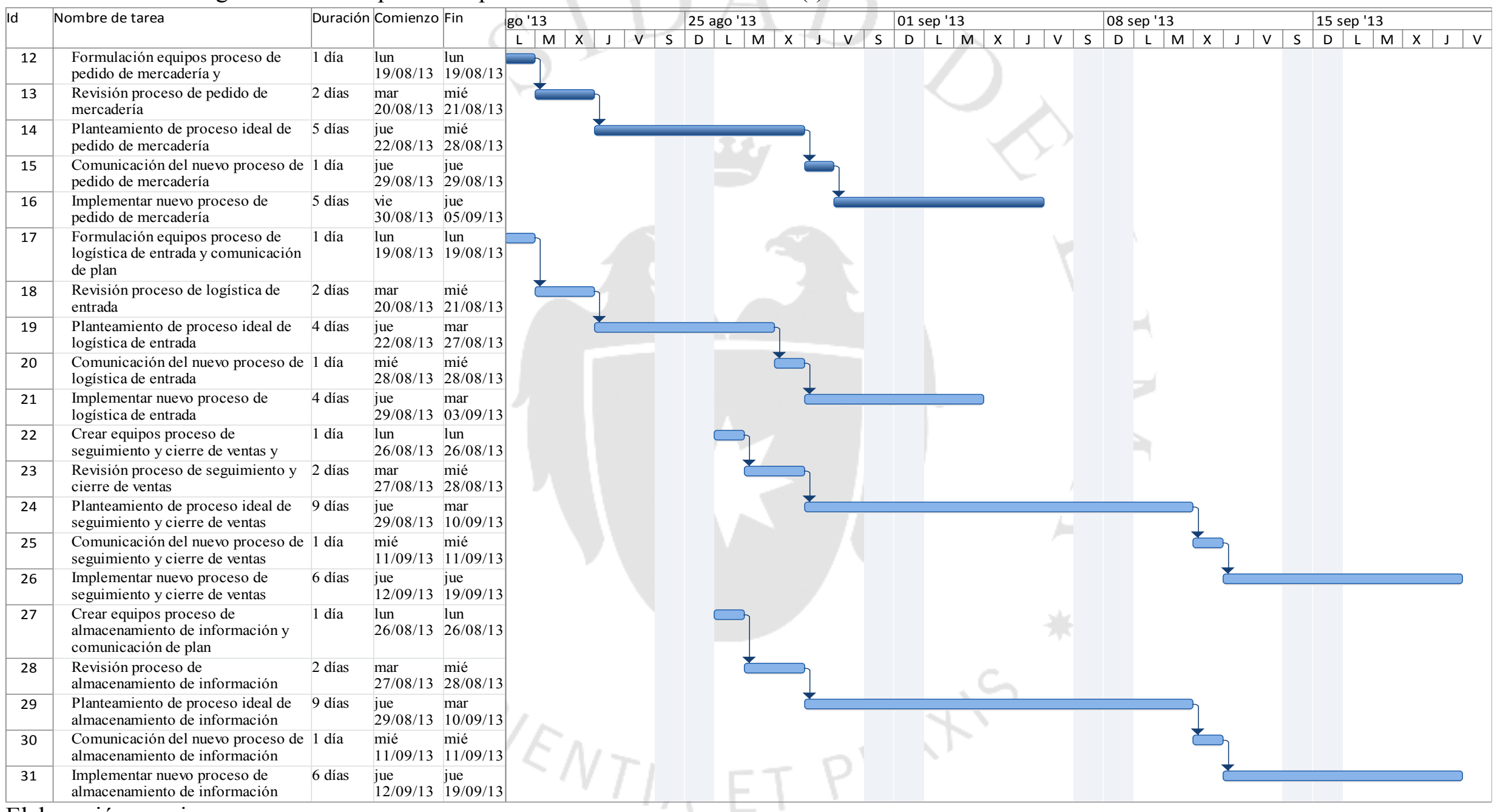

Elaboración propia 
Figura 5.11

Continuación del diagrama de Gantt para la implementación de las soluciones (II)

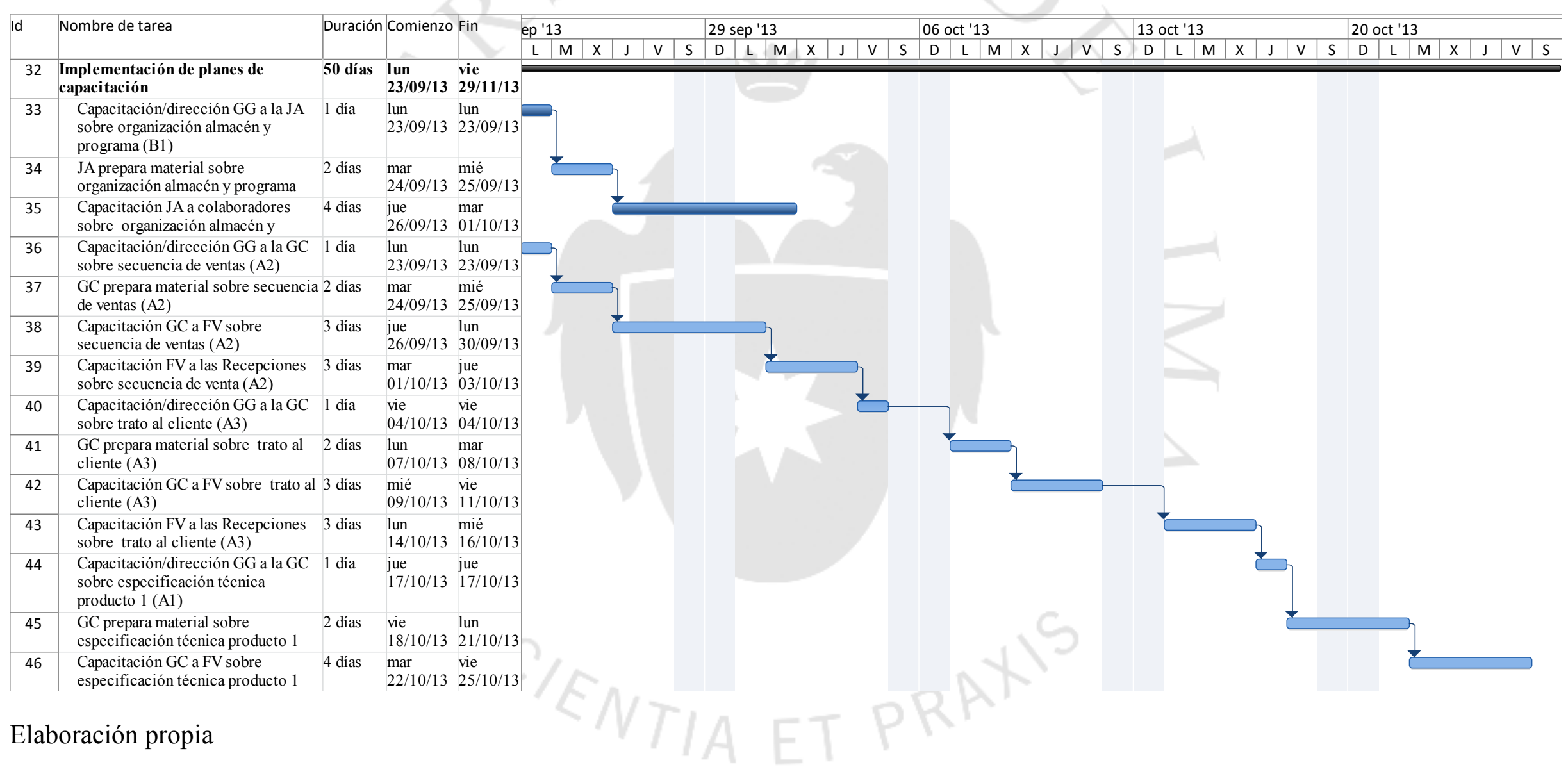


Figura 5.12

Continuación del diagrama de Gantt para la implementación de las soluciones (III)

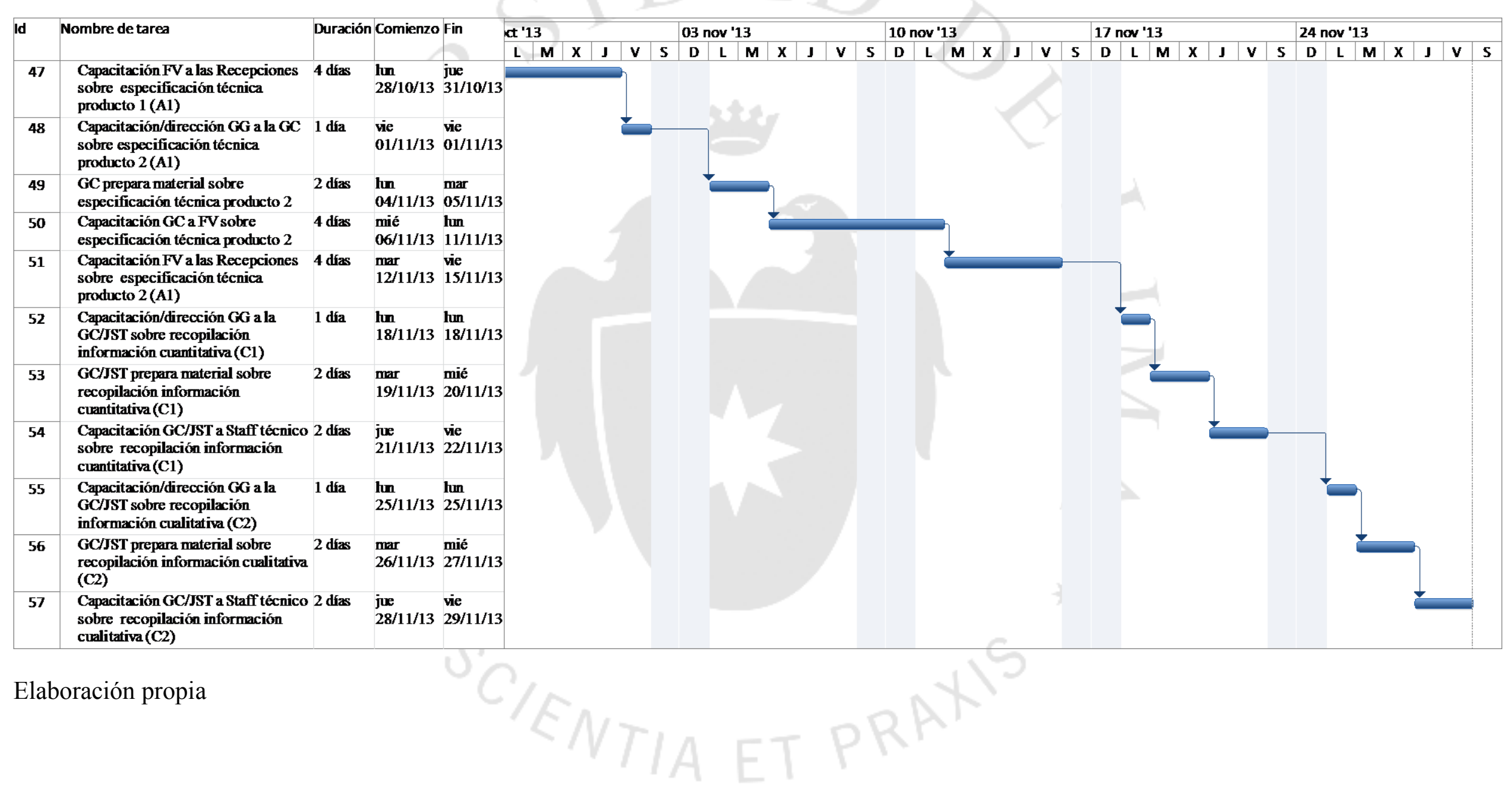




\section{CAPITULO VI. EVALUACIÓN DE LA SOLUCIÓN Y BENEFICIOS ESPERADOS}

\subsection{Evaluación económica de la solución}

La empresa financiará la solución con recursos propios, por lo cual la evaluación a realizar sólo será económica. Con la intensión de evaluar cómo podrían afectar las soluciones planteadas a la empresa en un plazo de tiempo corto, se presentarán tres escenarios posibles: el positivo, el conservador y el negativo.

Los tres escenarios manejarán las mismas variables (internas y externas) y serán estas las que determinen las cifras que se mostrarán en los Estados de Resultados comparativos (diciembre de 2013 y diciembre de 2014).

Las variables a tener en cuenta son:

- Compromiso de la gerencia: Todo cambio requiere de un plan y un líder que lo pueda desarrollar con éxito. La figura de la Gerencia General en un primer momento y luego de las otras jefaturas, es determinante. Ellos deben de ser los primeros comprometidos con el negocio y con los cambios que se plantean para él. Este compromiso debe de ser transmitido a todos los colaboradores a fin de conseguir las metas planteadas. Si es que no se logra involucrar a las Gerencias en estos cambios, estos probablemente nunca se lleguen a efectuar.

- Compromiso del personal: Igual de importante que los líderes de cada organización, son los equipos que la conforman. Contar con personal motivado y creyente en el cambio es determinante para lograr resultados positivos. Si el equipo de trabajo no cree en los cambios que se están realizando, es probable que no colaboren en la 
elaboración de los mismos o, incluso, busquen la manera de sabotearlos y así no cambiar sus hábitos de trabajo.

- Intervención bancaria: Sin lugar a dudo uno de los mayores temores de la empresa es que los Bancos decidan, dada la precaria situación que vive el negocio, cortar las líneas de crédito. Si esto llega a pasar antes de ver los resultados de las soluciones propuestas, sería nefasto para la empresa y prácticamente significaría la bancarrota. La Gerencia, encargada de las negociaciones con los bancos, debe de manejar este tema con mucho cuidado y ver de no levantar sospechas y temores en sus sectoristas.

- Situación económica del sector o en la economía: Dado que la empresa depende de las ventas que se realicen, la situación económica del país, o incluso de sectores relacionados como lo son la construcción o la manufactura, es clave para el futuro de cualquier negocio. Un mal desempeño económico del país o un sector puede determinar el fracaso de cualquier negocio y es por ello que siempre se tiene contar con un plan de contingencia. Aquellos negocios que puedan aplicar este plan y soportar ese mal momento, tendrán una excelente oportunidad de crecimiento una vez que las cosas mejoren, especialmente si es que sus competidores no tuvieron una respuesta tan acertada.

- Situación política del país: Considerando que la empresa se ve afectada por las decisiones políticas y legales que se tomen, es importante mencionar esta variable. Un cambio legislativo en relación a pagos de impuestos, en el trato de las carteras de cuentas por cobrar o pagar o incluso en temas laborales de los trabajadores, puede afectar a la empresa de manera positiva o negativa.

- Entorno tecnológico: Si bien es cierto que de momento, según refirieron algunos trabajadores de la empresa, el sector está lejos de tener una revolución tecnológica que pueda significar una oportunidad o una amenaza en el corto plazo, es una 
variable que será tomada en cuenta, ya que puede impactar de manera significativa en las ventas del negocio.

Es importante mencionar que el entorno social de los competidores, clientes y trabajadores no será tomado en cuenta para este apartado, ya que para que estos cambien, de manera positiva o negativa, implica mucho tiempo de transición. A diferencia del entorno tecnológico, las variables sociales requieren más tiempo de maduración y es casi imposible empezar un cambio por un golpe de suerte, como lo puede ser un descubrimiento tecnológico.

Una vez detalladas las variables que afectarán a los distintos escenarios, se procederá a explicar cómo variará cada escenario con respecto al otro y las consideraciones que se tendrán en cuenta para la construcción de los Estados de Resultados comparativos.

\section{A) Escenario Positivo:}

El escenario positivo, como su nombre lo indica, mostrará la mejor de las situaciones. Las variables, tanto internas como externas, mostrarán excelentes resultados, los cuales favorecerán a la empresa. El compromiso de la gerencia y de los trabajadores será completo, lo que permitirá conseguir una rápida aplicación de las soluciones propuestas, generando la posibilidad de aumentar en las ventas y reducir los gastos; los resultados serán excelentes, por lo que los bancos seguirán apoyando económicamente a la empresa; el sector tendrá un repunte, lo que permitirá que efectivamente las ventas puedan aumentar e incluso, permitirá el ingreso de nuevos equipos, los cuales serán muy buscados por los clientes finales en un primer momento de lanzamiento. Así, este escenario podrá reportar:

- Incremento en 4\% de las ventas correspondientes a maquinaria y consumibles para el año 2013 con respecto a la proyección sin mejora que mantiene el nivel de ventas del año anterior, alcanzando los 10 millones de nuevos soles. En el año 2014 se podría registrar un nuevo aumento de $10 \%$ con respecto al año anterior, alcanzando los 11 millones de soles (ambos incrementos de acuerdo a lo estimado por la gerencia general). 
- Reducción en 5\% de los gastos de venta contra el año anterior en el 2013 y de $15 \%$ en el 2014, gracias a menos personal y mejores procesos de control (meta de la gerencia comercial)

B) Escenario conservador:

Este escenario mostrará que la situación económica del país y del sector mantiene la tendencia y podría significar una leve alza de las ventas; la situación política tampoco será un factor determinante en los próximos años y no habrá un descubrimiento tecnológico que pueda revolucionar el sector. En cuanto al compromiso de la gerencia y del personal, este aumentará, ya que son conscientes de que la empresa requiere un cambio, pero no será total como en el caso anterior, por lo cual se alcanzarían resultados más bajos.

\section{Este escenario podría reportar:}

- Las ventas correspondientes a maquinaria y consumibles en el año 2013 aumentarán levemente (2\%) llegando a los 9,9 millones de soles a diciembre de 2013 y a los 10.1 millones a diciembre de 2014, gracias a un aumento similar.

- Reducción en 3\% de los gastos de ventas en el 2013 y 8\% en el 2014, en comparación con el año 2012, gracias a mejores controles y menos personal.

\section{C) Escenario negativo:}

En este caso se planteará un escenario desfavorable para el negocio. El compromiso de la gerencia y del personal será bajo, por lo tanto las soluciones planteadas serán aplicadas pero en menor medida y requiriendo más tiempo; la situación política y económica del país y del sector se mantendrá igual y por lo tanto las ventas también. Este escenario podría reportar:

- Las ventas en el año 2013 y del año 2014 se mantendrán igual a las obtenidas a diciembre de 2012, esto significa 9.7 millones de soles por año.

- Leve reducción de los gastos de venta ( $2 \%$ en 2013 y $6 \%$ en $2014 \%$ ) gracias a mejores controles y menos personal. 
Para la elaboración de los estados de resultados, consideraremos el mismo nivel de gastos e ingresos financieros del año 2012, así como el margen bruto promedio de los últimos años (37\%), puesto que en el año 2012 el costo de ventas fue demasiado alto, debido a un ajuste de Estados Financieros. Asimismo, no consideramos depreciación ya que la misma no es parte de la evaluación económica de las soluciones propuestas. A continuación se muestra el cuadro resumen:

Tabla 6.1

Estados de resultados por escenarios

\begin{tabular}{|c|c|c|c|c|c|c|c|}
\hline \multirow[b]{3}{*}{ EERR } & \multirow{3}{*}{$\begin{array}{l}2013 \text { sin } \\
\text { mejora }\end{array}$} & \multicolumn{6}{|c|}{ Escenarios con mejora } \\
\hline & & \multicolumn{2}{|c|}{ Positivo } & \multicolumn{2}{|c|}{ Conservador } & \multicolumn{2}{|c|}{ Negativo } \\
\hline & & 2013 & 2014 & 2013 & 2014 & 2013 & 2014 \\
\hline $\begin{array}{l}\text { Ingreso por } \\
\text { ventas }\end{array}$ & $9,738,372$ & $10,083,093$ & $11,091,402$ & $9,910,733$ & $10,108,947$ & $9,738,372$ & $9,738,372$ \\
\hline Costo de ventas & $6,135,174$ & $6,352,349$ & $6,987,584$ & $6,243,762$ & $6,368,637$ & $6,135,174$ & $6,135,174$ \\
\hline Utilidad bruta & $3,603,198$ & $3,730,744$ & $4,103,819$ & $3,666,971$ & $3,740,310$ & $3,603,198$ & $3,603,198$ \\
\hline $\begin{array}{l}\text { Gastos de } \\
\text { ventas }\end{array}$ & $2,272,539$ & $2,158,912$ & $1,931,658$ & $2,204,363$ & $2,090,736$ & $2,227,088$ & $2,136,187$ \\
\hline $\begin{array}{l}\text { Gastos } \\
\text { administrativos }\end{array}$ & $1,152,481$ & $1,152,481$ & $1,152,481$ & $1,152,481$ & $1,152,481$ & $1,152,481$ & $1,152,481$ \\
\hline $\begin{array}{l}\text { Utilidad } \\
\text { Operativa }\end{array}$ & 178,178 & 419,351 & $1,019,680$ & 310,127 & 497,094 & 223,628 & 314,530 \\
\hline $\begin{array}{l}\text { Ingresos } \\
\text { financieros }\end{array}$ & $1,531,557$ & $1,531,557$ & $1,531,557$ & $1,531,557$ & $1,531,557$ & $1,531,557$ & $1,531,557$ \\
\hline $\begin{array}{l}\text { Gastos } \\
\text { Financieros }\end{array}$ & $1,145,635$ & $1,145,635$ & $1,145,635$ & $1,145,635$ & $1,145,635$ & $1,145,635$ & $1,145,635$ \\
\hline $\begin{array}{l}\text { Utilidad antes } \\
\text { de impuestos }\end{array}$ & 564,100 & 805,273 & $1,405,602$ & 696,049 & 883,016 & 609,550 & 700,452 \\
\hline Impuesto & 169,230 & 241,582 & 421,681 & 208,815 & 264,905 & 182,865 & 210,136 \\
\hline Utilidad Neta & 394,870 & 563,691 & 983,921 & 487,234 & 618,111 & 426,685 & 490,316 \\
\hline
\end{tabular}

Fuente: ABC S.A.C. y propia Elaboración propia

Es importante mencionar que en ninguno de estos escenarios se está evaluando una mejora en los promedios de las relaciones de ventas vs costo de ventas, ventas vs gastos administrativos. Si la empresa logra aplicar los procesos nuevos de manera adecuada se lograrán mejores eficiencias, los que reducirá los niveles de costos y gastos, logrando mejores márgenes. Por ejemplo, el promedio de los últimos 10 años de la relación entre ventas y costo de ventas es de 0.63 . Si se consigue mejorar los procesos, obteniendo un 
diagnóstico más acertado, el cual permita consolidar más pedidos, reduciendo los gastos de importación, esa relación podría mejorar quizás a 0.61. Lamentablemente medir todas esas variables no es posible y solo se determinarán mejoras más adelante, conforme se vayan midiendo los resultados de las soluciones propuestas.

Conseguidos los Estados de Resultados proyectados, pasamos a calcular un Estado de Resultados que calcule el diferencial entre los proyectados y la base, que en este caso será un hipotético resultado a diciembre 2013, en el caso en el que no se hubiera ejecutado la mejora. Este resultado se calcula con los mismos niveles de venta y de gasto que en el año 2012, ajustando el costo de ventas de acuerdo al margen promedio.

El cuadro se muestra a continuación:

Tabla 6.2

Variación de EE.RR.

\begin{tabular}{|l|c|c|c|c|c|c|}
\hline \multirow{2}{*}{ EERR } & \multicolumn{2}{c|}{ Positivo } & \multicolumn{2}{c|}{ Conservador } & \multicolumn{2}{c|}{ Negativo } \\
\cline { 2 - 7 } & $\mathbf{2 0 1 3}$ & $\mathbf{2 0 1 4}$ & $\mathbf{2 0 1 3}$ & $\mathbf{2 0 1 4}$ & $\mathbf{2 0 1 3}$ & $\mathbf{2 0 1 4}$ \\
\hline Ingreso por ventas & 344,721 & $1,353,030$ & 172,361 & 370,575 & 0 & 0 \\
\hline Costo de ventas & 217,174 & 852,409 & 108,587 & 233,462 & 0 & 0 \\
\hline Utilidad bruta & 127,547 & 500,621 & 63,773 & 137,113 & 0 & 0 \\
\hline Gastos de ventas & $-113,627$ & $-340,881$ & $-68,176$ & $-181,803$ & $-45,451$ & $-136,352$ \\
\hline Gastos administrativos & 0 & 0 & 0 & 0 & 0 & 0 \\
\hline Utilidad Operativa & 241,174 & 841,502 & 131,950 & 318,916 & 45,451 & 136,352 \\
\hline Ingresos financieros & 0 & 0 & 0 & 0 & 0 & 0 \\
\hline Gastos Financieros & 0 & 0 & 0 & 0 & 0 & 0 \\
\hline $\begin{array}{l}\text { Utilidad antes de } \\
\text { impuestos }\end{array}$ & $\mathbf{2 4 1 , 1 7 4}$ & $\mathbf{8 4 1 , 5 0 2}$ & $\mathbf{1 3 1 , 9 5 0}$ & $\mathbf{3 1 8 , 9 1 6}$ & $\mathbf{4 5 , 4 5 1}$ & $\mathbf{1 3 6 , 3 5 2}$ \\
\hline Impuesto & 72,352 & 252,451 & 39,585 & 95,675 & 13,635 & 40,906 \\
\hline Utilidad Neta & $\mathbf{1 6 8 , 8 2 2}$ & $\mathbf{5 8 9 , 0 5 1}$ & $\mathbf{9 2 , 3 6 5}$ & $\mathbf{2 2 3 , 2 4 1}$ & $\mathbf{3 1 , 8 1 6}$ & $\mathbf{9 5 , 4 4 7}$ \\
\hline
\end{tabular}

Fuente: ABC S.A.C.

Elaboración propia

Con la variación del resultado del ejercicio, se procede a preparar tres flujos de caja, uno para cada escenario. Estos flujos de caja serán necesarios para poder calcular el VAN y el TIR de la mejora, el positivo, el conservador y el negativo. 
Para la elaboración del flujo de caja se ha tenido en cuenta las siguientes condiciones:

- El incremento de las ventas y del costo de ventas recién se considera desde el mes de setiembre. Esto se debe a que el proceso de diagnóstico y planteamiento de soluciones se realizará en el mes de junio y recién en el mes de julio se empezarán a ejecutar las mejoras. Se podrían obtener resultados favorables desde setiembre de 2013 según lo conversado con la gerencia general.

- De igual manera, los ahorros en los gastos de ventas recién se considerarán desde el mes de setiembre en todos los escenarios.

- En cuanto a la inversión total, los montos correspondientes a las fases de diagnóstico y de planteamiento de las soluciones será desembolsado en el mes de julio. En los meses siguientes y hasta diciembre de 2013 se dividirá la suma del seguimiento y asesoría de la implementación, los costos de oportunidad para las capacitaciones y el material necesario.

- Asimismo, se considera el pago de la liquidación del personal (S/. 20,560.00) en el primer mes de implementación (julio).

- La evaluación se realiza a 18 meses.

A continuación se muestran los flujos para cada uno de los escenarios planteados: 
Tabla 6.3

Flujo de caja escenario positivo (S/.)

\begin{tabular}{|l|r|r|r|r|r|r|r|r|r|}
\hline FLUJO DE CAJA & jul-13 & $\mathbf{a g 0 - 1 3}$ & sep-13 & oct-13 & nov-13 & dic-13 & ene-14 & feb-14 & mar-14 \\
\hline INGRESOS & & & & & & & & & \\
\hline Incremento de Ventas & & & 86,180 & 86,180 & 86,180 & 86,180 & 112,753 & 112,753 & 112,753 \\
\hline Ahorro de gastos de ventas & & & 28,407 & 28,407 & 28,407 & 28,407 & 28,407 & 28,407 & 28,407 \\
\hline TOTAL INGRESOS & $\mathbf{0}$ & $\mathbf{0}$ & $\mathbf{1 1 4 , 5 8 7}$ & $\mathbf{1 1 4 , 5 8 7}$ & $\mathbf{1 1 4 , 5 8 7}$ & $\mathbf{1 1 4 , 5 8 7}$ & $\mathbf{1 4 1 , 1 5 9}$ & $\mathbf{1 4 1 , 1 5 9}$ & $\mathbf{1 4 1 , 1 5 9}$ \\
\hline EGRESOS & & & & & & & & \\
\hline Increm. de costo de ventas & & & $-54,294$ & $-54,294$ & $-54,294$ & $-54,294$ & $-71,034$ & $-71,034$ & $-71,034$ \\
\hline Incremento de IR & & & $-18,088$ & $-18,088$ & $-18,088$ & $-18,088$ & $-21,038$ & $-21,038$ & $-21,038$ \\
\hline Inversión inicial & $-26,560$ & & & & & & & & \\
\hline Capacitaciones y mant. & & $-3,816$ & $-3,816$ & $-3,816$ & $-3,816$ & $-3,816$ & & & \\
\hline TOTAL EGRESOS & $\mathbf{- 2 6 , 5 6 0}$ & $\mathbf{- 3 , 8 1 6}$ & $\mathbf{- 7 6 , 1 9 7}$ & $\mathbf{- 7 6 , 1 9 7}$ & $\mathbf{- 7 6 , 1 9 7}$ & $\mathbf{- 7 6 , 1 9 7}$ & $\mathbf{- 9 2 , 0 7 2}$ & $\mathbf{- 9 2 , 0 7 2}$ & $\mathbf{- 9 2 , 0 7 2}$ \\
\hline FLUJO NETO & $\mathbf{- 2 6 , 5 6 0}$ & $\mathbf{- 3 , 8 1 6}$ & $\mathbf{3 8 , 3 9 0}$ & $\mathbf{3 8 , 3 9 0}$ & $\mathbf{3 8 , 3 9 0}$ & $\mathbf{3 8 , 3 9 0}$ & $\mathbf{4 9 , 0 8 8}$ & $\mathbf{4 9 , 0 8 8}$ & $\mathbf{4 9 , 0 8 8}$ \\
\hline
\end{tabular}

\begin{tabular}{|c|c|c|c|c|c|c|c|c|c|}
\hline FLUJO DE CAJA & abr-14 & may-14 & jun-14 & jul-14 & ago-14 & sep-14 & oct-14 & nov-14 & dic-14 \\
\hline \multicolumn{10}{|l|}{ INGRESOS } \\
\hline Incremento de Ventas & 112,753 & 112,753 & 112,753 & 112,753 & 112,753 & 112,753 & 112,753 & 112,753 & 112,753 \\
\hline Ahorro de gastos de ventas & 28,407 & 28,407 & 28,407 & 28,407 & 28,407 & 28,407 & 28,407 & 28,407 & 28,407 \\
\hline TOTAL INGRESOS & 141,159 & 141,159 & 141,159 & 141,159 & 141,159 & \begin{tabular}{|r|}
141,159 \\
\end{tabular} & 141,159 & 141,159 & 141,159 \\
\hline \multicolumn{10}{|l|}{ EGRESOS } \\
\hline Increm. de costo de ventas & $-71,034$ & $-71,034$ & $-71,034$ & $-71,034$ & $-71,034$ & $-71,034$ & $-71,034$ & $-71,034$ & $-71,034$ \\
\hline Incremento de IR & $-21,038$ & $-21,038$ & $-21,038$ & $-21,038$ & $-21,038$ & $-21,038$ & $-21,038$ & $-21,038$ & $-21,038$ \\
\hline Inversión inicial & & $(7)$ & & & & & $C=$ & & \\
\hline \multicolumn{10}{|l|}{ Capacitaciones y mant. } \\
\hline TOTAL EGRESOS & $-92,072$ & $-92,072$ & $-92,072$ & $-92,072$ & $-92,072$ & $-92,072$ & $-92,072$ & $-92,072$ & $-92,072$ \\
\hline FLUJO NETO & 49,088 & 49,088 & 49,088 & 49,088 & 49,088 & 49,088 & 49,088 & 49,088 & 49,088 \\
\hline
\end{tabular}

Elaboración propia 
Tabla 6.4

Flujo de caja escenario conservador (S/.)

\begin{tabular}{|l|r|r|r|r|r|r|r|r|r|}
\hline FLUJO DE CAJA & jul-13 & ago-13 & sep-13 & oct-13 & nov-13 & dic-13 & ene-14 & feb-14 & mar-14 \\
\hline INGRESOS & & & & & & & & & \\
\hline Incremento de Ventas & & & 43,090 & 43,090 & 43,090 & 43,090 & 30,881 & 30,881 & 30,881 \\
\hline Ahorro de gastos de ventas & & & 17,044 & 17,044 & 17,044 & 17,044 & 15,150 & 15,150 & 15,150 \\
\hline TOTAL INGRESOS & $\mathbf{0}$ & $\mathbf{0}$ & $\mathbf{6 0 , 1 3 4}$ & $\mathbf{6 0 , 1 3 4}$ & $\mathbf{6 0 , 1 3 4}$ & $\mathbf{6 0 , 1 3 4}$ & $\mathbf{4 6 , 0 3 2}$ & $\mathbf{4 6 , 0 3 2}$ & $\mathbf{4 6 , 0 3 2}$ \\
\hline EGRESOS & & & & & & & & \\
\hline Increm. de costo de ventas & & & $-27,147$ & $-27,147$ & $-27,147$ & $-27,147$ & $-19,455$ & $-19,455$ & $-19,455$ \\
\hline Incremento de IR & & & $-9,896$ & $-9,896$ & $-9,896$ & $-9,896$ & $-7,973$ & $-7,973$ & $-7,973$ \\
\hline Inversión inicial & $-26,560$ & & & & & & & & \\
\hline Capacitaciones y mant. & & $-3,816$ & $-3,816$ & $-3,816$ & $-3,816$ & $-3,816$ & & & \\
\hline TOTAL EGRESOS & $\mathbf{- 2 6 , 5 6 0}$ & $\mathbf{- 3 , 8 1 6}$ & $\mathbf{- 4 0 , 8 5 9}$ & $\mathbf{- 4 0 , 8 5 9}$ & $\mathbf{- 4 0 , 8 5 9}$ & $\mathbf{- 4 0 , 8 5 9}$ & $\mathbf{- 2 7 , 4 2 8}$ & $\mathbf{- 2 7 , 4 2 8}$ & $\mathbf{- 2 7 , 4 2 8}$ \\
\hline FLUJO NETO & $\mathbf{- 2 6 , 5 6 0}$ & $\mathbf{- 3 , 8 1 6}$ & $\mathbf{1 9 , 2 7 5}$ & $\mathbf{1 9 , 2 7 5}$ & $\mathbf{1 9 , 2 7 5}$ & $\mathbf{1 9 , 2 7 5}$ & $\mathbf{1 8 , 6 0 3}$ & $\mathbf{1 8 , 6 0 3}$ & $\mathbf{1 8 , 6 0 3}$ \\
\hline
\end{tabular}

\begin{tabular}{|l|r|r|r|r|r|r|r|r|r|}
\hline FLUJO DE CAJA & abr-14 & may-14 & jun-14 & jul-14 & ago-14 & sep-14 & oct-14 & nov-14 & dic-14 \\
\hline INGRESOS & & & & & & & & & \\
\hline Incremento de Ventas & 30,881 & 30,881 & 30,881 & 30,881 & 30,881 & 30,881 & 30,881 & 30,881 & 30,881 \\
\hline Ahorro de gastos de ventas & 15,150 & 15,150 & 15,150 & 15,150 & 15,150 & 15,150 & 15,150 & 15,150 & 15,150 \\
\hline TOTAL INGRESOS & $\mathbf{4 6 , 0 3 2}$ & $\mathbf{4 6 , 0 3 2}$ & $\mathbf{4 6 , 0 3 2}$ & $\mathbf{4 6 , 0 3 2}$ & $\mathbf{4 6 , 0 3 2}$ & $\mathbf{4 6 , 0 3 2}$ & $\mathbf{4 6 , 0 3 2}$ & $\mathbf{4 6 , 0 3 2}$ & $\mathbf{4 6 , 0 3 2}$ \\
\hline EGRESOS & & & & & & & & & \\
\hline Increm. de costo de ventas & $-19,455$ & $-19,455$ & $-19,455$ & $-19,455$ & $-19,455$ & $-19,455$ & $-19,455$ & $-19,455$ & $-19,455$ \\
\hline Incremento de IR & $-7,973$ & $-7,973$ & $-7,973$ & $-7,973$ & $-7,973$ & $-7,973$ & $-7,973$ & $-7,973$ & $-7,973$ \\
\hline Inversión inicial & & & & & & & & & \\
\hline Capacitaciones y mant. & & & & & & & & & \\
\hline TOTAL EGRESOS & $\mathbf{- 2 7 , 4 2 8}$ & $\mathbf{- 2 7 , 4 2 8}$ & $\mathbf{- 2 7 , 4 2 8}$ & $\mathbf{- 2 7 , 4 2 8}$ & $\mathbf{- 2 7 , 4 2 8}$ & $\mathbf{- 2 7 , 4 2 8}$ & $\mathbf{- 2 7 , 4 2 8}$ & $\mathbf{- 2 7 , 4 2 8}$ & $\mathbf{- 2 7 , 4 2 8}$ \\
\hline FLUJO NETO & $\mathbf{1 8 , 6 0 3}$ & $\mathbf{1 8 , 6 0 3}$ & $\mathbf{1 8 , 6 0 3}$ & $\mathbf{1 8 , 6 0 3}$ & $\mathbf{1 8 , 6 0 3}$ & $\mathbf{1 8 , 6 0 3}$ & $\mathbf{1 8 , 6 0 3}$ & $\mathbf{1 8 , 6 0 3}$ & $\mathbf{1 8 , 6 0 3}$ \\
\hline
\end{tabular}

Elaboración propia 
Tabla 6.5

Flujo de caja escenario negativo

\begin{tabular}{|c|c|c|c|c|c|c|c|c|c|}
\hline FLUJO DE CAJA & jul-13 & ago-13 & sep-13 & oct-13 & nov-13 & dic-13 & ene-14 & feb-14 & mar-14 \\
\hline \multicolumn{10}{|l|}{ INGRESOS } \\
\hline Incremento de Ventas & 0 & 0 & 0 & 0 & 0 & 0 & 0 & 0 & 0 \\
\hline Ahorro de gastos de ventas & 0 & 0 & 11,363 & 11,363 & 11,363 & 11,363 & 11,363 & 11,363 & 11,363 \\
\hline TOTAL INGRESOS & $\mathbf{0}$ & $\mathbf{0}$ & 11,363 & 11,363 & 11,363 & 11,363 & 11,363 & 11,363 & 11,363 \\
\hline \multicolumn{10}{|l|}{ EGRESOS } \\
\hline Increm. de costo de ventas & A & & & 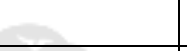 & 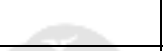 & & & $+\quad$ & \\
\hline Incremento de IR & 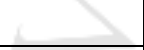 & 0 & $-3,409$ & $-3,409$ & $-3,409$ & $-3,409$ & $-3,409$ & $-3,409$ & $-3,409$ \\
\hline Inversión inicial & $-26,560$ & & 2 & 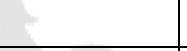 & 7 & & 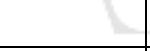 & & \\
\hline Capacitaciones y mant. & & $-3,816$ & $-3,816$ & $-3,816$ & $-3,816$ & $-3,816$ & & 4 & \\
\hline TOTAL EGRESOS & $-26,560$ & $-3,816$ & $-7,225$ & $-7,225$ & $-7,225$ & $-7,225$ & $-3,409$ & $-3,409$ & $-3,409$ \\
\hline FLUJO NETO & $-26,560$ & $-3,816$ & 4,138 & 4,138 & 4,138 & 4,138 & 7,954 & 7,954 & $\mathbf{7 , 9 5 4}$ \\
\hline
\end{tabular}

\begin{tabular}{|c|c|c|c|c|c|c|c|c|c|}
\hline FLUJO DE CAJA & abr-14 & may-14 & jun-14 & jul-14 & ago-14 & sep-14 & oct-14 & nov-14 & dic-14 \\
\hline INGRESOS & $-\infty$ & & & 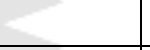 & 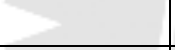 & 1 & 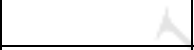 & & \\
\hline Incremento de Ventas & 0 & 0 & 0 & 0 & 0 & 0 & 0 & 0 & 0 \\
\hline Ahorro de gastos de ventas & 11,363 & 11,363 & 11,363 & 11,363 & 11,363 & 11,363 & 11,363 & 11,363 & 11,363 \\
\hline TOTAL INGRESOS & 11,363 & 11,363 & 11,363 & 11,363 & 11,363 & 11,363 & 11,363 & 11,363 & 11,363 \\
\hline \multicolumn{10}{|l|}{ EGRESOS } \\
\hline Increm. de costo de ventas & 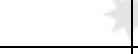 & & & & - & & 3 & & \\
\hline Incremento de IR & $-3,409$ & $-3,409$ & $-3,409$ & $-3,409$ & $-3,409$ & $-3,409$ & $-3,409$ & $-3,409$ & $-3,409$ \\
\hline Inversión inicial & & $1+2$ & & & & & +2 & & \\
\hline \multicolumn{10}{|l|}{ Capacitaciones y mant. } \\
\hline TOTAL EGRESOS & $-3,409$ & $-3,409$ & $-3,409$ & $-3,409$ & $-3,409$ & $-3,409$ & $-3,409$ & $-3,409$ & $-3,409$ \\
\hline FLUJO NETO & 7,954 & 7,954 & 7,954 & 7,954 & 7,954 & 7,954 & 7,954 & $\mathbf{7 , 9 5 4}$ & $\mathbf{7 , 9 5 4}$ \\
\hline
\end{tabular}

Elaboración propia 
Considerando que la empresa calcula su inversión con un costo de oportunidad de anual de $15 \%$ que convertido a mensual equivale a $1.17 \%$, al aplicar las formulas del VAN y el TIR obtenemos los siguientes resultados:

Tabla 6.6

Indicadores de evaluación económica

\begin{tabular}{|l|c|c|c|}
\hline & Positivo & Conservador & Negativo \\
\hline $\begin{array}{l}\text { Costo de } \\
\text { oportunidad }\end{array}$ & $1.17 \%$ & $1.17 \%$ & $1.17 \%$ \\
\hline TIR & $77 \%$ & $45 \%$ & $16 \%$ \\
\hline VAN & 625,508 & 236,382 & 68,326 \\
\hline
\end{tabular}

Elaboración propia

Como se observa en la tabla, los resultados son en todos los casos positivos. Sin lugar a duda un aumento en las ventas (escenarios positivo y conservador) mejorarán los resultados. En cambio, si las ventas no mejoran sino que se mantienen iguales que el año anterior (escenario negativo), la implantación es favorable, pero probablemente no suficiente como para hacer frente a la inquietud de los bancos. Si bien es cierto que se llega a una utilidad positiva y el retorno de la inversión es favorable para la empresa, es posible que para los bancos esto no sea suficiente.

\subsection{Análisis del impacto social y ambiental de la solución}

Si bien las soluciones propuestas no tienen un impacto ambiental directo en el corto plazo, a largo plazo, cuando la situación financiera de la empresa se encuentre en mejores condiciones, esta podrá tener un mayor foco en buscar innovación con maquinarias más amigables con el medio ambiente. De esta manera, a futuro se podrán comercializar máquinas con menores niveles de contaminación sonora y que generen menos merma o menos residuos. Sin lugar a duda el agente que puede y debe de generar un cambio es el propio gobierno y debe de partir desde la industria de la primera transformación, pero ese es otro tema de estudio. 
En lo que respecta al impacto social, este puede ser aún más importante. $\mathrm{ABC}$ S.A.C., como ya se mencionó en capítulos anteriores, es la principal empresa del sector comercializador de maquinaria para madera de la segunda transformación. Con una mejora en el desempeño de la empresa, el sector seguirá aumentando su competitividad, lo cual se traduce en una mayor y mejor oferta, dando posibilidades a más clientes finales de emprender negocios de carpintería y surgir.

Otro punto importante es que el negocio siempre ha buscado introducir maquinaria innovadora, que cada vez sea más segura y amigable, y que pueda mejorar la productividad del sector y sus clientes, para que a su vez ellos puedan ser competitivos en la industria local e incluso en la internacional. Esta competitividad no solo se mide en niveles de producción, sino también en la calidad de ambiente laboral que se pueda ofrecer a los trabajadores de las diferentes empresas clientes de $\mathrm{ABC}$ SAC.

En el caso hipotético que la empresa no pueda afrontar esta crisis interna de manera exitosa y tenga que cerrar en un periodo de tiempo corto, habrá un déficit de oferta de productos y servicios que tendrá que ser afrontado por los competidores, quienes no cuentan con una estructura adecuada y que podrían dañar aún más el sector. 


\section{CONCLUSIONES}

A continuación se muestran algunas conclusiones que derivan del desarrollo del trabajo y los respectivos resultados.

- La empresa ABC S.A.C. requiere una intervención rápida y que consuma la menor cantidad de recursos, tanto económicos como de tiempo. Considerando la situación actual de la empresa, de no hacer mayores cambios en su organización y procesos, quedaría muy expuesta a continuar generando resultados negativos y precipitando una posible quiebra.

- Las mejores opciones para lograr una mejora en la empresa están relacionadas con el mejor manejo de la información y la creación de procedimientos del proceso de ventas, a lo que debe seguir un programa de capacitación que asegure un correcto despliegue del uso de indicadores y procedimientos.

- La utilización de un sistema de indicadores de gestión a través de una herramienta como el cuadro de mando integral obligará a la empresa a generar información, con lo cual podrá llevar un control de sus procesos internos para posteriormente tomar mejores decisiones y medir el logro de sus objetivos, principalmente los relacionados al nivel de ventas y el ahorro en los gastos de este proceso.

- La creación de procedimientos del proceso de ventas brindará una guía para mejorar las prácticas actuales, lo cual, apoyado en el sistema de indicadores, debe traducirse en un mejor cálculo de pronósticos de ventas, un incremento en las ventas tanto de maquinaria como de consumibles y una mejor relación comercial con los clientes que permita controlar el nivel de cuentas cobrar.

- La implementación de un programa de capacitaciones ayudará a que los trabajadores mejoren el conocimiento que tienen del negocio y puedan poner en práctica este conocimiento adquirido. Asimismo esto no solo contribuye con el resultado del negocio, sino también a generar un compromiso del personal con la empresa al valorar la formación que se les está brindando.

- Si las mejoras planteadas se ejecutan de acuerdo a lo esperado, la intervención en la empresa $\mathrm{ABC}$ S.A.C. resultará exitosa y con ello se podría conseguir el objetivo general y los específicos planteados en el Capítulo I. De acuerdo a lo 
conversado con la Gerencia General, se esperaría alcanzar un incremento en las ventas de hasta $10 \%$ a fines del año 2014 y un ahorro de gastos de ventas que puede alcanzar hasta el 15\% (tomando como base el año 2013 sin aplicar la mejora).

- Las tres soluciones planteadas no dependen de agentes externos ni situaciones que no puedan ser controladas por la empresa, por lo que su implementación es perfectamente viable y el éxito de la misma depende de la capacidad de las personas de la organización

- A pesar de que el costo de prescindir de un vendedor con contrato a plazo indeterminado puede ser alto e incluso puede terminar en alguna batalla legal, es un riesgo que la empresa debe y puede correr a fin de poder conseguir los resultados mostrados. 


\section{RECOMENDACIONES}

A continuación se presentan algunas de las recomendaciones que la empresa pueda tener en cuenta en un futuro próximo.

- La empresa debe de mantener, en la medida de lo posible, mucha reserva acerca del momento y los cambios por los que está pasando. Este mal momento puede ser utilizado por la competencia para desacreditar los productos o servicios que aún está ofreciendo ABC S.A.C. y perjudicar su posición actual en el mercado, lo que resultaría con una posible desaceleración de las ventas.

- En el caso que las soluciones planteadas rindan beneficios económicos al negocio, se debería de reducir la deuda con los bancos y así alcanzar un nivel de endeudamiento acorde al tamaño real del negocio, reduciendo el riesgo financiero.

- En un futuro, una vez que la estabilidad financiera esté a punto de ser alcanzada, la empresa debería de evaluar el verdadero tamaño de mercado y las oportunidades o amenazas que este presenta. Así se podrá determinar si debe de invertir o potenciar otras líneas de negocio relacionadas. Estas pueden ser el servicio técnico, los consumibles o algún otro producto que actualmente no vende la empresa.

- Es importante además que las gerencias, especialmente la general, lidere este cambio motivando a sus colaboradores y tratando de que mantengan la calma. Un periodo de cambios puede preocupar a muchos de los trabajadores y la incertidumbre laboral puede ser negativa al momento de implementar las soluciones.

- Sin lugar a duda el proceso de recopilación de información es de suma importancia para la empresa. Si es que un negocio no tiene un correcto sistema de almacenamiento de información y data, es casi imposible presentar mejoras, ya que ni si quiera se pueda preparar un adecuado diagnóstico.

- La compra de un sistema informático, ya sea un ERP o un CRM debe de ingresarse en la agenda de la empresa, una vez que la situación esté más estabilizada. 


\section{REFERENCIAS}

Caldas Vílchez, José Luis. (2002) Mejora integral de una empresa de confecciones.

(Tesis para optar por el título de Ingeniero Industrial) Universidad de Lima.

Escalante Ávila, Ángel Enrique. (2014) Mejora integral en la empresa Cartonería y

Envases Piura S.A.C. (Tesis para optar por el título de Ingeniero Industrial) Universidad de Lima.

Delgado Moscoso, Giordano Esaú. (2013) Mejora en el proceso de producción de una empresa de artes gráficas. (Tesis para optar por el título de Ingeniero Industrial) Universidad de Lima.

Equifax. (s.f.) Reporte de Crédito - Infocorp Plus. Recuperado de: http://www.equifax.com/personales/products_services/infocorp_plus/es_pe

Instituto Nacional de Estadística e Informática (INEI). (2013). Serie de cuentas nacionales 1950 - 2013. Cifras de crecimiento en el Perú. Recuperado de: http://www.inei.gob.pe/media/MenuRecursivo/publicaciones_digitales/Est/Lib 1160/index.html

León-Gambetta Martín-Arranz, Alvaro. (2011) Estudio para la mejora integral del fundo San Crispín, productor de café. (Tesis para optar por el título de Ingeniero Industrial) Universidad de Lima.

Superintendencia Nacional de Aduanas y de Administración Tributaria (SUNAT) (s.f.) Consulta por importador/exportador. Recuperado de: http://www.aduanet.gob.pe/cl-aditconsultadwh/ieITS01Alias?accion $=$ consultar\&CG_consulta $=1$

Thibaut, Jean Pierre. (1994) Manual de diagnóstico en la empresa ( $1^{\mathrm{a}}$ ed.). Madrid: Paraninfo. 


\section{BIBLIOGRAFÍA}

Cetep. (s.f). La importancia de la capacitación en las empresas. Las ventajas de realizar capacitaciones al personal. Recuperado de http://www.cetep.cl/web/?p=7501

Chiavenato, Idalberto, y Sapiro, Arao. (2011). Planeación estratégica fundamento y aplicaciones ( $2^{\mathrm{a}}$ ed.). México DF: McGraw Hill.

Daft, Richard. (2000) Teoría y diseño organizacional. (6 $6^{\mathrm{a}}$ ed.). México, Internacional Thomson Editores.

Flórez Uribe, Juan Antonio. (2015) Plan de negocio: para pequeñas empresas (2 ${ }^{\mathrm{a}} \mathrm{ed}$.). Bogotá: Ediciones de la U.

Instituto Nacional de Estadística e Informática (INEI). (junio 2013) Boletín estadístico: Indicadores Económicos y Sociales. Lima: INEI.

Instituto Nacional de Estadística e Informática (INEI). (octubre 2014) Informe técnico: Producción nacional. Lima: INEI

Instituto Nacional de Estadística e Informática (INEI). (2014) Principales Indicadores Macroeconómicos" Cifras de crecimiento en el Perú. Recuperado de: http://www.inei.gob.pe/estadisticas/indice-tematico/economia

Neira Rodriguez, Jose Antonio. (2012) Cómo preparar un plan de empresa (2a ed.). Bogotá: Alfaomega Fundación Confemetal. 
Rodríguez Mansilla, Darío. (2005) Diagnóstico organizacional (6 $6^{\mathrm{a}}$ ed.). México D.F., Alfaomega, Ediciones Universidad Católica de Chile

Serna Gómez, Humberto. (1996) Planeación y gestión estratégica. (4 ${ }^{\mathrm{a}}$ ed.). Bogotá: RAM.

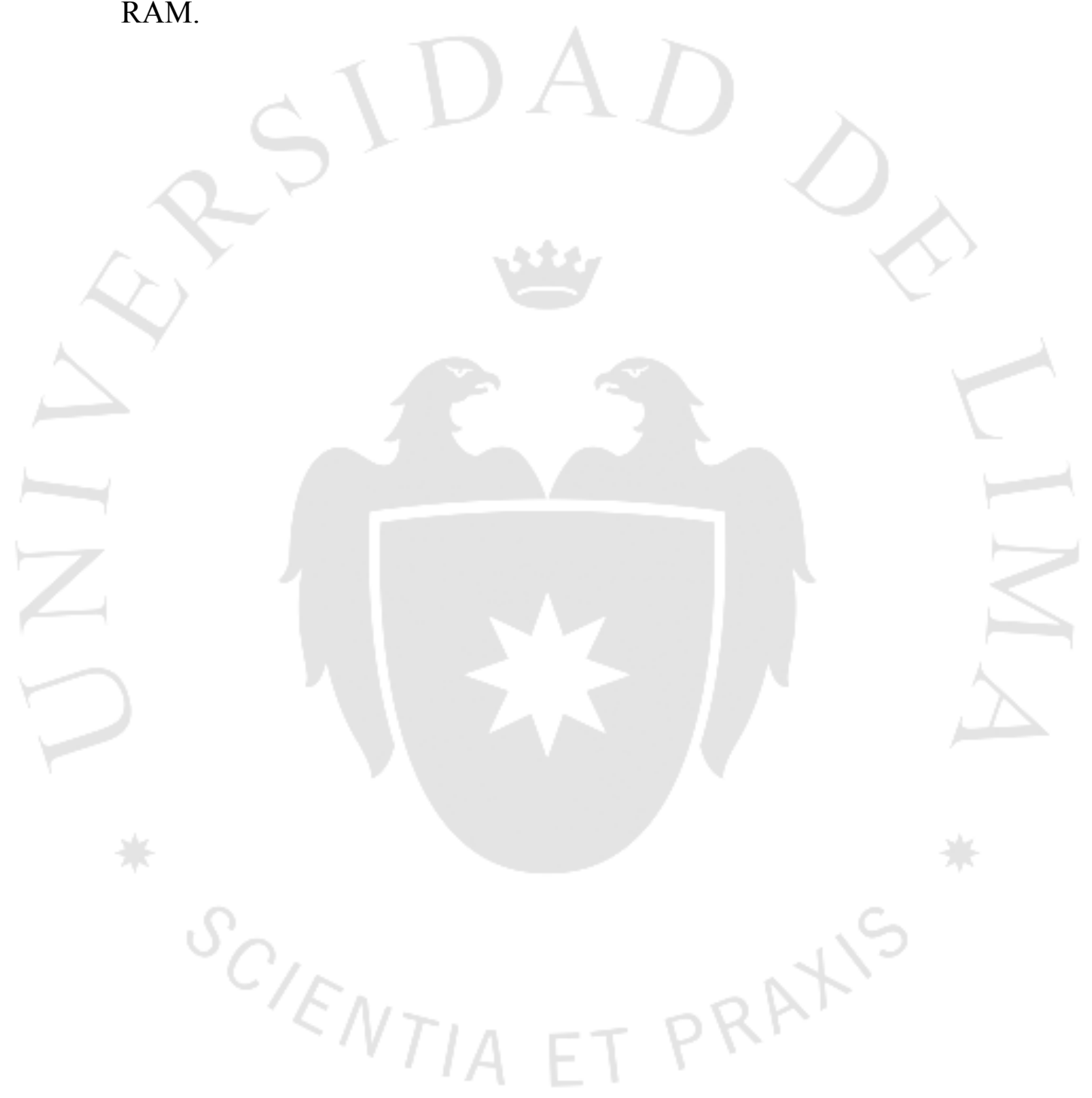




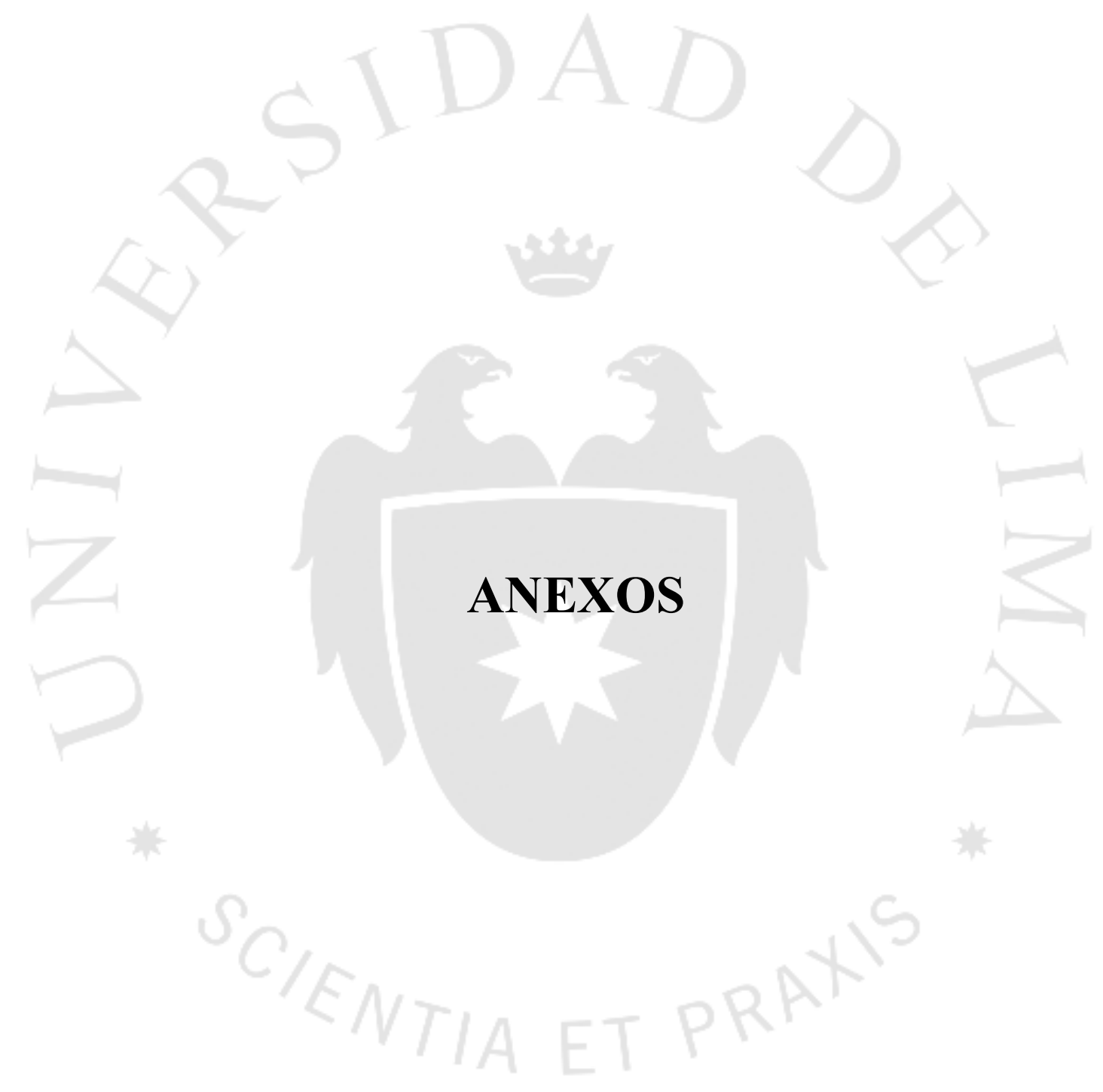




\section{ANEXO N¹: FORMATO DE AUTORIZACIÓN DE PRE- DESPACHO}

FECHA:

\section{AUTORIZACION DE PRE-DESPACHO}

TECNICO EVALUADOR Y EMISOR:

\section{DATOS DE RECEPTOR:}

Receptor Responsable:

Lugar de Entrega:

\section{Cliente:}

Nombre o Razón Social:

Lugar de destino:

\section{DATOS DE MÁQUINA:}

Marca:

Modelo: Serie:

Año:

Código ABC SAC:

\begin{tabular}{|c|l|c|l|}
\hline ITEM & \multicolumn{1}{|c|}{ INSPECCIÓN } & V / & COMENTARIOS \\
\hline 1 & Estado de limpieza & & \\
\hline 2 & Estado de pintura & & \\
\hline 3 & Máquina operativa & & \\
\hline 4 & Máquina completa & & \\
\hline 5 & $\begin{array}{l}\text { Estado de parte de la } \\
\text { máquina }\end{array}$ & & \\
\hline 6 & Voltaje de la máquina & & \\
\hline 7 & Estado de herramientas & & \\
\hline 8 & Placa ABC SAC & & \\
\hline 9 & Opcional aspirador & & \\
\hline 10 & Opcional cable & & \\
\hline 11 & Opcional disco & & \\
\hline 12 & Manual de operaciones & & \\
\hline 13 & Otros opcionales & & \\
\hline
\end{tabular}

Observaciones:

Por la presente certifico que la máquina esta lista para operar y cuenta con todos los aditamentos necesarios para el despacho.

Firma: 


\section{ANEXO N²: CONFORMIDAD PARA PUESTA EN MARCHA DE MAQUINARIA}

ESCUADRADORA HORIZONTAL

FECHA:

\begin{tabular}{|c|c|c|}
\hline \multicolumn{3}{|c|}{ DATOS DEL CLIENTE } \\
\hline RUC & \multicolumn{2}{|l|}{ NOMBRE } \\
\hline DIRECCIÓN & \multicolumn{2}{|l|}{ CONTACTO } \\
\hline CIUDAD & \multicolumn{2}{|l|}{ TELÉFONO } \\
\hline \multicolumn{3}{|c|}{ DATOS DE LA MÁQUINA } \\
\hline MARCA & MODELO & \\
\hline \multicolumn{3}{|c|}{ CONFORMIDAD } \\
\hline \multicolumn{3}{|c|}{ Piso nivelado con un área de $6 \times 8$ metros y $20 \mathrm{~cm}$ de espesor } \\
\hline \multicolumn{3}{|c|}{ Linea de alimentacion eléctrica estable $3 \emptyset 220 \mathrm{VAC}$ ó $380 \mathrm{VAC} 60 \mathrm{~Hz}$. } \\
\hline \multicolumn{3}{|c|}{ Potencia requerida de $10 \mathrm{Kw}}$. \\
\hline \multicolumn{3}{|c|}{ Interruptor termomagnetico $3 \varnothing$ de $32 \mathrm{~A}$. } \\
\hline \multicolumn{3}{|c|}{ Cable 4 × 12 AWG metraje del interruptor hacia la maquina. (Provincia $5 \times 12$ AWG) } \\
\hline \multicolumn{3}{|c|}{ Pozo a tierra 3 - 5 ohmios } \\
\hline \multicolumn{3}{|c|}{ Sistema de aspiracion correcto. } \\
\hline \multicolumn{3}{|c|}{ Material para prueba (1 plancha de melamine). } \\
\hline \multicolumn{3}{|c|}{ Maquina esta ubicada en el lugar exacto para su instalacion. } \\
\hline \multicolumn{2}{|c|}{ SOBRE EL PERSONAL QUE VA OPERAR LA MÁQUINA } & $\mathrm{SI} / \mathrm{NO}$ \\
\hline
\end{tabular}

Observaciones:

Declaro haber cumplido con todas las condiciones, arriba mencionadas, de manera fidedigna para la correcta puesta en marcha de la máquina. De no haberlos cumplido, asumiré el concepto de puesta en marcha frustrada. En caso de provincia, asumiré además el pago de concepto de pasajes más viáticos.

Firma:

Nombre:

DNI:

Cargo:

Teléfono:

Notas:

1 - La garantía de la máquina quedará anulada por el incumplimiento de una o más de estas conformidades

2 - Una vez llenado el presente documento, favor escanearlo y enviarlo al correo soporte@abcsac.com para la programación de su instalación. El área de Servicio Técnico se pondrá en contacto para las coordinaciones de la instalación. 


\section{ANEXO N'3: ACTA DE PUESTA EN MARCHA DE LA MÁQUINA}

\begin{tabular}{|l|l|l|l|}
\hline \multicolumn{4}{|c|}{ ACTA DE PUESTA EN MARCHA DE MAQUINARIA } \\
\hline Máquina & & Fecha inicio & \\
\hline Marca & Fecha fin & \\
\hline Modelo & Cliente & \\
\hline № Serie & Telefono & \\
\hline № Placa & Técnico & \\
\hline
\end{tabular}

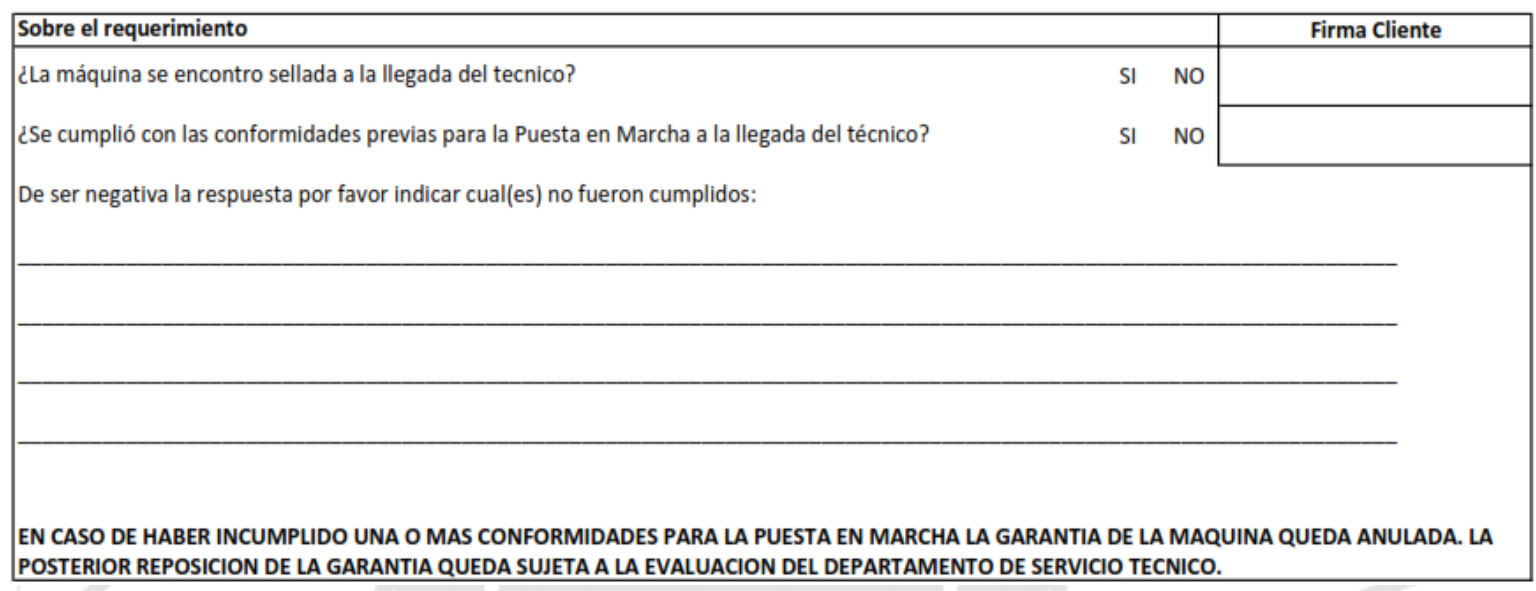

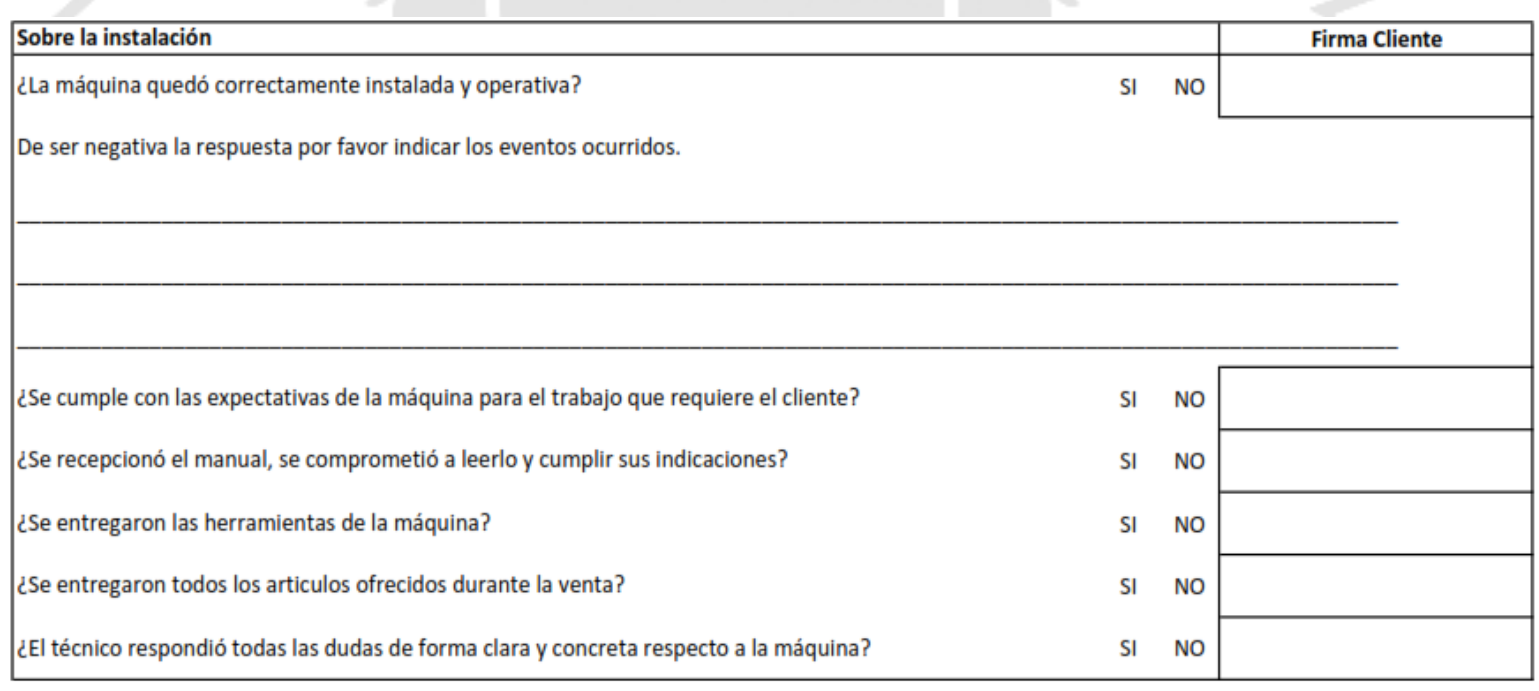




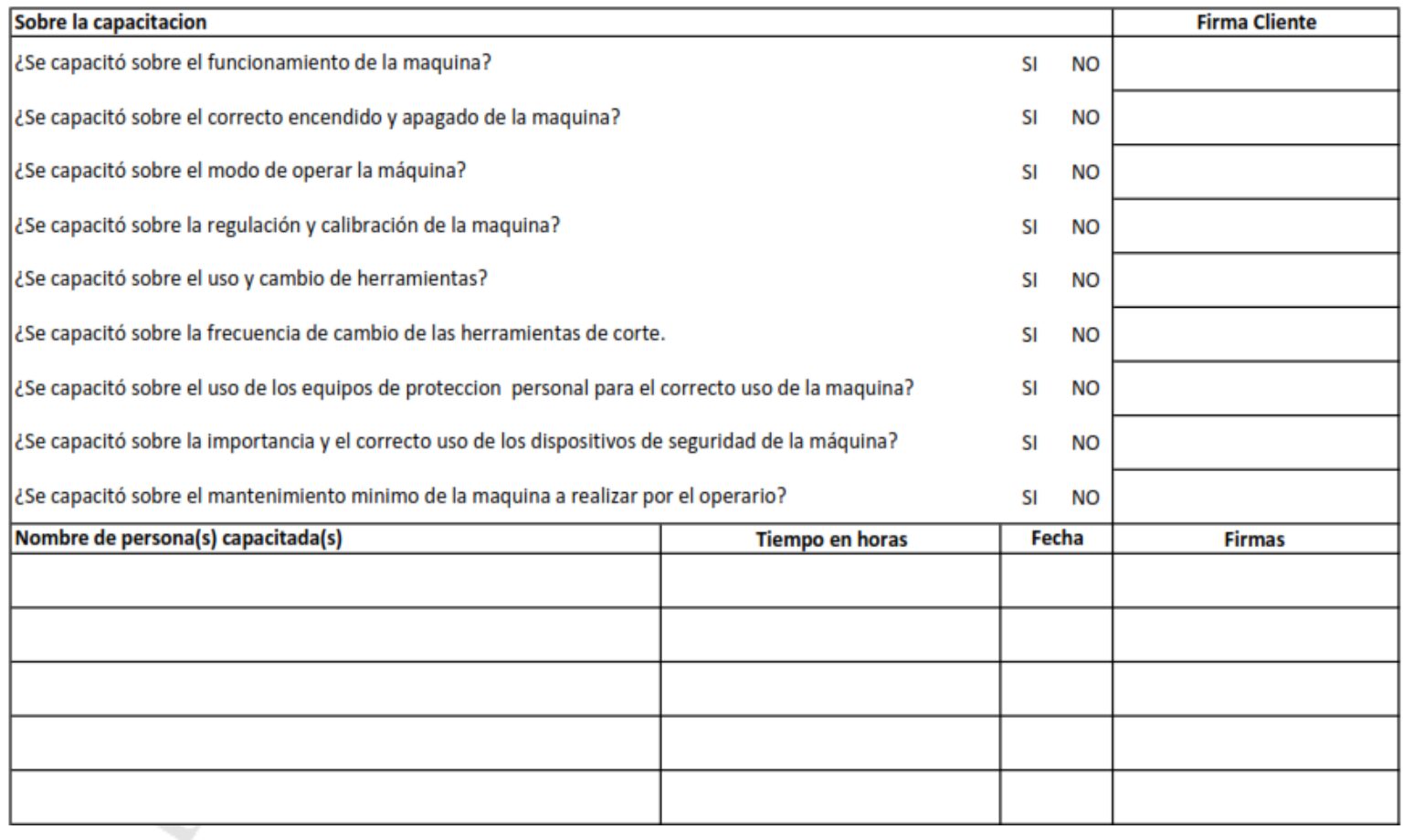

\begin{tabular}{|l|l|l|}
\hline Observaciónes y recomendaciones del Técnico & Firma del cliente \\
\hline & & \\
\hline & & \\
\hline & & \\
\hline
\end{tabular}

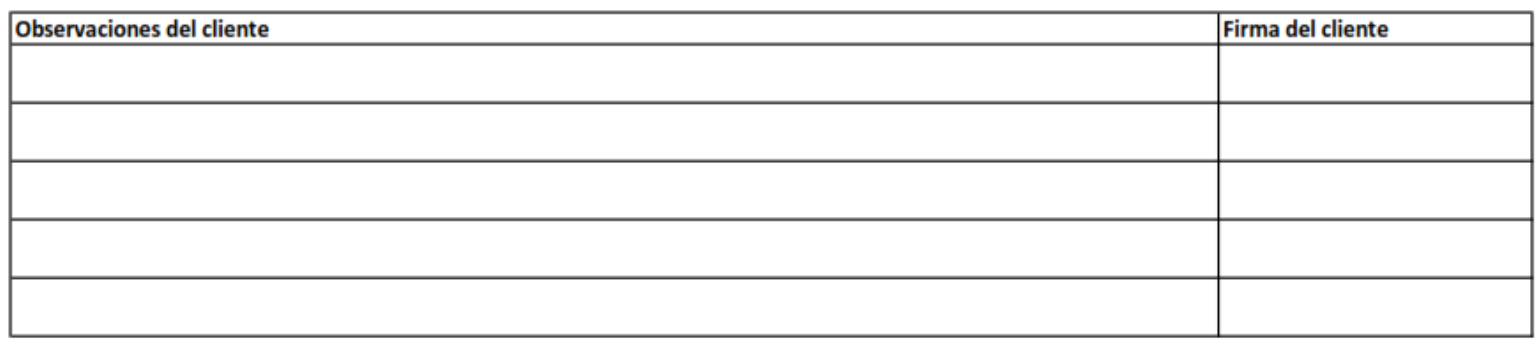

Técnico Instalador y Capacitador Nombre:
Cliente:

Nombre:

Cargo: 


\section{ANEXO N 4: SUMILLAS DE CURSOS DE CAPACITACIÓN}

A. Fuerza de ventas:

Curso A1:

- El tema a tratar:

- Especificaciones de productos y servicios ofrecidos y la respectiva comparación con los principales competidores y sus respectivos productos y servicios

- Se dictará un curso para cada producto que ofrece ABC S.A.C., empezando por aquellos productos que tienen mayor rentabilidad e importancia estratégica para el negocio. En un principio se han calculado 10 cursos.

- Los logros que se quieren conseguir

- Homogenizar los conocimientos de los vendedores respecto a los productos que ofrece la empresa y que cada vendedor conozca las principales características técnicas y de funcionamiento de los mismos.

- Comparar las ventajas y desventajas de los productos con los que ofrece la competencia.

- Se realizará una actividad grupal en cada curso, la cual consistirá en plantear argumentos de venta contundentes para cada producto. Estos deben de incluir incluso argumentos financieros y de rentabilidad para sus clientes.

- Cada vendedor, al final de la capacitación, tendrá más argumentos técnicos e económicos que le facilitarán la venta, consiguiendo mejores resultados.

- Cantidad de horas requeridas

- Día 1:

- 30 minutos para evaluación de entrada

- Una hora para temas técnicos y comparativos.

- Día 2:

- 45 minutos para la parte práctica. 
- Día 3:

- 45 minutos para preparar argumentos de venta.

- Día 4:

- 30 minutos para una evaluación.

○ Total de horas: 3.5 horas.

- La Gerencia General y la Gerencia Comercial evaluarán de repetir el curso más adelante, dependiendo de los resultados obtenidos en la evaluación y en la evolución de las ventas.

- Encargado de la exposición:

- Gerencia Comercial y el mejor evaluado de la Fuerza de Venta.

- Apoyo por parte de un técnico en parte práctica.

○ Supervisión por parte de Gerencia General, Gerencia Comercial y mejor evaluado de la Fuerza de Venta

- Cantidad de participantes y cargos.
○ 5 vendedores
○ 3 encargados de las recepciones.

\section{Curso A2:}

- El tema a tratar:

- Secuencia de la venta: búsqueda y calificación de prospectos, preparación para la visita, la visita, presentación y demostración y finalmente el seguimiento

- Los logros que se quieren conseguir

- Homogenizar los conocimientos de los vendedores respecto al proceso de venta ideal, utilizando ejemplos propios del negocio.

- Buscar que todos los vendedores tengan una misma secuencia de ventas general, de tal manera que se pueda fortalecer la imagen corporativa del negocio.

- Así mismo, tener una misma secuencia de ventas ayudará a los procesos internos de la empresa y la recopilación de información, la cual podrá ser utilizada o intercambiada por los distintos empleados.

- Cantidad de horas requeridas

○ Día 1: 
- 30 minutos para evaluación de entrada

- Una hora para temas técnicos de la primera parte.

- Día 2:

- Una hora para temas técnicos de la segunda parte.

- Día 3:

- 30 minutos para una evaluación.

○ Total de horas: 3 horas.

- La Gerencia General y la Gerencia Comercial evaluarán de repetir el curso más adelante, dependiendo de los resultados obtenidos en la evaluación, en la evolución de las ventas y en la recopilación de información.

- Encargado de la exposición:

- Gerencia Comercial y el mejor evaluado de la Fuerza de Venta.

- Apoyo por parte de un técnico en parte práctica.

- Supervisión por parte de Gerencia General, Gerencia Comercial y mejor evaluado de la Fuerza de Venta

- Cantidad de participantes y cargos.
○ 5 vendedores
○ 3 encargados de las recepciones.

\section{Curso A3:}

- El tema a tratar:

- Trato al cliente y manejo de situaciones difíciles seguimiento

- $\quad$ Los logros que se quieren conseguir

- Homogenizar los conocimientos de los vendedores respecto a las posibles situaciones de tratos con los clientes.

- Buscar que todos los vendedores tengan una misma actitud y respuesta a diferentes situaciones, de tal manera que se pueda fortalecer la imagen corporativa del negocio.

- Cantidad de horas requeridas

- Día 1:

- 30 minutos para evaluación de entrada

- Una hora para temas técnicos de la primera parte.

- Día 2: 
- Una hora para juego de roles.

- Día 3:

- 30 minutos para una evaluación.

○ Total de horas: 3 horas.

- La Gerencia General y la Gerencia Comercial evaluarán de repetir el curso más adelante, dependiendo de los resultados obtenidos en la evaluación, en la evolución de las ventas y en la recopilación de información relacionada.

- Encargado de la exposición:

○ Gerencia Comercial y el mejor evaluado de la Fuerza de Venta.

- Apoyo por parte de un técnico en parte práctica.

- Supervisión por parte de Gerencia General, Gerencia Comercial y mejor evaluado de la Fuerza de Venta

- Cantidad de participantes y cargos.

○ 5 vendedores

○ 3 encargados de las recepciones.

B. Área logística:

Curso B1:

- El tema a tratar:

- Organización del almacén y uso del programa contable y de almacenaje con el que cuenta la empresa actualmente (Siigo) para conseguir una mejor atención a los clientes internos y externos.

- Los logros que se quieren conseguir

- Homogenizar los conocimientos de los participantes de la logística de la empresa en relación a la organización del almacén, de tal manera que cualquiera de ellos pueda ubicar un producto en el almacén.

- Los participantes deberán de conocer de manera general además el uso del programa contable y de almacenaje Siigo.

- Actividad grupal: plantear idea sobre de cómo debería de organizarse el almacén.

- Cantidad de horas requeridas 
- Día 1:

- 30 minutos para la evaluación de entrada.

- 30 minutos para temas teóricos acerca del almacenaje

○ Día 2:

- Una hora para teoría y rutas de acceso y procedimiento del Siigo.

○ Día 3:

- 30 minutos para elaborar la actividad grupal

- Día 4:

- 30 minutos para la evaluación.

○ Total de horas: 3 horas.

- Encargado de la exposición:

- Jefatura administrativa

○ Supervisión por parte de Gerencia General.

- Cantidad de participantes y cargos.

○ 1 almacenero

- 1 apoyo administrativo

- 1 administrador de DEF S.A.C.

○ Personal de recepción

C. Staff técnico, personal de reparto de DEF S.A.C. y vendedores ABC S.A.C.:

\section{Curso C1:}

- El tema a tratar:

- Importancia de la información cuantitativa

- Los logros que se quieren conseguir

○ Que el personal tenga claro la importancia de la recolección de este tipo de información.

- Lo importante que es traspasar información precisa, para que esta sea confiable.

- Poner a prueba al personal.

- Conseguir que el personal se sensibilice con este nuevo proceso.

- Cantidad de horas requeridas

- Día 1:

- 15 minutos evaluación de entrada 
- Una hora para exponer el tema.

- Día 2:

- Una hora con 15 minutos para evaluaciones individuales y prácticas.

- Encargado de la exposición:

- Gerencia Comercial y Jefatura de Servicio Técnico.

- Supervisión por parte de Gerencia General.

- Cantidad de participantes y cargos.

- Todo el staff técnico de ABC S.A.C..

○ Personal de reparto de DEF S.A.C..

○ Vendedores ABC S.A.C..

\section{Curso C2:}

- El tema a tratar:

- Importancia de la información cualitativa.

- Los logros que se quieren conseguir

- Que el personal tenga claro la importancia de la recolección de este tipo de información.

- Lo importante que es traspasar información precisa, para que esta sea confiable.

- Poner a prueba al personal.

- Conseguir que el personal se sensibilice con este nuevo proceso.

- Cantidad de horas requeridas

- Día 1:

- 15 minutos evaluación de entrada

- Una hora para exponer el tema.

- Día 2:

- Una hora con 15 minutos para evaluaciones individuales y prácticas.

- Encargado de la exposición:

- Gerencia Comercial y Jefatura de Servicio Técnico.

- Supervisión por parte de Gerencia General.

- Cantidad de participantes y cargos.

○ Todo el staff técnico de ABC S.A.C.. 
○ Personal de reparto de DEF S.A.C..

Vendedores ABC S.A.C..

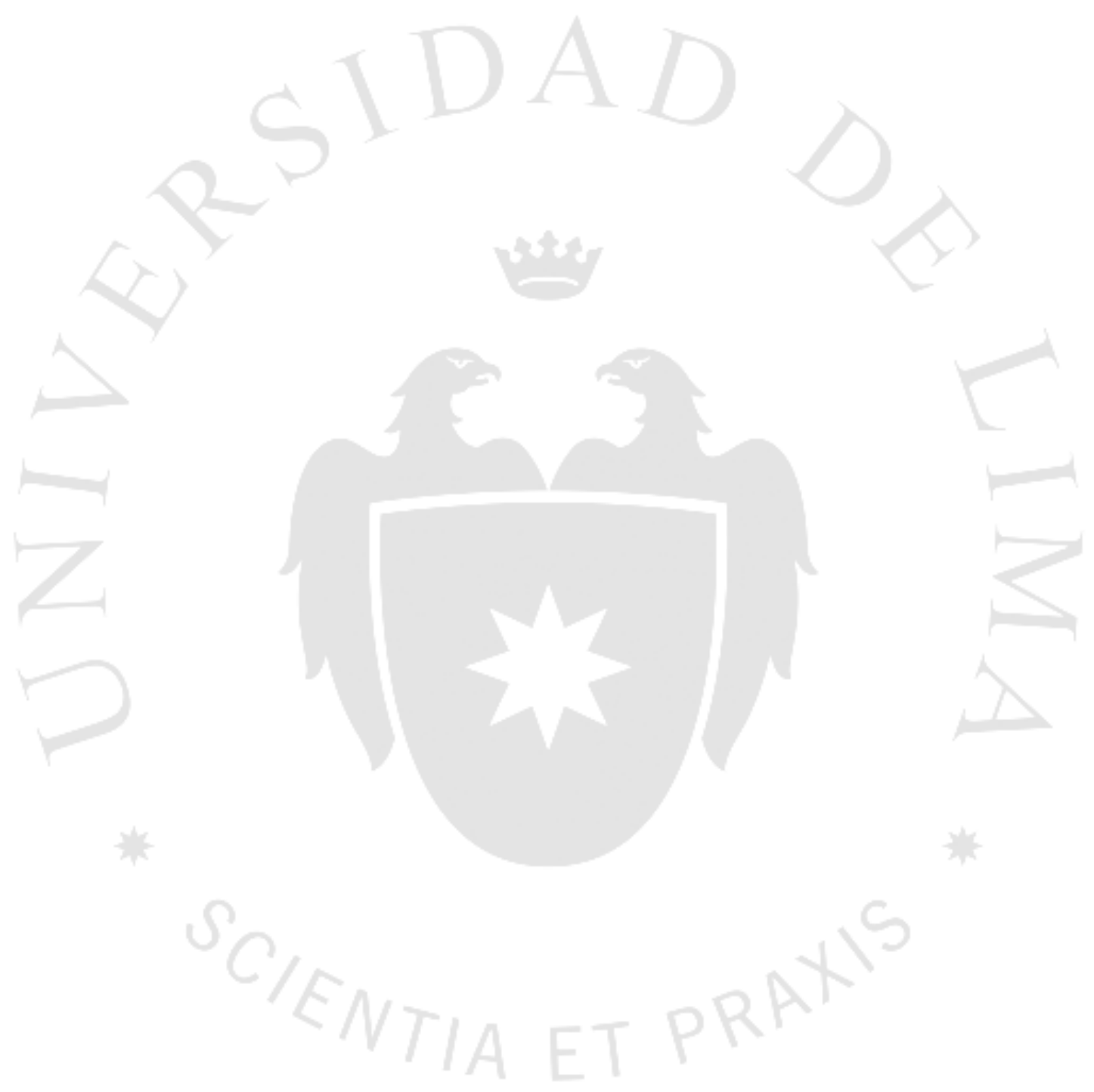

